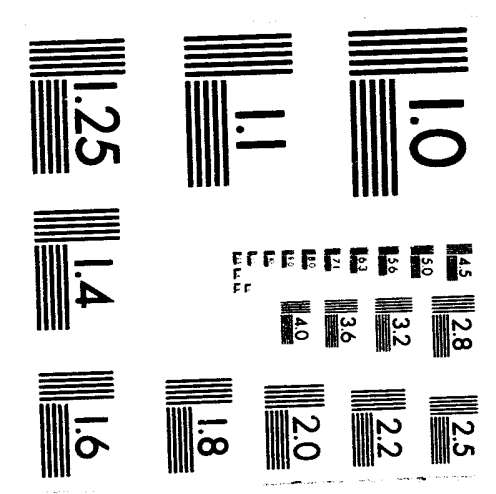



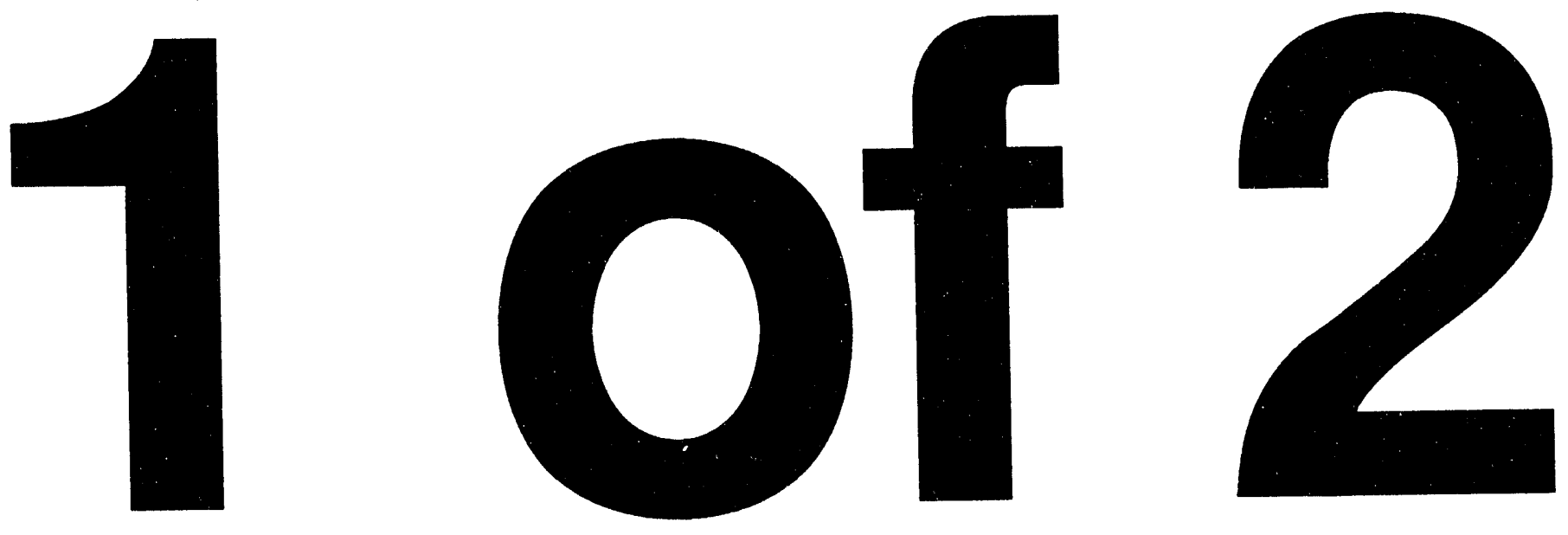


\section{COMBUSTION PROPERTIES OF KRAFT BLACK LIQUORS}

By:

W. Jim Frederick, Jr.

Mikko Hupa

APRIL 1993

Work Performed Under Contract No. DE-FG02-90CE40936

Co-Funded by Tampella Power Ltd. and The Ministry of Trade and Industry in Finland, Project No. 2-24

Within the Combustion Research Program LIEKKI

For:

U.S. Department of Energy

Office of Industrial Technologies

Washington, D.C. 20585 and

Tampella Power Ltd. - FINLAND

By:

Oregon State University

Corvallis, Oregon and

Abo Akademi University

Turku, Finland 


\section{DISCLAIMER}

This repon was prepared as an account of work sponsored by an agency of the United States Government. Neither the United States Government nor any agency thereof. nor any of their employees. makes any warranty, express or implied, or assumes any legal liability or responsihility for the accuracy, completeness, or usefulness of any information. apparatus. product, or process disclosed. or represents that its use would not infringe privalely owned rights. Reference herein to any specific commercial product, process, or service by trade name. trademark. manuficturer. or otherwise does not necessirily constitute or imply its endorsement, recommendation. or favoring by the United States Govermment or any agency thereof. The views and opinions of authors expressed herein do not necessarily state or reflect those of the United States Government or any agency thereof.

This report has been reproduced directly from the best available copy.

Available to DOE and DOE contractors from the Office of Scientific and Technical Information, P.O. Box 62. Oak Ridge, TN 37831; prices available from (615) 576-8401.

Available to the public from the U.S. Department of Commerce. Technology Administation, National Technical Information Service, Springfield, VA 22161. (70)3) $487-4650$. 


\title{
COMBUSTION PROPERTIES OF KRAFT BLACK LIQUORS
}

by

\author{
W.J. Frederick, Jr. and M. Hupa
}

April 1993

Report for the joint research projects:

"Combustion Properties of Kraft Black Liquors," by the Institute of Paper Science and Technology, Atlanta, Georgia 30318, funded by the United States Department of Energy through the Contract No. DE-IG02-90CE40936, Subcontract 91-001

and

"Release of Inorganic Constituents During Black Liquor Pyrolysis and Combustion," by the Åbo Akademi University, 20520 Turku, Finland, co-funded by Tampella Power Ltd and the Ministry of Trade and Industry in Finland through the Project No. 2-24 within the Combustion Research Program LIEKKI.

\section{Prepared for:}

Stanley F. Sobczynski

Program Manager, CE-14

Office of Industrial Programs

Conservation and Renewable Energy

Washington, D.C. 20585 USA

and

Tampella Power Ltd

P.O. Box 626

SF-33101 Tampere, Finland

and

Ministry of Trade and Industry

Energy Department

P.O. Box 37

SF-00131 Helsinki, Finland 


\section{PREFACE}

The efforts toward understanding the process of black liquor combustion through steady-state process modeling have increased markedly in the past five years. An international consortium of research groups from Canada, Finland, and the U.S. are currently developing a new steadystate model for recovery boilers.

A key component of these models is the numerical model of the in-flight combustion of black liquor droplets. The most recent single droplet combustion model, developed by Frederick in 1990 , required certain basic combustion information for black liquor droplets which was not available. This included information on volatiles and char yields from pyrolysis, a quantitative understanding of the factors which determined the onset of devolatilization and the concurrent rapid swelling, and a more complete quantification of the swelling of black liquor droplets during combustion. The study reported here was undertaken to provide this information. Additional data on droplet surface temperatures were obtained for evaluating the model and the rate-limiting processes in the combustion of black liquor droplets.

The experimental program was conducted at the Combustion Chemistry Laboratory, Abo Akademi University, Turku, Finland. The study was co-sponsored by Tampella Power Inc., The Finnish Ministry of Trade and Industry through the LIEKKI Program, and the U.S. Department of Energy.

Many people contributed to the success of this project. Timo Uusikartano, Kirsi Laaksonen, and Tom Sundell of Abo Akademi University obtained the experimental data used in this study, and assisted with its compilation and interpretation. Rolf Hernberg and Jari Stenberg of Tampere University of Technology provided the two-color optical pyrometer, the data processing software, and assistance in interpreting the raw data. Sture Böstrom, Prosessikemia Ky, provided invaluable assistance in interpreting the two-color optical pyrometer raw data. Paavo Hyöty, Tampella Power Inc. provided valuable input in planning the program and in interpreting the data. Tom Grace, T.M. Grace Company, and Peter Solomon, Advanced Fuel Research, contributed to interpretation of the results through valuable discussions. Jarkko Nurmi, Ábo Akademi University, programmed the in-flight droplet combustion model. Jaakko Saastamoinen, the Technical Research Centre of Finland at Jyväskylä, provided the detailed droplet combustion model. Sun-ki Kang, Oregon State University, was responsible for the detailed droplet combustion calculations with the Saastamoinen model and also prepared many of the figures in this report.

This report is simultaneously published as an Abo Akademi University Report in Finland and as a U.S. Department of Energy Report in the United States.

Corvallis - Turku, April 1993

W.J. Frederick, Jr. and M. Hupa 


\section{TABLE OF CONTENTS}

Page

1. EXECUTIVE SUMMARY .................... 1-1

1.1 Summary of Key Results . . . . . . . . . . . . . . . . 1-1

1.1.1 Volatiles and Char Carbon Yields ............... 1-1

1.1.2 The Onset of Devolatilization and Swelling . . . . . . . . . . 1-2

1.1.3 Droplet Surface and Internal Temperatures ........... 1-3

1.1.4 Swelling of Black Liquor Droplets .............. 1-3

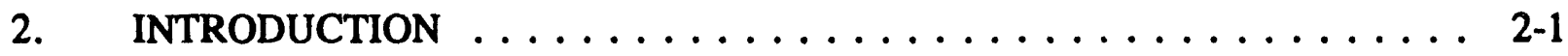

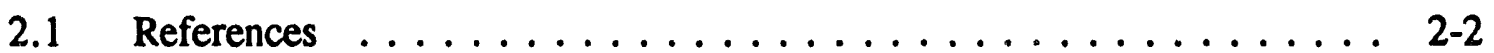

3. VOLATILES AND CHAR CARBON YIELDS $\ldots \ldots \ldots \ldots \ldots \ldots$

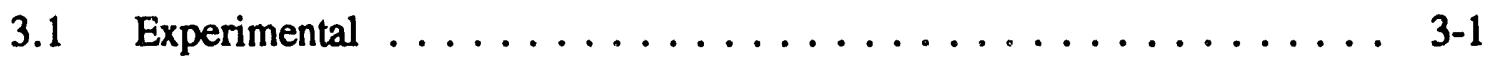

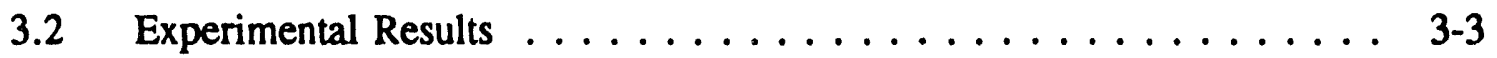

3.2.1 Effect of Droplet Mass . . . . . . . . . . . . . 3-3

3.2.2 Effect of Exposure Time ................ 3-4

3.2 .3 Effect of Temperature . . . . . . . . . . . . . 3-15

3.2 .4 Effect of Liquor Type ... . . . . . . . . . . . 3-15

3.2.5 Effect of Dry Solids Content . . . . . . . . . . . . . 3-19

3.3 Interpretation and Application to Modeling . . . . . . . . . . 3-19

3.4 Proposed Model for Volatiles Yields Under Nonisothermal

Conditions . . . . . . . . . . . . . . . . . . . . . . . . . . 3-24

3.4.1 Modeling Approach ................. 3-25

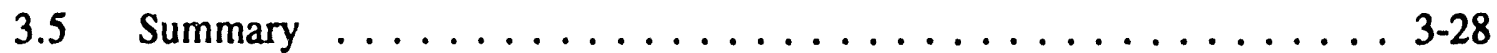

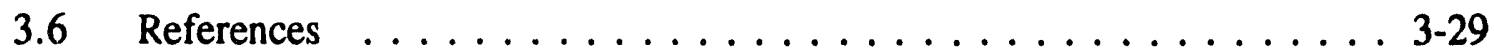

4. THE ONSET OF DEVOLATILIZATION AND IGNITION . . . . . . . . . 4-1

4.1 Onset of Devolatilization . . . . . . . . . . . . . . . 4-1

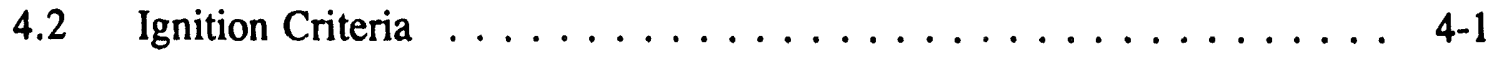


4.3 Analysis of Time to Ignition Data $\ldots \ldots \ldots \ldots \ldots \ldots \ldots$

4.4 Surface Temperature and Volatiles Evolution Rate $\ldots \ldots \ldots \ldots$. . . .

4.4.1 Definition of the Onset of Volatiles Evolution . . . . . . . 4-12

4.5 Model for Predicting the Onset of Devolatilization and Swelling . . . . 4-15

4.6 Recommended Procedure for Application of the Onset of Devolatilization Model to Calculauions in a Nonuniform Temperature Yield . . . . . . 4-25

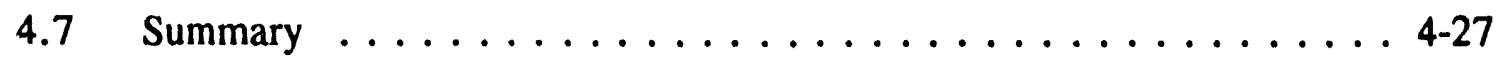

$4.8 \quad$ References $\ldots \ldots \ldots \ldots \ldots \ldots \ldots \ldots \ldots \ldots \ldots \ldots \ldots \ldots$ 4-27

5. BLACK LIQUOR DROPLET TEMPERATURE MEASUREMENTS DURING

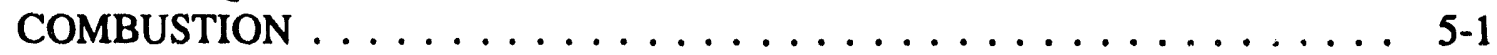

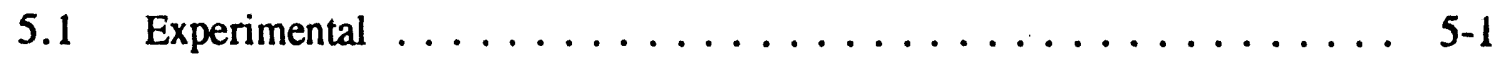

5.2 Internal Droplet Temperatures $\ldots \ldots \ldots \ldots \ldots \ldots \ldots \ldots$ 5-2

5.3 Surface Temperature Measurements $\ldots \ldots \ldots \ldots \ldots \ldots \ldots$ 5-7

5.3.1 Two-Color Pyrometer Data Reduction . . . . . . . . . . 5-7

5.3.2 Surface Temperatures During Pyrolysis in $\mathrm{N}_{2} / \mathrm{CO} \ldots \ldots \ldots$. $5-10$

5.3.3 Surface Temperatures in a $\mathrm{CO}_{2} / \mathrm{N}_{2}$ Atmosphere ...... 5-10

5.3.4 Surface Temperatures During Combustion . . . . . . . 5-13

5.4 Testing of Droplet Combustion Models with Droplet Temperature

Data . . . . . . . . . . . . . . . . . . . . . 5-20

5.5 Implications to Combustion Processes . . . . . . . . . . . . 5-22

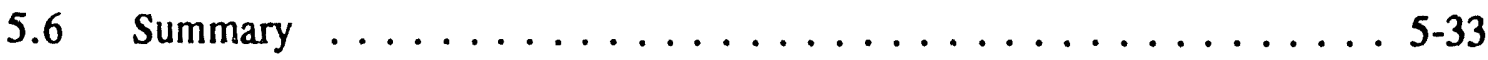

5.7 References $\ldots \ldots \ldots \ldots \ldots \ldots \ldots \ldots \ldots \ldots \ldots \ldots \ldots \ldots$

6. ESTIMATION OF SWELLING FACTORS $\ldots \ldots \ldots \ldots \ldots$ 6-1

6.1 Swelling During Drying $\ldots \ldots \ldots \ldots \ldots \ldots \ldots \ldots \ldots$

6.2 Swelling During Devolatilization $\ldots \ldots \ldots \ldots \ldots \ldots$ 6-1

6.2.1 Effect of Furnace Temperature and Gas Composition . . . . . 6-2

6.2.2 Effect of Dry Solids Content .............. 6-7 
6.2.3 Recommended Procedure for Estimating Swelling Factors During Devolatilization . . . . . . . . . . . . . . 6-7

6.2.4 Effect of a Nonisothermal Gas Environment on $\mathrm{SV}_{\text {MAX }} \ldots \ldots$ 6-9

6.3 Particle Shrinkage During Char Burning $\ldots \ldots \ldots \ldots$. . . . . . 6-9

6.4 Sumrnary $\ldots \ldots \ldots \ldots \ldots \ldots \ldots \ldots \ldots \ldots \ldots \ldots \ldots \ldots \ldots$

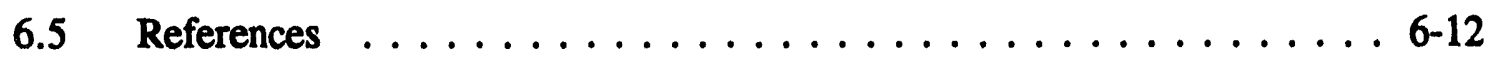

\section{APPENDICES}

1. Droplet Trajectory Program RATA2

2. Maximum Surface Temperatures During Char Burning for Black Liquor Droplets Burned in Oxygen-Nitrogen Mixtures

3. Mass Transfer and Pore Diffusion Effects Evaluation Program THIELE2

4. Composition and Heating Values for the Liquors Used in the Volatiles and Char Carbon Yield Studies 


\section{LIST OF FIGURES}

Figure

Page

3.1 Laboratory furnace used for the single droplet pyrolysis and combustion experiments

3.2 Volatiles yield versus droplet mass for liquors $\mathrm{C}$ and $\mathrm{J}$ pyrolyzed for 10 seconds at $800^{\circ} \mathrm{C} \ldots \ldots \ldots \ldots \ldots \ldots . \ldots \ldots \ldots$

3.3 Volatiles yield versus droplet mass for liquor A pyrolyzed at $1000-1200^{\circ} \mathrm{C}$. $60 \%$ initial dry solids content . . . . . . . . . . . . . . . 3-6

3.4 Carbon residual in char versus droplet mass for liquors $\mathrm{C}$ and $\mathrm{J}$ pyrolyzed for 10 seconds at $800^{\circ} \mathrm{C} \ldots \ldots \ldots \ldots \ldots \ldots$

3.5 Carbon residual in char versus droplet mass for liquor $\mathbf{A}$ pyrolyzed at $1000-1200^{\circ} \mathrm{C}$. $60 \%$ initial dry solids content . . . . . . . . . . . . . 3-8

3.6 Volatiles yield versus pyrolysis time for liquor A pyrolyzed at $700-900^{\circ} \mathrm{C}$, $95 \% \mathrm{~N}_{2} / 5 \% \mathrm{CO}$ gas environment. $60 \%$ initial dry solids content . . . . . .

3.7 Carbon residual in char versus pyrolysis time for liquor A pyrolyzed at $700-900^{\circ} \mathrm{C}, 95 \% \mathrm{~N}_{2} / 5 \% \mathrm{CO}$ gas environment. $60 \%$ initial dry solids content

3.8 Sodium in droplet residue as percent of sodium originally in black liquor droplet. Liquor a, pyrolysis in $5 \% \mathrm{CO}, 95 \% \mathrm{~N}_{2} \ldots \ldots \ldots . \ldots \ldots$

3.9 Carbon remaining in char versus time for black liquor droplets pyrolyzed in $\mathrm{CO} / \mathrm{N}_{2}$ mixtures with different $\mathrm{CO}$ concentrations. (A) $700^{\circ} \mathrm{C}$; (B) $800^{\circ} \mathrm{C}$;

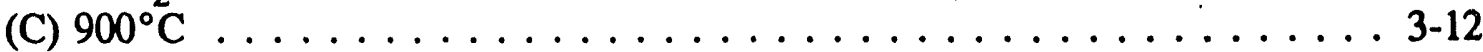

3.10 Volatiles yield versus temperature for liquor $1.10 \mathrm{~s}$ pyrolysis time, $60-65 \%$ dry solids content. Error bars indicate \pm 1 standard deviation. . . . . 3-16

3.11 Carbon content of char versus temperature for liquor $1.10 \mathrm{~s}$ pyrolysis time, $60-65 \%$ dry solids content. Error bars indicate \pm 1 standard deviation

3.12 Carbon mass in char as percent of carbon originally in black liquor solids (darker bars, left side of each pair) and volatiles yield as percent of black liquor solids (lighter bars, right side of each pair) for eight liquors pyrolyzed for 10 seconds at $800^{\circ} \mathrm{C}$ in $5 \% \mathrm{CO}, 95 \%$ nitrogen 
3.13 Char burning time per mg water versus dry solids content for a birch kraft liquor burned in air. Lines are predictions from the single droplet combustion model (Frederick, 1990) . . . . . . . . . . . . 3-20

3.14 Char burning time per $\mathrm{mg}$ black liquor solids versus dry solids content for three liquors at $700^{\circ} \mathrm{C}$. Lines are predictions from the single droplet combustion model (Frederick, 1990) . . . . . . . . . . . 3-21

3.15 Char carbon at the end of pyrolysis versus furnace temperature for three kraft liquors

3.16 Simple two-reaction pyrolysis model. From Kobayashi et al., 1977, where k indicates a rate constant, $\mathrm{V}$ is a volatiles yield, $\mathrm{R}$ is a char residue yield. $\alpha_{i}$ is the fraction of the black liquor solids following pathway $i$ which is converted to volatiles . . . . . . . . . . . . 3-26

3.17 Basis for devolatilization model which accounts for individual elements

4.1 Effect of solids content at ignition on droplet trajectories for $2.0 \mathrm{~mm}$ droplets initially at $60 \%$ solids content injected into a furnace at $1000^{\circ} \mathrm{C}, 5 \% \mathrm{O}_{2}$, $13 \% \mathrm{CO}_{2}, 8.4 \% \mathrm{H}_{2} \mathrm{O}$. Maximum swollen volume of the droplets is $50 \mathrm{~cm}^{3} / \mathrm{g}$ black liquor solids. The trajectories were calculated using the program RATA (Appendix 1). Points A, B, and C indicate the onset of devolatilization and swelling for droplets which ignite at 65,80 , and $100 \%$ solids content, respectively $\ldots \ldots \ldots \ldots \ldots \ldots \ldots \ldots \ldots \ldots \ldots$

4.2 Distributions of times to ignition for $2.2 \mathrm{~mm}$ diameter droplets burned in air at 700 and $800^{\circ} \mathrm{C}$ for one hundred liquors $\ldots \ldots \ldots \ldots$

4.3 Distributions of calculated solids mass fractions at ignition at 700 and $800^{\circ} \mathrm{C}$ for one hundred liquors $\ldots \ldots \ldots \ldots \ldots \ldots \ldots$

4.4 Calculated solids mass fraction at ignition for a softwood draft liquor (166) as a function of droplet mass and temperature . . . . . . . . . . .

4.5 Estimated average droplet temperature at ignition for droplets which do not ignite at or before dryness $\ldots \ldots \ldots \ldots \ldots \ldots \ldots \ldots$

4.6 Calculated solids mass fraction at ignition versus furnace temperature for two liquors and averages for all liquors. The error bars indicate \pm 1 standard deviation for all liquors tested

4.7 Water vapor and volatiles flow for a $2 \mathrm{~mm}$ droplet burned in air at $800^{\circ} \mathrm{C}$ as calculated by Saastamoinen's model. For comparison, the drying, devolatilization, and char burning times calculated by Frederick's models (1990) are also shown 
4.8 Water vapor and volatiles flow for $2.5 \mathrm{~mm}$ droplets burned in air at $600-1000^{\circ} \mathrm{C}$ as calculated by Saastamoinen's model . . . . . . . . . 4-14

4.9 Water vapor and volatiles flow for 1.-, 2.5, and $5.0 \mathrm{~mm}$ droplets burned in air at $900^{\circ} \mathrm{C}$ as calculated by Saastamoinen's model . . . . . . . 4-16

4.10 Water vapor and volatiles flow for $2.5 \mathrm{~mm}$ droplets initially at 60,70 , and $80 \%$ dry solids content when burned in air at $900^{\circ} \mathrm{C}$ as calculated by Saastamoinen's model . . . . . . . . . . . . . . . . . . 4-17

4.11 Water vapor and volatiles flow for $2.5 \mathrm{~mm}$ droplets with different maximum swollen volumes when burned in air at $900^{\circ} \mathrm{C}$ as calculated by Saastamoinen's model . . . . . . . . . . . . . . . . . . . . . 4-18

4.12 Experimental times to ignition (Frederick et al., 1991b) and dry solids contents at ignition as calculated by the single droplet drying model of Frederick (1990) . . . . . . . . . . . . . . . . . . . . 4-21

4.13 A plot of $S_{i}$ for an average liquor (represented by Eqs. (4.1) and (4.2)) with $S_{\mathrm{i}}$ data for liquor 166 (from Table 4.2) $\ldots \ldots \ldots \ldots \ldots \ldots \ldots$ 4-22

4.14 Effect of initial droplet mass and heat flux to droplet on $S_{i}$ as calculated by the algorithm presented here for droplets initially at $70 \%$ dry solids content

4.15 Time delay between dryness and the onset of devolatilization as a function of initial droplet mass and heat flux $\ldots \ldots \ldots \ldots \ldots \ldots \ldots$

5.1 Droplet temperature versus time measured from thermocouple on which droplet was suspended (Hupa et al., 1985). Kraft black liquor, $1.3 \mathrm{~mm}$ droplet initial diameter, $60 \%$ initial dry solids content, $800^{\circ} \mathrm{C}$ air atmosphere. From Hupa et al., $1987 \ldots \ldots \ldots \ldots \ldots \ldots \ldots$

5.2 Measured internal droplet temperatures (heavy line) and calculated surface temperatures (light line) during drying and devolatilization for two kraft liquor droplets burned in air at $800^{\circ} \mathrm{C}$. The experimental data $\left(\mathrm{T}_{\text {int }}\right)$ are from Solin and Hupa $(1984) \ldots \ldots \ldots \ldots \ldots \ldots$. . . . . .

5.3 Calculated temperature profiles for a $2 \mathrm{~mm}$ black liquor droplet burned in air at $800^{\circ} \mathrm{C}$ based on Saastamoinen's model (Saastamoinen, 1984, 1992)

5.4 Typical data at three wavelengths as measured directly with the optical pyrometer. Data are for a droplet pyrolyzed in 5\% CO, $95 \%$ nitrogen at $800^{\circ} \mathrm{C}$. The droplet entered the field of view of the optical probe at about $1.25 \mathrm{~s}$. Pyrolysis continued beyond 5 seconds, but the rest of the data are not shown 
5.5 Surface temperature versus time for two $17 \mathrm{mg}$ droplets pyrolyzed in $95 \% \mathrm{~N}_{2} / 5 \% \mathrm{CO}$ at $800^{\circ} \mathrm{C}$. The curve for droplet $\mathrm{B}$ is shifted downward approximately $40^{\circ} \mathrm{C}$ so that both curves can be seen clearly . . . . . . 5-11

5.6 Surface temperature versus time for a $15 \mathrm{mg}$ droplet in $20 \% \mathrm{CO}_{2} / 80 \% \mathrm{~N}_{2}$

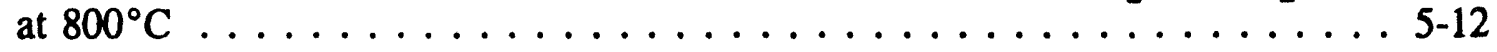

5.7 Surface temperature versus time for two droplets pyrolyzed in burned air at $800^{\circ} \mathrm{C}$. Experimentally observed times to ignition, disappearance of the flame, and the end of char burning are also shown ......... 5-14

5.8 Surface temperature versus time for two $3.6 \mathrm{mg}$ droplets burned in air

5.9 Surface temperature versus time for four droplets burned in air at $800^{\circ} \mathrm{C}$. The curves are each shifted upward by multiples of $200^{\circ} \mathrm{C}$ so that each is visible . . . . . . . . . . . . . . . . . . . 5-17

5.10 Comparison of maximum surface temperatures for droplets burned in air with maximum internal droplet temperatures measured earlier by Solin and Hupa (1984) . . . . . . . . . . . . . . . . . . . . . . . 5-18

5.11 Surface temperature versus time for four droplets burned in $15.8 \% \mathrm{O}_{2}$ at $800^{\circ} \mathrm{C}$. The curves are each shifted upward by multiples of $200^{\circ} \mathrm{C}$ so that each is visible

5.12 Difference between the surface temperature and furnace temperature during char burning versus oxygen content of the surrounding gas for droplets burned in $\mathrm{O}_{2} / \mathrm{N}_{2}$ mixtures in an $800^{\circ} \mathrm{C}$ furnace

5.13 Droplet surface temperatures during pyrolysis in two noncombustion atmospheres

5.14 Comparison of the droplet surface temperature measured during combustion in air with the surface temperature predicted by Saastamoinen's model . . . 5 5-24

5.15 Comparison of the droplet surface temperature measured during pyrolysis in $\mathrm{N}_{2} / \mathrm{CO}$ with the surface temperature predicted by Saastamoinen's model (Saastamoinen, 1984, 1992) . . . . . . . . . . . . . . . . . 5-25

5.16 The ratio of the overall rate of reaction to the rate if mass transfer limited $\left(R_{i} / R_{m i}\right)$ or to the rate if chemical kinetic limited $\left(R_{i} / R_{c i}\right)$ for the char carbon oxidation and gasification reactions. Conditions are $9 \mathrm{~mm}$ char particles, $5 \% \mathrm{O}_{2}$ or $13 \% \mathrm{CO}_{2}, 5 \% \mathrm{CO}$ or $18 \% \mathrm{H}_{2} \mathrm{O}, 3 \% \mathrm{H}_{2}$; $122 \mathrm{~m}^{2} / \mathrm{g}$ char carbon specific area. The droplet surface temperature exceeds the furnace temperature by $50^{\circ} \mathrm{C}$ in these calculations 
5.17 Effectiveness factors for the char carbon oxidation and gasification reactions for the same conditions as in Figure $5.19 \ldots \ldots \ldots \ldots \ldots .30$

5.18 The ratio of the overall rate of reaction to the rate if mass transfer limited $\left(R_{i} / R_{m i}\right)$ or to the rate if chemical kinetic limited $\left(R_{i} / R_{c i}\right)$ for the char carbon oxidation reactions. Conditions are $3 \mathrm{~mm}, 9 \mathrm{~mm}$, and $15 \mathrm{~mm}$ char particles, $5 \% \mathrm{O}_{2}, 122 \mathrm{~m}^{2} / \mathrm{g}$ char carbon specific area. The droplet surface temperature exceeds the furnace temperature by $50^{\circ} \mathrm{C}$ in these calculations $\ldots \ldots \ldots \ldots \ldots \ldots \ldots$

5.19 The ratio of the overall rate of reaction to the rate if mass transfer limited $\left(R_{i} / R_{m i}\right)$ for the char carbon gasification reactions. Conditions are $3 \mathrm{~mm}, 9 \mathrm{~mm}$, and $15 \mathrm{~mm}$ char particles, $13 \% \mathrm{O}_{2}, 5 \% \mathrm{CO}$ r $18 \% \mathrm{H}_{2} \mathrm{O}$, $3 \% \mathrm{H}_{2}$. The droplet surface temperature used in these calculations was

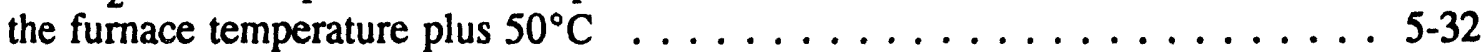

6.1 Effect of furnace temperature and gas composition on the maximum swollen volume for two kraft black liquors burned under different conditions in a laboratory furnace $\ldots \ldots \ldots \ldots \ldots \ldots \ldots \ldots \ldots \ldots . \ldots \ldots$

6.2 Maximum swollen volumes versus $\mathrm{T}_{\mathrm{g}}^{*}$ for the two liquors in Figure $6.1 \ldots$ 6-5

6.3 The effect of the temperature of the gases immediately surrounding a black liquor droplet on $\mathrm{SV}_{\max }$. The gas temperature environment $\left(\mathrm{T}_{\mathrm{g}}^{*}\right)$ was estimated from Eq. (6.5). The liquors are A, C - pine kraft, B - Douglas fir kraft, D - birch kraft, E - sodium base sulfite semichem. Liquors A and C-E were at $50 \%$ dry solids content and liquor $B$ at $68 \% \ldots \ldots \ldots \ldots$

6.4 Effect of initial dry solids content on $\mathrm{SV}_{\max }$ for three liquors burned in air at $700^{\circ} \mathrm{C}$ (from Frederick et al., 1991) . . . . . . . . .

6.5 Maximum swollen volume per gram of carbon in char versus the carbon content of char after 10 seconds pyrolysis in $95 \% \mathrm{~N}_{2} / 5 \% \mathrm{CO} \ldots \ldots \ldots \ldots . \ldots 6-10$ 


\section{LIST OF TABLES}

Table

Page

3.1 Liquors used in this study and their carbon and sodium contents . . . . . . 3-3

3.2 Ratio of sodium/carbon loss from black liquor droplet chars after devolatilization is complete. Based on data for droplets pyrolyzed in $5 \% \mathrm{CO} / 95 \% \mathrm{~N}_{2}$, evaluated from carbon and sodium measurements after 10 and 30 seconds in a hot furnace . . . . . . . . . . . . . . . . 3-13

3.3 Effect of $\mathrm{CO}$ concentration on the rate of char carbon conversion to gases at three temperatures. The uncertainty for the rates is on average $37 \% \ldots \ldots \ldots \ldots \ldots . \ldots \ldots$. . . . . . . . . . . . . . . . . . . . . . . . . . . .

3.4 Constants for estimating yield and char carbon for pine and birch pulps ........................... 3-22

4.1 Experimental times to ignition $\left(\mathrm{t}_{i}\right)$ and mean solids content at ignition calculated from the experimental t $t_{i}$ 's using the two resistance drying model. Results are for $2.2 \mathrm{~mm}$ diameter droplets at $60 \%$ solids content burned in air . . . . . . . 4-4

4.2 Slopes and intercepts for $S_{i}$ versus Mo for liquor 166 at different temperatures and $S_{\mathrm{i}}$ for $8 \mathrm{mg}$ droplets. The slopes and intercepts are based on the data in Figure $4.4 \ldots \ldots \ldots \ldots \ldots \ldots . \ldots \ldots \ldots$. . . . . . . . . . . . . . . . . . . . .

4.3 Calculated mean heat flux to a black liquor droplet in a laboratory furnace versus furnace temperature for $12 \mathrm{mg}$ initial droplet mass . . . . . . . . . 4-23

5.1 Internal droplet temperatures at the end of drying and devolatilization for droplets burned at different furnace temperatures in air. The means and standard deviations reported here are based on the experimental measurements of Solin and Hupa (1984) . . . . . . . . . . . . . 5-5

5.2 Maximum droplet temperatures during char burning versus oxygen content of the furnace gas for droplets burned at $800^{\circ} \mathrm{C} \ldots \ldots . . . . . . .55$ 


\section{EXECUTIVE SUMMARY}

In 1990, a study of the phenomena involved in the combustion of black liquor droplets was completed and a numerical model for the combustion of single black liquor droplets was developed. The model required certain black liquor specific combustion information which was then not currently available, and additional data were needed for evaluating the model.

The overall objectives of the project reported here was to provide experimental data on key aspects of black liquor combustion, to interpret the data, and to put it into a form which would be useful for computational models for recovery boilers. The specific topics to be investigated were:

- the volatiles and char carbon yields from pyrolysis of single black liquor droplets,

- a criterion for the onset of devolatilization and the accompanying rapid swelling, and

- the surface temperature of black liquor droplets during pyrolysis, combustion, and gasification.

The results of the experimental investigations of these three areas are presented in Chapters 3-5 of this report.

Additional information on the swelling characteristics of black liquor droplets was also obtained as part of the experiments conducted. A summary of the swelling characteristics of black liquor, containing new data from this study and in the form of a computational model, is included Chapter 6.

\subsection{Summary of Key Results}

\subsubsection{Volatiles and Char Carbon Yields}

Volatiles and char carbon yields were measured for six kraft and two NSSC liquors under a variety of conditions $\left(600-1200^{\circ} \mathrm{C}\right.$, pyrolysis and combustion conditions, $4-20 \mathrm{mg}$ droplets).

The amount of volatiles formed increased and the carbon content of the char decreased with increasing reaction time at constant furnace temperature. Carbon, sodium and total mass loss from the char particles continued beyond devolatilization. This is apparently the result of sodium carbonate decomposition.

The amount of volatiles increased approximately linearly and the carbon content of the residue decreased exponentially with reaction temperature for constant droplet exposure time in 
a pyrolysis environment. Droplet mass had no effect on volatiles or char carbon yield over the range studied.

The variation in volatiles and char carbon yields after pyrolysis did not vary greatly from liquor to liquor within the category of wood species when compared as percentages of the dry solids mass or carbon originally in the black liquor. These results are based on a limited number of liquors and need to be extended to a larger number of liquors and to liquors based on other wood species to further test these tentative conclusions.

A preliminary correlation has been developed for volatiles and char carbon yields during pyrolysis. The correlation accounts for differences in thermal environment but does not separate pyrolysis effects from inorganic reactions which occur in a nonreacting gas after pyrolysis is complete. A more detailed analysis of the data to separate these effects will be accomplished as part of the work on sulfur and sodium volatilization which follows the current project.

\subsubsection{The Onset of Devolatilization and Swelling}

During black liquor combustion, the processes of drying and devolatilization are clearly not separate and distinct, but can overlap considerably depending on the droplet size and heat flux to the droplet surface. Smaller droplets and droplets in lower temperature environments are more likely to dry completely before devolatilization begins. These conclusions are based on an analysis of time to ignition data for droplets burned in air and detailed modeling of single droplet combustiun.

An algorithm has been developed for estimating the point at which devolatilization of black liquor droplets begins in recovery boiler environments. For droplets which begin to devolatilize before drying completely, the algorithm predicts the mean droplet solids content at which devolatilization begins. For droplets which dry completely and continue heating before devolatilization begins, the model predicts the time delay between reaching dryness and the onset of devolatilization. The algorithm accounts for the effects of initial droplet mass, initial dry solids content, and the heat flux to the droplet. A methodology for dealing with nonisothermal temperature environments was also developed.

The broad spectrum of times to ignition has an important implication to liquor combustion stability: liquors which take longer to ignite may be harder to burn. This, together with the great liquor-to-liquor variability in swelling during devolatilization, could account for the difference between a liquor which is easy to burn and one which is difficult to burn. This may be an important issue in the operability of recovery boilers and it should be investigated experimentally. No direct measurements of differences in ignition points for black liquors have ever been reported.

Results from a detailed model for black liquor combustion indicates that volatiles evolution begins sooner for droplets at higher initial dry solids content. This may be related to the improvement in combustion stability in recovery boilers at higher solids firing. 


\subsubsection{Droplet Surface and Internal Temperatures}

The temperature of a black liquor droplet burned in air is well above the furnace temperature for the entire char burning stage. The surface temperature for droplets burned in air is typically $200^{\circ} \mathrm{C}$ higher than the furnace temperature at the end of the devolatilization stage and increases to $220-500^{\circ} \mathrm{C}$ above the furnace temperature during char burning. Internal droplet temperatures typically increased from about the furnace temperature at the end of devolatilization to $400^{\circ} \mathrm{C}$ above it during char burning for droplets burned in air.

At the lower oxygen contents typically found in recovery boilers, the droplet surface temperature is always greater than the furnace temperature during char burning. The difference is about $65^{\circ} \mathrm{C}$ for droplets burned in $5 \% \mathrm{O}_{2}$ in an $800^{\circ} \mathrm{C}$ furnace and increases with increasing oxygen content.

During char burning, the rates of the char oxidation reactions and the water vapor gasification reaction are limited by film mass transfer at most conditions in recovery furnaces. The rate of the char carbon gasification reaction with $\mathrm{CO}_{2}$ is limited mainly by pore diffusion at most furnace conditions.

\subsubsection{Swelling of Black Liquor Droplets}

The swelling factors for black liquor droplets during combustion can be estimated from simple correlations based on experimental data. The only liquor-specific parameter required is the maximum swollen volume during devolatilization. It must be measured experimentally. When $S V_{\max }$ data are available at a few temperatures, it is possible to estimate its value at other furnace gas compositions and temperatures for isothermal environments based on Eq. (6). It is not yet possible to account for the effects of a nonisothermal environment on the maximum swollen volume during devolatilization. This is currently being investigated. 


\section{INTRODUCTION}

The efforts toward understanding the process of black liquor combustion through steadystate process modeling, begun in the 1970's (Merriam et al., 1980) have increased markedly in the past five years. The efforts of Grace and coworkers (1989) and Karvinen, Hyöty and coworkers (1989) led to the first of these models with the potential for use in boiler design and evaluation. Since then the effort has intensified and nearly all of the major recovery boiler manufacturers either have or are developing recovery boiler models. An international consortium of research groups from Canada, Finland, and the U.S. are currently developing a new steady-state model for recovery boilers.

A limiting factor in the development of these models has always beelı a lack of basic information on the combustion characteristics of black liquor. The research teams of Hupa et al., 1982,1987; Noopila et al., 1991) and Clay et al. (1984, 1987; Miller and Clay, 1986) provided a great deal of both qualitative and quantitative information on how black liquor droplets burn and on their swelling characteristics. this formed the basis for the first rudimentary droplet combustion models which were used in the boiler models developed by Grace and coworkers and Karvinen, Hyöty, and coworkers.

In 1990, a study of the phenomena involved in the combustion of black liquor droplets was completed and a numerical model for the combustion of single black liquor droplets was developed (Frederick, 1990). The model required certain black liquor specific combustion information which was then not currently available. This included information on volatiles and char yields pyrolysis, a quantitative understanding of the factors which determined the onset of devolatilization and the concurrent rapid swelling, and a more complete quantification of the swelling of black liquor droplets during combustion. In addition, there were no data available for testing the model other than observed combustion times. The study reported here was undertaken to provide this information.

The work reported here is a result of a study undertaken to provide this information. The study was co-sponsored by Tampella Power Inc., The Finnish Ministry of Trade and Industry, and the U.S. Department of Energy. The objectives of the study were to provide experimental data on these key aspects of black liquor combustion, to interpret the data, and to put it into a form which would be useful for computational models for recovery boilers. The specific questions to be addressed were:

- What are the volatiles and char carbon yields from pyrolysis of single black liquor droplets, and how do they vary with combustion conditions and liquor type?

- What determines when devolatilization and the accompanying rapid swelling begin?

- What is the surface temperature of black liquor droplets during pyrolysis, combustion, and gasification? 
The results of the experimental investigations of these three areas are presented in Chapters 3 through 5 of this report.

The swelling characteristics of black liquor had been investigated earlier (Miller and Clay, 1986; Hupa, 1987; Frederick et al., 1991) and a numerical model for swelling developed (Frederick, 1990). Additional information on the swelling characteristics of black liquor droplets were obtained as part of this work, and the swelling model was improved significantly. A summary of the swelling data, expressed in terms of the improved numerical model, is included in Chapter 6.

An in-flight droplet model, RATA, was developed to investigate the effect of the various combustion parameters and furnace conditions on droplet combustion times and trajectories in simple flow and temperature fields. The in-flight droplet model is included in the Appendix of this report.

\subsection{References}

Clay, D.T. and Ragland, K.W., "Kraft black liquor combustion: sensitivity to key process variables," AIChE Winter National Meeting, 72f (1984).

Clay, D.T., Lien, S.J., Grace, T.M., Macek, A., Smerjian, H.C., Arnin, N., Charagundla, S.R., "Fundamental Studies of Black Liquor Combustion - Report No. 2," U.S. DOE Report DE88005756 (January 1987).

Frederick, W.J., "Combustion processes in black liquor recovery: analysis and interpretation of combustion rate data and an engineering design model," U.S. DOE Report DOE/CE/40637-T8 (DE90012712), March 1990.

Frederick, W.J., Noopila, T., and Hupa, M., "Swelling of pulping liquor droplets during combustion," J. Pulp Paper Sci. , 17(5):J164-J170 (1991).

Hupa, M, Backman, R., Hyöty, P., Proc. Black Liquor Recovery Boiler Symposium 1982, Helsinki (August 31-September 1, 1982).

Hupa, N., Solin, P., Hyöty, P., "Combustion Behavior of Black Liquor Droplets," J. Pulp Paper Sci. , 13(2):J67-72 (1987).

Hyöty, P., Uppstu, E., and Karvinen, R., "Alternative air register arrangement for recovery furnace," Proc. 1989 Intl. Chem. Recovery Conf., Ottawa, April 3-6, 1989.

Merriam, R.L., "Kraft-version 2.0, computer model of a kraft recovery boiler," American Paper Institute, New York, NY, December 1980.

Merriam, R.L., Richardson, D.L., Grace, T.M., Taylor, M.L., AIChE Symp. Ser., 200(76):99-112 (1980). 
Miller, P.T., Clay, D.T., "Swelling of kraft black liquor during pyrolysis," AIChE For. Prod. Div. Symp., V. 1 (1986), pp. 152-159.

Noopila, T., Alén, R., Hupa, M., "Combustion properties of laboratory-made black liquors," J. Pulp Paper Sci., 17(4):J105-J109 (1991).

Walsh, A., Jones, A., Sumnicht, D., and Grace, T., "Three-dimensional mathematical model of the kraft recovery furnace," Proc. 1989 Intl. Chem. Recovery Conf., Ottawa, April 3-6, 1989, pp. 1-8. 


\section{VOLATILES AND CHAR CARBON YIELDS}

During devolatilization of black liquor, the organic matter degrades thermally, releasing as volatiles $\mathrm{CO}_{2}, \mathrm{CO}, \mathrm{H}_{2} \mathrm{O}, \mathrm{H}_{2}, \mathrm{CH}_{4}$, other light hydrocarbcns, tars, $\mathrm{H}_{2} \mathrm{~S}$, and mercaptans (Kubes et al., 1982; Bhattacharya et al., 1986; Söderhjelm et al., 1989, Li and van Heiningen, 1991). Devolatilization begins when black liquor is heated above $200^{\circ} \mathrm{C}$ and is practically complete when the residue temperature reaches $650-750^{\circ} \mathrm{C}$, depending upon heating rate (Hupa et al, 1987; Frederick, 1990). The remaining solid material contains the residual nonvolatile organic along with most of the inorganic matter.

The volatiles yield is an important parameter in modeling black liquor combustion because it determines where locally in the furnace heat is released from combustion of the volatile gases. The char carbon content is also important because it determines the char burning time and influences the particle trajectory. While these parameters have been measured for other fuels (Lawn, 1987; Nunn et al., 1985), there has been almost no data available on volatiles yield and char carbon content for black liquor prior to this study.

For most fuels, the volatiles yield and the carbon content of the resulting char after devolatilization are determined by kinetic factors. The volatiles yield normally increases with increasing heating rate during devolatilization, and the char residue decreases (Anthony et al., 1974; Kobayashi et al., 1977; Solomon and Colket, 1978; Suuberg et al., 1978; Niksa et al., 1984). They therefore depend upon boti the temperature of the environment in which the fuel is heated, the size of the fuel particles, and possibly on the dry solids content of the fuel prior to pyrolysis.

The objectives of this study were to investigate the influence of furnace temperature, oxygen content, droplet size, and dry solids content on the volatiles yield and carbon content of char produced during devolatilization. The results are presented in this section, and equations relating them to furnace environment conditions, droplet size, and dry solids content are presented.

\subsection{Experimental}

To determine the volatiles yield and the carbon content of char, single droplets of black liquor of known dry solids content were weighed, suspended on a small platinum hook, and inserted into a hot $\mathrm{N}_{2} / \mathrm{CO}$ environment in a laboratory muffle furnace enclosed in an isolation container. After the desired exposure time, the droplets were removed through a nitrogen quench, cooled, and weighed. The residue was analyzed for carbon content and some of the droplet residues were also analyzed for sodium content. The carbon analyses were made with a Carhomat 1 ADG analyzer (Fa. Wösthoff oHG, Bochum, Germany) and the sodium by flame photometry after acid extraction. All analyses were performed by the Analytische Laboratorien, Fritz-Pregl-Strasse 24, D-5270 Gummersbach, Germany.

The laboratory furnace used in some of the experiments is shown in Figure 3.1. The isolation container is purged with the $\mathrm{N}_{2} / \mathrm{CO}$ mixture to prevent oxygen from reaching the sample during the pyrolysis experiments. This apparatus was used in experiments from 


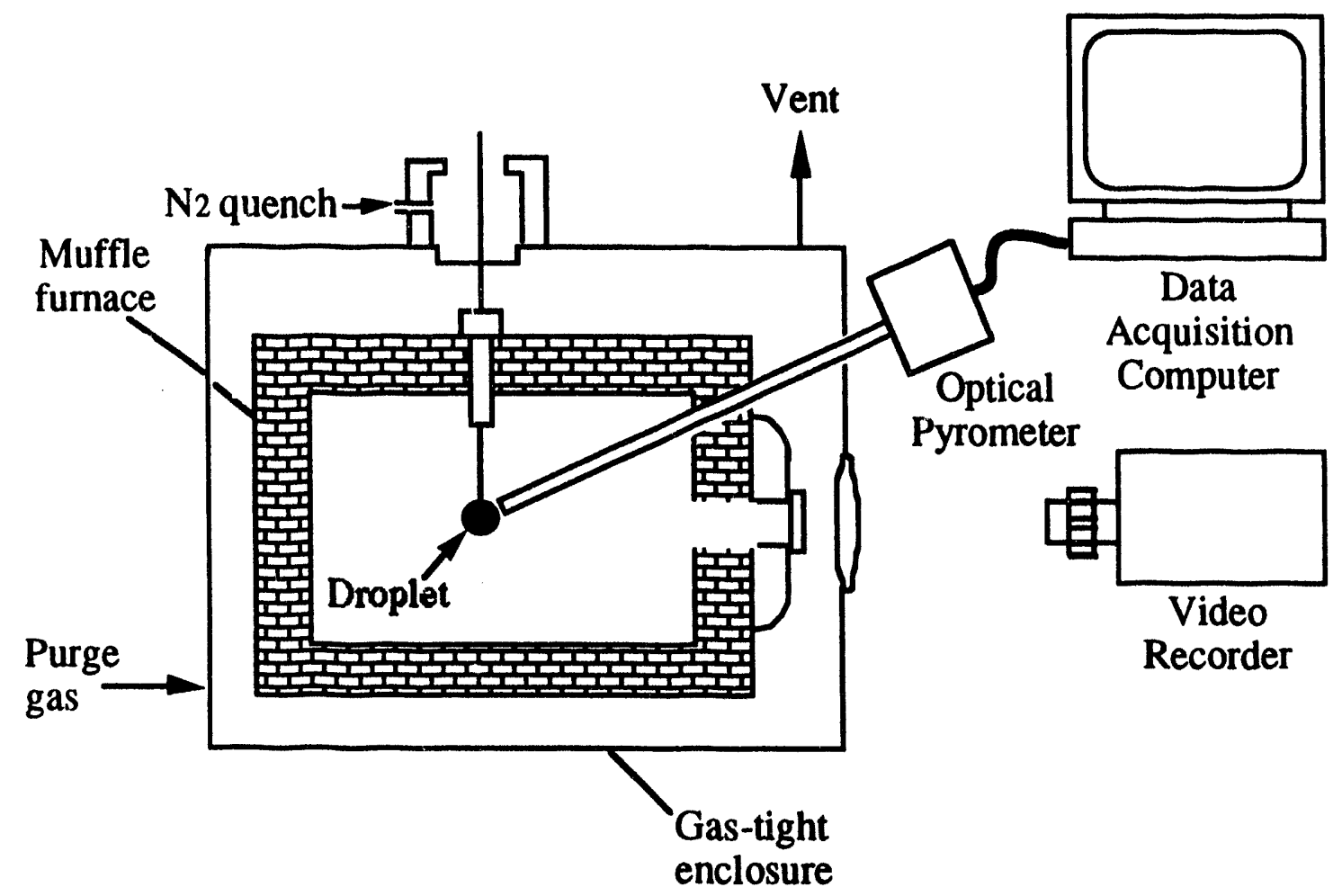

Figure 3.1. Laboratory furnace used for the single droplet pyrolysis and combustion experiments. 
$700-900^{\circ} \mathrm{C}$. In higher temperature experiments, a vertical tube furnace with a quartz tube liner was used. The tube was purged with $\mathrm{N}_{2} / \mathrm{CO}$ and the droplet inserted from above. A $\mathrm{N}_{2}$ quench at the tube exit cooled the char as it was removed and prevented combustion. Similar experiments were made under combustion conditions in air to determine the effect of dry solids content on char burning time.

A total of eight liquors, obtained from pulp mills in Finland, were used in the pyrolysis experiments in this study. The liquor types and the symbols used to designate them in the following analysis are listed in Table 3.1.

Table 3.1. Liquors used in this study and their carbon and sodium contents.

\begin{tabular}{|c|c|c|c|}
\hline Liquor & Type & Carbon, \% & Sodium, \% \\
\hline \hline A & Pine kraft & 39.8 & 15.5 \\
\hline B & Pine kraft & 30.2 & 18.9 \\
\hline C & Pine kraft & 35.1 & 20.0 \\
\hline D & Pine kraft & 35.8 & 19.8 \\
\hline E & Birch kraft & 37.0 & 18.7 \\
\hline F & Birch kraft & 31.1 & 21.0 \\
\hline G & Na-NSSC & 36.7 & 13.8 \\
\hline H & NH ${ }_{3}$-NSSC & 39.0 & 0.1 \\
\hline
\end{tabular}

Three additional liquors, a pine kraft, a birch kraft, and a sodium-base NSSC liquor, were used in the study of the effect of dry solids content on droplet combustion behavior.

\subsection{Experimental Results}

The volatiles yield during pyrolysis and the resulting char composition depend on the losses in both organic and inorganic matter which occur during pyrolysis. For the purpose of modeling combustion of black liquor in recovery boilers, it is important to know both the volatiles yield during pyrolysis and the carbon retained in the char. In the experiments reported here, we have measured both the volatiles yield (defined as the fractional dry solids mass loss) and the carbon retained in char after devolatilization. We will now examine the effect of spray and furnace parameters on those. 


\subsubsection{Effect of Droplet Mass}

To determine whether droplet size significantly influenced the fractional mass loss during pyrolysis, the volatiles yield for droplets of different size were plotted against initial droplet mass at constant exposure time. Some of the data is shown in Figures 3.2 and 3.3. In general the data indicate that there is no correlation of volatiles yield with droplet mass over the range of droplet masses examined in this study. The data at $1000^{\circ} \mathrm{C}$ in Figure 3.3 indicate a possible slight trend of decreasing volatiles yield with droplet size but the trend is not statistically significant.

Similar plots were made for the carbon content of the char (Figures 3.4 and 3.5). As with volatiles yield, there is no trend in carbon content of the char with initial droplet mass.

\subsubsection{Effect of Exposure Time}

Figures 3.6 and 3.7 show how volatiles yield and the carbon content of the char change with time. Both change very rapidly in the time during the first five seconds. The evolution of volatiles during pyrolysis is expected to correspond to the time interval when the droplet swells rapidly (Hupa et al, 1987; Frederick et al., 1991), but swelling is complete within the first five seconds at all three temperatures. In spite of this, the droplets continued to lose weight and carbon for the entire duration of the experiments.

In examining the volatiles yield data, an important point to remember is that what we report here as volatiles is actually the dry mass loss from the particle residue. Part of the volatiles is sodium. In our preliminary study of sodium release during pyrolysis, our results so far (Figure 3.8, data at 700 and $800^{\circ} \mathrm{C}$ ) indicate that $16-33 \%$ of the sodium in black liquor is volatilized during pyrolysis of single droplets of black liquor. The data on sodium loss during devolatilization currently available is quite limited (Frederick and Hupa, 1991; Verrill and Nichols, 1991), and a study aimed improving the understanding of sodium loss during all stages of droplet burning is now under way as part of the continuation of the overall project.

The loss of mass and carbon content beyond the end of the expected devolatilization period may be caused by the reduction of $\mathrm{Na}_{2} \mathrm{CO}_{3}$ (Stewart et al., 1981; Srinivasachar et al., 1990). This reaction produces $\mathrm{CO}$ or $\mathrm{CO}$ and $\mathrm{CO}_{2}$ as well as sodium vapor according to the following overall reaction:

$$
\mathrm{Na}_{2} \mathrm{CO}_{3}(\mathrm{l}) \stackrel{\mathrm{C}(\mathrm{s})}{\Rightarrow} \mathrm{Na}, \mathrm{CO}, \mathrm{CO}_{2}
$$

Our preliminary data on sodium loss under these conditions (Figure $3.8,900^{\circ} \mathrm{C}$ data) indicates that this may be the case. Volkov et al. (1980) reported similar results.

We obtained additional data on the volatilization of sodium and conversion char carbon to gases by pyrolyzing black liquor droplets in $5-50 \% \mathrm{CO}$ in $\mathrm{N}_{2}$. Plots of the carbon remaining in the droplets versus time for the different $\mathrm{CO}$ concentrations (Figure 3.9) show that 




Figure 3.2. Volatiles yield versus droplet mass for liquors $\mathrm{C}$ and J pyrolyzed for 10 seconds at $800^{\circ} \mathrm{C}$. 


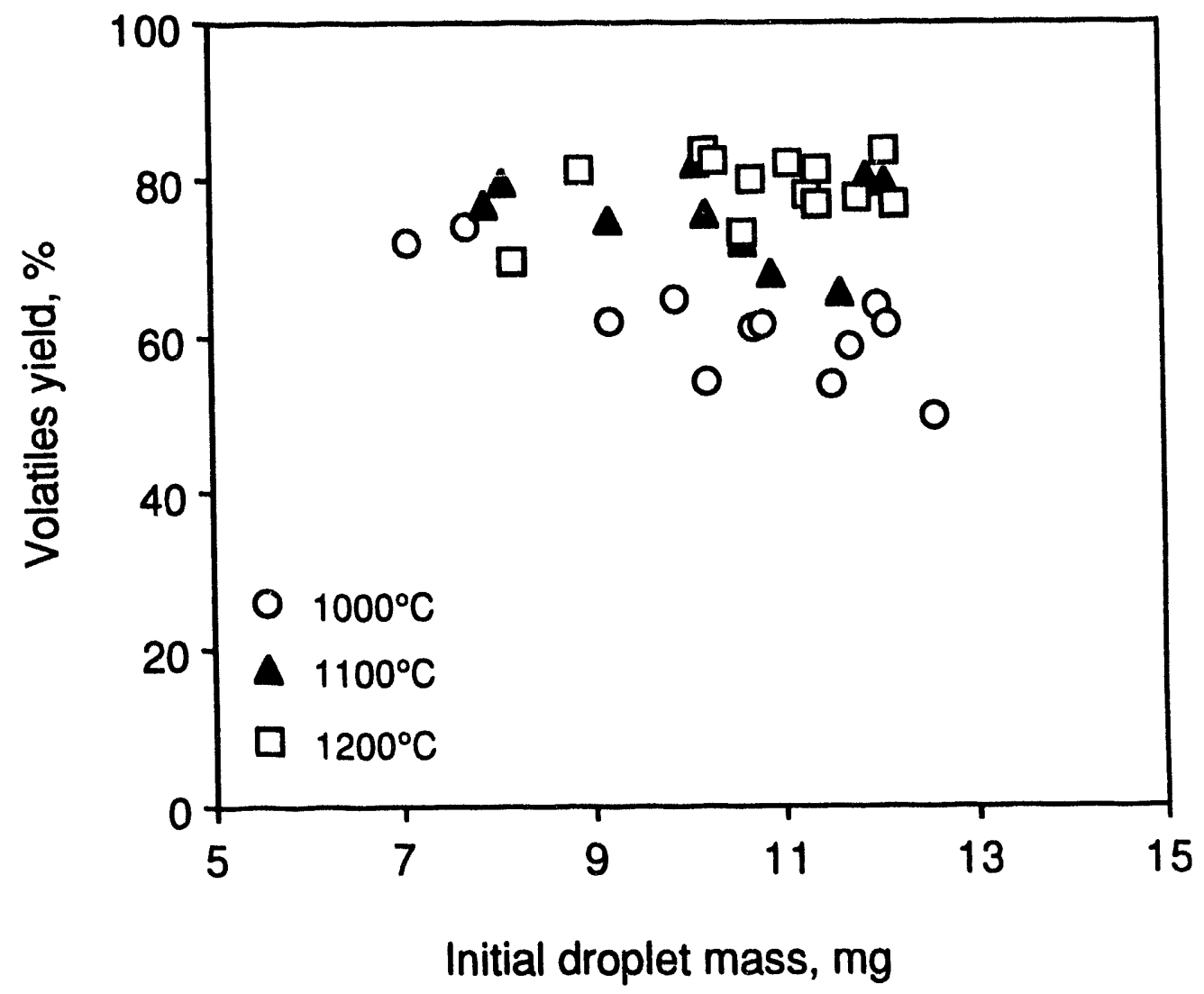

Figure 3.3. Volatiles yield versus droplet mass for liquor A pyrolyzed at 1000$1200^{\circ} \mathrm{C}$. $60 \%$ initial dry solids content. 


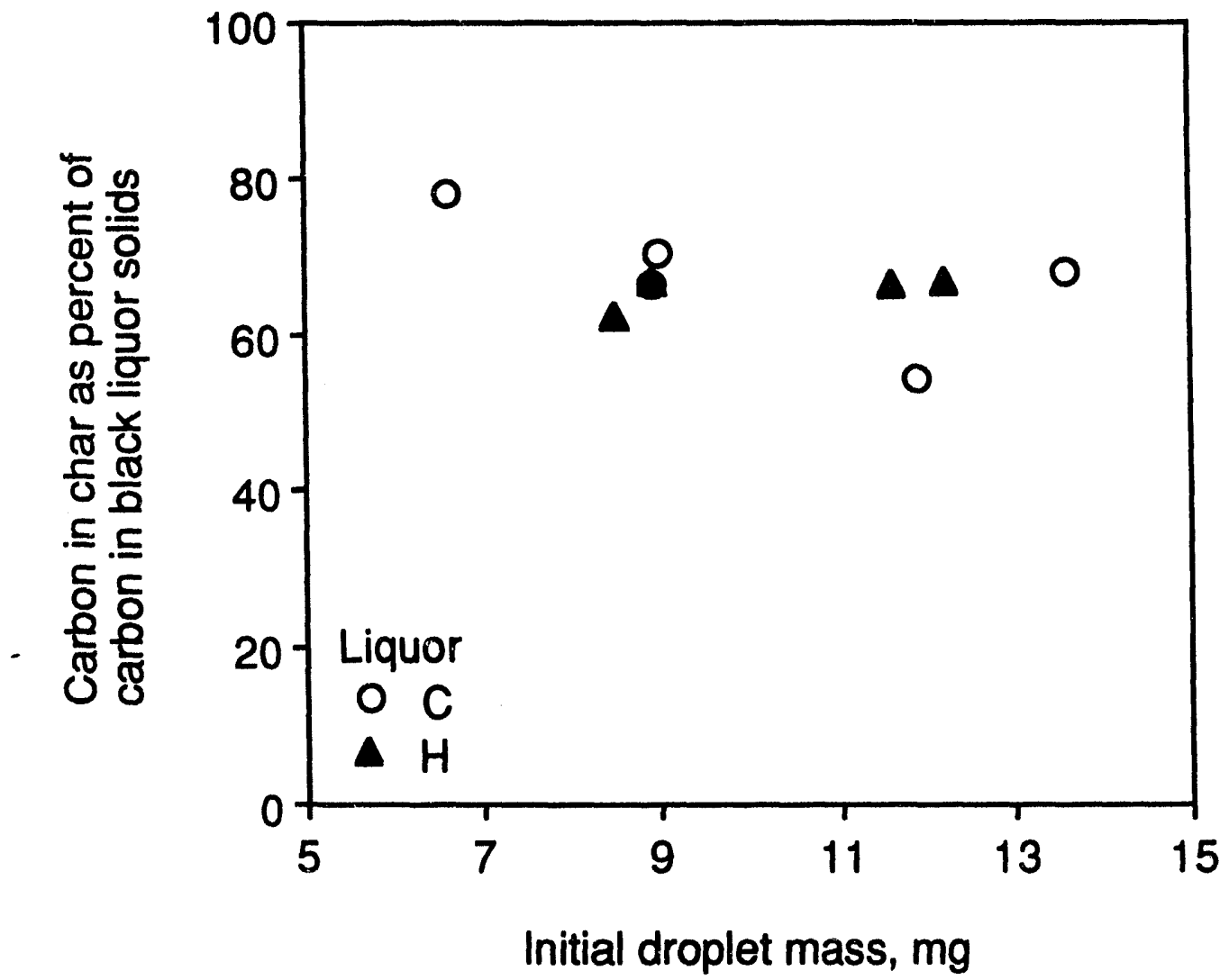

Figure 3.4. Carbon residual in char versus droplet mass for liquors $\mathrm{C}$ and $\mathrm{J}$ pyrolyzed for 10 seconds at $800^{\circ} \mathrm{C}$. 


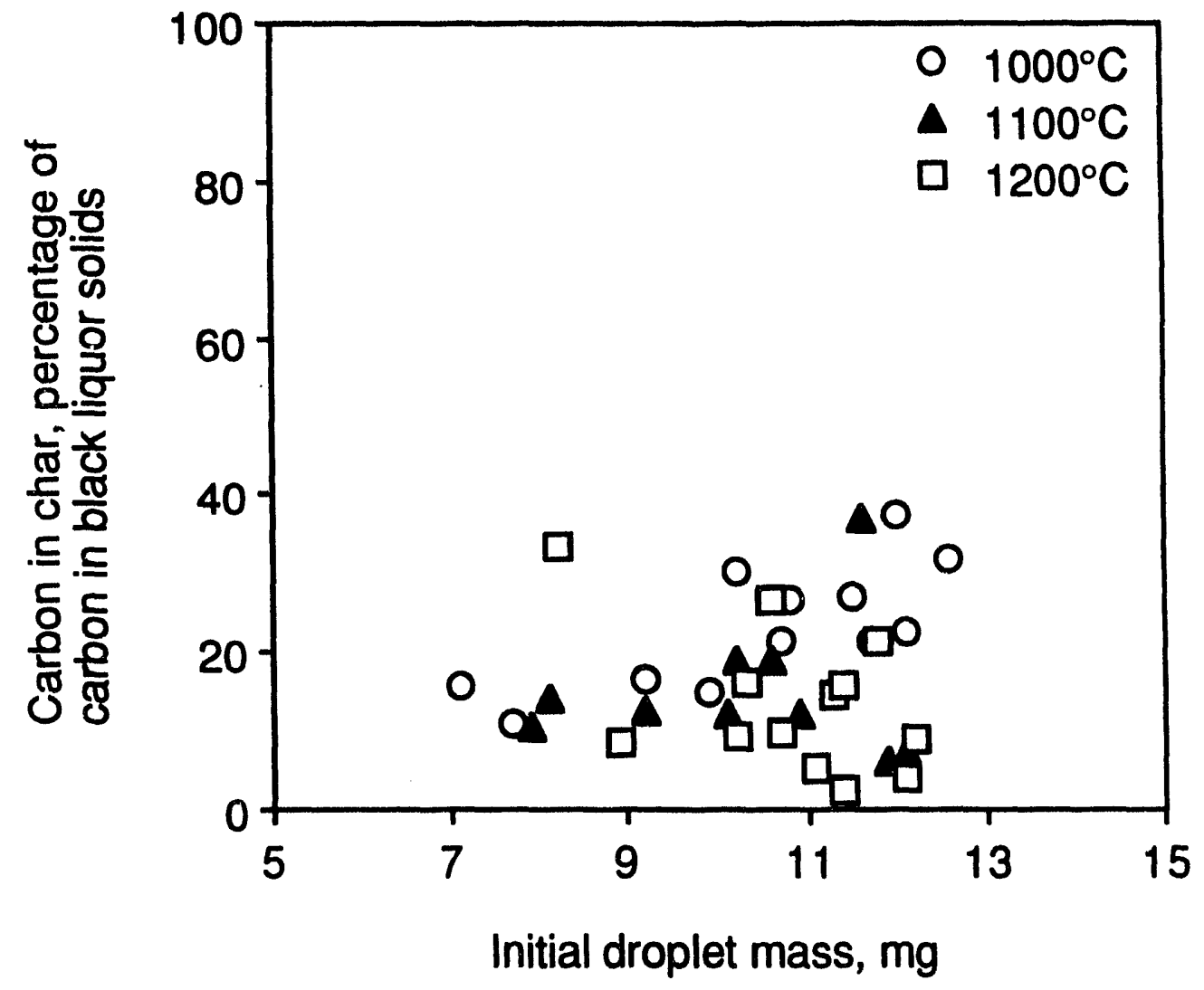

Figure 3.5. Carbon residual in char versus droplet mass for liquor $A$ pyrolyzed at $1000-1200^{\circ} \mathrm{C}$. $60 \%$ initial dry solids content. 


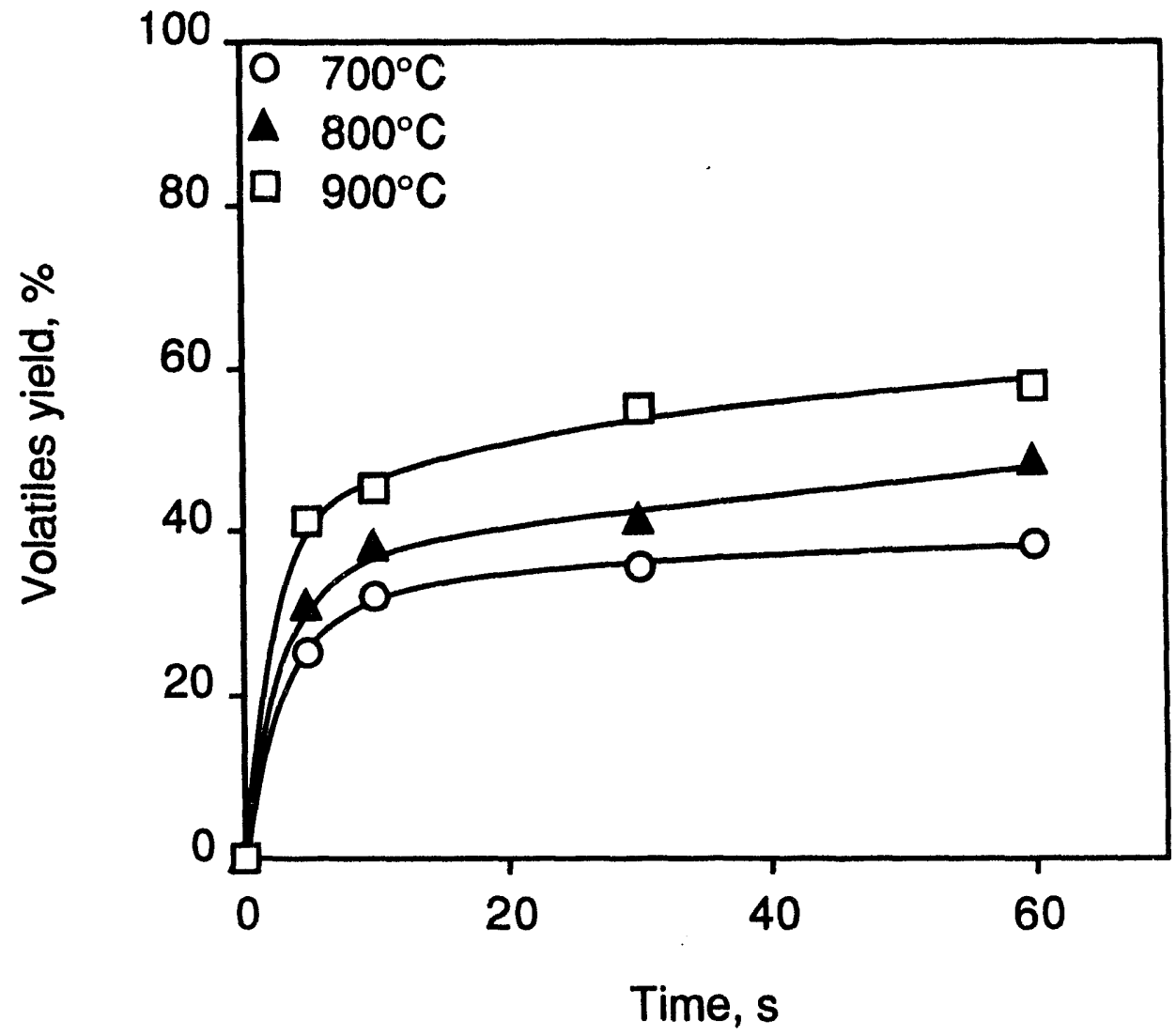

Figure 3.6. Volatiles yield versus pyrolysis time for liquor A pyrolyzed at 700$900^{\circ} \mathrm{C}, 95 \% \mathrm{~N}_{2} / 5 \% \mathrm{CO}$ gas environment. $60 \%$ initial dry solids content. 


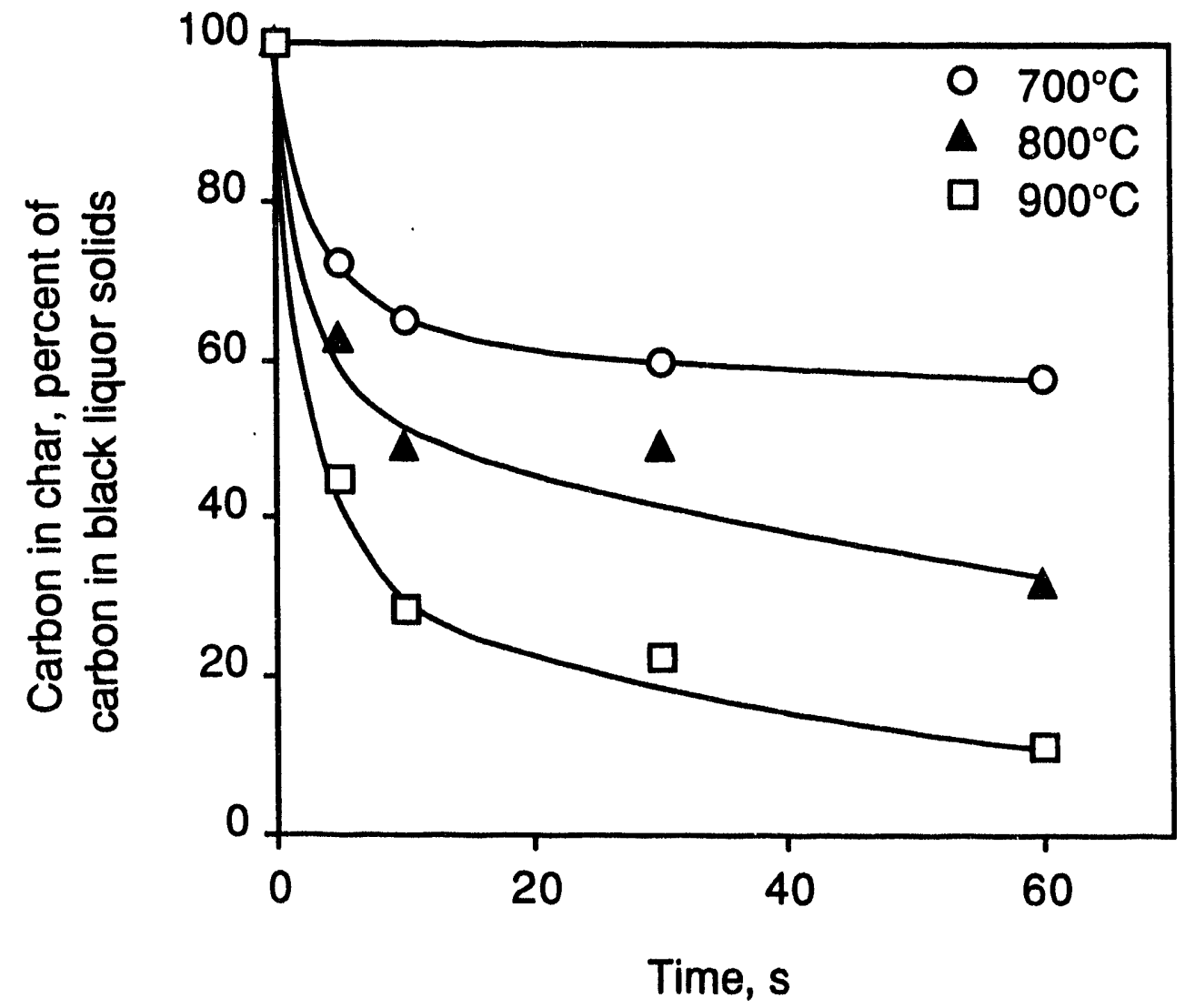

Figure 3.7. Carbon residual in char versus pyrolysis time for liquor $A$ pyrolyzed at $700-900^{\circ} \mathrm{C}, 95 \% \mathrm{~N}_{2} / 5 \% \mathrm{CO}$ gas environment. $60 \%$ initial dry solids content. 


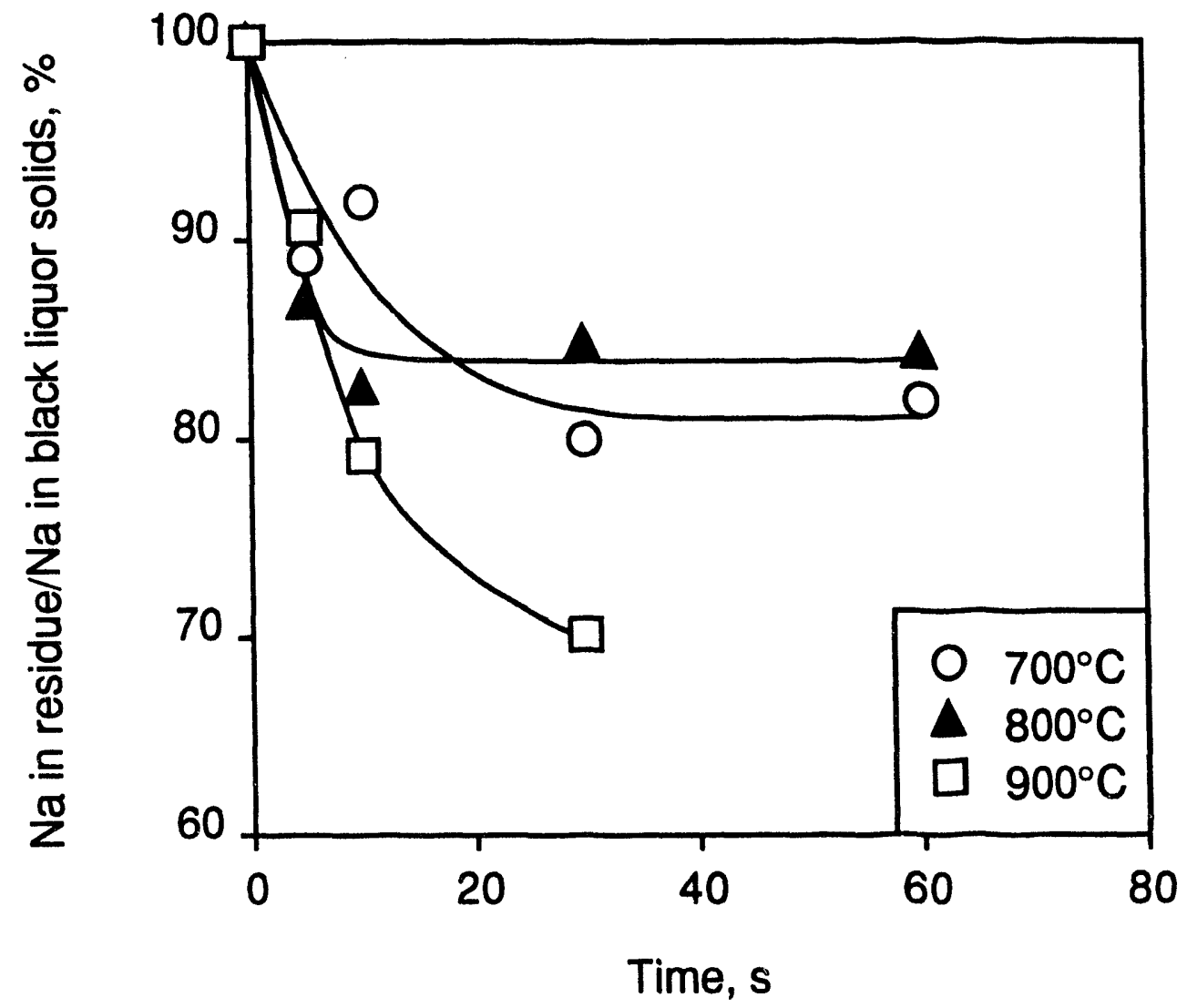

Figure 3.8. Sodium in droplet residue as percent of sodium originally in black liquor droplet. Liquor $\mathrm{A}$, pyrolysis in $5 \% \mathrm{CO}, 95 \% \mathrm{~N}_{2}$. 


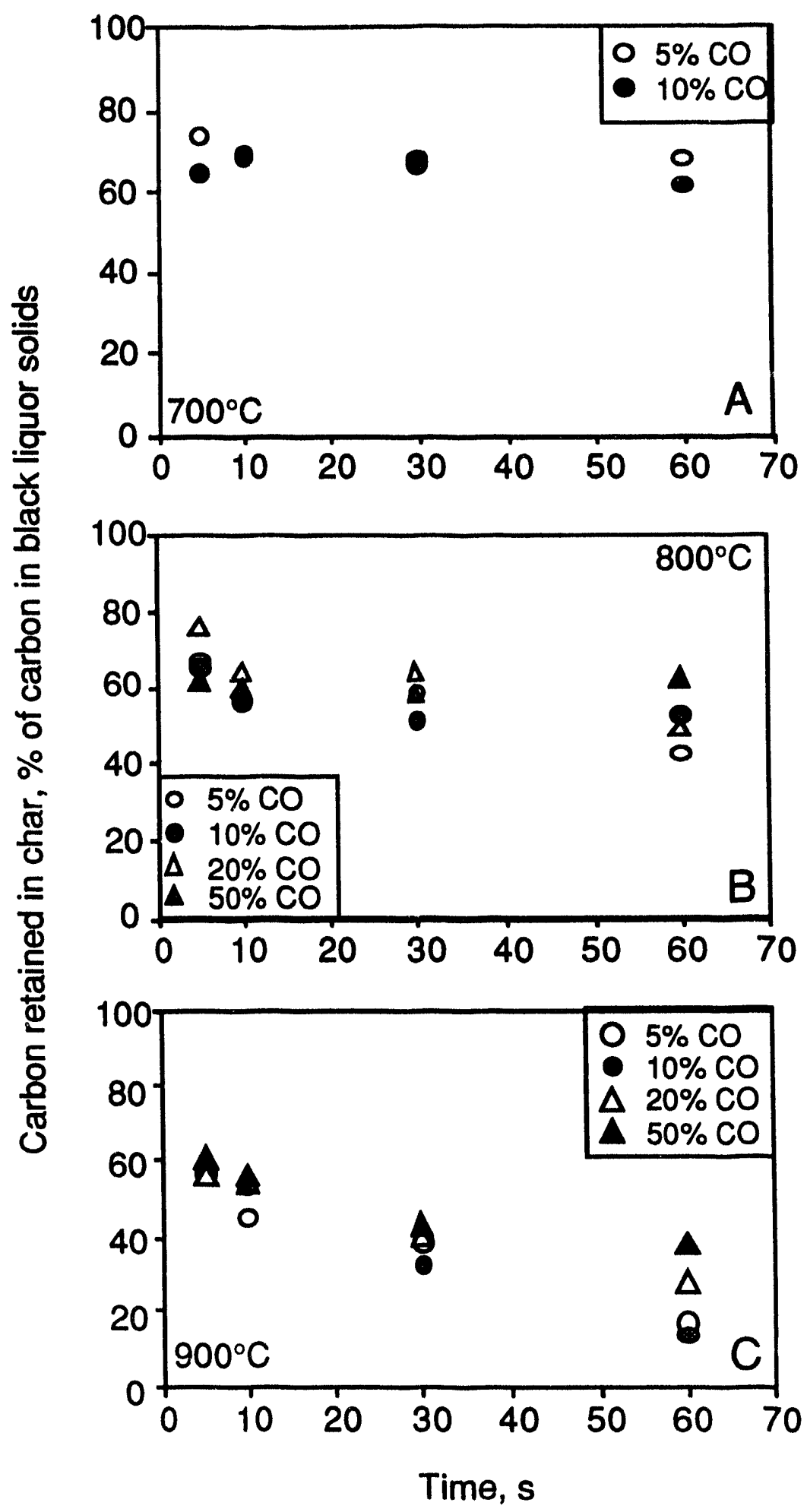

Figure 3.9. Carbon remaining in char versus time for black liquor droplets pyrolyzed in $\mathrm{CO} / \mathrm{N}_{2}$ mixtures with different $\mathrm{CO}$ concentrations. (A) $700^{\circ} \mathrm{C}$; (B) $800^{\circ} \mathrm{C}$; (C) $900^{\circ} \mathrm{C}$. 
at $700^{\circ} \mathrm{C}$, the carbon content of the residue did not change after pyrolysis (Figure 3.9A) and there was no effect of $\mathrm{CO}$ concentration on the amount of carbon remaining. The results at $800^{\circ} \mathrm{C}$ were similar to those at $700^{\circ} \mathrm{C}$ (Figure 3.9B) - there is no clear trend in char carbon content with $\mathrm{CO}$. At $900^{\circ} \mathrm{C}$, however, the char carbon content decrease with time after devolatilization (Figure 3.9C). The rate of char carbon loss is slower at the higher CO concentrations. Although the differences are small, this data at least is not inconsistent with sodium carbonate reduction via reactions 1 or 2 as a mechanism of carbon conversion and sodium volatilization via inorganic reactions after pyrolysis is complete.

As another test of the $\mathrm{Na}_{2} \mathrm{CO}_{3}$ reduction hypothesis, we calculated the ratio of the change in sodium content to the change in carbon content for the char residue after devolatilization was complete. The data, taken with a gas composition of $5 \% \mathrm{CO} / 95 \% \mathrm{~N}_{2}$, was smoothed by fitting to an exponential equation prior to calculation of the ratios. The results, shown in Table 3.2, indicate that the nolar ratio of sodium/carbon loss at $900^{\circ} \mathrm{C}$ is about $1 / 3$. This is less than the expected ratio for $\mathrm{Na}_{2} \mathrm{CO}_{3}$ decomposition via Eq. (3.1) (1.0 based on fixed carbon reacted) or Eq. (3.2) (2.0 based on fixed carbon reacted). This suggests that part of the carbon converted after devolatilization could be the result of $\mathrm{Na}_{2} \mathrm{CO}_{3}$ reduction and that the remaining carbon is converted to gases by another mechanism, perhaps by sulfate reduction, i.e.

$$
\mathrm{Na}_{2} \mathrm{SO}_{4}(\mathrm{l}) \stackrel{\mathrm{C}(\mathrm{s})}{\Rightarrow} \mathrm{Na}_{2} \mathrm{~S}(\mathrm{l}), \mathrm{CO}, \mathrm{CO}_{2}
$$

Table 3.2. Ratio of sodium/carbon loss from Liack liquor droplet chars after devolatilization is complete. Based on data for droplets pyrolyzed in $5 \% \mathrm{CO} / 95 \% \mathrm{~N}_{2}$, evaluated from carbon and sodium measurements after 10 and 30 seconds in a hot furnace.

\begin{tabular}{|c|c|}
\hline Temperature, ${ }^{\circ} \mathrm{C}$ & $\Delta \mathrm{Na} / \Delta \mathrm{C}$, mole/mole \\
\hline \hline 700 & 0.067 \\
\hline 800 & 0.023 \\
\hline 900 & 0.33 \\
\hline
\end{tabular}

At the lower temperatures, the very low ratios reflect the nearly zero loss of sodium after devolatilization at these temperatures. The conversion of carbon may occur almost entirely by sulfate reduction which occurs at a slow but appreciable rate at these temperatures.

The rate of carbon loss would show a decreasing magnitude of rate with increasing $\mathrm{CO}$ concentration if $\mathrm{Na}_{2} \mathrm{CO}_{3}$ decomposition via Eqs. (3.1) or (3.2) were responsible for the carbon consumption and if $\mathrm{CO}$ were involved in the rate-controlling step in $\mathrm{Na}_{2} \mathrm{CO}_{3}$ reduction. To check the effect of $\mathrm{CO}$ on the rate of carbon conversion to gases, the rates were estimated as the linear slope of the data in Figures 3.9A-C at each $\mathrm{CO}$ concentration. They are shown in 
Table 3.3. This data seems to indicate a decrease in the rate of carbon loss at the higher ( 20 and $50 \%$ ) $\mathrm{CO}$ concentrations.

Table 3.3. Effect of $\mathrm{CO}$ concentration on the rate of char carbon conversion to gases at three temperatures. The uncertainty for the rates is on average $37 \%$.

\begin{tabular}{|c|c|c|}
\hline Temperature, ${ }^{\circ} \mathrm{C}$ & $\mathrm{CO}, \%$ & Rate, $\mathrm{g} \mathrm{C} / 100 \mathrm{~g}$ BLS/s \\
\hline \multirow{2}{*}{700} & 5 & 0.029 \\
\cline { 2 - 3 } & 10 & 0.033 \\
\hline \multirow{3}{*}{800} & 5 & 0.15 \\
\cline { 2 - 3 } & 10 & 0.072 \\
\cline { 2 - 3 } & 20 & 0.17 \\
\cline { 2 - 3 } & 50 & 0.00 \\
\hline \multirow{3}{*}{900} & 5 & 0.27 \\
\cline { 2 - 3 } & 10 & 0.33 \\
\cline { 2 - 3 } & 20 & 0.22 \\
\cline { 2 - 3 } & 50 & 0.16 \\
\hline
\end{tabular}

An important question is whether $\mathrm{Na}_{2} \mathrm{CO}_{3}$ reduction would contribute significantly to the overall burning rate or the amount of sodium volatilized. To answer this question, we compare the rates of carbon conversion and sodium volatilization for burning droplets with the rates obtained from Figure 3.9C. At $900^{\circ} \mathrm{C}$, a $10 \mathrm{mg}$ black liquor droplet at $60 \%$ solids content contains about $0.6 \mathrm{mg}$ carbon at the end of devolatilization and burns in about 3 seconds in a $5 \% \mathrm{O}_{2}, 13 \% \mathrm{CO}_{2}, 15 \% \mathrm{H}_{2} \mathrm{O}$ atmosphere (estimated using the single droplet combustion model developed earlier; Frederick, 1990). This corresponds to a burning rate of about $0.2 \mathrm{mg} \mathrm{C} / \mathrm{s}$.

For the droplets pyrolyzed in nitrogen/CO (Figure 3.9C), the carbon mass change was about $28 \%$ of the carbon in the black liquor solids, or about $0.7 \mathrm{mg}$ in $55 \mathrm{~s}$ for a $10 \mathrm{mg}$ liquor droplet at $60 \%$ dry solids content. This corresponds to a rate of about $0.013 \mathrm{mg} \mathrm{C} / \mathrm{s}$, or more than an order of magnitude slower than the carbon burning rate with $\mathrm{O}_{2}, \mathrm{CO}_{2}$, and $\mathrm{H}_{2} \mathrm{O}$. At least at $900^{\circ} \mathrm{C}$, the rate of carbon conversion by inorganic processes after pyrolysis is not a major factor in the overall burning rate. The differences in rates could be smaller at higher temperatures and data at higher temperatures is needed before this question can be answered conclusively with respect to carbon conversion.

To check the importance of sodium volatilized after pyrolysis, we compare the total amounts of sodium volatilized during pyrolysis with that volatilized by the inorganic reactions after pyrolysis. During pyrolysis, about $20 \%$ of the sodium, or $0.24 \mathrm{mg} \mathrm{Na}$, is volatilized during pyrolysis. The rate of $\mathrm{Na}$ volatilization after pyrolysis, at the experimentally measured 
ratio of $0.33 \mathrm{moles} \mathrm{Na} / \mathrm{mole} \mathrm{C}$, would be $.00083 \mathrm{mg} \mathrm{Na} / \mathrm{s}$ which corresponds to $0.7 \%$ of $\mathrm{Na}$ in BLS/s or $0.14 \mathrm{~g} \mathrm{Na} / \mathrm{kg} \mathrm{BLS} / \mathrm{s}$. During the $3 \mathrm{~s}$ in which char burning occurs, the total amount of sodium volatilized by this mechanism would be $0.0025 \mathrm{mg}$. This is two orders of magnitude less than during pyrolysis. It therefore would contribute little to the total sodium fume evolved. A more in-depth study of the loss of sodium during black liquor combustion is currently under investigation and will be presented in detail in next year's report.

\subsubsection{Effect of Temperature}

The data in Figures 3.2-3.7 and 3.9 suggest trends in volatiles loss and residual carbon with temperature. The effect of temperature on volatiles yield is seen more clearly in Figure 3.10, where the data for liquor $A$ are plotted versus temperature. The average values are based

on data for all droplet masses. The results shows a clear trend of increasing volatiles yield with temperature.

A similar plot of residual carbon in the char particles (Figure 3.11) shows a corrcsponding rapid decrease in char carbon content with increasing temperature.

\subsubsection{Effect of Liquor Type}

Figure 3.12 shows volatiles yield data for eight different liquors measured at $800^{\circ} \mathrm{C}, 10 \mathrm{~s}$ exposure time. The char carbon content as a fraction of the original carbon content of the unburned droplet ranges from $26-48 \%$ for the kraft liquors and is higher for the NSSC liquors. There is surprisingly little variation for the four pine kraft liquors as a group, and also for the two birch kraft liquors. Similar observations can be made for the volatiles yield which ranged from $35-47 \%$ of the dry black liquor solids at these conditions.

These limited results suggest a moderate variation in both the volatiles yield and the carbon residual in char after pyrolysis as a percentage of the carbon originally in the black liquor at least within the category of wood species. However, the number of different liquors in this study was quite limited. This work needs to be extended a larger number of liquors and to liquors based on other wood species to determine the actual range of variation among liquors.

In Figure 3.12, the sulfite liquors have both a higher volatiles yield and retain more carbon in the char than do the kraft liquors. The higher volatiles yield is because of the lower inorganic content of the sulfite liquors. The higher fraction of carbon retained is probably due to the difference in chemical nature of the lignin in sulfite liquors and the differences in lig$\mathrm{nin} /$ carbohydrate ratio of the organic fraction. The higher residual carbon content of the char, along with the poorer swelling of sulfite liquors, accounts for the slower burning rates as reported earlier (Hupa et al., 1987) 


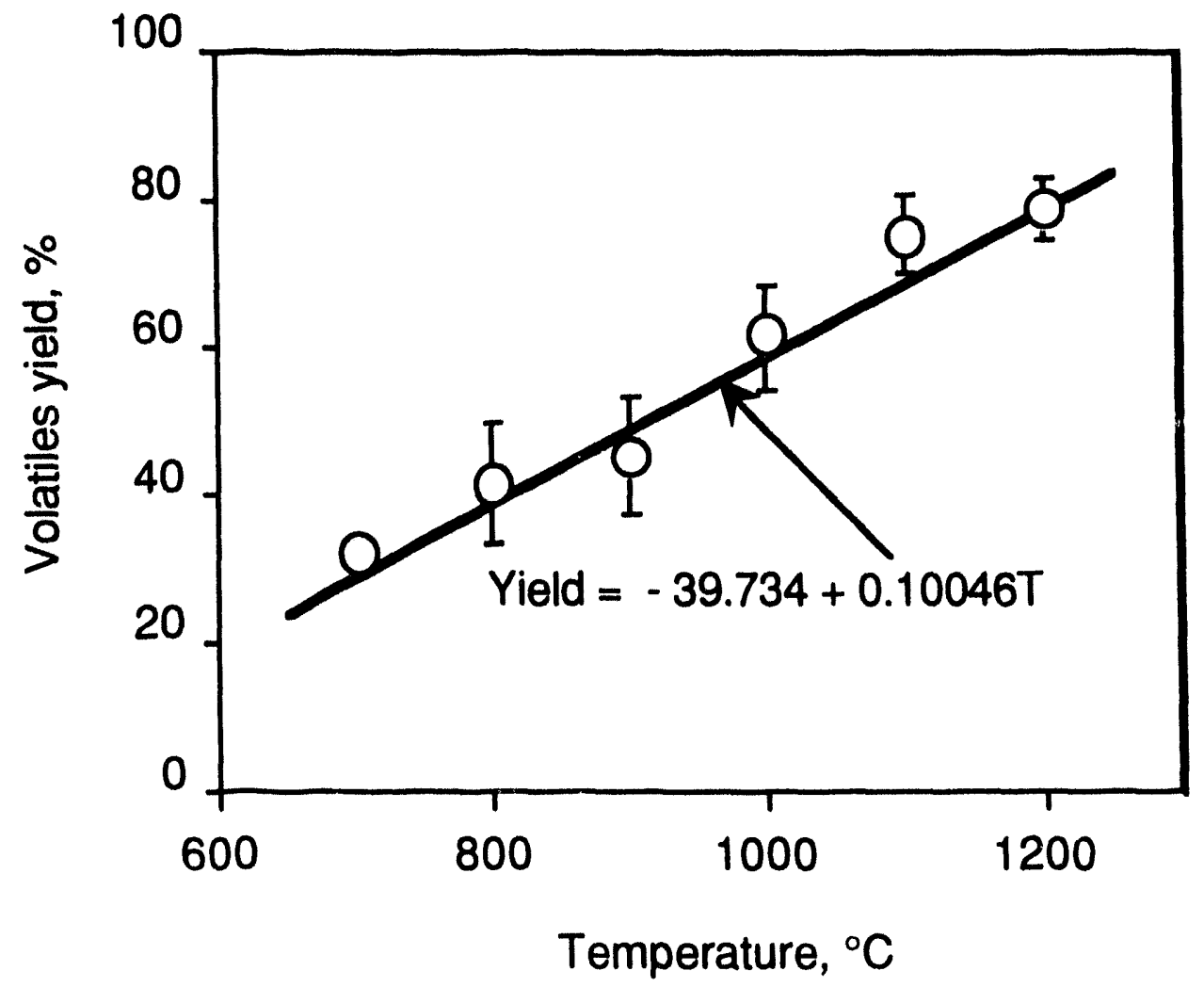

Figure 3.10. Volatiles yield versus temperature for liquor $1.10 \mathrm{~s}$ pyrolysis time, $60-65 \%$ dry solids content. Error bars indicate \pm 1 standard deviation. 


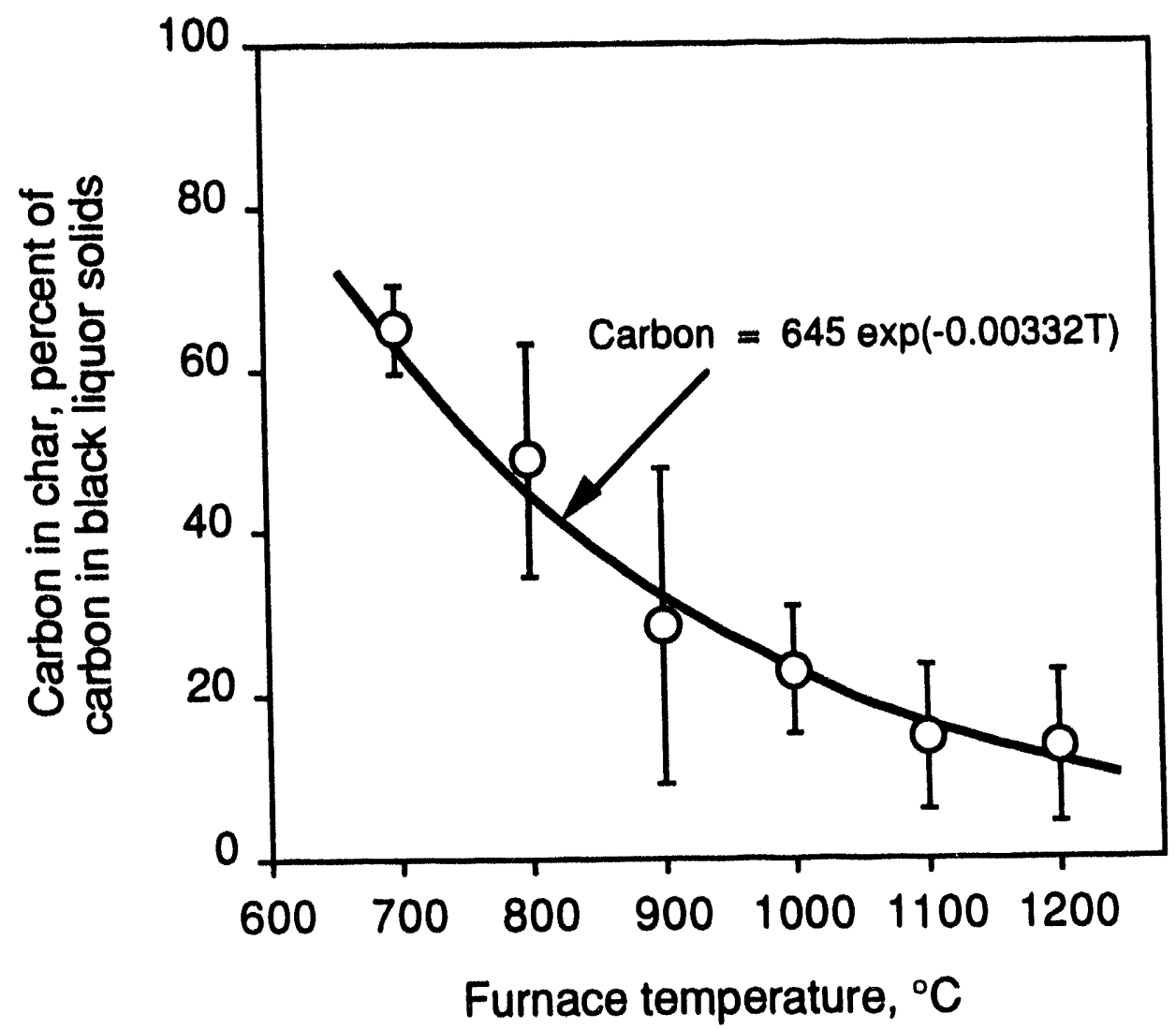

Figure 3.11. Carbon content of char versus temperature for liquor $1.10 \mathrm{~s}$ pyrolysis time, $60-65 \%$ dry solids content. Error bars indicate \pm 1 standard deviation. 




Figure 3.12. Carbon mass in char as percent of carbon originally in black liquor solids (darker bars, left side of each pair) and volatiles yield as percent of black liquor solids (lighter bars, right side of each pair) for eight liquors pyrolyzed for 10 seconds at $800^{\circ} \mathrm{C}$ in $5 \% \mathrm{CO}, 95 \%$ nitrogen. 


\subsubsection{Effect of Dry Solids Content}

The effect of dry solids content on the volatiles yield and carbon content of the char residue after pyrolysis were inferred from single droplet combustion measurements. Figures 3.13 and 3.14 show how the combustion time for black liquor char varies with dry solids content for three liquors. The points in these figures are experimental data. The data are for droplets of constant mass and therefore different dry solids mass per droplet; for that reason the results are presented as burning times per $\mathrm{mg}$ black liquor solids. The smooth curves are estimates of char burning times based on a char burning model developed earlier (Frederick, 1990). The calculations were made using experimental swelling measurements for each liquor and char carbon contents based on the correlation

$$
X_{c}=A-B T_{g}
$$

where $\mathrm{X}_{\mathrm{c}}$ is the carbon content of the char expressed as $\mathrm{g}$ carbon in char/g black liquor solids before pyrolysis, $(A, B)$ are respectively $\left(0.408,3.84 \times 10^{-4}\right)$ for the kraft liquors and $(0.542$, $4.97 \times 10^{-4}$ ) for the sulfite liquor, and $T_{g}$ is the bulk gas temperature surrounding the burning droplets in ${ }^{\circ} \mathrm{C}$. The carbon content of the char at the end of pyrolysis was assumed to be independent of the dry solids content of the droplet.

The data in Figures 3.13 and 3.14 show that the burning time per mg dry solids is independent of dry solids content. This in itself is strong evidence that the carbon content of char is independent of the dry solids content. If the volatiles yield and carbon content of char after pyrolysis were not greatly different for each liquor type as suggested by Figure 3.12, it would also imply that the volatiles yield is independent of dry solids content. Also, the measured and predicted char burning times in Figures 3.13 and 3.14 generally agree well. This is additional strong support of our assumption that the carbon content of the char at the end of pyrolysis is independent of the dry solids content of the droplet. We conclude that both the carbon content of char after pyrolysis and the volatiles yield are either independent or not strong functions of the dry solids content of the droplets burned.

\subsection{Interpretation and Application to Modeling}

With the results presented in this chapter, it is possible to make a preliminary estimate the volatiles yield and the carbon content of char after pyrolysis for a black liquor droplet which has been subjected to a furnace environment of constant temperature. The best algorithm currently available to estimate them in the temperature range $700-1200^{\circ} \mathrm{C}$ is as follows:

$$
\text { Yield }=\mathrm{A}+\mathrm{BT}
$$




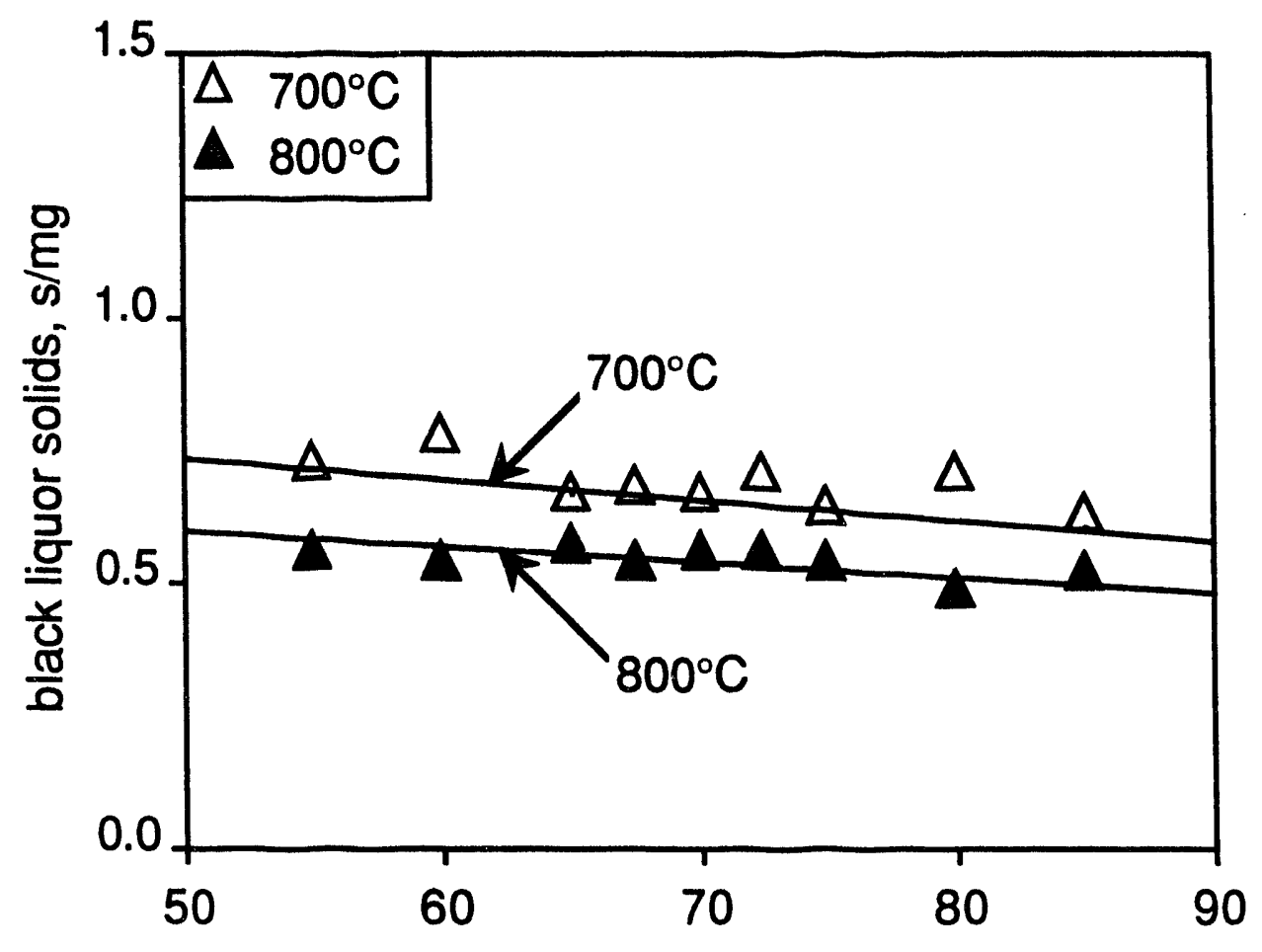

Figure 3.13. Char burning time per mg water versus dry solids content at for a birch kraft liquor burned in air. Lines are predictions from the single droplet combustion model (Frederick, 1990). 


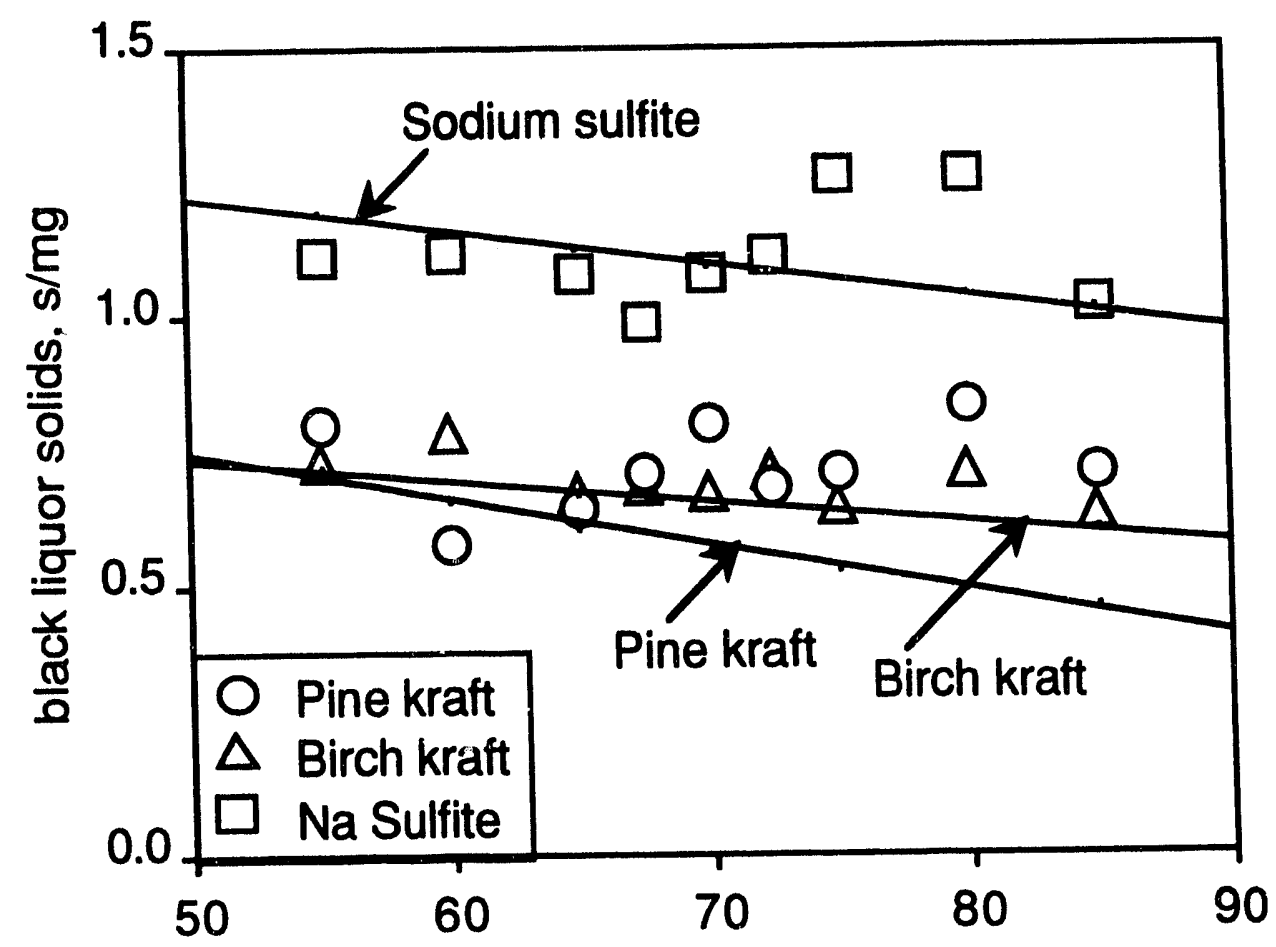

Figure 3.14. Char burning time per mg black liquor solids versus dry solids content for three liquors at $700^{\circ} \mathrm{C}$. Lines are predictions from the single droplet combustion model (Frederick, 1990). 
Carbon $=\mathrm{C} \exp (\mathrm{DT})$

No effect of droplet mass

No effect of dry solids content

No effect of gas environment

where yield is given as percent of dry liquor solids mass, carbon as percent of the carbon initially in the dry liquor solids, and temperature in ${ }^{\circ} \mathrm{C}$. The constants A-D, based on the data in Figures 3.10-3.12 to account for differences in pine and birch liquors, are given in Table 3.4.

Table 3.4. Constants for estimating yield and char carbon for pine and birch pulps.

\begin{tabular}{|c|c|c|}
\hline Liquor type & Pine & Birch \\
\hline \hline $\mathrm{A}$ & -39.7 & -39.7 \\
\hline $\mathrm{B}$ & 0.100 & 0.100 \\
\hline $\mathrm{C}$ & 645 & 421 \\
\hline $\mathrm{D}$ & -0.00332 & -0.00332 \\
\hline
\end{tabular}

In the char combustion model developed earlier (Frederick, 1990), the carbon content of the char is expressed as $X_{c}$, the fraction of the original black liquor solids which remains as carbon after pyrolysis. The correlation for carbon remaining after pyrolysis can be converted to $X_{c}$ by multiplying the right side of the equation by the carbon content of black liquor.

As a test of the correlation for carbon in char after pyrolysis, the data from Figure 3.10 are replotted as $X_{c}$ versus temperature in Figure 3.15. Also plotted in Figure 3.15 are $X_{c}$ values for two other kraft liquors, a pine and a birch liquor. The values for these two liquors were obtained from experimental char burning data, by adjusting $X_{c}$ in the calculations to force the experimental and calculated char burning times to agree. The single droplet combustion model developed earlier (Frederick, 1990) was used for these calculations.

The $\mathrm{X}_{\mathrm{c}}$ values based on droplet combustion times fall below the correlation based on pyrolysis measurements at low temperatures, but the two merge at about $900^{\circ} \mathrm{C}$. The discrepancy at the lower temperatures may arise because of the effect of the flame surrounding the particle for the droplets burned in air. However, the apparent agreement between the two in the temperature range of greater interest in recovery boilers $\left(900-1200^{\circ} \mathrm{C}\right)$ provides added support for the carbon in char versus temperature correlation. In addition, the combustion environment would rarely be air, but instead a lower $\mathrm{O}_{2}$ content combustion gas. The flame temperature is nearly the same as the furnace temperature when the $\mathrm{O}_{2}$ content is less than $10 \%$ (see Chapter 3), so the temperature environment for the burning droplet is in effect the surrounding 


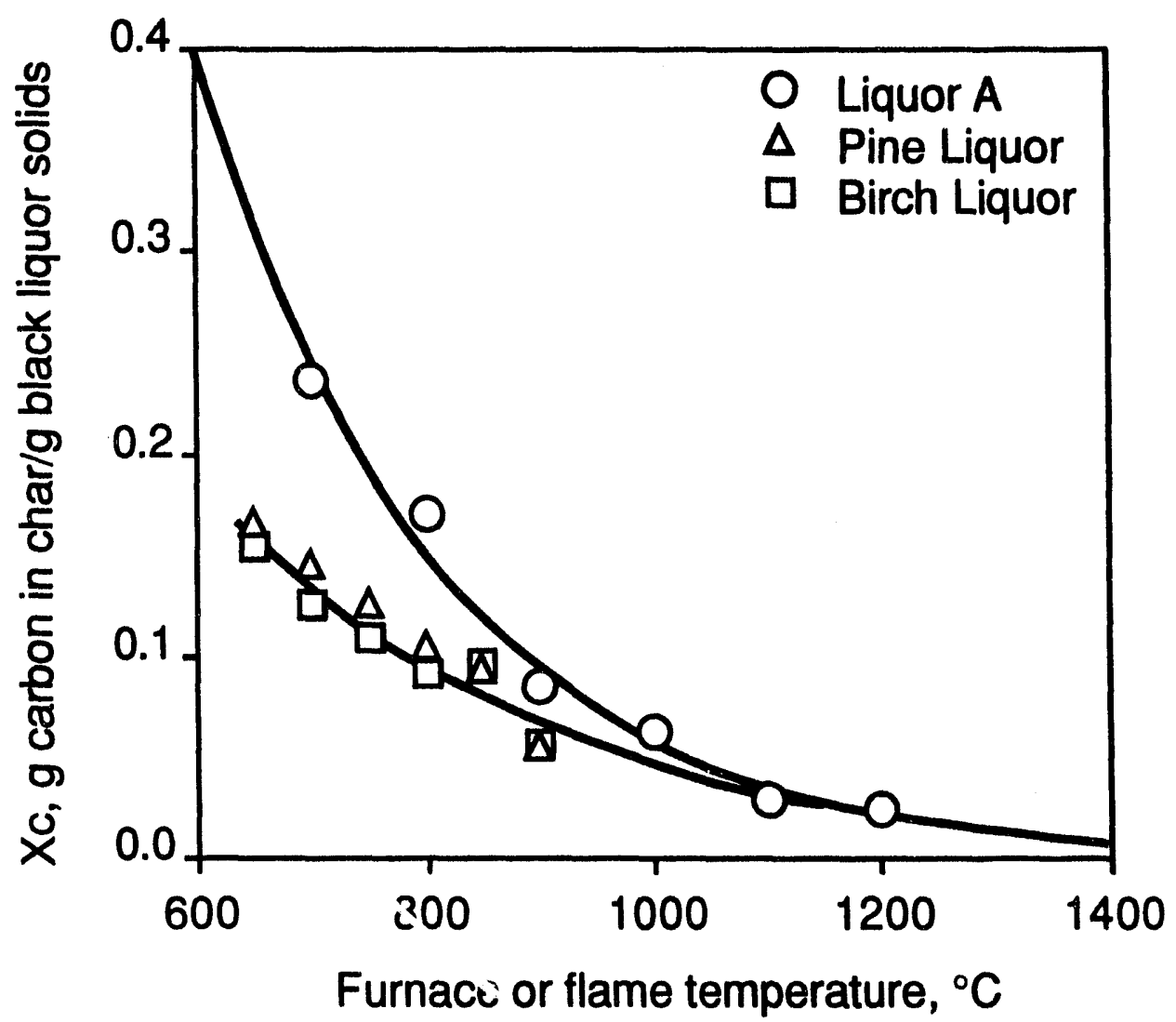

Figure 3.15. Char carbon at the end of pyrolysis versus furnace temperature for three kraft liquors. 
furnace gas environment. We therefore recommend that the correlation based on the experimentally measured carbon in char values be used to estimate this parameter in black liquor combustion. The last part of the algorithm, no effect of gas environment, results from this analysis based on Figure 3.15.

It should be noted that the algorithm presented here is preliminary and very approximate. A major limitation is that it is based on 10 second droplet pyrolysis data. At the higher temperatures, 10 seconds is well beyond the pyrolysis stage, and significant carbon is apparently consumed by sodium carbonate reduction or other mechanisms. A more detailed analysis of the data, to separate the devolatilization process from inorganic reactions which proceed following devolatilization is needed to model adequately the devolatilization process. This will be part of the work in the following project on sulfur and sodium release. A brief description of the work planned is presented in the following section.

\subsection{Proposed Model for Volatiles Yield Under Nonisothermal Conditions}

In modeling the in-flight combustion of single droplets, the temperature environment is not usually constant but varies with droplet position in the furnace. It is important to be able to estimate the volatiles yield and the carbon content of char after pyrolysis in terms of the temperature history of the droplet and environment. In addition to this problem, estimation of the volatiles yield and mass of the droplet residue is complicated by the following factors:

1. the droplet is not isothermal hut may have steep temperature gradients within (see Chapter 3),

2. the pyrolysis kinetics and product yield for the organic material depend on both the environment temperature and the heating rate of the particle,

3. carbon left in the residue after pyrolysis can be converted to $\mathrm{CO}$ and/or $\mathrm{CO}_{2}$ by direct oxidation of carbon and reduction of $\mathrm{Na}_{2} \mathrm{SO}_{4}$ and/or $\mathrm{Na}_{2} \mathrm{CO}_{3}$,

4. sulfur gases may be volatilized through decomposition of the inorganic salts in the liquor residue, and

5. Sodium is volatilized during pyrolysis.

The problems associated with nonisothermal droplets and gas environments have been solved with detailed modeling of black liquor droplets (Saastamoinen et al., 1988). Unfortunately the models required to calculate droplet temperature and composition profiles are very computation-intensive and far too slow for use in computational fluid dynamics (CFD) modeling of recovery boilers. A more approximate approach is required to provide computationally efficient yet sufficiently accurate droplet burning models for CFD codes. The approach to be used is discussed briefly here and will be used to develop a new droplet combustion model as part of the current project on sulfur and sodium release. 


\subsubsection{Modeling Approach}

The current black liquor droplet model (Frederick, 1990) describes the fate of the droplet mass during burning in terms of four quantities: water, volatiles, fixed (combustible) carbon, and inorganic ash. The new model to be developed will describe the fate of the chemical elements in black liquor: carbon sodium, sulfur, hydrogen, and oxygen. One requirement for the new droplet model is that it be sufficiently flexible so that other elements of interest (potassium, chlorine, nitrogen) can be added as volatilization and combustion rate data become available for them.

Several approaches have been used to deal with the temperature and heating rate dependency of organic volatiles yield (e.g. Kobayashi et al., 1977; Solomon and Colket, 1978). The simplest model which predicts an increase in volatiles yield with increasing temperature is that organic decomposition is governed by competing reactions which have different volatiles yields, and the reactions with the higher volatiles yield have larger activation energies. This method was used successfully by Kobayashi et al. (1977) to describe coal volatilization. In its simplest form, the model has two reactions as shown in Figure 3.16.

This model is too simple for black liquor because of the inorganic reactions which may occur and contribute to the loss of volatiles. A corresponding simple model for black liquor pyrolysis must also account for the formation of $\mathrm{Na}_{2} \mathrm{CO}_{3}$ as a product of the decomposition of sodium salts of the lignin and carbohydrate acids, and reduction of $\mathrm{Na}_{2} \mathrm{SO}_{4}$ and $\mathrm{Na}_{2} \mathrm{CO}_{3}$ with carbon. It could as well account for sodium and sulfur volatilization in a simplified way, and could be modified to account for potassium, chlorine, and nitrogen. Figure 3.17 shows schematically the basis for one such model.

The framework for the new droplet combustion model is indicated by Figure 3.17. To complete the model, key assumptions regarding droplet temperature, the effect of the environment on droplet temperature, and information on the kinetics of the various reactions which contribute to volatiles formation must be provided. The basis for each of these is described briefly in the following paragraphs. Development of the new droplet model and the kinetic data for it will be part of the sulfur and sodium volatilization project which follows this one (Frederick, 1990).

3.4.1.1 Droplet temperature. To simplify the problem of dealing with the temperature distribution within a droplet, a time-dependent mean droplet temperature will be used. The current droplet combustion model calculates the mean droplet temperature during drying and devolatilization and accounts for the effect of changing furnace temperature on the mean droplet temperat 'ure through the heat flux to the droplet surface (Frederick, 1990). This calculation procedure : vill be used in the new droplet model. A simplified droplet temperature calculation procedure which is applicable for the char burning and smelt reactions stages has been developed by Levenspiel (1989). It will be included in the new droplet model as well.

3.4.1.2 Organic decomposition reactions. Two parallel reactions with different activation energies are assumed to describe the pyrolysis process adequately. The kinetic data for these reactions will be obtained by extracting kinetic constants from the volatiles loss and 


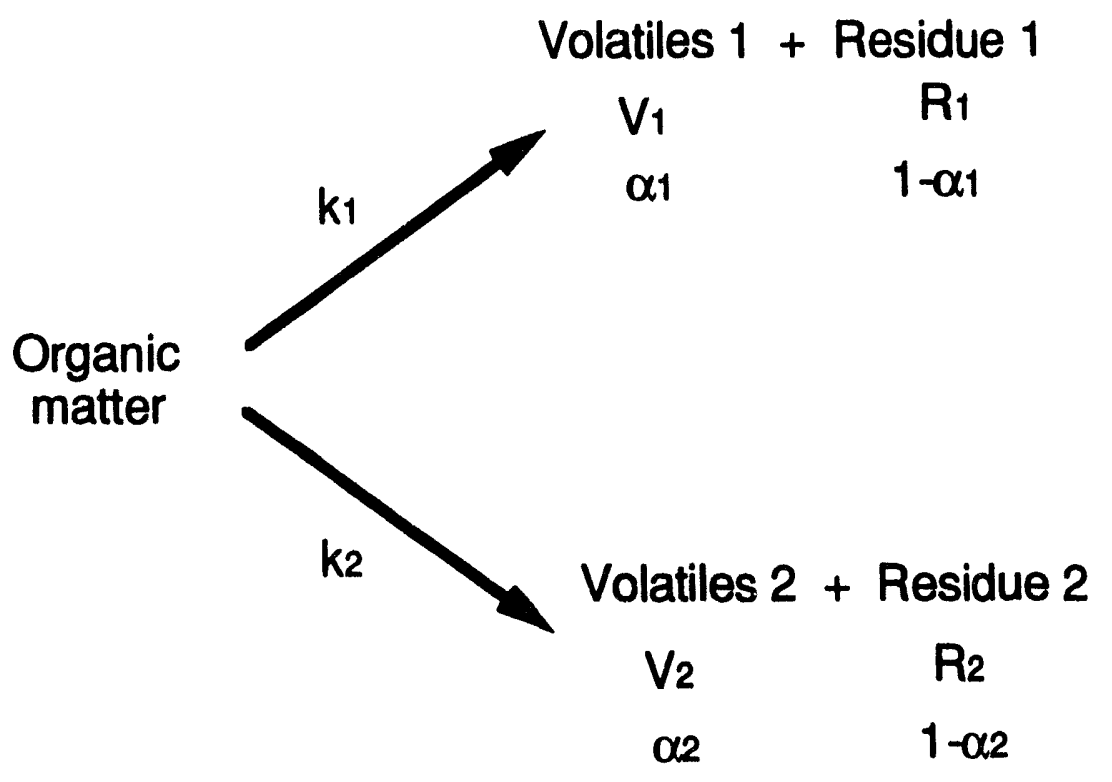

Figure 3.16. Simple two-reaction pyrolysis model. From Kobayashi et al., 1977 




Figure 3.17. Basis for devolatilization model which accounts for individual elements. 
char carbon content data from this study after accounting for sulfur and sodium volatilization rate. The data for these latter two processes will be obtained in the sulfur and sodium volatilization study to follow this on and the parallel study at the Institute of Paper Science and Technology (Verrill and Nichols, 1992.) Most of the data that currently is or will be available is for droplets which are not isothermal. The kinetic model which will be developed will therefore be in terms of pseudokinetics for the decomposition reactions based on the average temperature of the droplets during pyrolysis. In this respect, the kinetic equations obtained will be consistent with the temperature assumptions discussed above.

3.4.1.3 Inorganic reactions during pyrolysis. The reduction of sodium carbonate may contribute to sodium volatilization during pyrolysis of black liquor as discussed earlier in this chapter. Published data, available for $\mathrm{Na}_{2} \mathrm{CO}_{3}$ reduction reactions (Stewart et al., 1981; Srinivasachar et al., 1990; Cameron, 1988), will be used to evaluate the temperatures at which they would proceed at a rate fast enough to contribute to sodium volatilization during either pyrolysis or char combustion. Rate equations for each will be developed from the available data and tested with experimental sodium volatilization data which will be obtained as part of the sulfur and sodium volatilization study which follow the current work. Additional experiments may need to be made to determine how significantly gas composition affects the reaction rates.

3.4.1.4 Char burning reactions. The char burning model will include the contributions of film mass transfer and pore diffusion, but allowing for transition to rate control by the combustion and gasification reactions at lower temperatures. The Levenspiel (1989) model for predicting droplet temperatures will be a key element in this model since droplet surface temperature and reaction kinetics are coupled and determine when the transitions from kinetic to pore diffusion to film mass transfer control occur. The reaction kinetics will be based on published results for carbon burning with oxygen (Wendt, 1988) and by the sulfate-sulfide cycle (Cameron and Grace, 1985), and for carbon gasification with $\mathrm{CO}_{2}$ (Frederick and Hupa, 1991; $\mathrm{Li}$ and van Heiningen, 1990) and water vapor (Whittey et al., 1992; $\mathrm{Li}$ and van Heiningen, 1991).

The formation of elemental sodium by reduction of sodium carbonate or other inorganic reactions will be dealt with as described above.

\subsection{Summary}

Volatiles and char carbon yields were measured for six kraft and two NSSC liquors under a variety of conditions $\left(600-1200^{\circ} \mathrm{C}\right.$, pyrolysis and combustion conditions, 4-20 mg droplets).

The amount of volatiles formed increased and the carbon content of the char decreased with increasing reaction time at constant furnace temperature. Carboil, sodium and total mass loss from the char particles continued beyond devolatilization. We assume that this mass loss after devolatilization is the result of sodium carbonate decomposition. This remains to be verified, however. 
The amount of volatiles increased approximately linearly and the carbon content of the residue decreased exponentially with reaction temperature for constant droplet exposure time in a pyrolysis environment.

Droplet mass had no effect on volatiles or char carbon yield over the range studied.

Based on a limited number of experiments, the volatiles yield from black liquor solids at $800^{\circ} \mathrm{C}$ ranges from $35-47 \%$ of the dry liquor solids while the carbon in the char ranged from $26-48 \%$ of the carbon originally in the black liquor solids. A larger number of liquors and to liquors based on other wood species to better define the range of variation among liquors.

A preliminary correlation has been developed for volatiles and char carbon yield during pyrolysis. However, the correlation does not separate pyrolysis effects from inorganic reactions which occur in a nonreacting gas after pyrolysis is complete. A more detailed analysis of the data to separate these effects will be accomplished as part of the project on sulfur and sodium volatilization (Frederick, 1990) which follows the current project.

\subsection{References}

Anthony, D.B., Howard, J.B., Hottel, H.C., and Meissner, H.P., Proc. Fifteenth Symp. on Combustion, p. 1303, Combustion Institute, Pittsburgh (1974).

Bhattacharya, P., Vidyasekara, P., Kunzru, D., "Pyrolysis of black liquor solids," Ind. Eng. Chem. Proc. Des. Dev., 25:420-6 (1986).

Cameron, J.H. and Grace, T.M., "Kinetic study of sulfate reduction with kraft black liquor char," I\&EC Fundamentals, 24(4):443 (1985).

Cameron, J.H., J. Pulp Paper Sci., 14:J76-81 (1988).

Frederick, W.J. and Hupa, M., "Sodium volatilization during pyrolysis of black liquor," Tappi J., 11:192 (1991).

Frederick, W.J., "Combustion processes in black liquor recovery: analysis and interpretation of combustion rate data and an engineering design model, " US DOE Report DOE/CE/40637-T8 (DE90012712), March, 1990.

Frederick, W.J., Noopila, T., and Hupa, M., "Swelling of pulping liquor droplets during combustion," J. Pulp Paper Sci., 17(5):J164-J170 (1991).

Frederick, W.J., "Combustion parameters for black liquor," A research proposal to the U.S. Department of Energy, May 1990.

Frederick, W.J., "Sulfur and sodium volatilization and recapture during black liquor combustion," Proposal to the U.S. Department of Energy, February 1990. 
Hupa, M., Solin, P., Hyöty, P., "Combustion behavior of black liquor droplets," JPPS, 13(2):J67-72 (1987).

Kobayashi, H., Howard, J.B., Sarofim, A.F., 16th Symp. (Intl.) on Combustion, The Combustion Institute, Pittsburgh, PA (1977), pp. 411-425.

Kubes, G.J., J. Pulp Pap. Sci., 10(3):J63 (1984).

Lawn, C.J., Principles of Combustion Engineering for Boilers, Academic Press, London (1987).

Levenspiel, O., Chemical Reactor Omnibook, OSU Bookstores, Corvallis, Oregon, 1989.

Li, J. and van Heiningen, A.R.P., I\&EC Research, 29(9):1776-1785 (1990).

Li, J., van Heiningen, A.R.P., Tappi J., 74(3):237-239 (1991).

Niksa, S., Heyd, L.E., Russel, W.B., and Saville, D.A., 20th Symp. (Intl.) on Combustion, The Combustion Institute,(1984), pp. 1445-1453.

Nunn, T.R., Howard, J.B., Longwell, J.P., and Peters, W.A., I\&EC Proc. Des. Dev., 24:836-844 (1985).

Saastamoinen, J. "Modelling of coal pyrolysis and combustion," Am. Flame Rsch Comm. 1988 Fall Int'l Symp., Pittsburgh, October 4-6, 1988.

Söderhjelm, L., Hupa, M., and Noopila, T., J. Pulp and Paper Science, 15(4):J117-J122 (1989).

Solomon, P.R., Colket, M.B., "Coal devolatilization," 17th Symp. (Intl.) on Combustion, The Combustion Institute,(1978), pp. 131-143.

Srinivasachar, S., Heble, J.J., Ham, D.O., Domazetis, G., Prog. Energy Combust. Sci., 16:303-309 (1990).

Stewart, G.W., Chakrabarti, A., More, W.R., "Reactions of alkali containing species in combustion streams," USDOE Proceedings: High-Temperature, High-Pressure Particulate and Alkali Control in Coal Combustion Process Streams. Science Applications Inc., McLean, VA (1981) pp. 275-300.

Suuberg, E.M., Peters, W.A., Howard, J.B., 17th Symp. (Intl.) on Combustion, The Combustion Institute, (1978), pp. 117-131.

Verrill, C.L, Nichols, K.M., "Fume formation during black liquor droplet combustion: the importance of sodium release during devolatilization", Proc. 1992 TAPPI-CPPA Intl. Chemical Recovery Conf., TAPPI Press, Atlanta, pp. 609-615. 
Volkov, A.D., Evseev, O.D., Ibatullina, R.I., Dravolina, E.I., Mezhvuz. Sb. Nauchn. Tr. Ser. Khim. Teknol. Tsellyul. no. 7, 72-5 (1980), English translation, the Institute of Paper Science and Technology, Atlanta.

Wendt, J.O.L., "Char combustion," Combustion of Solid Fuels (course notes), Intl. Flame Research Foundation, ljmuiden, the Netherlands (1988), p. 6.25.

Whitty, K.J., Frederick, W.J., Hupa, M., "Gasification of Black Liquor Char With $\mathrm{H}_{2} \mathrm{O}$ at Elevated Pressures," Proc. 1992 TAPPI-CPPA Intl. Chemical Recovery Conf., TAPPI Press, Atlanta, pp. 627-639. 


\section{THE ONSET OF DEVOLATILIZATION AND IGNITION}

An important question with respect to droplet combustion in recovery boilers is when does devolatilization begin? The onset of devolatilization is important because it affects the mass and swolien volume of a droplet during combustion, and through these variables the trajectory of the droplet. Droplets which ignite in-flight before completely drying have a greater mass at the onset of devolatilization and are decelerated less by the effects of swelling. This is illustrated in Figure 4.1 which shows the trajectories for three droplets of the same initial mass, solids content, and swelling characteristics. The regions of volatiles release and combustion and of char burning are shifted further to the right and slightly downward (further into and lower in the furnace) as the solids content at ignition increases.

Our earlier analysis, based on data for black liquor droplets burned in air, indicated that ignition occurred before drying was complete for droplets burned in air above $700^{\circ} \mathrm{C}$ (Frederick, 1990). This analysis was based on limited data but seemed to be valid for a wider range of liquors.

In this chapter, we first examine the factors which influence devolatilization and ignition. We then present new data for combustion of single droplets of black liquor at a wider range of temperatures, and interpret it in terms of the available information on devolatilization and ignition and the droplet temperature data presented in Chapter 3.

\subsection{Onset of Devolatilization}

In this report, we define devolatilization is the loss of combustible mass from dry black liquor solids upon heating. Black liquor behaves like a solid fuel in that nearly all of the nonaqueous volatiles have been stripped away when the liquor is concentrated in evaporators prior to combustion, and devolatilization occurs only through pyrolytic degradation of the remaining organic matter.

There is limited data available for the onset of devolatilization in black liquor during pyrolysis, gasification, or combustion. Söderhjelm et al. (1989) and Kubes et al. (1984) measured the rate of devolatilization for black liquors at low $\left(10-20^{\circ} \mathrm{C} / \mathrm{min}\right)$ heating rates. Their results indicate that volatiles evolution begins near $200^{\circ} \mathrm{C}$ and increases in rate with increasing temperature. There is no data available for pyrolysis at heating rates of the order $100^{\circ} \mathrm{C} / \mathrm{s}$ or greater encountered by black liquor droplets in recovery boilers.

\subsection{Ignition Criteria}

In much of the work on single black liquor droplet combustion, ignition of the droplet has been taken as the point when drying is complete and devolatilization begins (e.g. Hupa et al., 1987; Clay et al., 1988). Most of these results are for droplets burned at relatively low temperatures compared with recovery boiler environments. As indicated in the introduction to this chapter, the onset of devolatilization before drying is complete can have a significant impact 


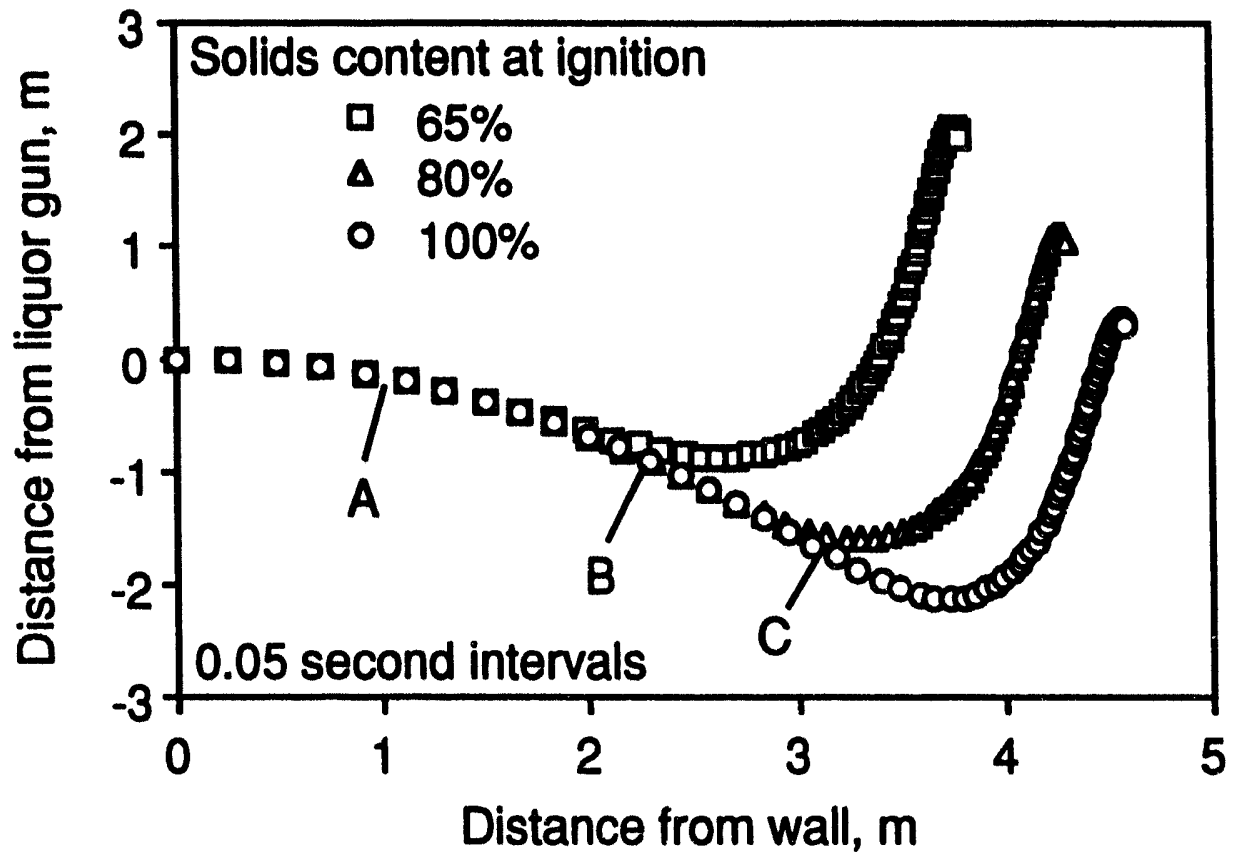

Figure 4.1. Effect of solids content at ignition on droplet trajectories for 2.0 $\mathrm{mm}$ droplets initially at $60 \%$ solids content injected into a furnace at $1000^{\circ} \mathrm{C}$, $5 \% \mathrm{O}_{2}, 13 \% \mathrm{CO}_{2}, 8.4 \% \mathrm{H}_{2} \mathrm{O}$. Maximum swollen volume of the droplets is 50 $\mathrm{cm}^{3} / \mathrm{g}$ black liquor solids. The trajectories were calculated using the program RATA (Appendix 1). Points A, B, and C indicate the onset of devolatilization and swelling for droplets which ignite at 65,80 , and $100 \%$ solids content respectively. 
on droplet trajectories and heat release in a recovery boiler. At higher furnace temperatures, significant devolatilization may occur before drying is complete. In this section we examine the criteria for ignition of volatiles from a volatilizable fuel as a basis for examining droplet combustion data in more detail.

The ignition of volatiles from a pyrolyzing particle surface is a complex process and is not completely understood. However, the criteria under which ignition occurs have been defined. For a single volatilizable particle in the absence of an ignition source, ignition will occur when the composition of the pyrolysis products and oxygen exceed the flammability limit. The flammability limit depends on the temperature of the mixture; higher concentrations of fuel and oxygen are required for ignition at lower temperatures. When an ignition source such as a flame is present nearby, ignition occurs at or near the temperature set by the flammability limit. When no ignition source is present, ignition usually occurs at a higher temperature (Lawn, 1987, pp. 88-89)

For volatilizable fuels which contain no water, ignition does not occur immediately in a hot environment, but only after the fuel is heated and volatiles are evolved at a rate sufficient to exceed the flammability limit. The time required for a particle to reach ignition is referred to as the ignition delay and corresponds to the time required to heat the particle to that point. When water is present, enough of it must be evaporated so that the temperature of the particle or the particle surface is high enough for devolatilization to begin.

Dry, nonvolatilizable fuels may also ignite, but for these fuels ignition implies combustion of the solid fuel. It usually corresponds to a high rate of oxidation at the particle surface, forming $\mathrm{CO}$, and combustion of the $\mathrm{CO}$ near the particle surface. These fuels react with oxygen at temperatures below ignition as well. The criterion for ignition to occur is that the rate of heat generation by the oxidation reaction exceeds the rate of heat loss from the particle. When this criterion is satisfied, the particle surface temperature rises abruptly, indicating ignition. The oxidation of both carbon to $\mathrm{CO}$ at the solid surface and $\mathrm{CO}$ to $\mathrm{CO}_{2}$ in the gas surrounding the particle contribute to the onset of combustion for nonvolatilizable solids. This criterion for ignition also applies to char particles after devolatilization is complete and accounts for the extinguishing of burning char as the temperature or oxygen content of the environment surrounding the particle decreases.

Both particle size and the rate of heating affect ignition. Devolatilization is generally assumed to be slightly endothermic or thermally neutral. Transfer of heat from the surroundings results in a temperature gradient in the devolatilizing particle; for larger particles, the temperature gradient will be greater. Higher heating rates also increase the temperature gradient. For initially wet particles, this can result in the outer surface of a particle drying completely and beginning to devolatilize while drying is still occurring within the particle. This was observed by Srinivasachar et al. (1986) in coal-water mixtures with small particles at heating rates of $10^{5} \mathrm{~K} / \mathrm{s}$. An overlap between devolatilization and char burning has also been reported by others (Howard and Essenhigh, 1967; Jüntgen and van Heek, 1968; Saastamoinen et al., 1992). 


\subsection{Analysis of Time to Ignition Data}

We begin our analysis of the onset of devolatilization during black liquor combustion by examining time to ignition data for about 100 liquors from the Abo Akademi University data base. This data had been obtained in experiments in which 10 to 12 liquor droplets of different initial mass were burned in air at both 700 and $800^{\circ} \mathrm{C}$. The time at which ignition occurred was recorded for each droplet and the resulting 10 to 12 measurements were fitted to a regression equation. The time to ignition for a $2.2 \mathrm{~mm}$ diameter $(8 \mathrm{mg})$ droplet for each liquor/temperature combination was obtained by interpolation of the regression equation. The procedure is described in detail by Noopila and Hupa (1988).

The distribution of times to ignition is shown in Figure 4.2. The mean time to ignition decreases with increasing furnace temperature as expected. The times to ignition can be described by a normal distribution about the mean as confirmed by statistical analysis. The distribution of times to ignition is surprisingly broad. The coefficient of variation for the 700 and $800^{\circ} \mathrm{C}$ data (Table 4.1) indicates that the breadth of the distributions relative to their means is independent of temperature.

Table 4.1. Experimental times to ignition $\left(t_{i}\right)$ and mean solids content at ignition calculated from the experimental $t_{i}$ 's using the two resistance drying model. Results are for $2.2 \mathrm{~mm}$ diameter droplets at $60 \%$ solids content burned in air.

\begin{tabular}{|l|c|c|}
\hline Furnace temperature, ${ }^{\circ} \mathrm{C}$ & 700 & 800 \\
\hline Experimental time to ignition, $\mathrm{s}$ & $2.89 \pm 0.82$ & $2.02 \pm 0.54$ \\
Coefficient of variation, \% & 28 & 27 \\
\hline $\begin{array}{l}\text { Solids mass fraction at ignition }{ }^{1} \\
\text { Coefficient of variation, } \% 1\end{array}$ & 0.92 & 0.78 \\
\hline $\begin{array}{l}{ }^{1} \text { Calculated from the time to ignition data using the two-resistance, heat transfer-based } \\
\text { drying model (Frederick, 1990). }\end{array}$ \\
\hline
\end{tabular}

A two resistance heat transfer drying model (Frederick, 1990) was used to calculate the solids mass fraction at ignition $\left(\mathrm{S}_{\mathrm{i}}\right)$ from the experimental time to ignition data. In these calculations, the droplets were assumed to swell by a factor of 1.54 in diameter during drying (Frederick et al., 1991a); no other adjustable parameters were used in the calculations. The resulting distributions of the solids content at ignition $\left(S_{i}\right)$ at both furnace temperatures are shown in Figure 4.3. The data indicates that on average the droplets ignite before drying completely, with the mean solids content at ignition decreasing from $92 \%$ at $700^{\circ} \mathrm{C}$ to $78 \%$ at $800^{\circ} \mathrm{C}$. These results are in reasonable agreement with the values reported earlier based on similar calculations for a single liquor $\left(0.89\right.$ at $700^{\circ} \mathrm{C}, 0.81$ at $800^{\circ} \mathrm{C}$; Frederick, 1990), although the data reported here indicate a somewhat stronger effect of temperature. The data 

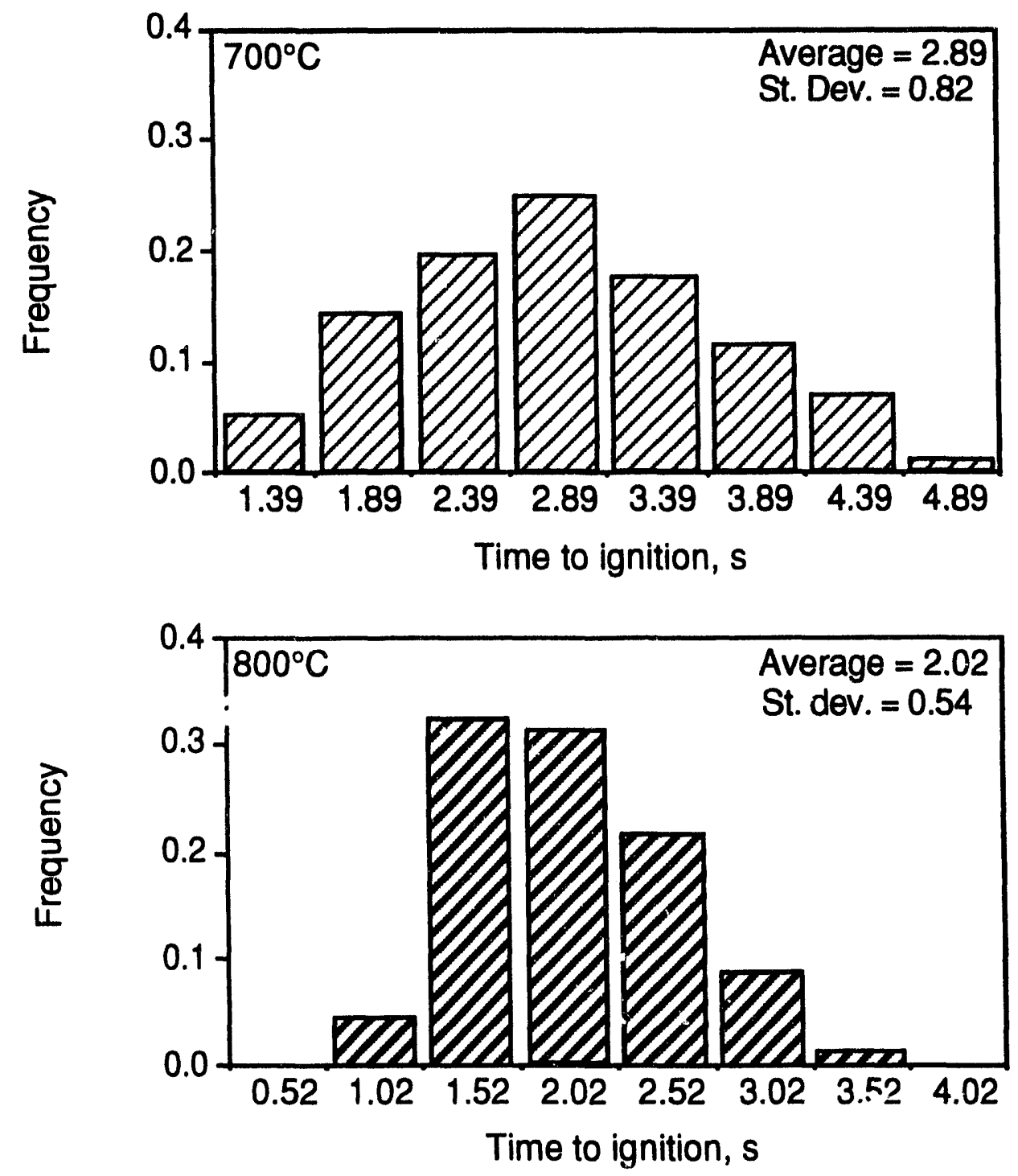

Figure 4.2. Distributions of times to ignition for $2.2 \mathrm{~mm}$ diameter droplets vurned in air at 700 and $800^{\circ} \mathrm{C}$ for one hundred liquors. 

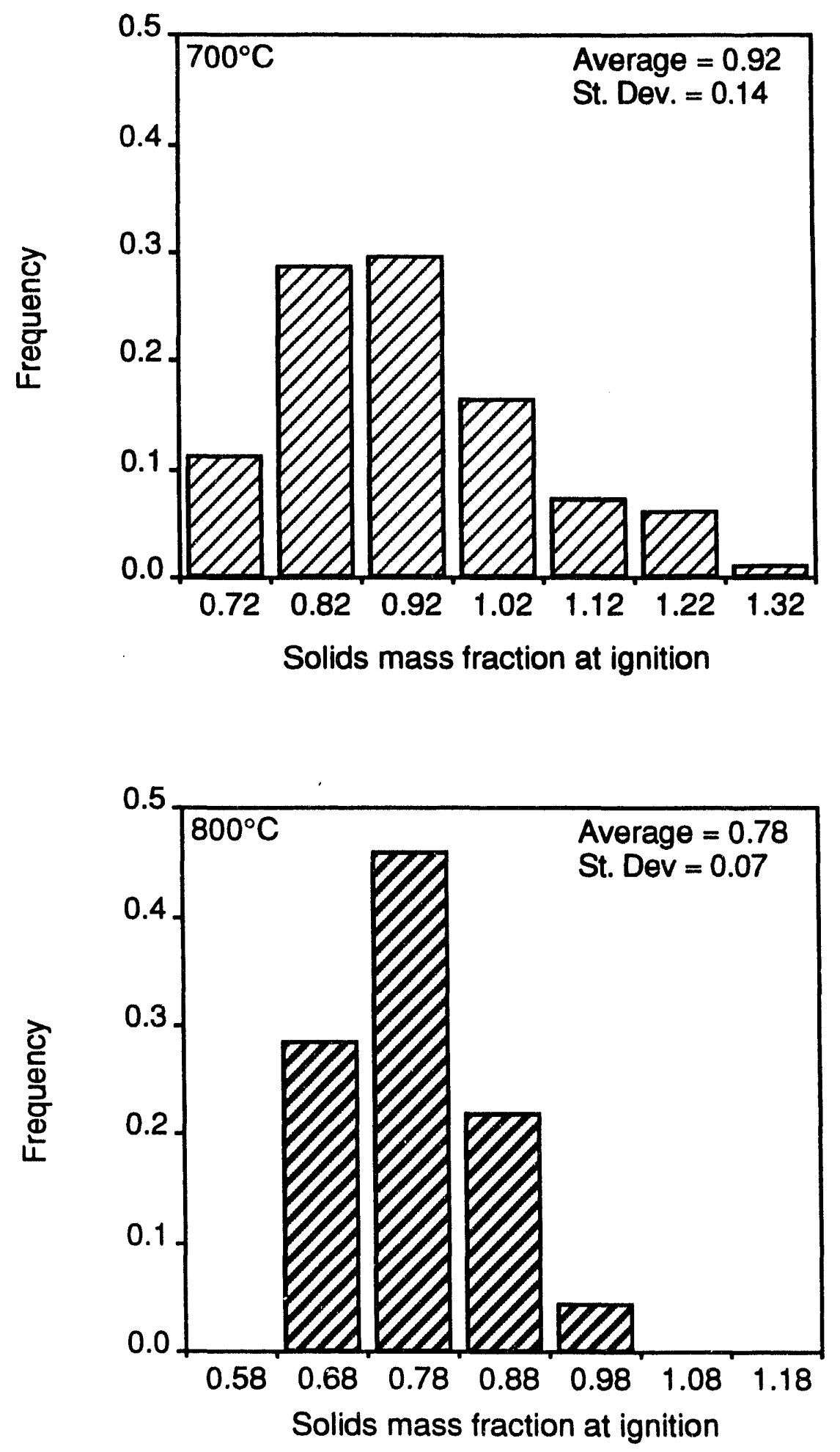

Figure 4.3. Distributions of calculated solids mass fractions at ignition at 700 and $800^{\circ} \mathrm{C}$ for one hundred liquors. 
in Figure 4.3 can be described by a normal distribution about the mean as confirmed by statistical analysis. The coefficients of variation for the calculated $S_{i}$ 's are smaller than for the times to ignition due to the nonlinear nature of the drying model.

Some of the $S_{i}$ values at $700^{\circ} \mathrm{C}$ in Figure 4.3 exceed 1.0. Values greater than 1.0 are of course physically impossible, and in reality imply that the droplets dry completely and continue to heat before igniting.

Figure 4.4 shows how initial droplet mass and furnace temperature affect $S_{i}$. It contains $S_{i}$ values calculated from combustion time data for individual droplets of a single softwood kraft liquor burned in air at furnace temperatures between 600 and $900^{\circ} \mathrm{C}$. At furnace temperatures greater than $800^{\circ} \mathrm{C}, \mathrm{S}_{\mathrm{i}}$ is always below 1.0 and increases with increasing droplet mass. The positive slope indicates that ignition under these conditions is determined by the rate of volatiles evolution at the surface. Smaller droplets have a greater surface area per droplet mass and they would ignite sooner (relative to reaching dryness) if volatiles evolution rate per unit mass is the critical variable for ignition. Although smaller droplets would be expected to heat and therefore dry more uniformly than larger ones, the higher external surface area appears to be the dominant effect here. The smaller droplets evolve volatiles at a sufficient rate for ignition to occur at a lower average solids content than the larger droplets do.

Another important observation regarding the data in Figure 4.4 is that the slopes of $S_{i}$ versus initial droplet mass decrease with increasing furnace temperature and approach zero at $900^{\circ} \mathrm{C}$. The decrease in slope with increasing temperature is further support for the concept of ignition as a surface phenomenon. At higher furnace temperatures, the temperature gradient within a droplet but near its surface is steeper and becomes less dependent on droplet mass. This in effect eliminates any dependence of the surface phenomena on initial droplet mass.

The solids content at ignition calculated this way is often greater than 1.0 for droplets burned at or below $750^{\circ} \mathrm{C}$ (Figure 4.4A), which implies that the droplets dry completely and continue heating before igniting. The average droplet temperature at which ignition occurs when $\mathrm{S}_{\mathrm{i}}>1$ was estimated by calculating the heat absorbed by a droplet in a hot furnace between dryout and ignition. The results, obtained from the data in Figure 4.4A, are shown in Figure 4.5. Based on these calculations, complete dryness would correspond to an average droplet temperature of $150^{\circ} \mathrm{C}$.

Figure 4.5 indicates that the droplets burned in furnaces below $800^{\circ} \mathrm{C}$ probably were heated substantially after they reached dryness. The results for 650 and $700^{\circ} \mathrm{C}$ are reasonable in that the calculated ignition temperatures are below the furnace temperatures. However, the analysis breaks down for the data at $600^{\circ} \mathrm{C}$, where the calculated ignition temperature would be greater than the furnace temperature. This probably means that the criterion for ignition (volatiles and oxygen content of the gases near the droplet surface) are marginally satisfied at $600^{\circ} \mathrm{C}$, that the droplets reach $600^{\circ} \mathrm{C}$ and remain there, and that significant pyrolysis losses occur before ignition occurs. Further evidence for this is provided by the observation that black liquor droplets do not ignite in air at temperatures below $600^{\circ} \mathrm{C}$ (Noopila and Hupa, 1988).

Figure 4.6 shows the solids content at ignition (calculated from the drying model) as a function of temperature. The data for the two individual liquors differ markedly at lower 

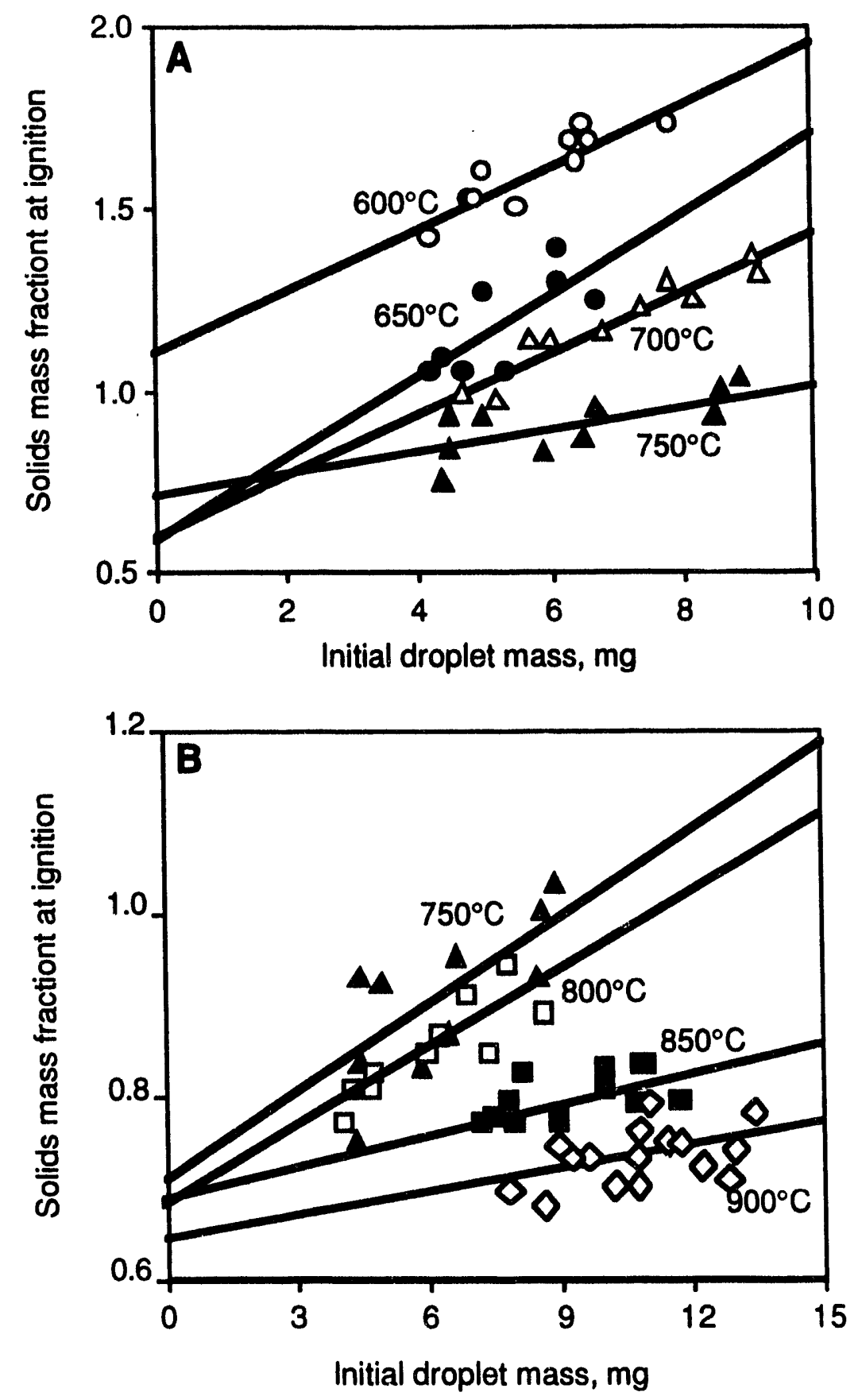

Figure 4.4. Calculated solids mass fraction at ignition for a softwood kraft liquor (166) as a function of droplet mass and temperature. 


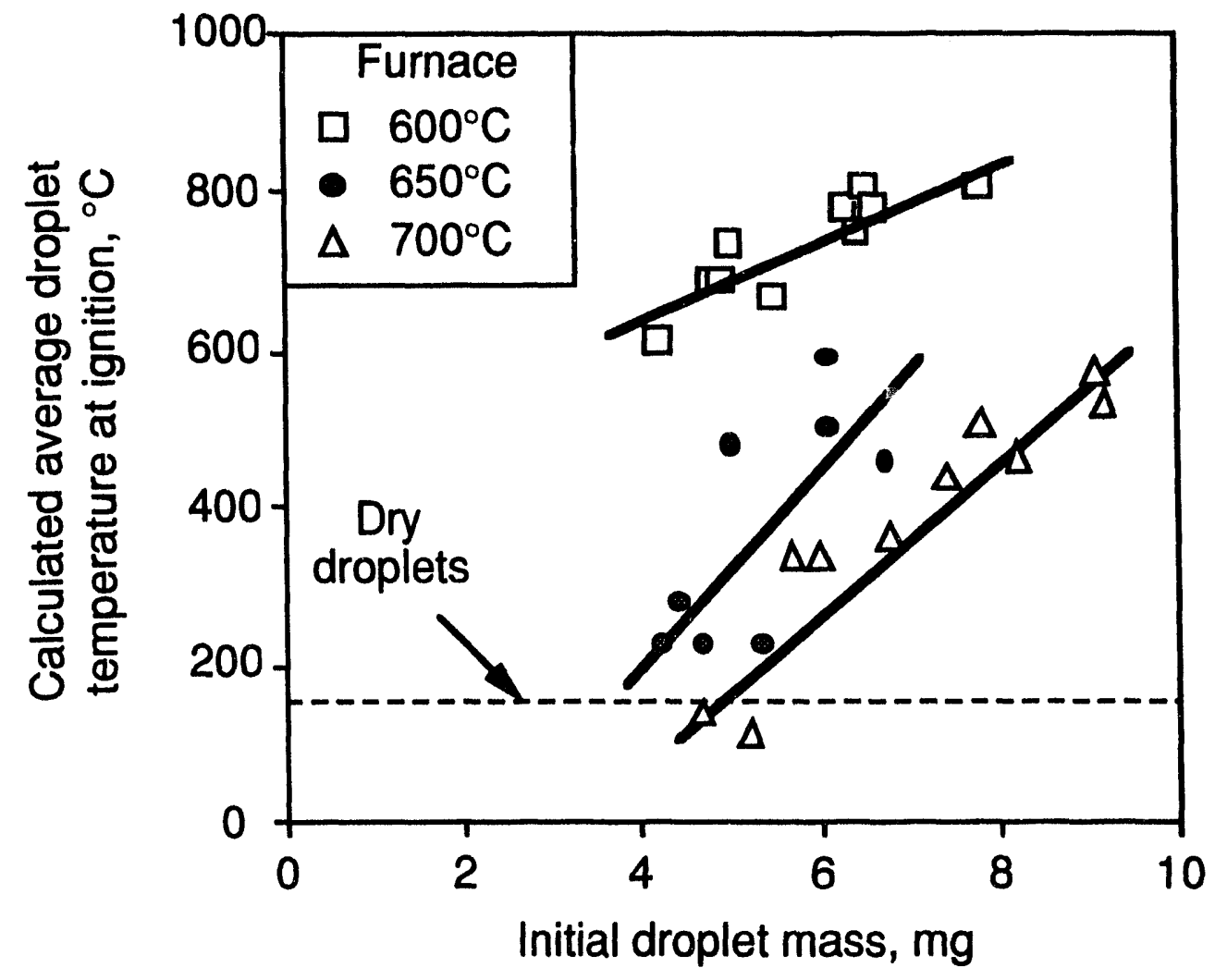

Figure 4.5. Estimated average droplet temperature at ignition for droplets which do not ignite at or before dryness. 


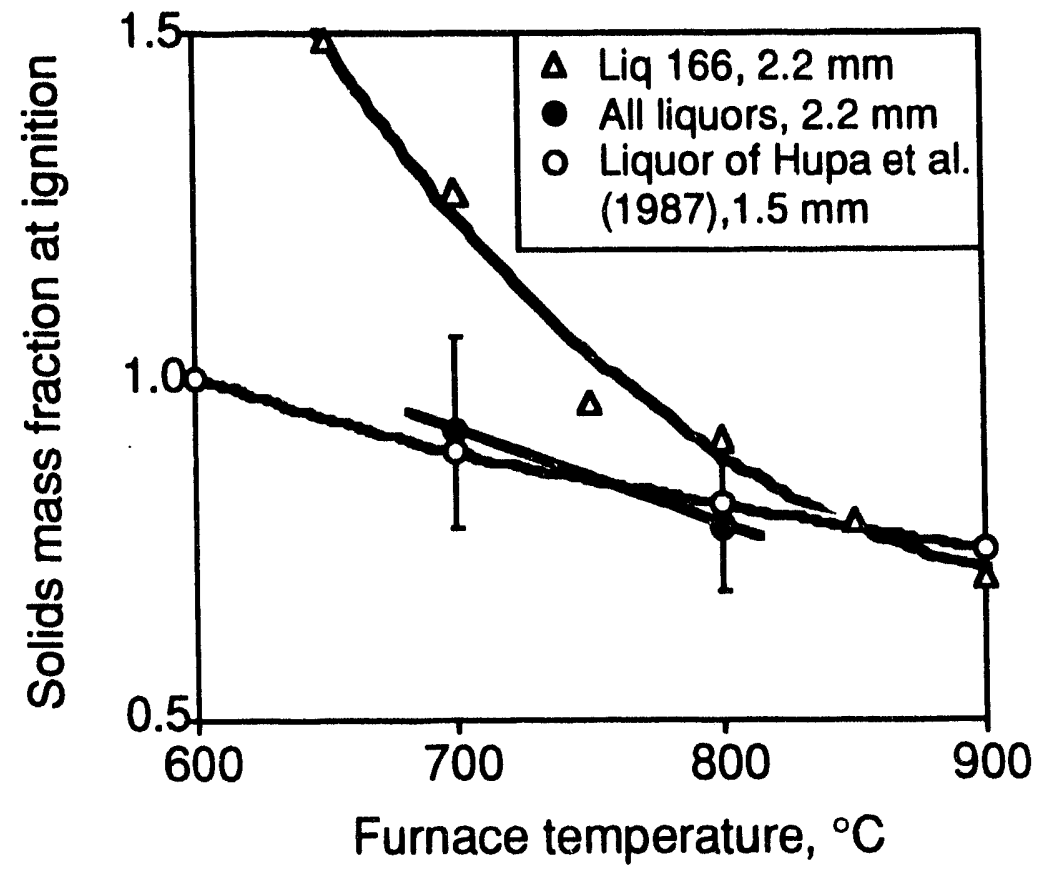

Figure 4.6. Calculated solids mass fraction at ignition versus furnace temperature for two liquors and averages for all liquors. The error bars indicate \pm 1 standard deviation for all liquors tested. 
temperatures, but seem to converge above $800^{\circ} \mathrm{C}$. One of the liquors behaves about the same as the average data for the 100 liquors.

The broad distribution of times to ignition for different liquors at the same furnace temperature (scatter bars in Figure 4.6) may suggest that the ignition process is influenced by a pyrolysis process whose onset is liquor-specific. The process does not seem to be entirely stochastic because the data we have been discussing is based on an averaging technique and not on individual droplets. Another possible explanation, differences in swelling during drying, seems unlikely based on the increasing evidence that swelling during drying is not liquor-specific and is independent of furnace temperature, gas environment, and liquor solids content (Frederick et al., 1991a).

The broad spectrum of times to ignition has an important implication to liquor combustion stability: liquors which take longer to ignite may even be harder to burn. This, together with the great liquor-to-liquor variability in swelling during devolatilization, may account for the difference between a liquor which is easy to burn and one which is difficult to burn. This may be an important issue in the operability of recovery boilers and it should be investigated experimentally. No direct measurements of differences in ignition points for black liquors have ever been reported.

A one resistance heat transfer model which was rejected previously as inadequate to describe drying (Frederick, 1990) was also used to calculate the solids content at ignition. The mean values of $\mathrm{S}_{\mathrm{i}}$ obtained were 1.85 at $700^{\circ} \mathrm{C}$ and 1.03 at $800^{\circ} \mathrm{C}$. A value of 1.85 would correspond to a mean droplet temperature of about $860^{\circ} \mathrm{C}$ at ignition, or $160^{\circ} \mathrm{C}$ greater than the furnace temperature. This is further evidence of the inadequacy of the one resistance heat transfer model.

\subsection{Surface Temperature and Volatiles Evolution Rate}

It is very difficult to test these conclusions about the onset of devolatilization because of the difficulty in measuring variables such as the surface temperature during drying or the rate of evolution of volatiles for black liquor droplets in a furnace environment. An alternate approach is to use detailed modeling of the heat and mass transfer and reaction kinetics to predict surface and internal droplet temperatures and volatiles evolution rates. The models can be tested with measurable combustion parameters such as surface and internal temperatures and combustion stage times to provide some verification. They can then be used to estimate the more difficult to measure variables such as drying and volatiles evolution rates.

In this study we used a detailed model for the combustion of single fuel particles which was developed and adapted to black liquor droplets by Saastamoinen et al. (1984, 1992). Saastamoinen treated particle combustion in terms of a one dimensional, unsteady-state model which accounts for heat and mass transfer to/from a particle surface, and heat transfer, evaporation of water, volatiles evolution, and combustion spatially within the particle. The rate of volatiles evolution and particle swelling are based empirically on experimental data for woody biomass and black liquor respectively. Details of the model are presented elsewhere (Saastamoinen, 1984, 1992). 
We first tested Saastamoinen's model by comparing the surface temperatures which it predicts with measured values from this study. The comparison, which is included in Chapter 5, indicates that the Saastamoinen model predicts quite well the surface temperature of droplets burned in air or air/nitrogen mixtures.

In this chapter, we use the Saastamoinen model to test whether drying is complete before the onset of devolatilization. We first look at the results of typical calculations and define criteria for the onset of volatiles evolution. Then we examine the effect of various combustion parameters on the behavior of the model. Finally we analyze the results from the model with respect to the question of drying and the onset of devolatilization.

\subsubsection{Definition of the Onset of Volatiles Evolution}

Figure 4.7 shows the rate at which water vapor and combustible volatiles leave the surface of a burning black liquor particle as predicted by the Saastamoinen model for one set of combustion conditions. The vertical lines indicate the onset of devolatilization and the completion of devolatilization and char burning as calculated by Frederick's models (1990). There are two (dashed) lines used to indicate the onset of devolatilization, corresponding to a completely dried $\left(S_{i}=1.0\right)$ or an incompletely dried $\left(S_{i}=0.82\right)$ droplet at the onset of devolatilization. The volatiles evolved prior to char burning are pyrolysis products while those evolved during char burning are $\mathrm{CO}$ formed by the incomplete combustion of carbon at the char surface.

For the conditions in Figure 4.7, Saastamoinen's model indicated that there is an overlap between drying and devolatilization. The extent of volatiles evolution during drying can be assessed by integrating the volatiles evolution rate curve in Figure 4.7 and normalizing it to the total volatiles released prior to the onset of char burning. This accounts for the actual organic decomposition products evolved but not the $\mathrm{CO}$ formed by char oxidation. According to the data in Figure 4.7, between 28 and 53\% of the volatiles released during devolatilization are evolved before the appearance of a flame as predicted by Frederick's model (1990). The two values of volatiles released prior to ignition correspond to ignition at $S_{i}=0.82$ and $S_{i}=1.0$ respectively. Frederick's model is based on the assumption that the onset of rapid swelling and the appearance of a flame mark the onset of devolatilization (Hupa et al, 1987). Another way of examining these results is to see what percentage of the volatiles evolved during devolatilization are actually evolved before $90 \%$ of then water is removed. For the conditions in Figure 4.7, 43\% of the pyrolysis products are evolved before $90 \%$ of the water initially in the droplet is evolved.

Figure 4.8 shows the calculated rate of water vapor and volatiles leaving the droplet prior to the onset of char burning at the outer surface for droplets burned in air at four different furnace temperatures. Saastamoinen's model allows outer charred surface to ignite before devolatilization is complete within droplet. The model's predictions are that this occurs well before drying is complete at the low temperatures $\left(600,700^{\circ} \mathrm{C}\right)$ and that very little volatiles are evolved prior to the onset of char burning. While this is consistent with the devolatilization behavior observed in laboratory experiments at $600^{\circ} \mathrm{C}$, it does not agree well with observations at $700^{\circ} \mathrm{C}$ where a substantial flame burns for several seconds as the droplet swells. At $800^{\circ} \mathrm{C}$ 


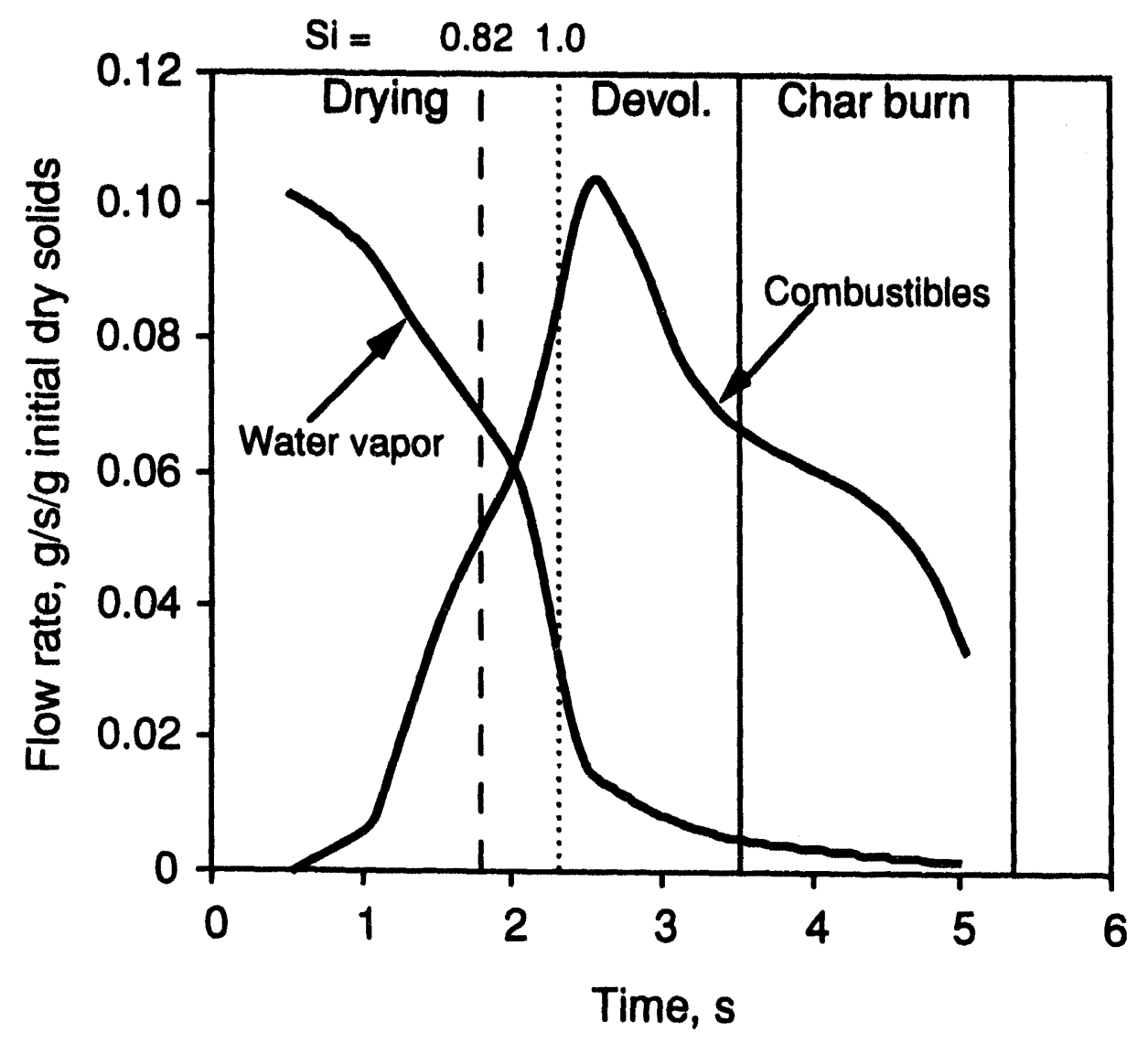

Figure 4.7. Water vapor and volatiles flow for a $2 \mathrm{~mm}$ droplet burned in air at $800^{\circ} \mathrm{C}$ as calculated by Saastamoinen's model. For comparison, the drying, devolatilization, and char burning times calculated by Frederick's models (1990) are also shown. 

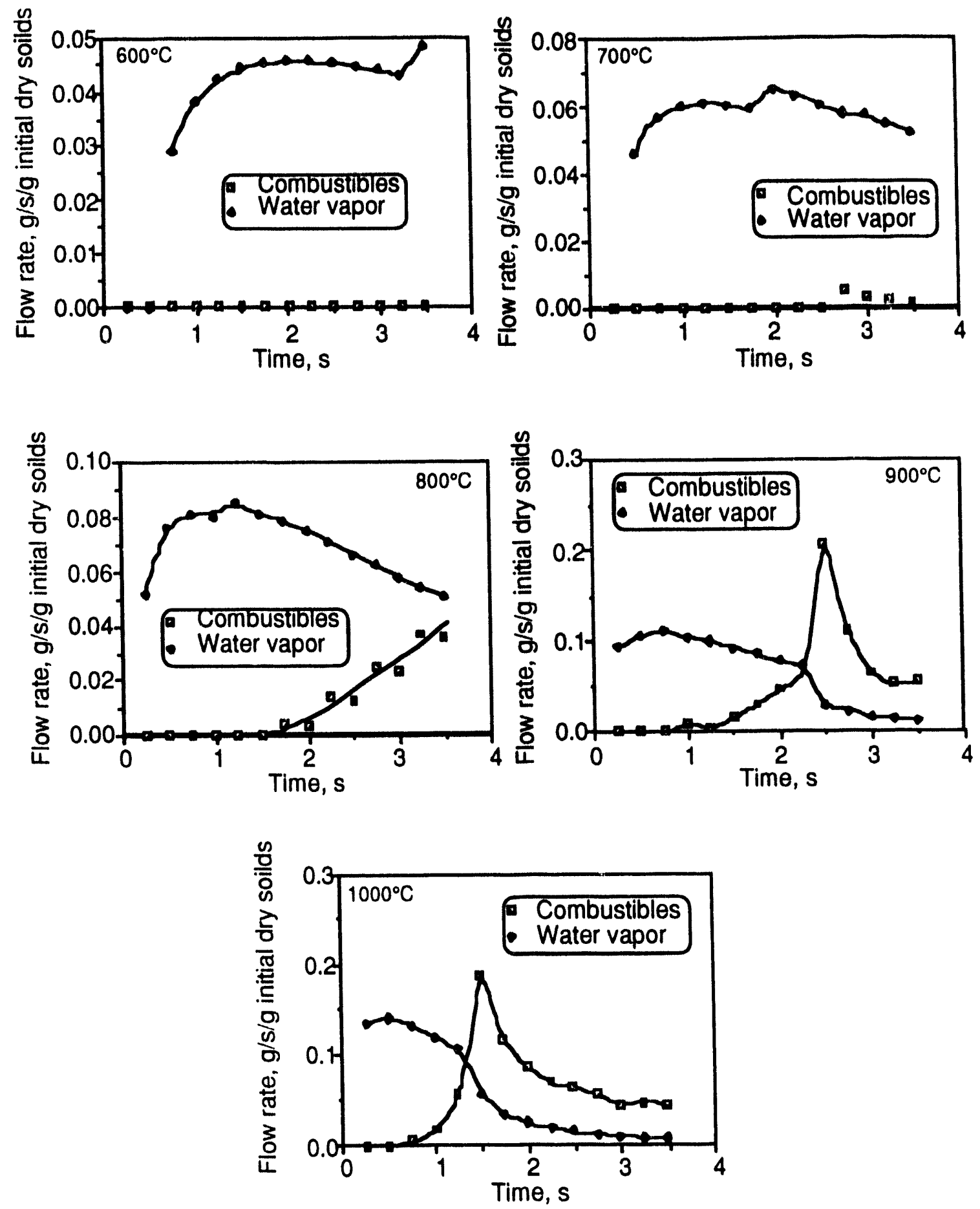

Figure 4.8. Water vapor and volatiles flow for $2.5 \mathrm{~mm}$ droplets burned in air at $600-1000^{\circ} \mathrm{C}$ as calculated by Saastamoinen's model. 
and above, significant volatiles evolution is predicted prior to the onset of char burning. At these temperatures, volatiles evolution begins well before drying is complete.

The three graphs in Figure 4.9 show the calculated water and volatiles evolution rates for three droplets of different initial mass at the same combustion conditions. There is some overlap between drying and devolatilization for all three droplet sizes, but the overlap is greatest with the smallest droplet. This means that $S_{i}$ would be lowest for small droplets which is consistent with our experimental findings.

Figure 4.10 shows the effect of initial dry solids content on the rates of water and volatiles evolution. As solids content increases, the amount of water actually evaporated during the period when volatiles are evolved decreases. The volatiles evolution rate also increases with increasing dry solids content. This suggests that a liquor would be easier to burn at high solids content. The increased volatiles evolution rate may mean a higher local temperature in the vicinity of the droplet which would increase the volatiles yield and reduce the char carbon. This in turn would reduce the char burning time, again improving burnability and reducing carry-over of burning particles.

The effect of swelling during devolatilization is shown in Figure 4.11. Swelling during devolatilization seems to have essentially no effect on volatiles evolution rate. The slight differences in maxima for the volatiles evolution rate may be due to the relatively large $(0.25 \mathrm{~s})$ calculation time interval. More of the water is released prior to the onset of significant volatiles release at higher $S V_{\max }$.

\subsection{Model For Predicting the Onset of Devolatilization and Swelling}

In Figure 4.6, the $S_{i}$ versus temperature data for $8 \mathrm{mg}$ droplets from Frederick (1990) is very close to the average data for 100 liquors. A correlation which describes the data is

$$
\begin{gathered}
S_{i}(8 \mathrm{mg})=2.055-0.00236 \mathrm{~T}+10^{-6} \mathrm{~T}^{2}, 600 \leq \mathrm{T} \leq 1180^{\circ} \mathrm{C} \\
S_{\mathrm{i}}(8 \mathrm{mg})=0.662, \mathrm{~T}>1180^{\circ} \mathrm{C}
\end{gathered}
$$

Equations (4.1) and (4.2) are for droplets initially at $60 \%$ dry solids content. Equation (4.1) has a minimum at $1180^{\circ} \mathrm{C}$ which corresponds to $S_{i}=0.662$ and that is assumed to be the value which applies at higher temperatures.

Equations (4.1) and (4.2) do not take into account the effect of droplet mass on $S_{i}$. The data in Figure 4.4 can be used to account for it as follows. Table 4.2 contains the slopes and intercepts of the lines in Figure 4.4. With the exception of the data at $600^{\circ} \mathrm{C}$, the intercepts are nearly constant and an average value is used as an approximation. The slopes from $650-900^{\circ} \mathrm{C}$ decrease exponentially with increasing furnace temperature. A simple model which describes $S_{i}$ as a function of initial droplet mass and furnace temperature, based on the data in Figure 4.4 is 

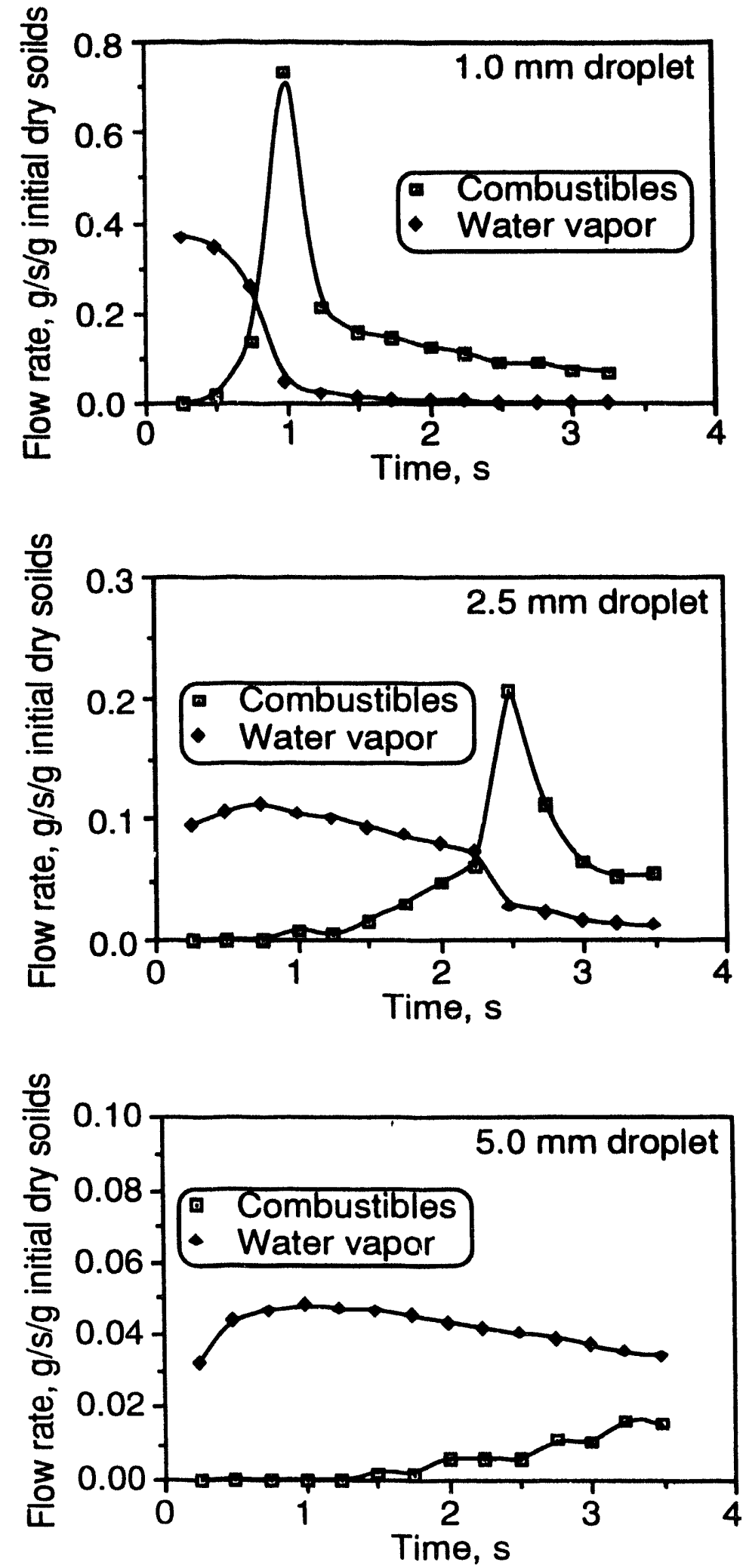

Figure 4.9. Water vapor and volatiles flow for $1.0,2.5$, and $5.0 \mathrm{~mm}$ droplets burned in air at $900^{\circ} \mathrm{C}$ as calculated by Saastamoinen's model. 

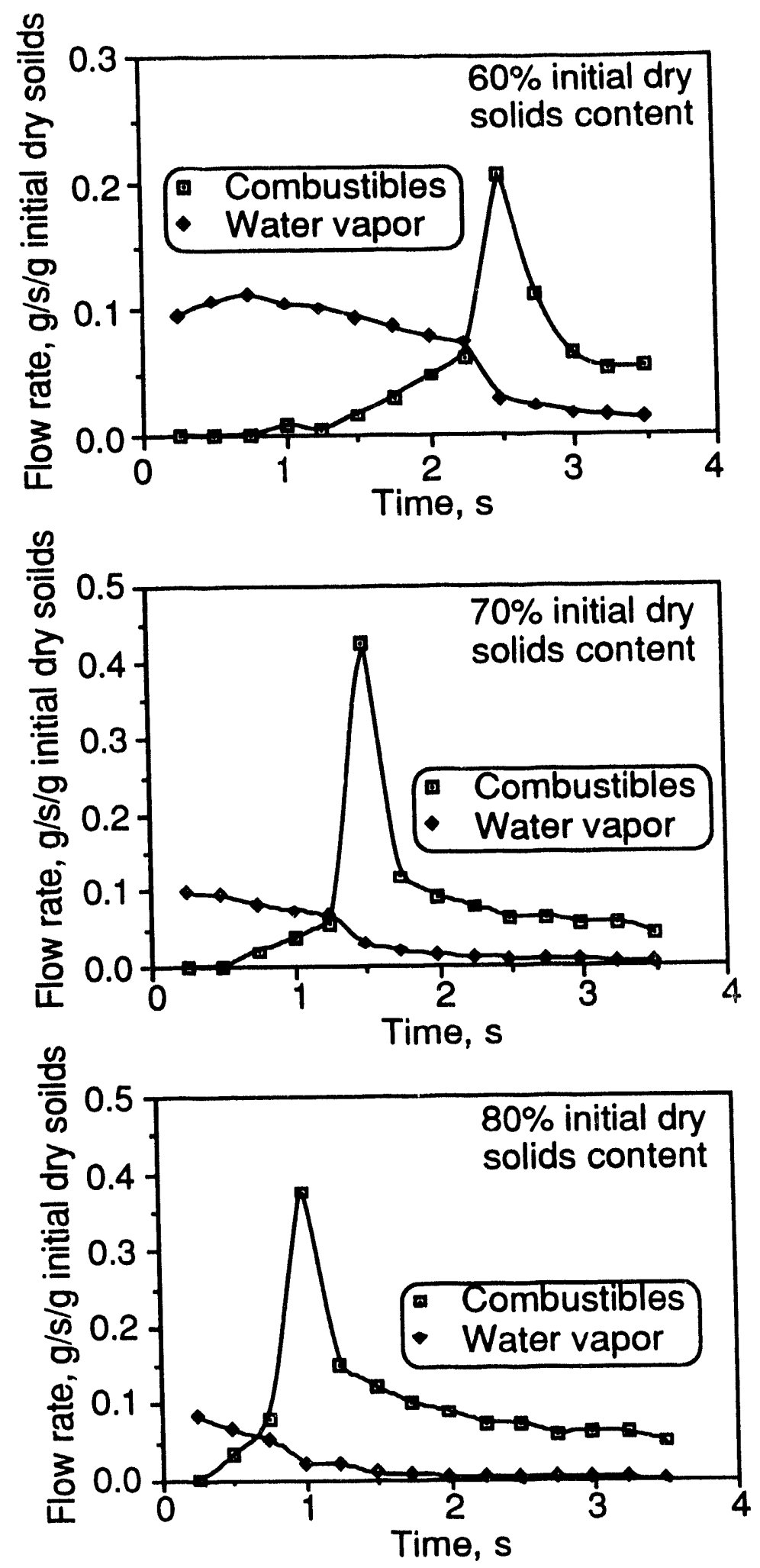

Figure 4.10. Water vapor and volatiles flow for $2.5 \mathrm{~mm}$ droplets initially at 60,70 , and $80 \%$ dry solids content when burned in air at $900^{\circ} \mathrm{C}$ as calculated by Saastamoinen's model. 

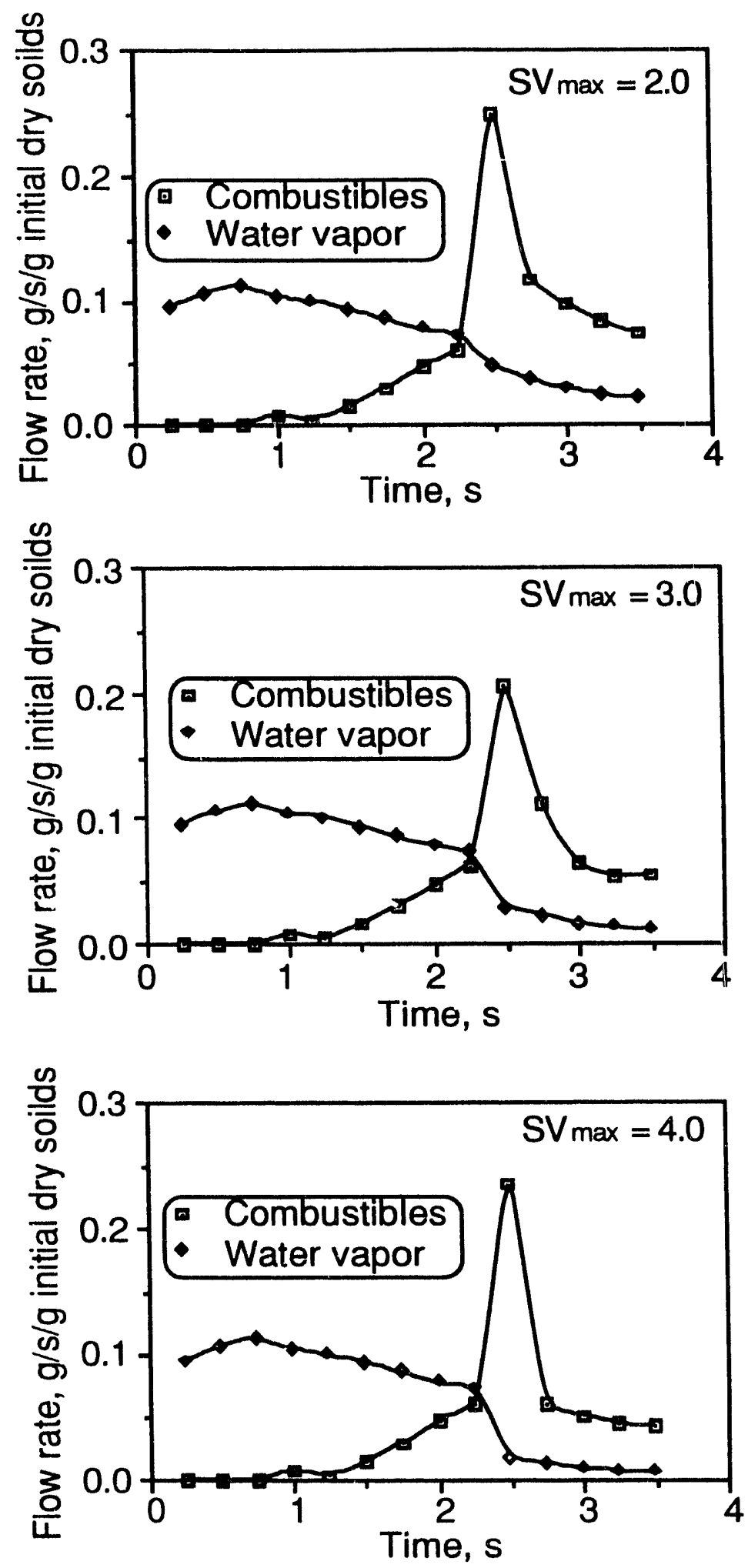

Figure 4.11. Water vapor and volatiles flow for $2.5 \mathrm{~mm}$ droplets with different maximum swollen volumes when burned in air at $900^{\circ} \mathrm{C}$ as calculated by Saastamoinen's model. 


$$
\begin{gathered}
S_{i}=A+B * M o \\
A=0.651,650 \leq \mathrm{T} \leq 900^{\circ} \mathrm{C} \\
B=202.5 \times 10^{-0.0049433 T}, 650 \leq \mathrm{T} \leq 900^{\circ} \mathrm{C}
\end{gathered}
$$

where $\mathrm{T}=\left[{ }^{\circ} \mathrm{C}\right\}$ and $\mathrm{Mo}=[\mathrm{mg}]$. The term $\mathrm{B}^{*} \mathrm{Mo}$ becomes negligible at higher temperatures $\left(>650^{\circ} \mathrm{C}\right.$ for $0.5 \mathrm{~mm}(0.05 \mathrm{mg})$ droplets, $>1250^{\circ} \mathrm{C}$ for $5.0 \mathrm{~mm}(50 \mathrm{mg})$ droplets) and the limiting value for $S_{i}$ as temperature increases is 0.651 . This correlation applies for droplets of Liquor 166 initially at $60 \%$ dry solids content. A method for estimating $S_{i}$ for other liquors and initial dry solids contents is presented later.

Table 4.2. Slopes and intercepts for $S_{i}$ versus Mo for Liquor 166 at different temperatures and $S_{i}$ for $8 \mathrm{mg}$ droplets. The slopes and intercepts are based on the data in Figure 4.4.

\begin{tabular}{|c|c|c|c|}
\hline Temperature, ${ }^{\circ} \mathrm{C}$ & Intercept & Slope & Si for 8 mg droplets \\
\hline \hline 600 & 1.1103 & 0.0861 & 1.80 \\
\hline 650 & 0.5905 & 0.1120 & 1.49 \\
\hline 700 & 0.5893 & 0.0847 & 1.27 \\
\hline 750 & 0.6873 & 0.0344 & 0.96 \\
\hline 800 & 0.6794 & 0.0284 & 0.91 \\
\hline 850 & 0.7106 & 0.0096 & 0.79 \\
\hline 900 & 0.6476 & 0.0080 & 0.71 \\
\hline
\end{tabular}

Equation (4.3) was obtained from droplet combustion data taken in a laboratory muffle furnace where the temperature of the gas and furnace walls is the same. In recovery furnaces, the gas, walls, and char bed, all of which contribute to droplet heating, are at different temperatures. Therefore a more appropriate independent variable in Eq. (4.3) is heat flux to the droplet rather than temperature.

To convert Eq. (4.3) we used a single droplet drying model (Frederick, 1990) to calculate the heat flux to a droplet during drying at different temperatures, The heat flux changes slightly with droplet size and a droplet mass of $12 \mathrm{mg}$ was used. When the slopes from Táble 4.2 are correlated with heat flux, the term B in Eq. (4.5) becomes

$$
\mathrm{B}=1.4475 * \exp (-.05518 \mathrm{q}), 40<\mathrm{q}<100 \mathrm{~kW} / \mathrm{m}^{2}
$$


Equations (4.3), (4.4), and (4.6) describe $S_{i}$ in terms of heat flux and droplet mass for a liquor droplet initially at $60 \%$ dry solids content. To account for differences in initial dry solids content, we assume that the remaining water/initial dry solids mass for a given droplet size is independent of initial dry, solids content. We attempted to test this assumption with time to ignition data for droplets at $55-85 \%$ initial dry solids content at $800^{\circ} \mathrm{C}$ but found that the droplets for the liquors used dried completely at nearly all solids contents at these conditions (Figure 4.12). This assumption is, however, consistent with the calculated results in Figure 4.10.

Based on this assumption, the water which remains in the droplet at the onset of devolatilization is then

$$
\frac{M_{o} S_{o}}{S_{i}}\left(1-S_{i}\right)=\frac{0.6 M_{o}}{S_{i 0.6}}\left(1-S_{i 0.6}\right)=K
$$

where $S_{i 0.6}$ is $S_{i}$ calculated from the correlation based on data for droplets initially at $60 \%$ dry solids content (Eqs. (4.3), (4.4), and (4.6)) and $K$ is the constant which is evaluated as the middle term in Eq. (4.7).

Equation (4.7) can be solved for $S_{i}$ as

$$
S_{i}=\frac{M_{0} S_{o}}{K+M_{o} S_{o}}
$$

The correlations developed so far are based on data for a single liquor (166) which behaves differently than the average liquor in the Ábo Akademi data base (Figure 4.6). To estimate $S_{i}$ for an average liquor, we convert $S_{i}$ for liquor 166 (from Eqs. (4.3), (4.4), (4.5), and (4.8)) to $S_{i}$ for an average liquor using the correlation

$$
S_{i} \text { (average liquor) }=0.838+0.27 \ln \left(S_{i}\right. \text {, liquor 166) }
$$

Equation (4.9) was obtained from the cross-plot of Eq. (4.1) with the $S_{i}$ data in Table 4.2 (Figure 4.13).

To summarize the procedure for calculating $S_{i}$ for an average black liquor:

a. Calculate $S_{i}$ for liquor 166 at $60 \%$ initial solids content from Eqs. (4.3), (4.4), and (4.6). This is $\mathrm{Si}_{0.6}$.

b. Calculate $\mathrm{K}$ from Eq. (4.7) using $\mathrm{Si}_{0.6}$.

c. Use $\mathrm{K}$ to calculate $S_{\mathrm{i}}$ for liquor 166 at the actual initial dry solids content from Eq. (4.8).

d. Calculate $S_{i}$ for an average liquor using the value from step $c$ in Eq. (4.9). 


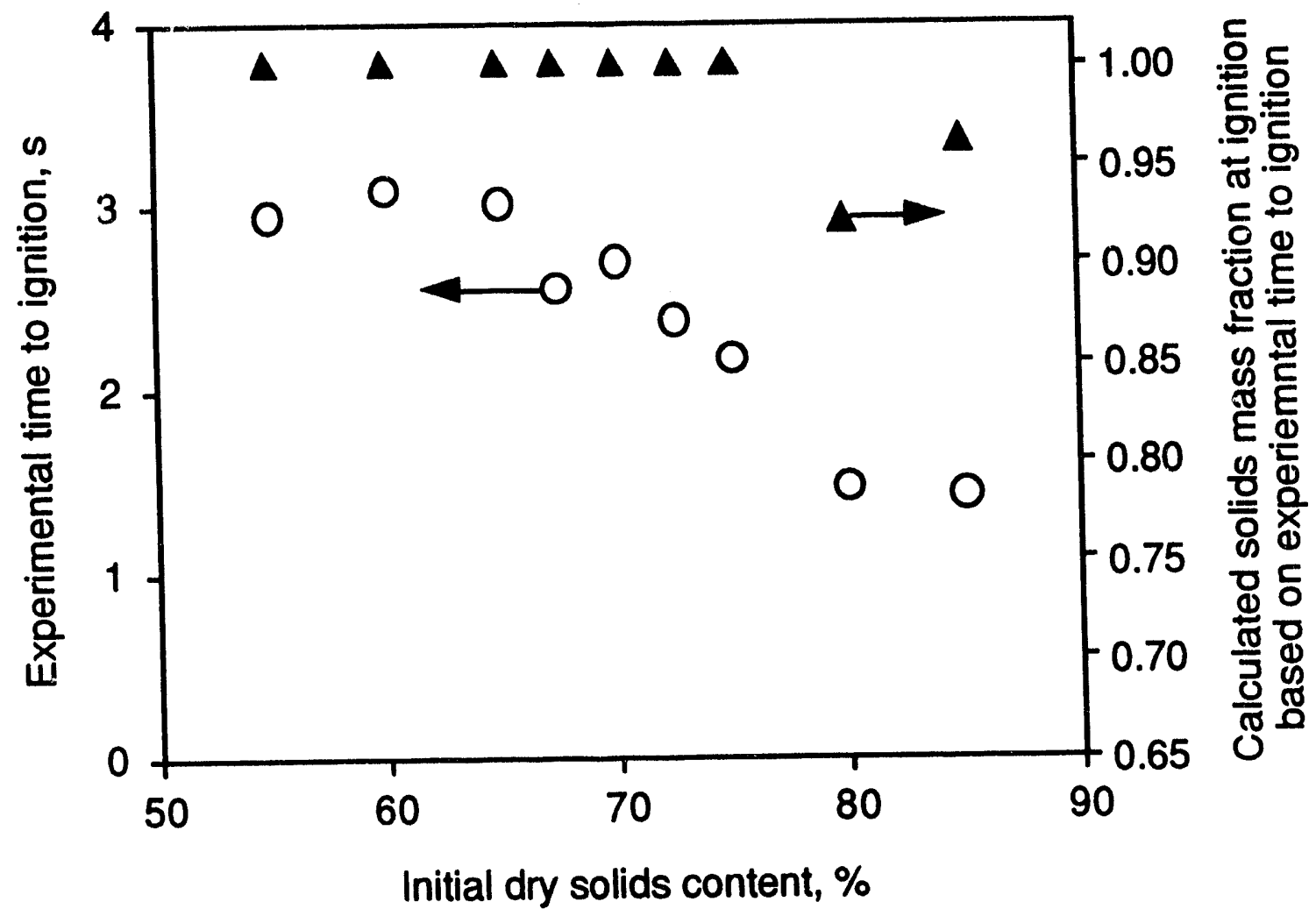

Figure 4.12. Experimental times to ignition (Frederick et al., 1991b) and dry solids contents at igntion as calculated by the single droplet drying model of Frederick (1990). 




Figure 4.13. A plot of $S_{i}$ for an average liquor (represented by Equations 1 and 2) with $S_{i}$ data for liquor 166 (from Table 4.2). 
Figure 4.14 shows how $S_{i}$ calculated by this method varies with initial droplet mass and heat flux to the droplet surface for droplets initially at $70 \%$ dry solids content. For comparison, the heat fluxes and corresponding laboratory furnace temperatures for $12 \mathrm{mg}$ black liquor droplets are shown in Table 4.3. The heat fluxes in a recovery furnace will be similar in magnitude.

Table 4.3. Calculated mean heat flux to a black liquor droplet in a laboratory furnace versus furnace temperature for $12 \mathrm{mg}$ initial droplet mass.

\begin{tabular}{|c|c|}
\hline Temperature, ${ }^{\circ} \mathrm{C}$ & Heat flux, $\mathrm{kW} / \mathrm{m}^{2}$ \\
\hline 600 & 40.9 \\
\hline 800 & 74.1 \\
\hline 1000 & 117 \\
\hline 1200 & 187 \\
\hline
\end{tabular}

The curves in Figure 4.14 show the following limiting characteristics with respect to heat flux and droplet size:

- At low heat fluxes, droplets reach dryness $(\mathrm{Si}>1)$ before devolatilization begins.

- At high heat fluxes, droplets begin to devolatilize without drying very much.

- Very small droplets begin to devolatilize without drying very much.

The limiting case where the model predicts that $S_{i}$ excerds 1 needs to be dealt with separately. $\mathrm{Si}>1$ means that the droplets are heating after drying and that there will be a delay after reaching dryness before they begin to swell and lose volatiles. This occurs with smaller droplets and at lower furnace temperatures. We can estimate the time delay associated with heating beyond dryness as

$$
\Delta t_{\text {heating }}=\frac{\Delta Q_{\text {heating }}}{q A_{\text {dry }}}
$$

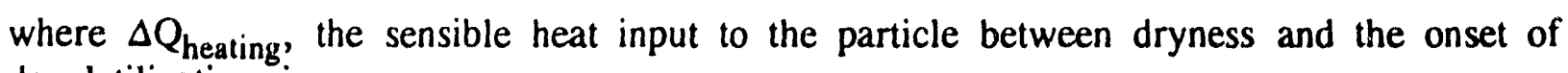
devolatilization, is

$$
\Delta Q_{\text {heating }}=m_{B L S} C_{p B L S}\left(T_{\text {devol }}-T_{\text {dry }}\right)
$$

where $q$ is the heat flux to the particle, and $A_{d r y}$ is the external surface area of the particle while drying, or 2.4 times the initial droplet external surface area (Frederick et al., 1991a). 


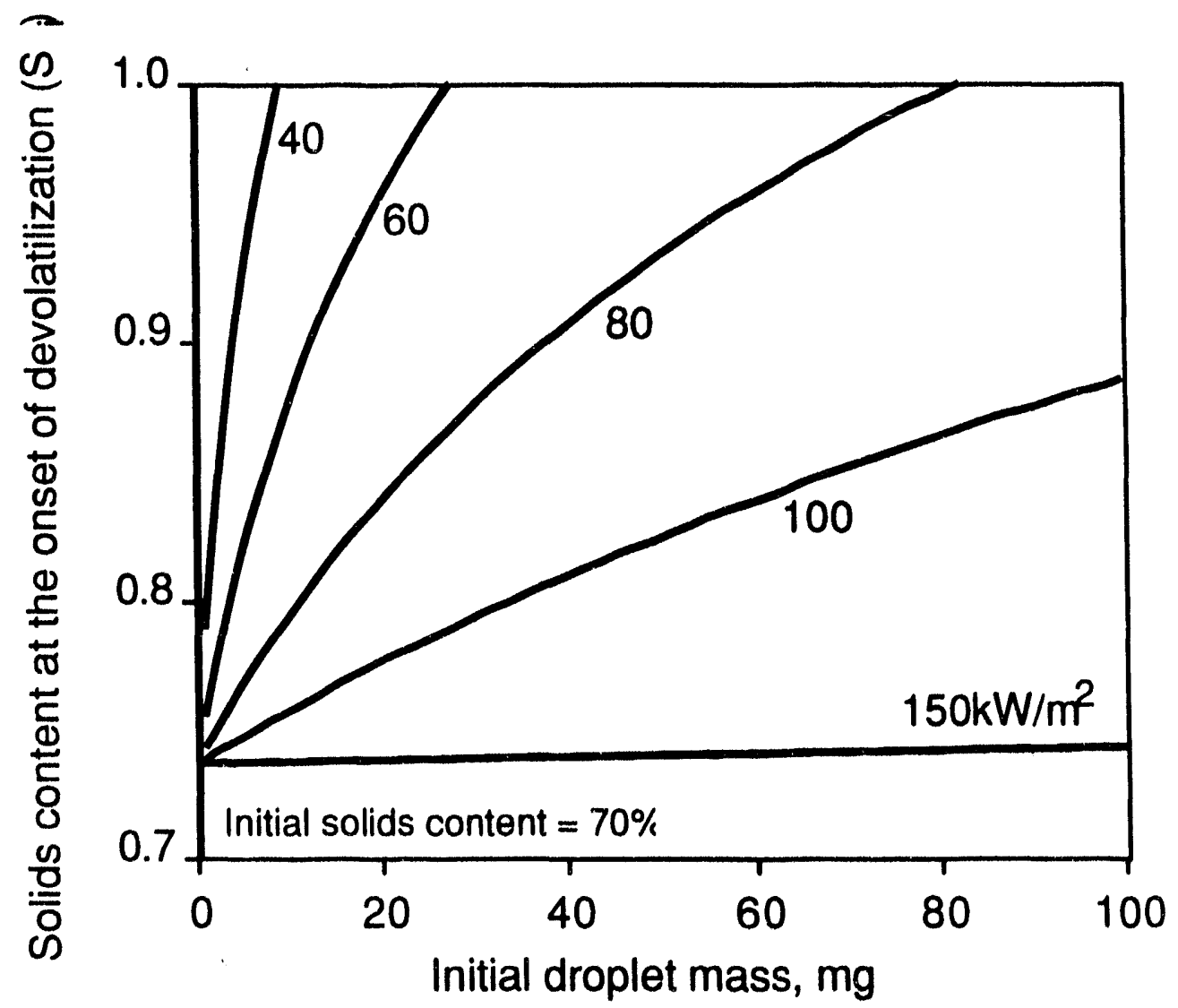

Figure 4.14. Effect of initial droplet mass and heat flux to droplet on $S_{i}$ as calculated by the algorithm presented here for droplets initially at $70 \%$ dry solids content. 
The temperature which a droplet reaches before the onset of devolatilization can be estimated from the data in Figure 4.5. The data at 650 and $700^{\circ} \mathrm{C}$ Although the data in Figure 4.5 are shown with straight lines through them, it is more likely that they approach a limiting upper temperature at which devolatilization will occur. We choose this upper limit as $600^{\circ} \mathrm{C}$ based on the experimental results of Hupa et al. (1987) who found that $600^{\circ} \mathrm{C}$ was a critical temperature to reach before ignition would occur. An equation which approximates the data at 650 and $700^{\circ} \mathrm{C}$ in Figure 4.5 is:

$$
\frac{\mathrm{T}_{\text {devol }}-\mathrm{T}_{\text {dry }}}{\mathrm{T}_{\text {devmax }}-\mathrm{T}_{\text {dry }}}=\max \left[150^{\circ} \mathrm{C}, 1-\exp \left\{-0.2\left(\mathrm{M}_{\mathrm{o}}-\mathrm{M}_{\mathrm{o}}^{*}\right)\right\}\right]
$$

where $\mathrm{M}_{\mathrm{o}}^{*}=3.0 \mathrm{mg}$ at $650^{\circ} \mathrm{C}$ and 4.5 at $700^{\circ} \mathrm{C} . \mathrm{T}_{\text {devol }}=\left[{ }^{\circ} \mathrm{C}\right]$ and $\mathrm{M}_{\mathrm{o}}=[\mathrm{mg}]$.

The heat capacity of dry black liquor solids is (Adams and Frederick, 1988):

$$
\mathrm{C}_{\mathrm{pBLS}}(\mathrm{J} / \mathrm{gK})=1.675+.00331 \mathrm{~T}
$$

and $m_{B L S}$ is the dry solids mass of the droplet.

The time delay between dryness and the onset of devolatilization, calculated using Eqs. (4.10)-(4.13), is shown in Figure 4.15 for droplets initially at $70 \%$ dry solids content and at three different heat fluxes. The curves are shown only in the ranges where devolatilization may be delayed (see Figure 4.14). The time delays are significant with respect to droplet burning times and need to be taken into account in in-flight droplet combustion calculations in regions of lower furnace temperature.

\subsection{Recommended Procedure for Application of the Onset of Devolatiliza- tion Model to Calculations in a Nonuniform Temperature Field}

In a recovery boiler, a black liquor droplet passes through a nonuniform temperature field while in flight. The procedure developed as so far been presented in terms of an isothermal flow field. To determine whether devolatilization has begun in a nonisothermal flow field, the following procedure should be used:

1. Determine the heat flux to the droplet at the cell gas temperature.

2. Calculate the current solids content of the droplet.

3. Calculate $S_{i}$ for the local cell conditions (heat flux) and initial droplet mass using Eqs. (4.3)-(4.9).

4. If the solids content of the droplet exceeds the calculated $S_{i}$ for the cell conditions but does not exceed 1.0, then swelling begins here. If not, repeat this procedure again in the next cell. 


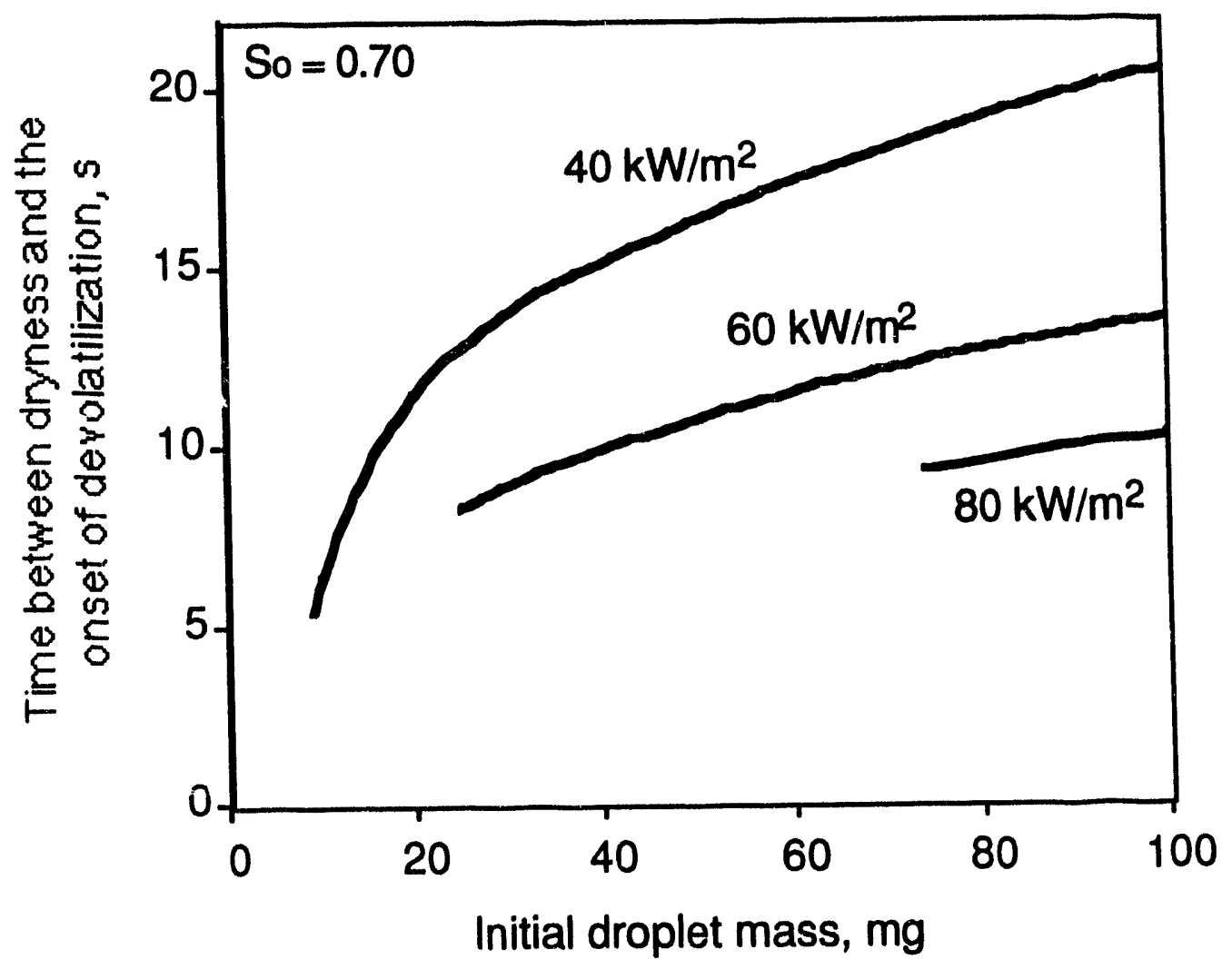

Figure 4.15. Time delay between dryness and the onset of devolatilization as a function of initial droplet mass and heat flux. 
5. If $S_{i}$ exceeds 1.0 , calculate the time delay between dryness and the onset of devolatilization using Eqs. (4.10)-(4.13).

\subsection{Summary}

During black liquor combustion, the processes of drying and devolatilization are clearly not separate and distinct. They can overlap considerably depending on the droplet size and heat flux to the droplet surface. This has been reported for other fuels as well. These conclusions are based on an analysis of time to ignition data for droplets burned in air and detailed modeling of single droplet combustion. The results show that smaller droplets and droplets in lower temperature environments are more likely to dry completely before devolatilization begins.

An algorithm has been developed for estimating the point at which devolatilization of black liquor droplets begins in recovery boiler environments. For droplets which begin to devolatilize before drying completely, the algorithm predicts the mean droplet solids content at which devolatilization begins. For droplets which dry completely and continue heating before devolatilization begins, the model predicts the time delay between reaching dryness and the onset of devolatilization. The algorithm accounts for the effects of initial droplet mass, initial dry solids content, and the heat flux to the droplet. A methodology for dealing with nonisothermal temperature environments was also developed.

The broad spectrum of times to ignition has an important implication to liquor combustion stability: liquors which take longer to ignite may even be harder to burn. This, together with the great liquor-to-liquor variability in swelling during devolatilization, may account for the difference between a liquor which is easy to burn and one which is difficult to burn. This may be an important issue in the operability of recovery boilers and it should be investigated experimentally. No direct measurements of differences in ignition points for black liquors have ever been reported.

Results from a detailed model for black liquor combustion indicates that volatiles evolution begins sooner for droplets at higher initial dry solids content. This may account for why higher solids firing improves combustion stability in recovery boilers.

\subsection{References}

Adams, T.N., Frederick, W.J., Kraft Recovery Boiler Physical and Chemical Processes, American Paper Institute (1988).

Clay, D.T., Lien, S.J., Grace, T.M., Macek, A., Amin, N., Semerjian, H.G., Charagundla, S.R., "Fundamental study of black liquor combustion - Report No. 2-Phase 1," U.S. DOE DE-ACO2-83CE40637, January 1988.

Frederick, W.J., "Combustion processes in black liquor recovery: analysis and interpretation of combustion rate data and an engineering design model," U.S. DOE Report DOE/CE/40637-T8 (DE90012712), March 1990. 
Frederick, W.J., Noopila, T., and Hupa, M., "Swelling of pulping liquor droplets during combustion," J. Pulp Paper Sci., 17(5):J164-J170 (1991a).

Frederick, W.J., Noopila, T., Hupa, M., "Combustion behavior of black liquor at high solids firing conditions," Tappi J., 74(12):163-170 (1991b).

Howard, J.B., Essenhigh, R.H., I \& EC Proc. Des. Dev., 6, 74-84 (1967).

Hupa, M., Solin, P., Hyöty, P., "Combustion behavior of black liquor droplets" J. Pulp Paper Sci., 13(2):J67-72 (1987).

Jüntgen, V.H., van Heek, N.H., Fuel, 47, 103-117 (1968).

Kubes, G.J., J. Pulp Pap. Sci., 10(3):J63(1984).

Lawn, C.J., Principles of Combustion Engineering for Boilers, Academic Press, London (1987).

Noopila, T. and Hupa, M., "Measuring the combustion properties of black liquors by different techniques, " Combustion Chemistry Research Group Report 88-5, Abo Akademi, Turku, Finland (1988).

Saastamoinen, J., Aho, M., "The simultaneous drying and pyrolysis of single wood particles and pellets made of peat," Am. Flame Research Comm. 1984 Intl. Symp. on Alternative Fuels and Hazardous Wastes, Tulsa, OK, October 9-11, 1984.

Saastamoinen, J., Aho, M., Linna, V., "Simultaneous pyrolysis and char combustion," accepted for publication in FUEL (1992).

Söderhjelm, L., Hupa, M., and Noopila, T., J. Pulp and Paper Science, 15(4):J117-J122 (1989).

Srinivasachar, S., Kang, S.W., Timothy, L.D., Froelich, D., Sarofim, A.F., Béer, J.M., Proc. 8th (Int.) Symp. Coal slurry Fuels Preparation and Utilization, pp. 330-342, Pittsburgh Energy Technology Center, U.S. Department of Energy (1986). 


\section{Black Liquor Droplet Temperature Measurements During Combustion}

The temperature of a black liquor droplet during combustion is an important modeling variable for several reasons. First, the drying and devolatilization stages are essentially heat transfer processes. The rate of heat transfer, particularly during devolatilization, can be very sensitive to the droplet surface temperature because the surface temperature approaches the ambient gas temperature. In addition, a droplet temperature criterion is used to determine when devolatilization is complete.

Another important factor is that during char burning, the process which controls the burning rate depends upon the droplet temperature. At low enough ambient gas temperatures, the char particles oxidize slowly and the char burning rate is controlled by the chemical reaction kinetics. Under these conditions, the char will not have ignited (see Chapter 4, Section 4.3). As the ambient temperatures and/or oxygen concentration is increased the char burns more rapidly and the rate is limited first by diffusion of oxygen within the particle and ultimately by the rate at which oxygen reaches the external particle surface. Char burning is further complicated by the fact that endothermic reactions of char with $\mathrm{CO}_{2}$ and water vapor, producing $\mathrm{CO}$ and $\mathrm{H}_{2}$, may occur in parallel with the combustion reactions. In interpreting single droplet combustion data and in modeling droplet combustion in recovery boilers, it is important to know what controls the rate of char burning under the experimental or local boiler conditions. The char particle temperature provides important information in this respect.

In this chapter, we present new data on the surface ternperature of black liquor droplets during pyrolysis, gasification, and combustion based on two-color pyrometry. We also present earlier unpublished data on internal temperature measurements of black liquor droplets during combustion in air (Solin and Hupa, 1984). The experimental results are compared with predicted droplet temperatures based on the black liquor droplet combustion model reported earlier (Frederick, 1990). Finally, correlations are presented for droplet temperatures during char burning.

\subsection{Experimental}

Combustion experiments were conducted by suspending single droplets of spent pulping liquors in a stagnant gas within laboratory muffle furnaces (see Figure 3.1). For those experiments where gases other than air were used, the furnace was placed in an enclosure, and a gas mixture of controlled composition flowed through the enclosure to isolate the furnace from the ambient environment.

Droplet surface temperatures were recorded using a two-color optical pyrometer (Hernberg et al., 1992). An optical fiber probe with a quartz tip was inserted through a sealed port in the furnace and positioned about $2 \mathrm{~cm}$ from the position where the droplet would be when it entered the furnace. The signals from the pyrometer were recorded on a Mikromikko 80386 computer. 
The combustion events were recorded using a video camera. The elapsed times for each combustion stage were read from the video recordings. Droplet dimension versus time data were also obtained from the recordings. This experimental procedure is described in more detail elsewhere (Hupa et al., 1982, 1987; Noopila and Hupa, 1988).

Data for internal droplet temperatures during combustion were obtained from the unpublished results of Solin and Hupa (1984). In their experiments, small (1-2 mm diameter) single droplets of black liquor at an initial dry solids content of $60 \%$ were burned in air while suspended from a bare fine wire thermocouple junction. The thermocouple signal was recorded on a strip chart recorder. The combustion event for each droplet was recorded on $8 \mathrm{~mm}$ movie film during their experiments, and data on combustion stage times and swelling for each droplet were available.

\subsection{Internal Droplet Temperatures}

Figure 5.1 shows a typical internal droplet temperature versus time plot for a black liquor droplet (Hupa et al., 1987). The temperature was measured by burning a droplet while suspended on the bare junction of a small thermocouple. The temperature during drying rises slowly but steadily, to about $300^{\circ} \mathrm{C}$ at ignition. It then rises more rapidly during devolatilization, approaching the furnace temperature $\left(810^{\circ} \mathrm{C}\right)$ at the end of devolatilization, and continues to rise during the char burning stage. The temperature peaks shortly after char burning is complete, during the inorganic reactions stage, and then drops slowly to the furnace temperature.

Table 5.1 shows additional internal droplet temperature data obtained by Solin and Hupa (1984). During drying the internal droplet temperatures increased continuously to a value at ignition which depended on the furnace temperature. The internal droplet temperatures at ignition for the four liquors were on average about $280^{\circ} \mathrm{C}$ in an $800^{\circ} \mathrm{C}$ furnace, but (for the kraft liquor) were lower at furnace temperatures of $700^{\circ} \mathrm{C}$ and $900^{\circ} \mathrm{C}$. The temperature at the end of devolatilization apparently increases with increasing furnace temperature, but the uncertainty in the data is very large. For the kraft liquor, the maximum droplet temperatures reached during char burning increase slighlly with increasing furnace temperature. The char burning temperature data appear to be liquor-specific and much less scattered than the drying and devolatilization data.

The high variability for the drying and devolatilization temperatures in Table 5.1 may indicate that the thermocouple was sometimes nearer the center of the droplet and sometimes nearer to its external surface, while the lower variation in the char burning measurements suggest less spatial variation in the temperature within the droplet. To test this, the measured internal droplet temperatures during drying and devolatilization were compared with the droplet surface temperatures calculated from the numerical drying and devolatilization models of Frederick (1990). The results for two of the droplets are plotted in Figure 5.2. 


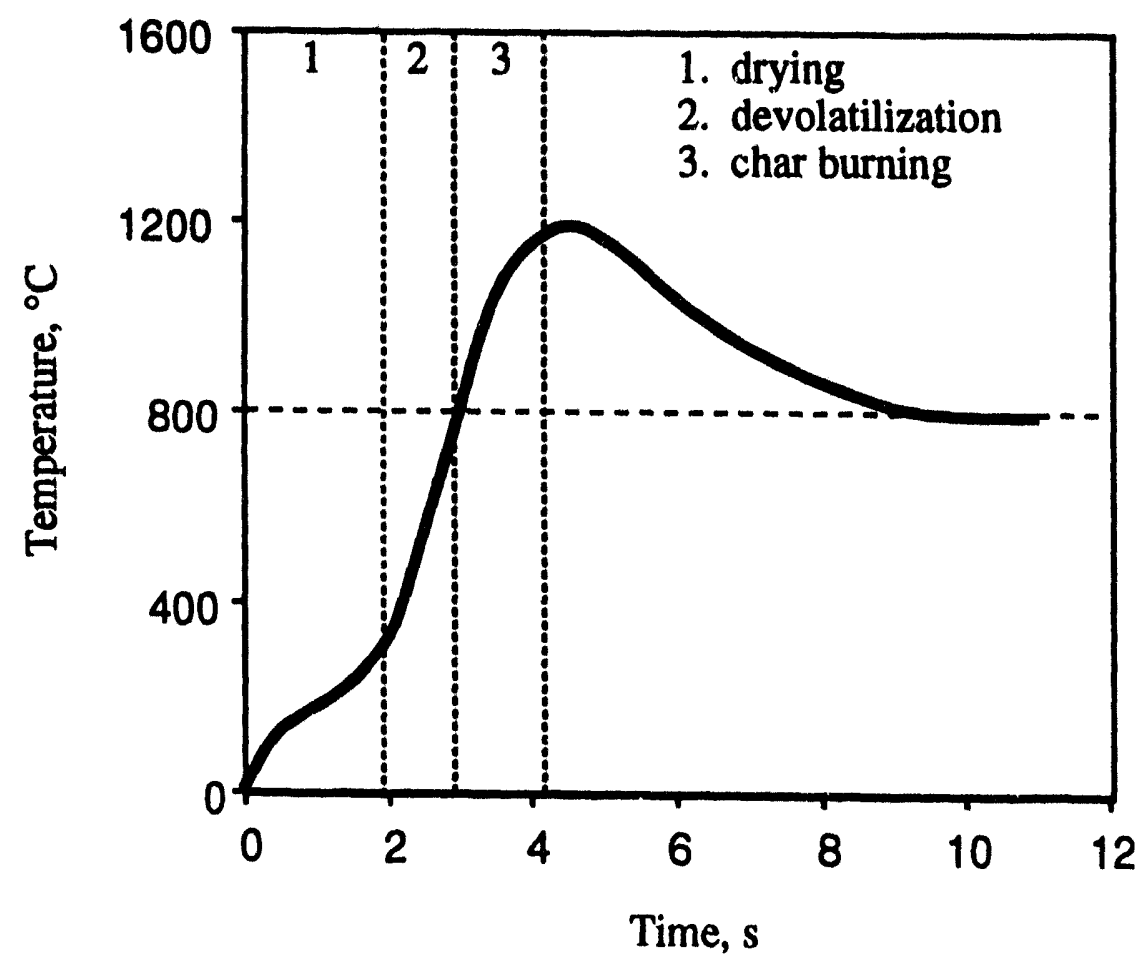

Figure 5.1. Droplet temperature versus time measured from thermocouple on which droplet was suspended (Hupa et al., 1985). Kraft black liquor, $1.3 \mathrm{~mm}$ droplet initial diameter, $60 \%$ initial dry solids content, $800^{\circ} \mathrm{C}$ air atmosphere. From Hupa et al., 1987. 

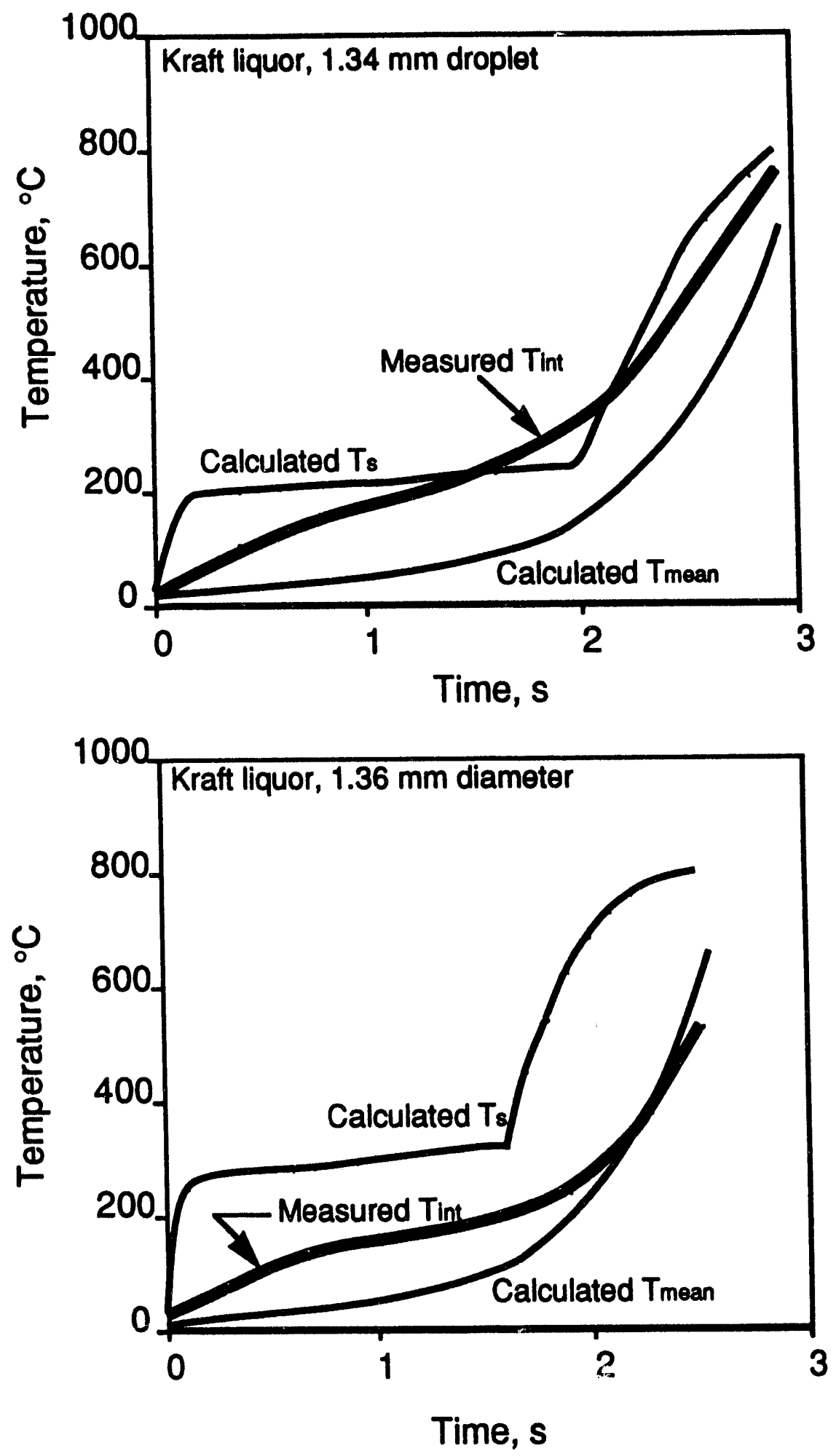

Figure 5.2. Measured internal droplet temperatures (heavy line) and calculated surface temperatures (light line) during drying and devolatilization for two kraft liquor droplets burned in air at $800^{\circ} \mathrm{C}$. The experimental data (Tint) are from Solin and Hupa (1984). 
Table 5.1. Internal droplet temperatures at the end of drying and devolatilization for droplets burned at different furnace temperatures in air. The means and standard deviations reported here are based on the experimental measurements of Solin and Hupa (1984).

\begin{tabular}{||c|c|c|c|c|}
\hline \multirow{2}{*}{$\begin{array}{c}\text { Liquor } \\
\text { type }\end{array}$} & $\begin{array}{c}\text { Furnace } \\
\text { temp., }{ }^{\circ} \mathrm{C}\end{array}$ & ignition, ${ }^{\circ} \mathrm{C}$ & end of devol., ${ }^{\circ} \mathrm{C}$ & $\begin{array}{c}\text { Max. } \\
\text { Temperature } \\
\text { (char burning), } \\
{ }^{\circ} \mathrm{C}\end{array}$ \\
\cline { 3 - 5 } & 700 & 186 & 510 & 1180 \\
\hline Kraft & 800 & $277 \pm 60$ & $670 \pm 170$ & $1210 \pm 29$ \\
\hline Kraft & 900 & $150 \pm 43$ & $710 \pm 300$ & $1280 \pm 24$ \\
\hline Kraft & 800 & $330 \pm 110$ & $640 \pm 210$ & $1210 \pm 32$ \\
\hline Na-sulfite & 800 & $282 \pm 18$ & $803 \pm 59$ & $1272 \pm 5$ \\
\hline Na-sulfite & 800 & $250 \pm 100$ & $570 \pm 430$ & $1104 \pm 1$ \\
\hline Mg-sulfite & \multicolumn{3}{|c}{} \\
\hline
\end{tabular}

For the first data set in Figure 5.2, the calculated surface temperature and the measured internal temperature are nearly the same during devolatilization. The calculated mean droplet temperature is well below the measured internal temperature. In the second data set, the measured internal temperature is well below the calculated surface temperature and is quite close to the calculated mean temperature. We interpret this to mean that the thermocouple was probably very near the droplet surface during devolatilization in the first data set, but not in the second. The data also suggests that there can be a significant temperature gradient within the droplet during both drying and devolatilization. Most of Solin and Hupa's data behaved more like the first set, suggesting that the thermocouple was near the droplet surface during devolatilization in most of the runs.

Another test of this concept is provided by the calculated temperature gradients within a burning black liquor droplet shown in Figure 5.3. These gradients were calculated using Saastamoinen's detailed dynamic model of a black liquor particle during combustion (Saastamoinen, 1984, 1992). The calculated temperature gradients are indeed very steep, greater than $600^{\circ} \mathrm{C} / \mathrm{mm}$ at 3 and 5 seconds exposure time. As shown later in this chapter, Saastamoinen's model predicts quite well the surface temperatures of black liquor droplets during combustion.

One interpretation of the temperature data at ignition for the kraft liquor is that there is a tradeoff between temperature per se and the rate of volatiles evolution that determine when ignition occurs. In other words, a higher concentration of volatiles would be needed to reach ignition at a lower temperature. The basis for this is that a droplet heats rapidly at the external surface, due largely to the strongly temperature-dependent radiant heat flux from the furnace walls, and a temperature gradient develops within the droplet. Ignition occurs when the volatiles 


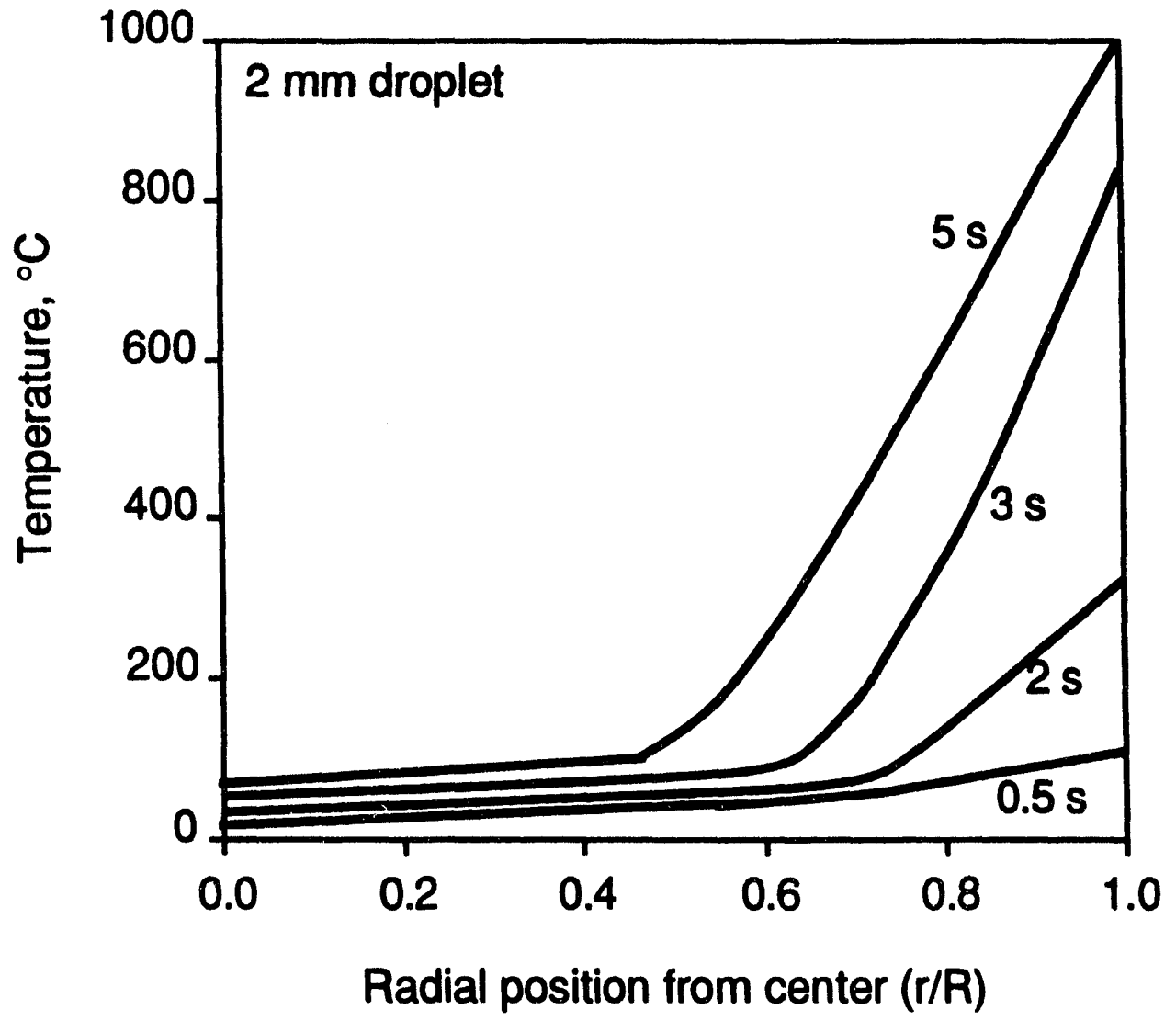

Figure 5.3. Calculated temperature profiles for a $2 \mathrm{~mm}$ black liquor droplet burned in air at $800^{\circ} \mathrm{C}$ based on Saastamoinen's model (Saastamoinen, 1984, 1992). 
evolution rate from the droplet reaches a high enough level so that the flammability limit is exceeded in the vicinity of the droplet surface.

The maximum in the internal droplet temperature at ignition versus furnace temperature is explained as follows: at $900^{\circ} \mathrm{C}$, a droplet dries more rapidly at the external surface than at $800^{\circ} \mathrm{C}$ and a steeper temperature gradient develops within the droplet. Volatiles evolution sufficient to support ignition from the outer regions of the droplet occurs while the inner droplet is still relatively cool. The result is ignition at a lower internal droplet temperature than at $800^{\circ} \mathrm{C}$ (see Chapter 4, Section 4.4).

At $700^{\circ} \mathrm{C}$, the converse is true. Here, a droplet dries more uniformly than at $800^{\circ} \mathrm{C}$, and the temperature gradient within the droplet is less steep. Volatiles evolution sufficient to support ignition occurs at a lower internal droplet temperature than for droplets in an $800^{\circ} \mathrm{C}$ furnace because of the lower temper iture gradient. Although the rate of evolution of volatiles per unit volume of droplet is lower near the external surface of the droplet, more of the droplet is hot enough to contribute significant volatiles evolution. Thus, the internal droplet temperature is relatively low when ignition occurs, and is less than at $800^{\circ} \mathrm{C}$.

Additional support for this analysis is provided by the time to ignition data in Chapter 4 . Figure 4.6 shows the predicted solids content at ignition as a function of furnace temperature for droplet combustion experiments with two liquors plus average values for 100 liquors. The values of solids content at ignition in Figure 4.6 are those for which the experimental drying times and those calculated using the drying model described earlier are the same. The model predicts that the solids content at ignition decreases with increasing furnace temperature, in agreement with our interpretation of the data presented in Table 5.1. The results of a more detailed for one liquor (Figures 4.4-4.5) indicate that the droplets burned in furnaces below $800^{\circ} \mathrm{C}$ nearly always reached dryness before igniting, while at higher furnace temperatures they did not.

\subsection{Surface Temperature Measurements}

\subsubsection{Two-Color Pyrometer Data Reduction}

Two-color optical pyrometry has been used in various applications to measure the surface temperature of burning particles (e.g. Macek and Bulik, 1984; Tichenor et al., 1984, Hernberg et al., 1992). The method is based on the detection of radiation emitted at different wavelengths from the particle surface. The relationship between the pyrometric signals $R_{1}$ and $R_{2}$ (at wavelengths $\lambda_{1}, \lambda_{2}$ respectively) and the temperatures of the particle and background (furnace) is (Stenberg, et al., 1992) 


$$
\frac{R_{1}-R_{01}}{R_{2}-R_{02}}=\frac{F_{1}\left(T_{p}\right)-F_{1}\left(T_{f}\right)}{F_{2}\left(T_{p}\right)-F_{2}\left(T_{f}\right)}
$$

where $R_{i}, i=1,2$ are the pyrometric signal level when the droplet is in the field of view of the pyrometer and $R_{0 i}, i=1,2$ are the background (furnace) signal levels. $F_{i}(T)$ are the radiation functions at wavelengths $\lambda_{1}$ and $\lambda_{2}$. They are the responses of the pyrometer detectors to a black body at temperature $T$ and are obtained by calibration of the pyrometer. $T_{p}$ and $T_{f}$ are the particle surface temperature and the furnace temperature respectively. Details of the theoretical basis for this method are discussed by Hernberg et al. (1992).

Equation (5.1) is based on the assumption that the particle is either a gray body or at least that its emissivity is the same at wavelengths $\lambda_{1}$ and $\lambda_{2}$. It accounts for the reflection of furnace radiation from the particle surface (Hernberg et al., 1992). This is critical when the temperature of the particle is near or below the furnace temperature and reflected radiation can be a very significant fraction of the total radiation from the particle. Equation (5.1) is also based on the assumptions that the droplet is small relative to the furnace cavity and that reflections from the droplet and the optical pyrometer probe do not have a significant impact on the total radiation received by the probe (Hernberg et al., 1992). This method eliminates the need to know either the emissivity of the char particle or the fraction of the field of view which is filled by the droplet. However, information on particle size as well as surface temperature can be obtained from the measurements (Hernberg et al., 1992).

With Eq. (5.1), the temperature of the char particle $\left(T_{p}\right)$ can be determined from the measured $R_{i}$ values, the furnace temperature $\left(T_{f}\right)$, and the known temperature functions $F_{i}(T)$ obtained by calibration. The furnace temperature is obtained from measurements without the droplet present using the relationship

$$
\frac{R_{01}}{R_{02}}=\frac{F_{1}(T)}{F_{2}(T)}
$$

Figure 5.4 shows typical data as measured directly with the optical pyrometer. With the optical pyrometer, intensities of radiation from the char particle were sampled at two wavelengths. The measurements at each wavelength were made at discrete intervals and were not made simultaneously but at tin.e intervals differing by $6.7 \mathrm{~ms}$. This time shift can create significant errors in the calculated temperature (LaFollette et al., 1989). To avoid this problem, intensities at different wavelengths were obtained at corresponding times by linear interpolation of the data. Droplet temperatures were calculated from the time-shifted optical pyrometer intensities using proprietary software from Tampere University of Technology (Hernberg et al., 1992).

A requirement for acceptable data from the optical pyrometer was that

$$
0 \leq G_{d} \epsilon_{d} A_{d} / A_{p} \leq 1
$$




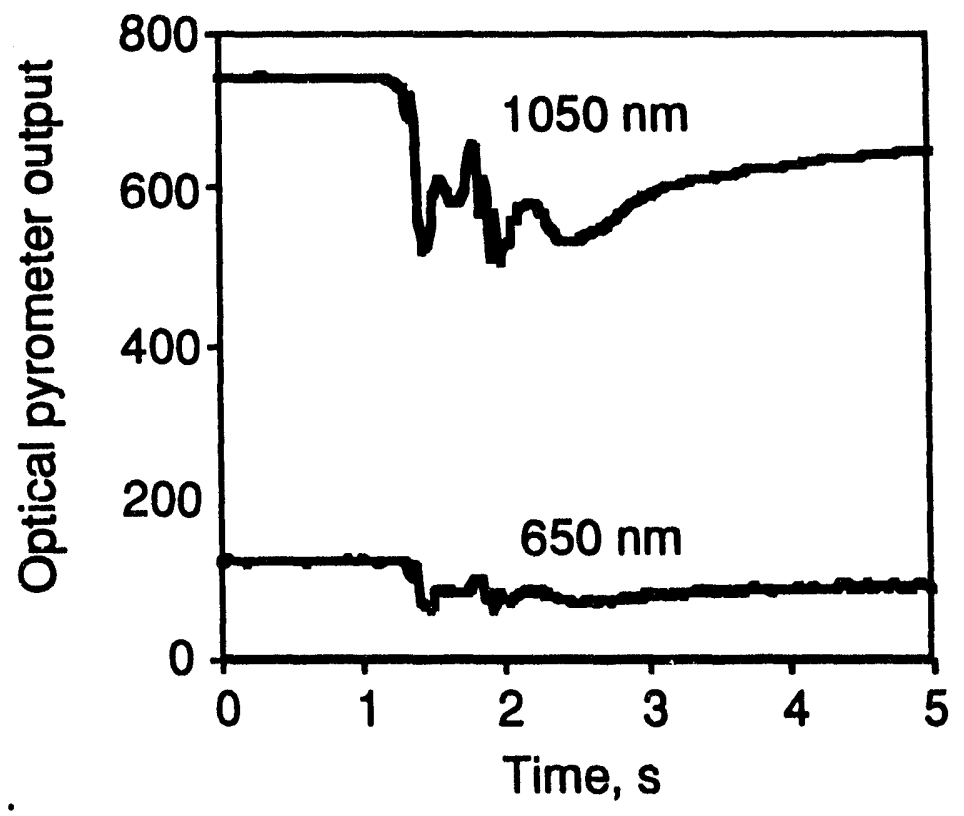

Figure 5.4. Typical data at three wavelengths as measured directly with the optical pyrometer. Data are for a droplet pyrolyzed in 5\% CO, 95\% nitrogen at $800^{\circ} \mathrm{C}$. The droplet entered the field of view of the optical probe at about 1.25 s. Pyrolysis continued beyond 5 seconds, but the rest of the data is not shown. 
where $G_{d}$ is the configuration factor from the droplet to the probe, $\epsilon_{d}$ is the emissivity of the droplet, $A_{d}$ is the projected surface area of the droplet, and $A_{p}$ is the area of the probe tip (Stenberg et al., 1992). This criterion eliminated data points for which the droplet temperature was too low, soot particles interfered, the area of the particle within the field of view of the probe was too small, and where the data was otherwise noisy. The calculation routine included a filter by which data which did not meet this criteria were eliminated. Filtering by this criterion did not eliminate many points for droplets burned in air and oxygen contents above $10 \%$; the points eliminated were either during the drying stage, during the initial stages of devolatilization when the flame first appeared, or for small particles at the end of char burning when the fraction of the pyrometer's field of view filled by the particle became too small. At lower oxygen contents more than half and sometimes all of the data points were often eliminated. This was probably due to the relatively weak signal when the droplet and furnace temperatures differed by too little. The pyrometer has a lower limit detection limit due to the weak signal from relatively cold particles when compared with reflected background radiation (Stenberg et al., 1992). The limit corresponds to a temperature $200^{\circ} \mathrm{C}$ below the furnace temperature for droplets in an $800^{\circ} \mathrm{C}$ furnace. Points which fell below this limit were also eliminated; these occurred when the particle first entered the field of view of the pyrometer.

\subsubsection{Surface Temperatures During Pyrolysis in $\mathrm{N}_{\mathbf{2}} / \mathrm{CO}$}

Figure 5.5 shows the droplet surface temperature for two replicate pyrolysis runs with droplets of roughly the same size $(17 \mathrm{mg})$ made in $95 \% \mathrm{~N}_{2} / 5 \% \mathrm{CO}$ at $800^{\circ} \mathrm{C}$. The curves are shifted so that time zero corresponds to the appearance of the droplet in the field of view of the cptical probe, and the curve for droplet B is shifted downward approximately $40^{\circ} \mathrm{C}$ so that both curves can be seen clearly. These two curves are nearly identical which indicates that the surface temperature is very reproducible as measured by this method. They also confirm that the pyrometer indicates the droplet temperature correctly (the same as the furnace temperature) after pyrolysis is complete.

It is not clear why the indicated surface temperature drops slowly immediately after the droplets enter the field of view of the optical probe since the droplet surface temperature is lowest at this point. When the temperature of the surface measured is substantially below the temperature of the surroundings, the radiant energy from the surroundings which is reflected from the particle surface can be much greater than the energy emitted by the particle. When this happens, optical pyrometry does not give accurate temperature measurements. This may be the case in Figure 5.5.

\subsubsection{Surface Temperatures in a $\mathrm{CO}_{2} / \mathrm{N}_{2}$ Atmosphere}

The surface temperature for a droplet pyrolyzed in $\mathrm{N}_{2} / \mathrm{CO}_{2}$ is shown in Figure 5.6. The droplet temperature during pyrolysis is similar to that in Figure 5.6 for pyrolysis in N2/CO. After pyrolysis, the carbon in the char begins to react with $\mathrm{CO}_{2}$ to yield $\mathrm{CO}$. The droplet surface temperature is $40-50^{\circ} \mathrm{C}$ below the furnace temperature during this time. This lower surface temperature is a result of the endothermic reaction between $\mathrm{CO}_{2}$ and carbon. The 


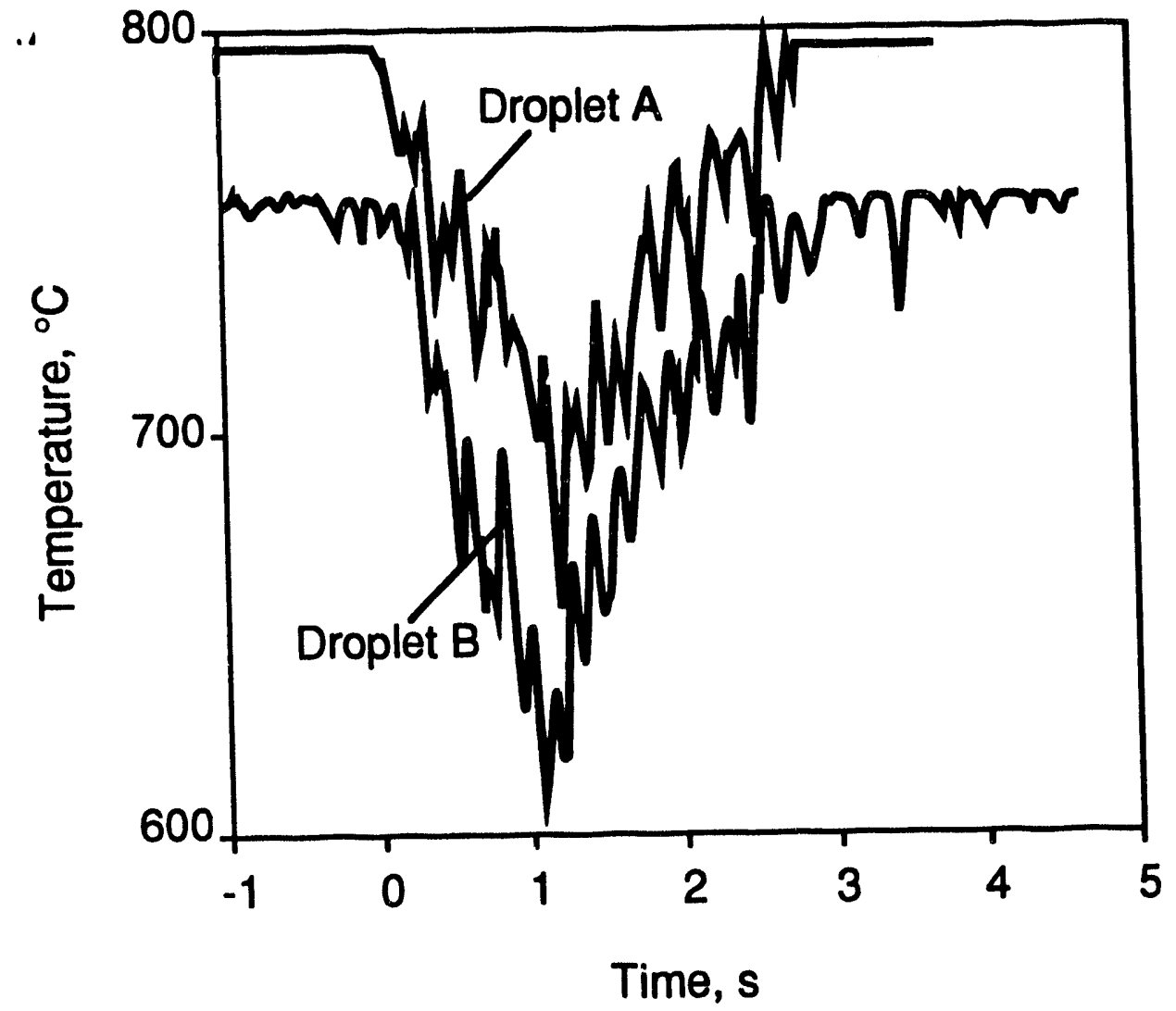

Figure 5.5. Surface temperature versus time for two $17 \mathrm{mg}$ droplets pyrolyzed in $95 \% \mathrm{~N}_{2} / 5 \% \mathrm{CO}$ at $800^{\circ} \mathrm{C}$. The curve for droplet $\mathrm{B}$ is shifted downward approximately $40^{\circ} \mathrm{C}$ so that both curves can be seen clearly. 


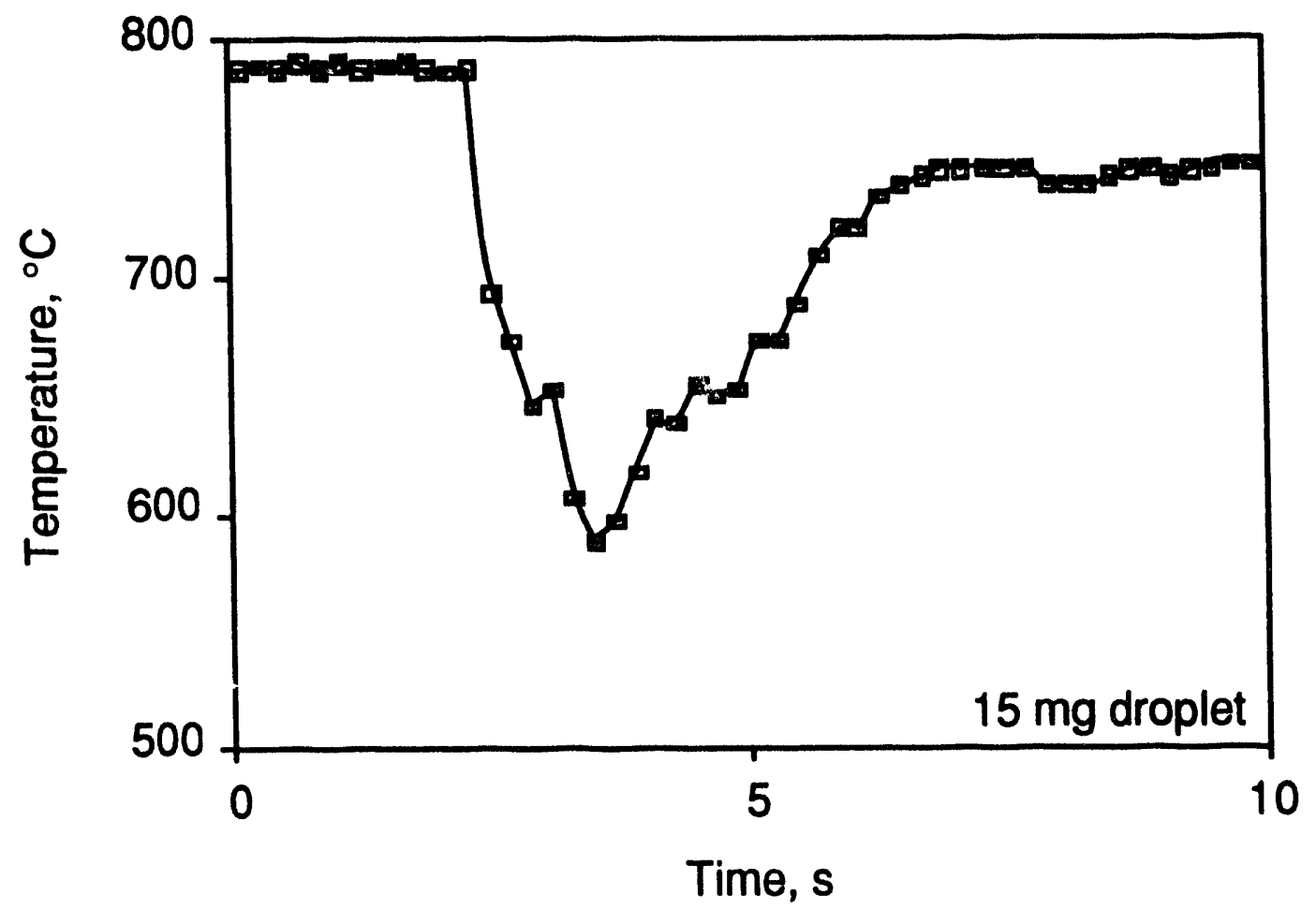

Figure 5.6. Surface temperature versus time for a $15 \mathrm{mg}$ droplet in $20 \%$ $\mathrm{CO}_{2} / 80 \% \mathrm{~N}_{2}$ at $800^{\circ} \mathrm{C}$. 
droplet surface temperature remains nearly constant at that value until gasification is complete. At $800^{\circ} \mathrm{C}$, complete gasification of black liquor char requires about 60 seconds, and the temperature increase when gasification is complete is not shown in Figure 5.6. For six droplets gasified in an $800^{\circ} \mathrm{C}$ furnace in $20 \% \mathrm{CO}_{2}$, the average surface temperature during gasification was $762^{\circ} \mathrm{C}$ with a standard deviation of $10^{\circ} \mathrm{C}$.

\subsubsection{Surface Temperatures During Combustion}

Figure 5.7 shows the indicated temperature for two droplets burned in air at $800^{\circ} \mathrm{C}$. The times that correspond to ignition, the end of devolatilization, and the end of char buming are also indicated. These figures show the following characteristics.

The droplet surface temperature is below that of the furnace prior to ignition. The temperature during this period was not always measured due to the problem of weak signals at temperatures lower than the surroundings as discussed earlier.

The indicated surface temperature rises steeply at ignition, and very high values were obtained during the early part of devolatilization. This rise was also not very reproducible for the $11 \mathrm{mg}$ droplet in Figure 5.7, the maximum temperature obtained was $960^{\circ} \mathrm{C}$, while for the $9.3 \mathrm{mg}$ droplet it exceeded $2500^{\circ} \mathrm{C}$. Optical pyrometers are not very accurate when the flame surrounding the particle contains soot particles; they can give temperatures several hundred degrees higher than either the soot or char particle unless the volume fraction and temperature of soot are known (Grosshandler, 1984, Lafollette, 1989, p. 100).

After this first temperature peak, the indicated surface temperatures during devolatilization are greater than the furnace temperature and are increasing with time. The rise continues until well into the char burning stage. These temperatures, following the initial peak, are more reproducible and more likely indicative of the true particle surface temperature. Apparently the density of the soot particles in the flame decreases sufficiently after the initial part of devolatilization so that the flame is transparent to visible radiation and the particle can be seen clearly by the probe from that point on. Burning black liquor droplets are usually not visible through the flame early in this stage but are later in the stage (Frederick et al., 1989). These visual observations are consistent with our optical temperature measurement results.

After the disappearance of the flame, the particle surface temperature rises steady through a maximum $300-400^{\circ} \mathrm{C}$ above the furnace temperature and then decreases slowly. The change in rate of temperature increase at the onset of char burning is generally greater with larger droplets. The surface temperature is still more than $200^{\circ} \mathrm{C}$ above the furnace temperature when char burning ends.

Followirg shar burning, additional heat is generated by oxidation of $\mathrm{Na}_{2} \mathrm{~S}$ to $\mathrm{Na}_{2} \mathrm{SO}_{4}$. This reaction is strongly exothermic $\left(-506 \mathrm{~kJ} / \mathrm{mole} \mathrm{O}_{2}\right)$ and it is produces more heat than combustion of carbon $\left(-394 \mathrm{~kJ} /\right.$ mole $\left.\mathrm{O}_{2}\right)$ on a per mole $\mathrm{O}_{2}$ basis. The rates of both reactions are film mass transfer limited under the conditions at which these experiments were conducted 


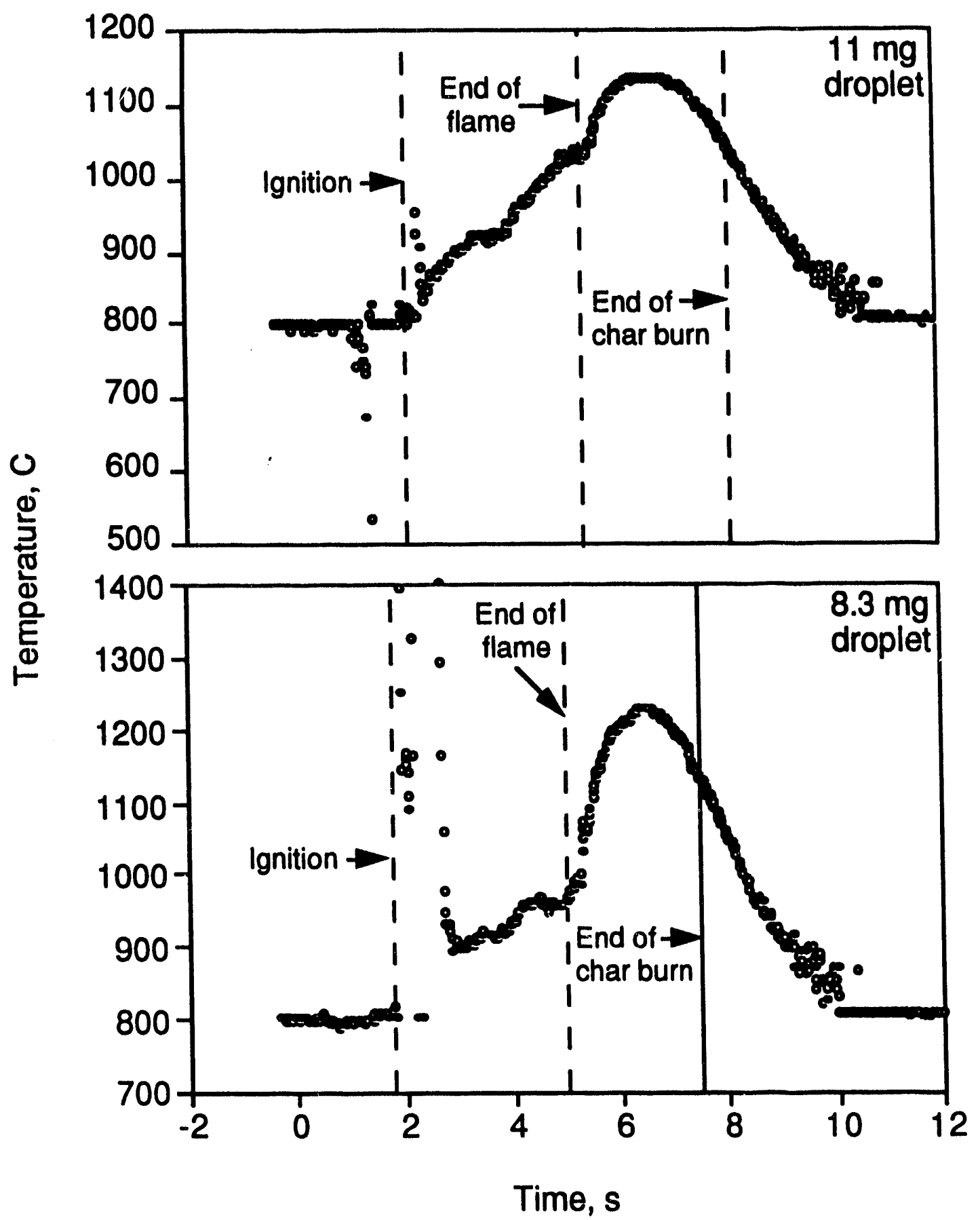

Figure 5.7. Surface temperature versus time for two droplets pyrolyzed in burned in air at $800^{\circ} \mathrm{C}$. Experimentally observed times to ignition, disappearance of the flame, and the end of char burning are also shown. 
as discussed later in this chapter. The heat generated by oxidation of $\mathrm{Na}_{2} \mathrm{~S}$ slows the rate of temperature decrease by the smelt particle. The particle finally reaches the furnace temperature a few seconds after char burning is complete.

The reproducibility of these runs in air was good as indicated by the data in Figure 5.8 for replicate runs at $800^{\circ} \mathrm{C}$ in air with $3.6 \mathrm{mg}$ droplets. The temperature spikes during devolatilization and the maximum temperatures during char burning are both nearly the same for the two droplets. The rather abrupt decrease in temperature at 3-4 $\mathrm{s}$ is due to these small cross sectional area of the droplet residue occupying too small a fraction of the pyrometer's field of view.

Figure 5.9 shows the surface temperatures for several droplets burned in air at $800^{\circ} \mathrm{C}$. The temperature curve for each successively larger droplet is shifted upward by a multiple of $200^{\circ} \mathrm{C}$ so that the curves can be distinguished from one another more clearly. The surface temperature always rises after devolatilization (following the temperature spike), goes through a maximum, and then decreases with time. For larger droplets, the maximum is very distinct and, in an $800^{\circ} \mathrm{C}$ furnace, the maximum surface temperature for different droplets varied widely, from $1020^{\circ} \mathrm{C}$ to $1303^{\circ} \mathrm{C}$. For smallur droplets, there is a less distinct temperature rise during char burning. The particle surface temperature is already higher than furnace temperature at end of devolatilization, and it is more uniform throughout char burning. These smaller particles heat more rapidly but generally do not reach as high a maximum temperature as do some of the larger droplets.

The maximum surface temperatures during char burning for data in air are compared in Figure 5.10 with the maximum internal droplet temperatures measured earlier by Solin and Hupa (1984). With one exception the surface temperatures either lower or about the same as the range of the internal droplet temperatures. The internal temperature can only exceed the surface temperature if some oxidation occurs within the droplet; otherwise the maximum internal temperature cannot exceed the surface temperature. The internal and surface temperature data in Figure 5.10 were measured for separate droplets of different liquors, so care must be used when drawing conclusions about the relative temperatures.

At lower oxygen contents, the temperature versus time profiles during char burning are much flatter (Figure 5.11). There is a much less distinct maximum in temperature with time during char burning, and the maximum surface temperature independent of the initial droplet mass.

The surface temperature data obtained were poorer at lower oxygen contents, presumably because the accuracy of the optical pyrometer is poorer when the particle temperature is not greatly different from the furnace temperature. Results from the runs at $800^{\circ} \mathrm{C}$ from which data was obtained are shown in Table 5.2. The range of variation for the data at $21 \%$ oxygen reflect the variation with initial droplet mass. At lower oxygen contents, there was no correlation between the maximum surface temperature and initial droplet mass (see Appendix 2). 


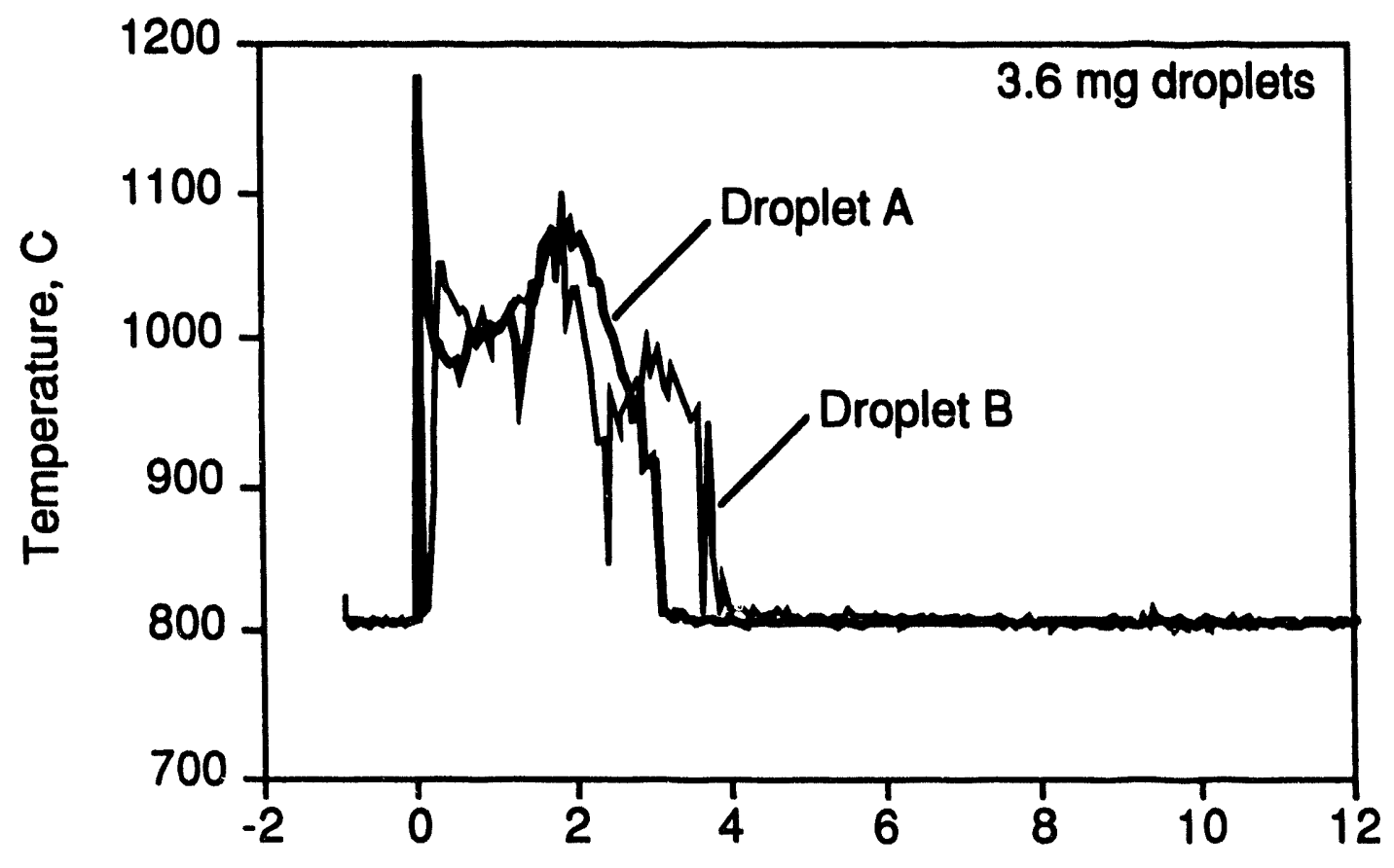

Time, s

Figure 5.8. Surface temperature versus time for two $3.6 \mathrm{mg}$ droplets burned in air at $800^{\circ} \mathrm{C}$. 


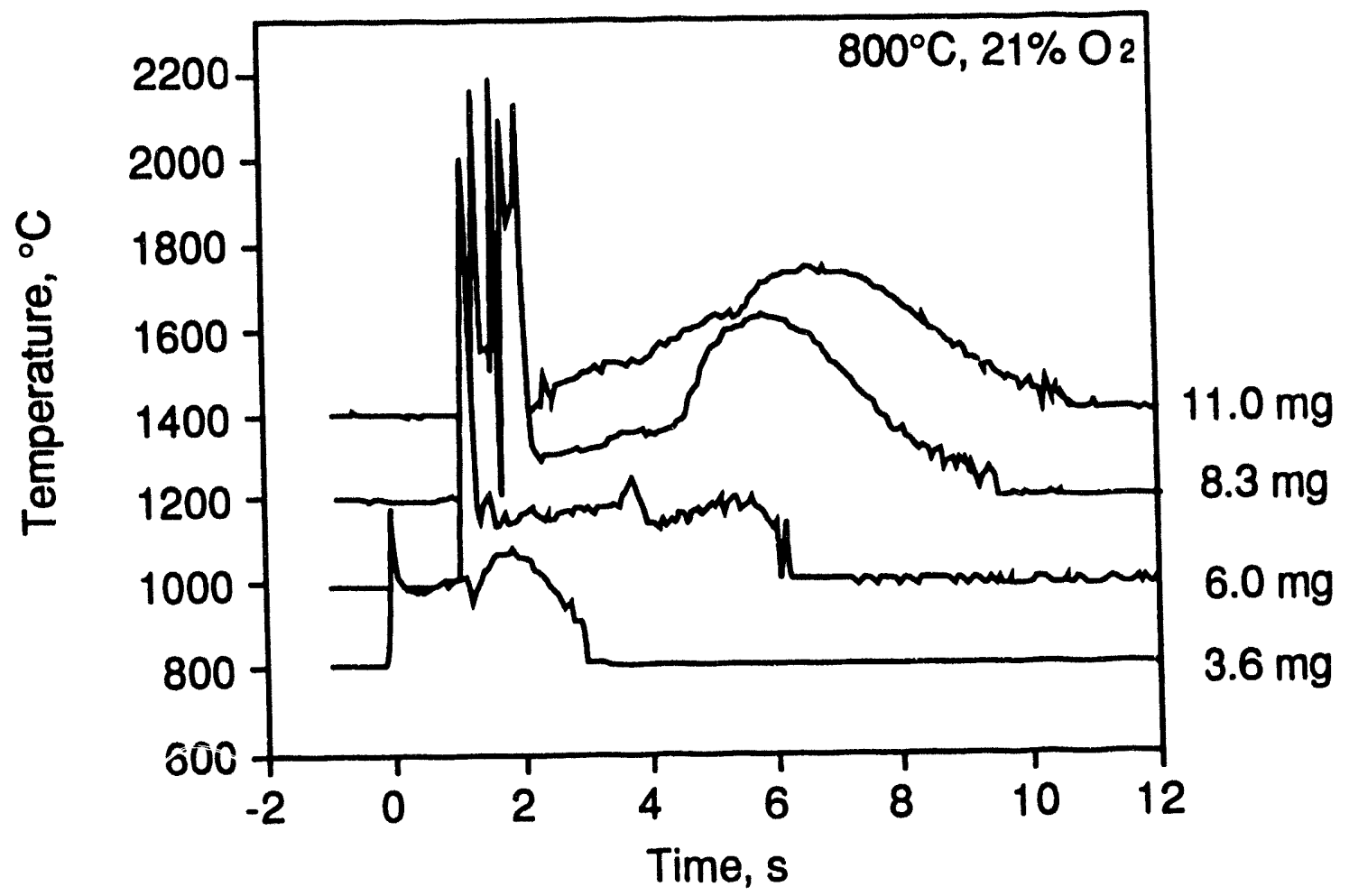

Figure 5.9. Surface temperature versus time for four droplets burned in air at $800^{\circ} \mathrm{C}$. The curves are each shifted upward by multiples of $200^{\circ} \mathrm{C}$ so that each is visible. 


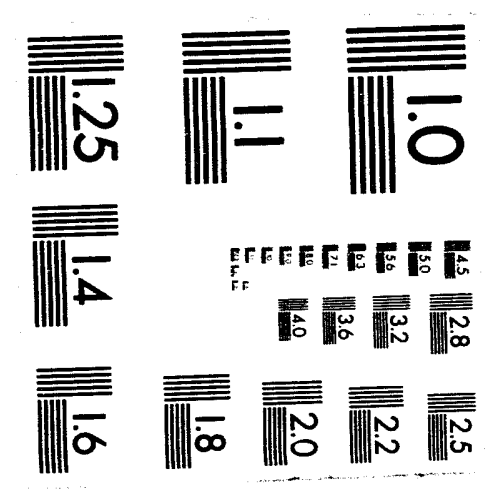



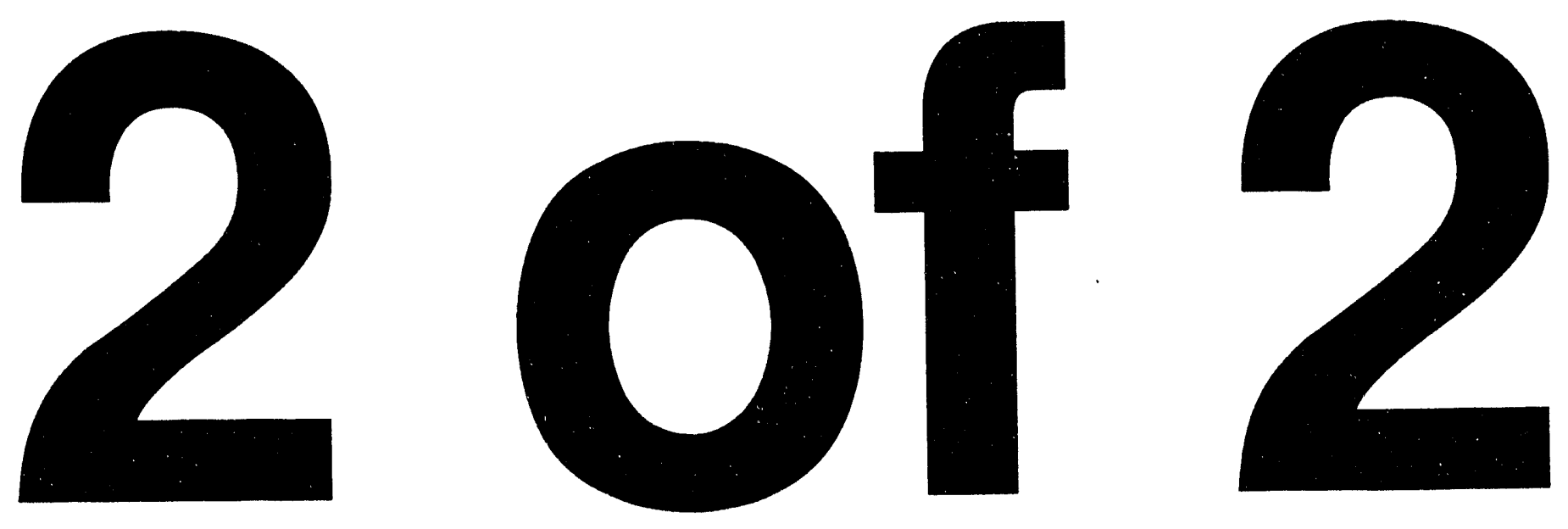


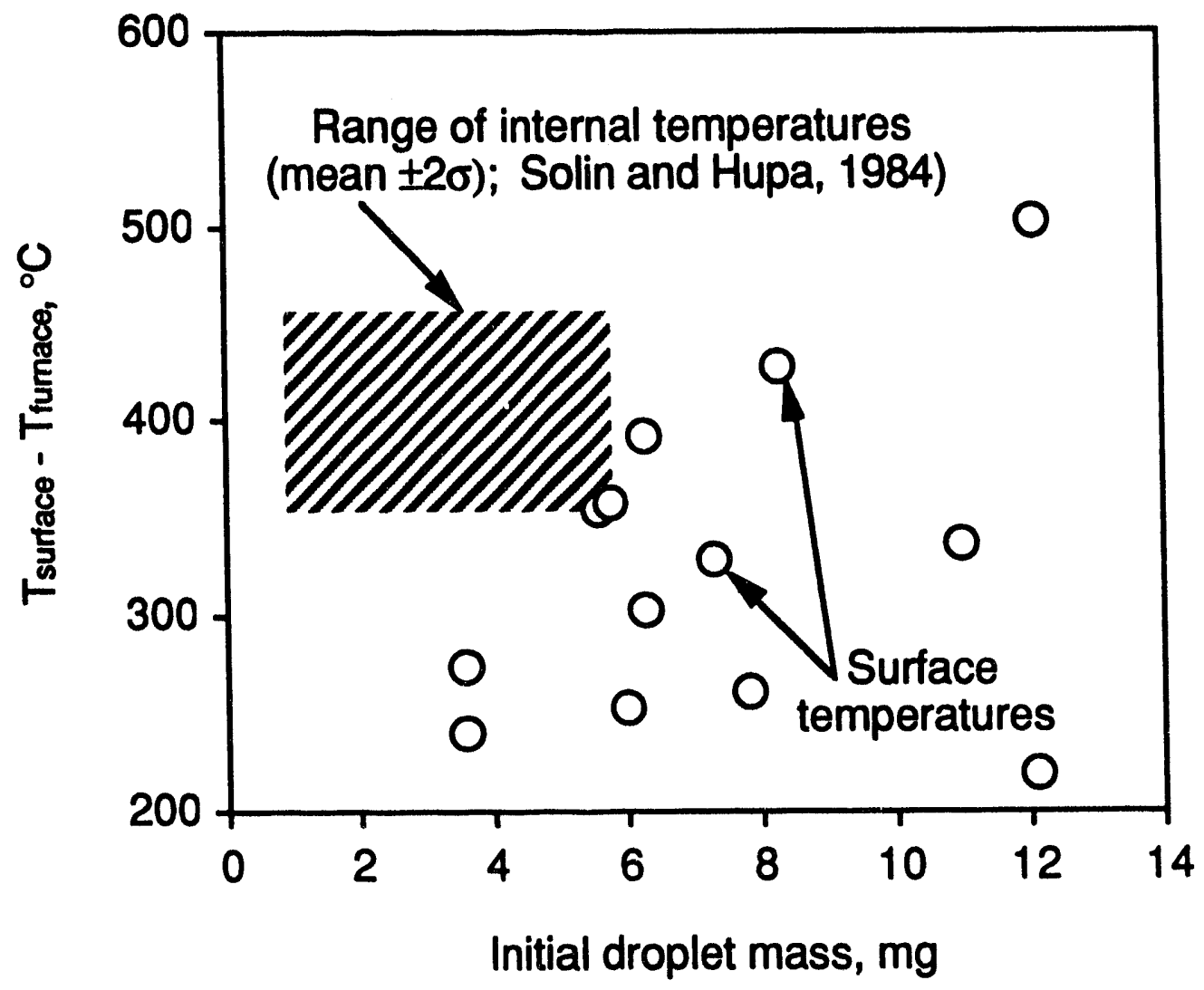

Figure 5.10. Comparison of maximum surface temperatures for droplets burned in air with maximum internal droplet temperatures measured earlier by Solin and Hupa (1984). 


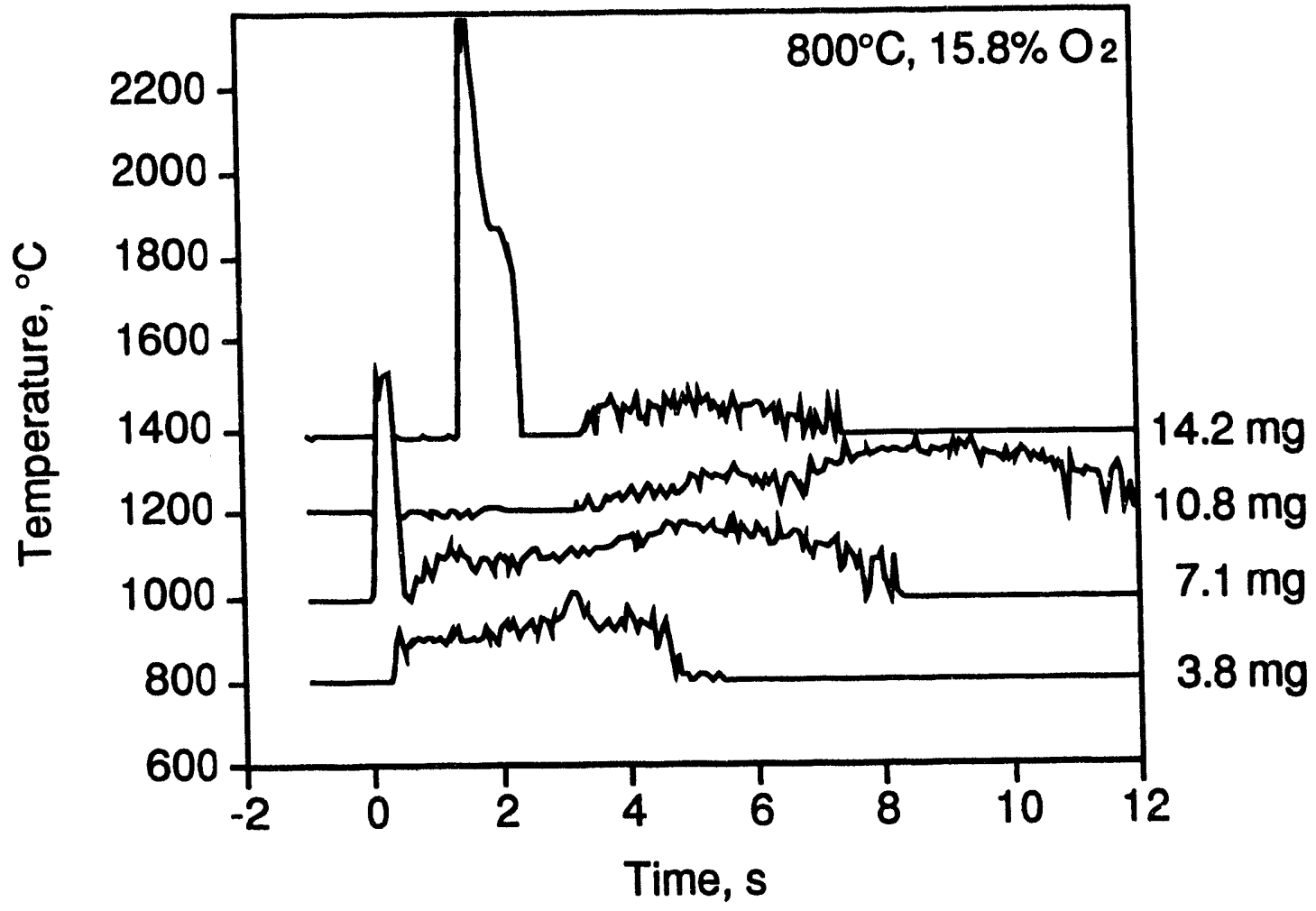

Figure 5.11. Surface temperature versus time for four droplets burned in $15.8 \% \mathrm{O}_{2}$ at $800^{\circ} \mathrm{C}$. The curves are each shifted upward by multiples of $200^{\circ} \mathrm{C}$ so that each is visible. 
Table 5.2. Maximum droplet temperatures during char burning versus oxygen content of the furnace gas for droplets burned at $800^{\circ} \mathrm{C}$.

\begin{tabular}{||c|c|c|c|c|c||}
\hline \multirow{2}{*}{$\begin{array}{c}\text { Oxygen } \\
\text { mole \% }\end{array}$} & \multicolumn{4}{|c|}{ Maximum droplet temperature } & \multirow{2}{*}{$\begin{array}{c}\text { Number of } \\
\text { data points }\end{array}$} \\
\cline { 2 - 6 } & Average & Std. Dev. & Min & Max & 2 \\
\hline \hline 5.3 & 888 & - & 875 & 900 & 5 \\
\hline 8.4 & 878 & 48 & 825 & 950 & 2 \\
\hline 10.5 & 927 & - & 920 & 933 & 9 \\
\hline 12.6 & 979 & 45 & 873 & 1023 & 4 \\
\hline 15.8 & 960 & 49 & 890 & 1005 & 10 \\
\hline 16.8 & 1024 & 68 & 917 & 1123 & 13 \\
\hline 21.0 & 1127 & 81 & 1020 & 1303 & \\
\hline
\end{tabular}

The difference between the average value for the maximum surface temperature during char burning and the furnace temperature is plotted in Figure 5.12 at each oxygen content along with the range for each oxygen concentration. The maximum surface temperature increases more rapidly than linearly with increasing oxygen content. It exceeds the furnace temperature on average by more than $300^{\circ} \mathrm{C}$ and by as much as $500^{\circ} \mathrm{C}$.

Comparison of data for droplets burned at 750 versus $800^{\circ} \mathrm{C}$ in $10.5 \% \mathrm{O}_{2}$ indicates a smaller increase in surface temperature $\left(90^{\circ} \mathrm{C}\right)$ at $750^{\circ} \mathrm{C}$ relative to the furnace temperature as compared with $130^{\circ} \mathrm{C}$ in an $800^{\circ} \mathrm{C}$ furnace. This is consistent with an increasing rate of combustion as temperature increases. It implies that the char combustion is not entirely at the external droplet surface at these temperatures and oxygen content. The droplet surface temperatures would be $840^{\circ} \mathrm{C}$ and $930^{\circ} \mathrm{C}$ in these cases; these are well below the region where the rate of char particle combustion is film mass transfer limited as will be shown later in this chapter. The surface temperatures also imply that the difference between the surface and furnace temperatures could be even greater at higher furnace temperatures.

\subsection{Testing of Droplet Combustion Models with Droplet Temperature Data}

The temperature data reported here provides an independent means of evaluating combustion models for black liquor droplets. In Section 5.3 we compared measured internal droplet temperatures i . n surface temperatures which we calculated with the droplet combustion model developed by Frederick (1990). The comparison indicated that the measured internal temperatures fell between the calculated surface and mean droplet temperatures (see Fig. 4.3). 


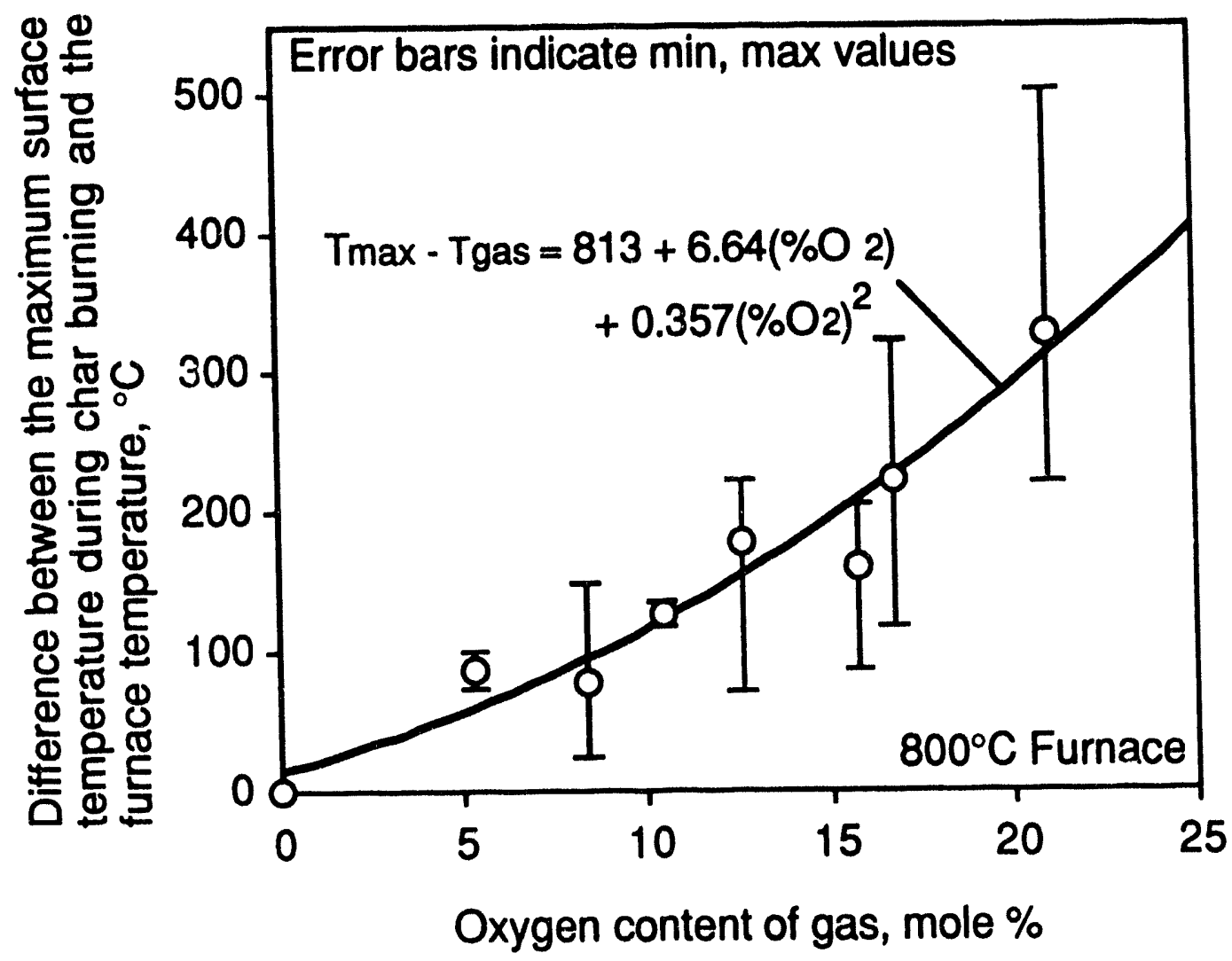

Figure 5.12. Difference between the surface temperature and furnace temperature during char burning versus oxygen content of the surrounding gas for droplets burned in $\mathrm{O}_{2} / \mathrm{N}_{2}$ mixtures in an $800^{\circ} \mathrm{C}$ furnace. 
In this section we compare droplet surface temperatures estimated using two different droplet combustion models with measured surface temperature data. The first model is the relatively simple single droplet combustion model by Frederick (1990). Figure 5.13 shows the experimental droplet surface temperature profiles during devolatilization for droplets pyrolyzed in $\mathrm{N}_{2} / \mathrm{CO}$ and in $\mathrm{CO}_{2} / \mathrm{N}_{2}$. Also shown are the surface temperatures calculated using the heat transfer rate model for devolatilization developed by Frederick (1990). There is reasonable agreement between the experimental surface temperature data and the calculated values. Given the relatively simple nature of this model the agreement is surprisingly good. This is additional evidence that this model can be relied on for reasonable estimates of black liquor droplet burning behavior.

The optical pyrometer was not capable of measuring surface temperatures during drying, and this model does not yet include temperature calculations during char burning. Therefore no comparisons of experimental versus calculated temperatures during those stages were possible.

The second model tested is the model developed by Saastamoinen $(1984,1992)$. This model is far more detailed. It estimates the heat and mass fluxes and temperature and mass concentration profiles within a burning black liquor droplet. The estimated surface temperature for a burning black liquor droplet is compared with surface temperature data measured after the flame temperature spike in Figure 5.14. The agreement is again surprisingly good. These results support our earlier conclusion that the droplet surface temperature during devolatilization is measured accurately after the early part of the stage when soot particles obscure the droplet surface. They also indicate that this model makes reasonable predictions for black liquor droplet combustion.

Figure 5.15 compares the measured surface temperatures from Figure 5.5 with the surface temperature predicted by Saastamoinen's model. The agreement here is not as good as in Figure 5.14. It is not clear whether this is due to problems in measuring surface temperatures when they are well below the furnace temperature. Further investigation is needed to clarify this point.

\subsection{Implications to Combustion Processes}

A key question with respect to understanding and modeling the combustion of black liquor char is what controls the rate of char combustion. With the surface temperature data available for black liquor droplets during combustion we can address this question by considering the relative importance of the film mass transfer and pore diffusion resistances as compared with the chemical kinetic rate at the particle surface temperature.

To make this comparison, we calculated the rates of oxidation of the carbon in black liquor char and the rates of gasification with $\mathrm{CO}_{2}$ and water vapor under both chemical kinetic and film mass transfer limited conditions. The rates when chemical kinetic limited were calculated using experimentally based rate equations. The rate of oxygen consumption by direct carbon oxidation (Eq. (5.4)) was based on Wendt's modification of Smith's correlation of carbon combustion rate data (Wendt, 1988) with a char carbon specific surface area of $122 \mathrm{~m}^{2} / \mathrm{g}$ 

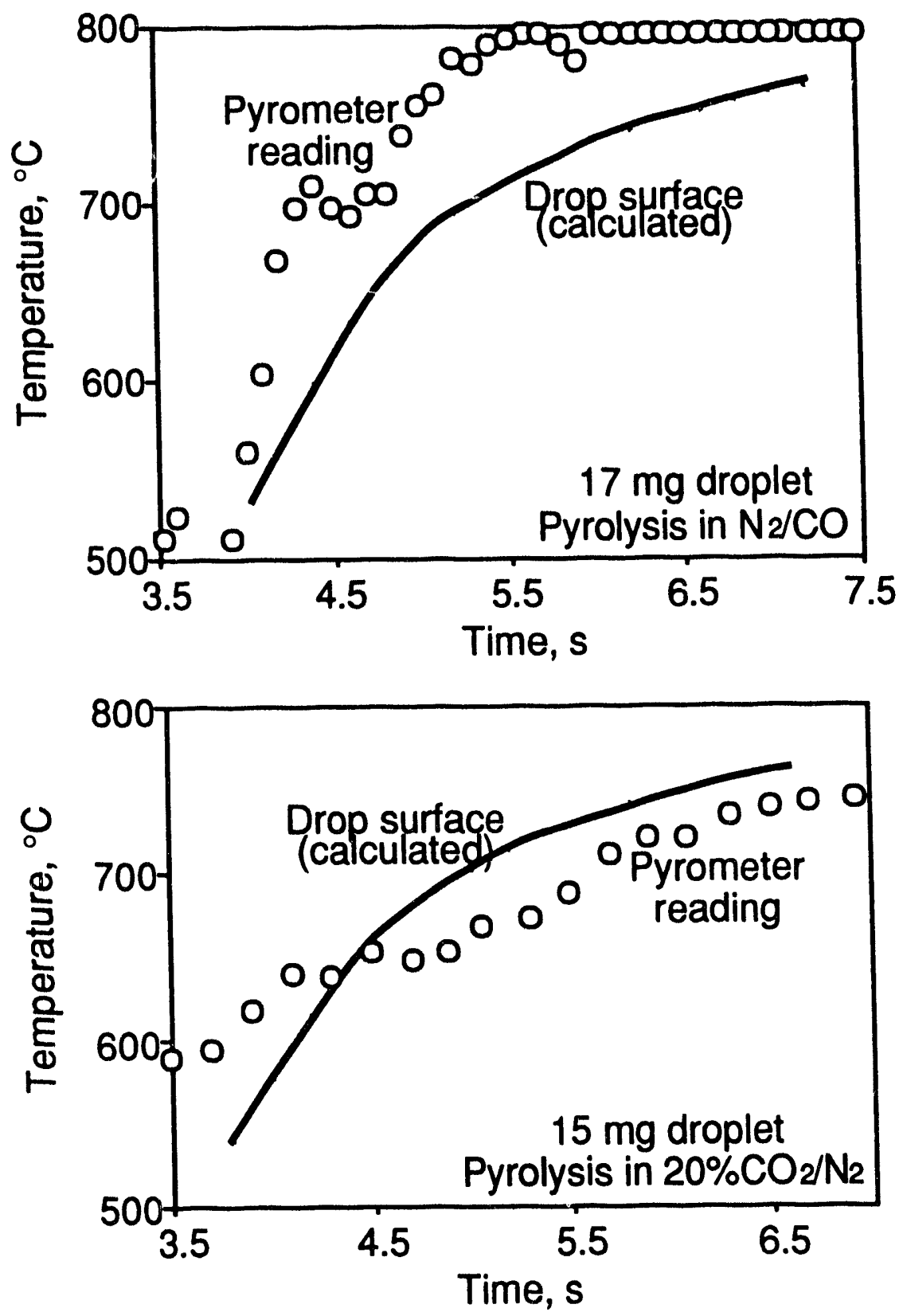

Figure 5.13. Droplet surface temperatures during pyrolysis in two noncombustion atmospheres. 


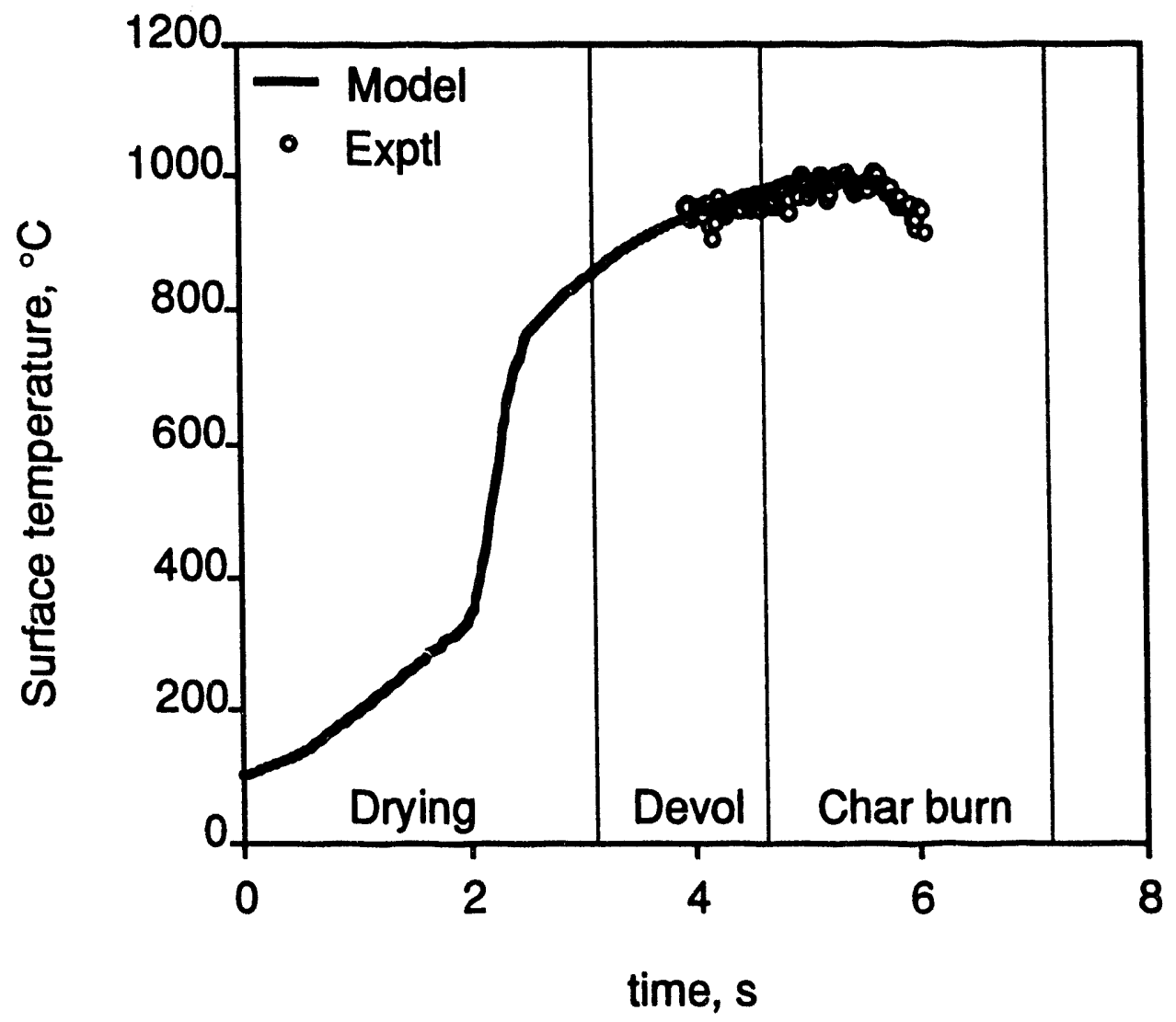

Figure 5.14. Comparison of the droplet surface temperature measured during combustion in air with the surface temperature predicted by Saastamoinen's model. 


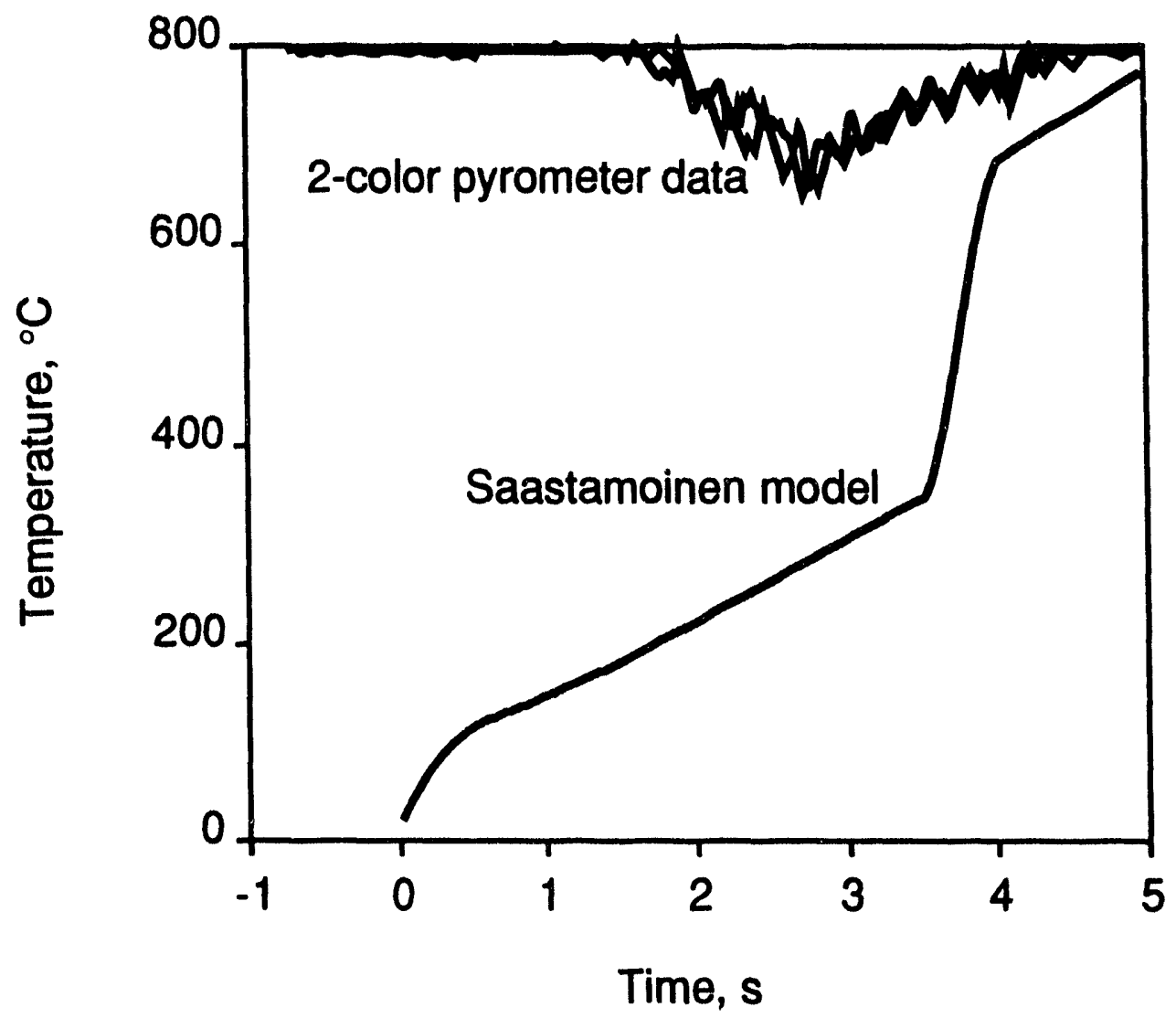

Figure 5.15. Comparison of the droplet surface temperature measured during pyrolysis in $\mathrm{N}_{2} / \mathrm{CO}$ with the surface temperature predicted by Saastamoinen's model (Saastamoinen, 1984, 1992). 
(van Heiningen et al., 1992). The direct carbon oxidation rate was reduced by a factor of 0.6 to account for the fact that molten sodium salts block access to some of the carbon surface. This value was based on Sumnicht's equation (Sumnicht, 1989) and corresponds to 50\% completion of char combustion.

$$
R_{c, 0 x}=9500 A_{i n t} P_{O_{2}} \exp \left(\frac{-33950}{R T}\right)
$$

Carbon burning can also proceed by oxidation of $\mathrm{Na}_{2} \mathrm{~S}$ to $\mathrm{Na}_{2} \mathrm{SO}_{4}$ followed by reduction of the $\mathrm{Na}_{2} \mathrm{SO}_{4}$ by carbon to produce $\mathrm{CO}$ or $\mathrm{CO}_{2}$. This process has been referred to as the sulfate-sulfide cycle (Cameron and Grace, 1985). Cameron and Grace's rate equation (Eq. (5.5)) was used for the rate of oxygen consumption by the sulfate-sulfide cycle.

$$
R_{c, s s}=2620\left[\mathrm{Na}_{2}\right] \frac{\left[\mathrm{SO}_{4}\right]}{.0011+\left[\mathrm{SO}_{4}\right]}[\mathrm{C}] \exp \left(\frac{-29200}{\mathrm{RT}}\right)
$$

The rate of oxygen consumption was taken as the sum of the rates for direct oxidation and via the sulfate - sulfide cycle.

The rate equations of $\mathrm{Li}$ and van Heiningen $(1990,1991)$ were used for the rates of consumption of $\mathrm{CO}_{2}$ and $\mathrm{H}_{2} \mathrm{O}$ via the carbon gasification reactions. These equations were based on data at temperatures well below typical furnace temperatures $\left(700-775^{\circ} \mathrm{C}\right.$ for $\mathrm{CO}_{2}$ gasification, $650-725^{\circ} \mathrm{C}$ for water vapor) but they were used to extrapolate the rates in the char bed model.

$$
\begin{aligned}
\mathrm{R}_{\mathrm{c}, \mathrm{CO}_{2}} & =32 \times 10^{6}\left[\mathrm{C}_{\mathrm{part}}\right] \frac{\mathrm{P}_{\mathrm{CO}_{2}}}{\mathrm{P}_{\mathrm{CO}_{2}}+3.4 \mathrm{P}_{\mathrm{CO}}} \exp \left(\frac{-22500}{\mathrm{~T}}\right) \\
\mathrm{R}_{\mathrm{c}, \mathrm{H}_{2} \mathrm{O}} & =2.56 \times 10^{9}\left[\mathrm{C}_{\mathrm{part}}\right] \frac{\mathrm{P}_{\mathrm{H}_{2} \mathrm{O}}}{\mathrm{P}_{\mathrm{H}_{2} \mathrm{O}}+1.42 \mathrm{P}_{\mathrm{H} 2}} \exp \left(\frac{-25300}{\mathrm{~T}}\right)
\end{aligned}
$$

The overall rates of $\mathrm{O}_{2}, \mathrm{CO}_{2}$, and water vapor consumption under film mass transfer limited conditions were calculated according to Eq. (5.8).

$$
R_{m, i}=k_{g i} A_{p} C_{i}
$$

where $N$ is the moles of gas transferred per second, $A_{p}$ is the external surface area of the particle, and $\mathrm{C}_{i}$ is the concentration of the gas species of interest in the bulk gas. The gas film mass transfer coefficient was estimated from a Sherwood number correlation which accounts for both free and forced convection effects (Treybal, 1981). 


$$
S h=\frac{k_{g} D}{E_{p}}=2+0.569(G r S c)^{0.25}+0.347\left(\operatorname{Re~Sc}{ }^{0.5}\right)^{0.62}
$$

The calculations were made at the terminal velocity of the droplets at their maximum swollen volume. The terminal velocity was estimated as (Adams and Frederick, 1988)

$$
v_{t}=11640 S^{0.71} D_{p}^{1.14}
$$

where $v_{t}$ is the terminal velocity of the particle $[\mathrm{m} / \mathrm{s}], S G$ is its specific gravity, and $D_{p}$ is the particle diameter $[\mathrm{m}]$. The overall rates of reaction for conditions between these limiting values were calculated according to

$$
\frac{1}{R_{i}}=\frac{1}{R_{m i}}+\frac{1}{\eta_{i} R_{c i}}
$$

The effectiveness factor $\eta_{i}$ accounts for the rate-limiting effect of pore diffusion on the overall rate $\mathbf{R}_{\mathbf{i}}$. It was estimated from the Thiele modulus as

$$
\eta_{\mathrm{i}}=\frac{\tanh \left(\mathrm{M}_{\mathrm{Ti}}\right)}{\mathrm{M}_{\mathrm{Ti}}}
$$

where the Thiele modulus was calculated as

$$
\mathrm{M}_{\mathrm{Ti}}=\frac{\mathrm{D}}{6}\left[\frac{\mathrm{k}_{\mathrm{i}}}{\mathrm{D}_{\mathrm{i}}}\right]^{1 / 2}
$$

$\mathrm{k}_{\mathrm{i}}$, the apparent first order rate constant, was calculated as

$$
k_{i}=\frac{R_{c i}}{V_{p} C_{i}}
$$

The density of the char particles is very low $\left(\approx 30-50 \mathrm{~kg} / \mathrm{m}^{3}\right)$ during char burning, so that the diffusivity of the reacting gases within the char particles was assumed to be the same as in the bulk gas. The diffusivity for each gas was assumed to be proportional to the absolute temperature to the 1.75 power.

These calculations were performed for particles at their maximum swollen volume because the film mass transfer and pore diffusion resistances are greatest when the particles are largest. The calculation program (THIELE2) is included in Appendix 3.

Figure 5.16 shows the results of these calculations for $9 \mathrm{~mm}$ char particles in three different gas atmospheres: $5 \% \mathrm{O}_{2} ; 13 \% \mathrm{CO}_{2}, 5 \% \mathrm{CO}$; and $18 \% \mathrm{H}_{2} \mathrm{O}, 3 \% \mathrm{H}_{2}$. These concentrations represent time and spatially averaged conditions in the lower furnace. The results 


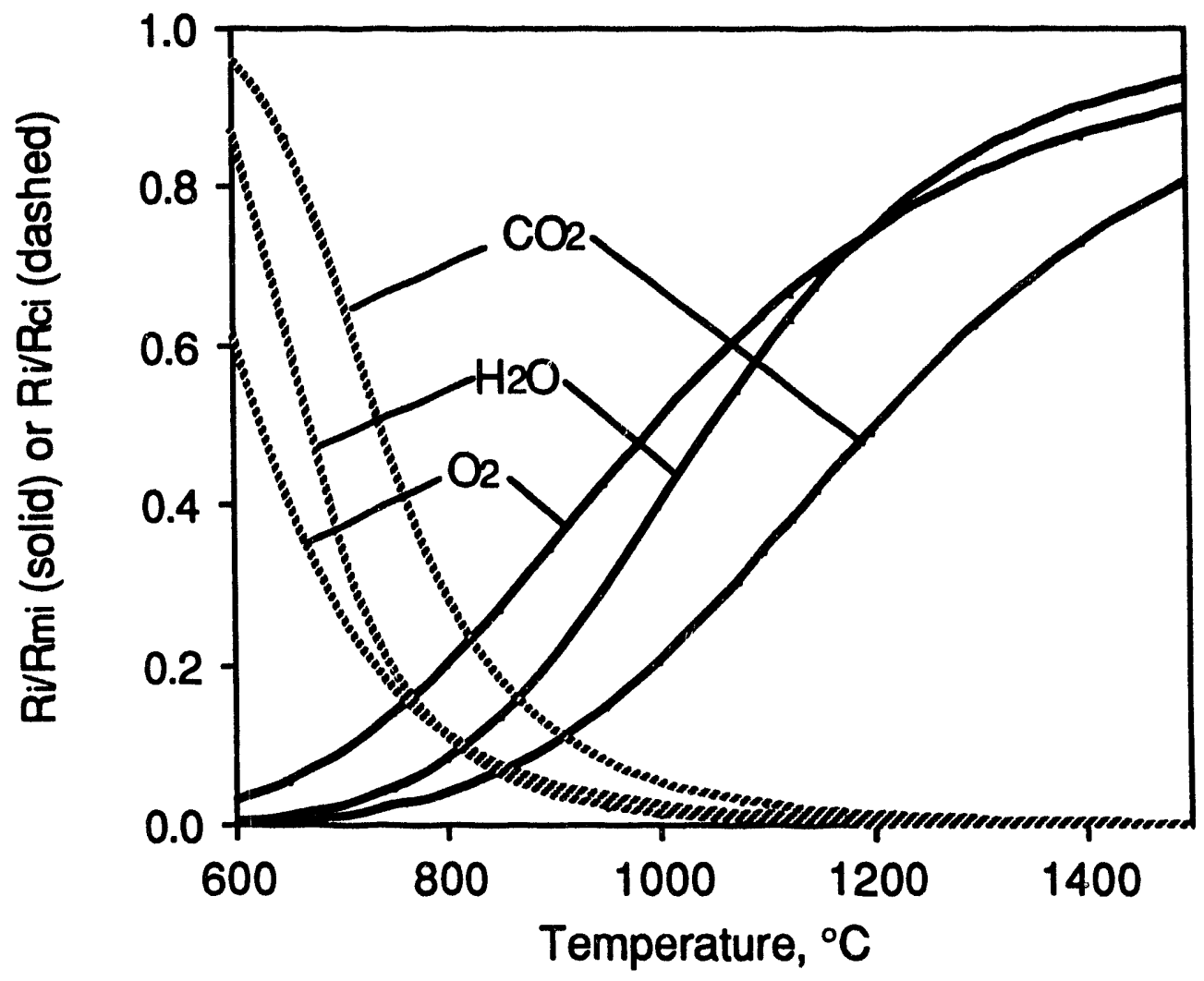

Figure 5.16. The ratio of the overall rate of reaction to the rate if mass transfer limited $\left(R_{i} / R_{m i}\right)$ or to the rate if chemical kinetic limited $\left(R_{i} / R_{c i}\right)$ for the char carbon oxidation and gasification reactions. Conditions are $9 \mathrm{~mm}$ char particles, $5 \% \mathrm{O}_{2}$ or $13 \% \mathrm{CO}_{2}, 5 \% \mathrm{CO}$ or $18 \% \mathrm{H}_{2} \mathrm{O}, 3 \% \mathrm{H}_{2} ; 122 \mathrm{~m}^{2} / \mathrm{g}$ char carbon specific area. The droplet surface temperature exceeds the furnace temperature by $50^{\circ} \mathrm{C}$ in these calculations. 
are presented as the ratio of the overall rate for each gas to either the film mass transfer rate $\left(\mathbf{R}_{\mathrm{i}} / \mathbf{R}_{\mathrm{mi}}\right)$ or the chemical kinetic rate $\left(\mathrm{R}_{\mathrm{i}} / \mathbf{R}_{\mathrm{ci}}\right)$ calculated as of they were the rate-limiting step. The $R_{i} / R_{m i}$ curves (solid lines) for oxidation and water vapor gasification begin to approach the film mass transfer limit (0.9) at temperatures above $1200^{\circ} \mathrm{C}$ while the $\mathrm{CO}_{2}$ gasification curve is still below the limit at $1500^{\circ} \mathrm{C}$. The $\mathrm{R}_{\mathrm{i}} / \mathrm{R}_{\mathrm{ci}}$ curve (dashed lines) for $\mathrm{CO}_{2}$ and water vapor gasification approach the chemical kinetic controlled limit only at temperatures near $600^{\circ} \mathrm{C}$ and below. The oxidation rate never approaches this limit in the range shown.

The effectiveness factors for the oxidation and gasification reactions for the same conditions as Figure 5.16 are shown in Figure 5.17. They drop rapidly to values well below 1 as temperature is increased above $600^{\circ} \mathrm{C}$, indicating that pore diffusion is important in determining the overall rate over most of the temperature range shown.

A plot similar to that of Figures 5.16 is shown for the oxidation reactions with three different droplet sizes in Figure 5.18. The effect of pore diffusion increases rapidly with increasing droplet size as indicated by the shift in the $R_{j} / R_{c i}$ curves. Droplet size has very little effect on the location of the $R_{i} / R_{c i}$ curves. This indicates that the temperature at which film mass transfer become rate-determining is not droplet size dependent.

The temperature in the furnace region of a recovery boiler varies considerably with location. The mean temperature below the bull nose usually exceeds $1200^{\circ} \mathrm{C}$ although regions of lower temperatures are found near the furnace walls and where the cooler air jets penetrate into the furnace. The oxygen content also varies considerably with location, from $21 \%$ in the air jets to nearly zero well away from them.

The data in Figures 5.16-5.18 would indicate that the char oxidation reactions occur under film mass transfer limited conditions in most parts of the furnace. When the gas temperature exceeds $1200^{\circ} \mathrm{C}$, film mass transfer is the most important resistance to mass transfer even at very low oxygen contents. In regions of higher oxygen content, the higher surface temperature of the particles means that film mass transfer dominates even at lower furnace temperatures. In Figures 5.12 we see that droplets in regions where the $\mathrm{O}_{2}$ content is $10 \%$ will burn at temperatures $100-200^{\circ} \mathrm{C}$ higher than the furnace temperature. In regions where the $\mathrm{O}_{2}$ content is $21 \%$, the temperature difference at the surface is $250-400^{\circ} \mathrm{C}$ (Figure 5.12) or higher (Table 5.1). At these higher oxygen contents, the furnace temperature where the oxidation rate is controlled by film mass transfer is lower than shown by these amounts minus the $50^{\circ} \mathrm{C}$ increment used in the calculations for Figures 5.16-5.18. Only in cooler regions of the furnace and where the oxygen content is well below $10 \%$ will the rate of the oxidation reactions be controlled by pore diffusion. It will almost never be controlled by chemical kinetics alone.

The rate of the gasification reaction with water vapor is also controlled by film mass transfer under most conditions in the furnace (Figures 5.16, 5.19). This reaction is endothermic which tends to lower the temperature of the particle. The water vapor concentration in the lower furnace tends to be more uniform and higher than the oxygen content. In regions where the oxygen content is low, the particle temperature will be lower than the surrounding gases. In these regions, film mass transfer will become dominant at higher furnace temperatures than when the oxygen content is higher. 


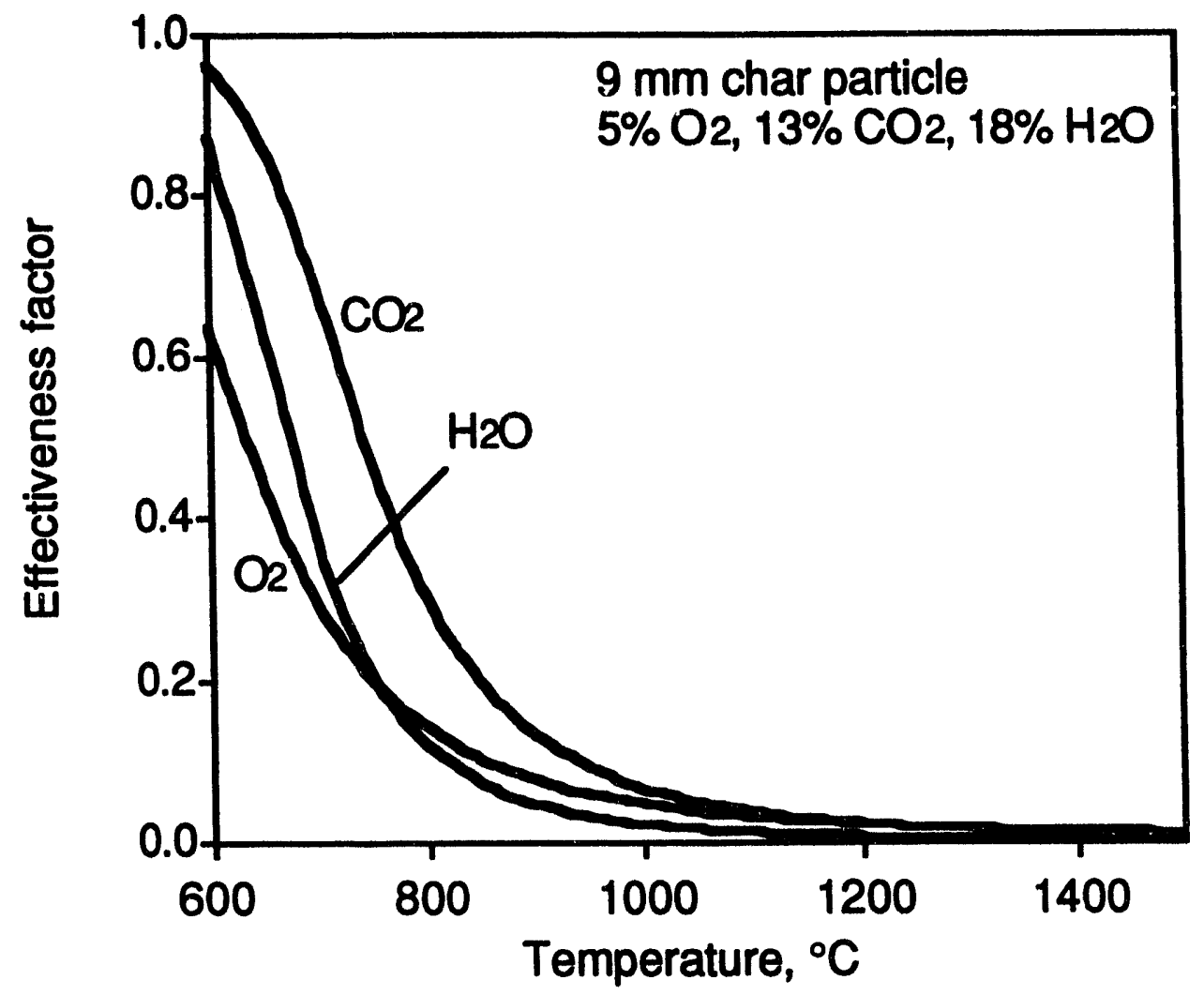

Figure 5.17. Effectiveness factors for the char carbon oxidation and gasification reactions for the same conditions as in Figure 19. 


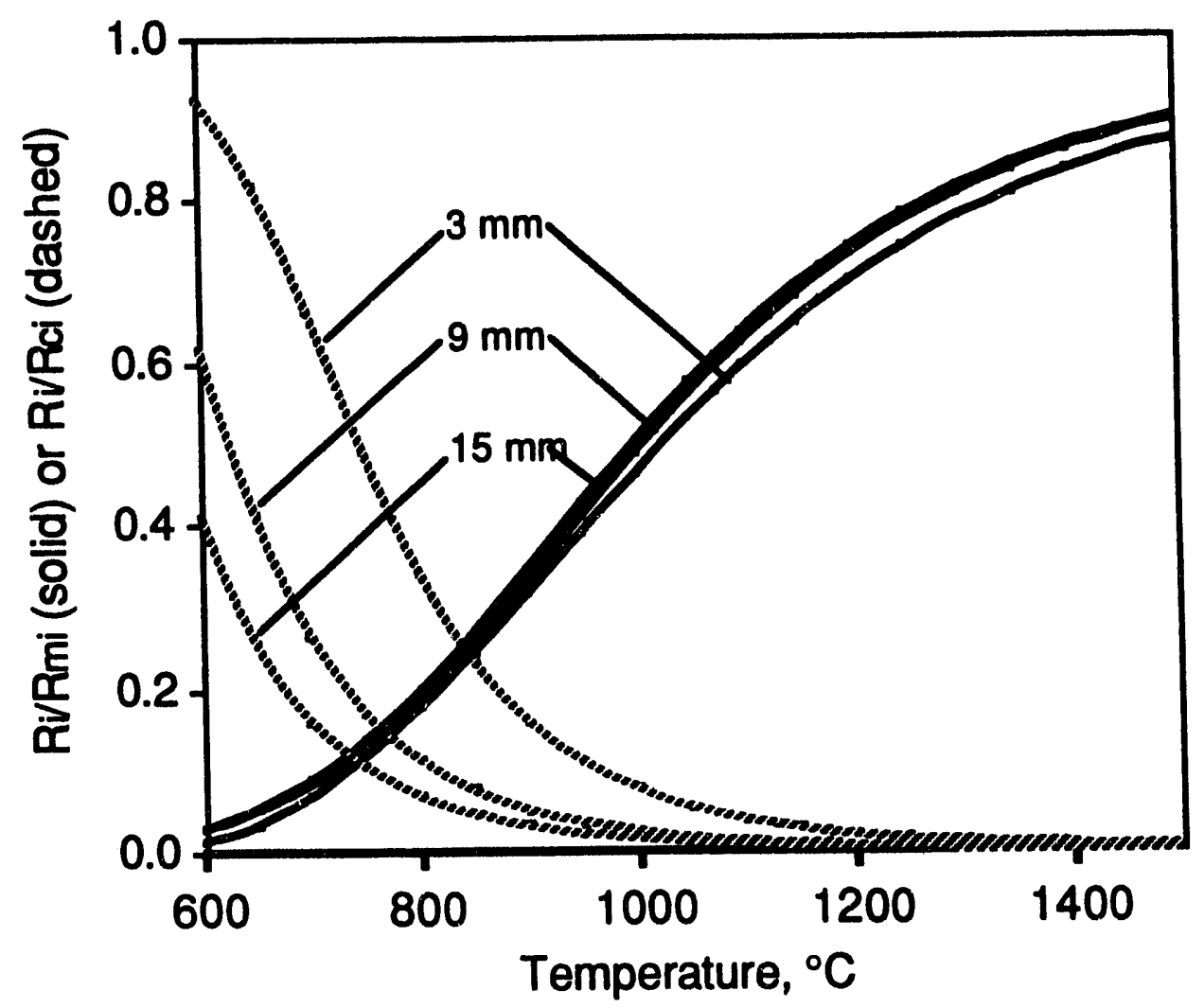

Figure 5.18. The ratio of the overall rate of reaction to the rate if mass transfer limited $\left(R_{i} / R_{m i}\right)$ or to the rate if chemical kinetic limited $\left(R_{i} / R_{c i}\right)$ for the char carbon oxidation reactions. Conditions are $3 \mathrm{~mm}, 9 \mathrm{~mm}$, and $15 \mathrm{~mm}$ char particles, 5\% $\mathrm{O}_{2}, 122 \mathrm{~m}^{2} / \mathrm{g}$ char carbon specific area. The droplet surface temperature exceeds the furnace temperature by $50^{\circ} \mathrm{C}$ in these calculations. 


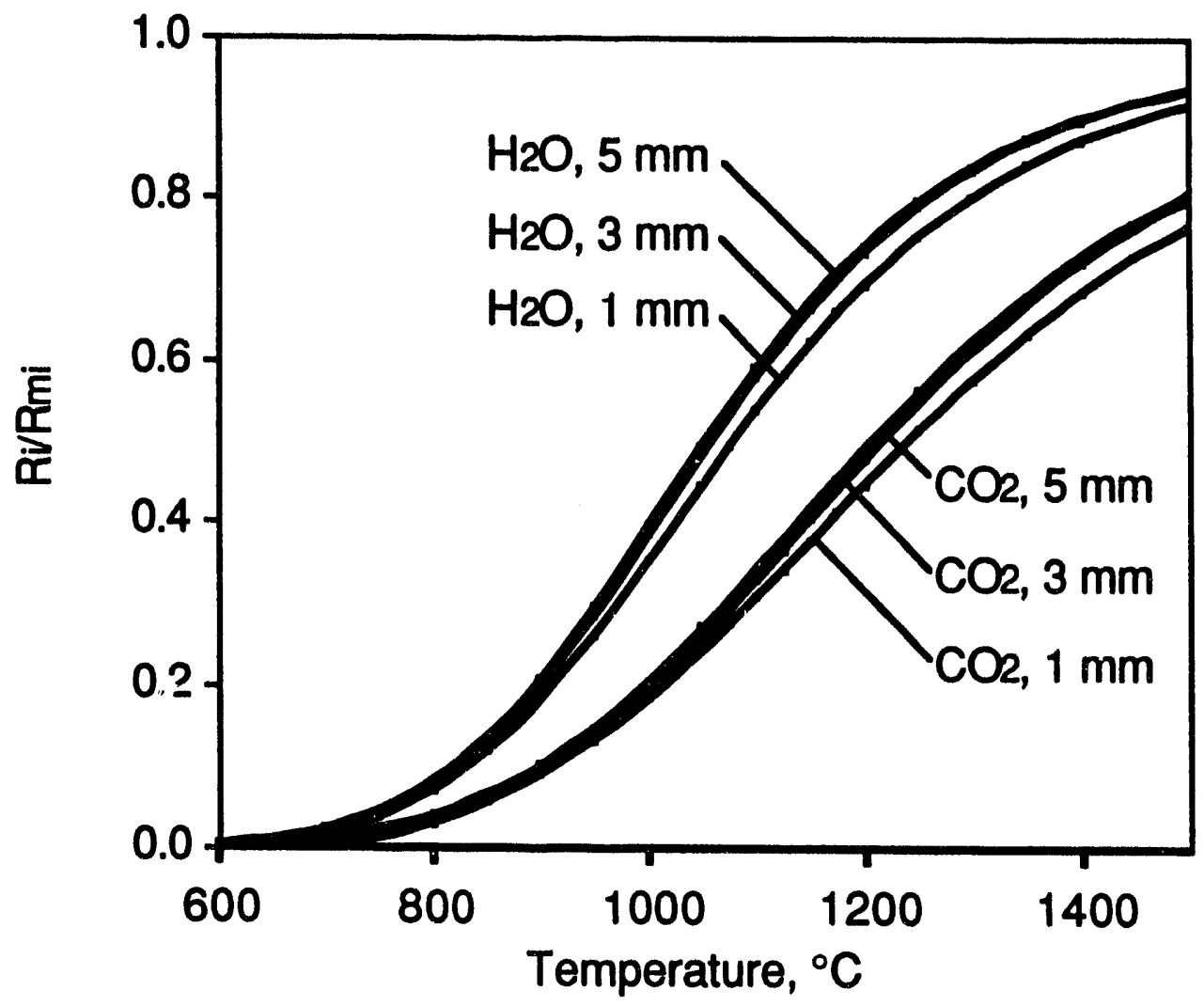

Figure 5.19. The ratio of the overall rate of reaction to the rate if mass transfer limited $\left(\mathrm{R}_{\mathbf{i}} / \mathbf{R}_{\mathbf{m i}}\right)$ for the char carbon gasification reactions. Conditions are 3 $\mathrm{mm}, 9 \mathrm{~mm}$, and $15 \mathrm{~mm}$ char particles, $13 \% \mathrm{CO}_{2}, 5 \% \mathrm{CO}$ or $18 \% \mathrm{H}_{2} \mathrm{O}, 3 \% \mathrm{H}_{2}$. The droplet surface temperature used in these calculations was the furnace temperature plus $50^{\circ} \mathrm{C}$. 
The rate of the gasification reaction with $\mathrm{CO}_{2}$ is not controlled by film mass transfer (Figures 5.16, 5.19). The rate is dominated by pore diffusion under most conditions, with chemical kinetics becoming dominant only at temperatures below $800^{\circ} \mathrm{C}$.

\subsection{Summary}

The temperature of a black liquor droplet burned in air is well above the furnace temperature for the entire char burning stage. The two-color optical pyrometer measurements show that the surface temperature for droplets burned in air is typically $200^{\circ} \mathrm{C}$ higher than the furnace temperature at the end of the devolatilization stage and increases to $220-500^{\circ} \mathrm{C}$ above the furnace temperature during char burning. Internal droplet temperatures measured in separate experiments and reported earlier indicate that the internal droplet temperature typically increased from about the furnace temperature at the end of devolatilization to $400^{\circ} \mathrm{C}$ above it during char burning for droplets burned in air.

At the lower oxygen contents typically found in recovery boilers, the droplet surface temperature is always greater than the furnace temperature during char burning. The difference is about $65^{\circ} \mathrm{C}$ for droplets burned in $5 \% \mathrm{O}_{2}$ in an $800^{\circ} \mathrm{C}$ furnace, and the difference increases with increasing oxygen content.

Measured surface temperature during devolatilization agrees reasonably well with the surface temperature predicted by the single droplet combustion model (Frederick, 1990) during this stage. This, along with the agreement between experimental and calculated devolatilization times (Frederick, 1990) serve to validate the devolatilization stage model for black liquor droplets.

During char burning, the rates of carbon oxidation by oxygen and gasification by water vapor are limited mainly by film mass transfer at most conditions in recovery furnaces. The rate of the char carbon gasification reaction with $\mathrm{CO}_{2}$ is limited mainly by pore diffusion at most furnace conditions.

\subsection{References}

Adams, T.N., Frederick, W.J., Kraft Recovery Boiler Physical and Chemical Processes, American Paper Institute (1988).

Cameron, J.H. and Grace, T.M., I\&EC Fundamentals, 24(4):443 (1985).

Frederick, W.J., "Combustion processes in black liquor recovery: analysis and interpretation of combustion rate data and an engineering design model," U.S. DOE Report DOE/CE/40637-T8 (DE90012712), March 1990.

Frederick, W.J., Noopila, T., Hupa, M., "An analysis of swelling during the combustion of pulping liquor droplets," Combustion Chemistry Research Group Report 89-12, Ábo Akademi University, Turku, Finland (1989). 
Grosshandler, W.L., Combustion and Flame, 1984, 55, 59.

Hernberg, R., Stenberg, J., Zethræus, B., "Simultaneous in situ measurements of temperature and size of burning particles in a fluidized bed furnace by means of fiber optic pyrometry," in press.

Hupa, M., Backman, R., Hyöty, P., Proc. Black Liquor Recovery Boiler Symposium 1982, Helsinki (August 31 - September 1, 1982).

Hupa, M., Solin, P., Hyöty, P., "Combustion behavior of black liquor droplets, " J. Pulp Paper Sci., 13(2):J67-72 (1987).

LaFollette, R.M., Hedman, P.O., Smith, P.J., Combustion Sci. and Tech., 1989, 66, 93-105.

Li, J., van Heiningen, A.R.P., Ind. Eng Chem. Res., 30(7):1594-1601 (1991).

Li, J., van Heiningen, A.R.P., Ind. Eng Chem. Res., 29(9), 1776-85 (1990).

Macek, A., Bulik, C., "Direct measurement of char-particle temperatures in fluidized-bed combustors," Twentieth Symp. (Intl.) on Combustion/The Combustion Institute, 1984, pp. 1213-1221.

Noopila, T. and Hupa, M., "Measuring the combustion properties of black liquors by different techniques," Combustion Chemistry Research Group Report 88-5, Ảbo Akademi, Turku, Finland (1988).

Saastamoinen, J., Aho, M., "The simultaneous drying and pyrolysis of single wood particles and pellets made of peat," Am. Flame Research Comm. 1984 Intl. Symp. on Alternative Fuels and Hazardous Wastes, Tulsa, OK, October 9-11, 1984.

Saastamoinen, J., Aho, M., Linna, V., "Simultaneous pyrolysis and char combustion," accepted for publication in FUEL (1992).

Solin, P., Hupa, M., Mustalipeän palamisen tutkimus laboratoriouunissa IV. Kokeet syksyllä 1983. Internal Report, Ảbo Akademi, Turku, Finland (May 5, 1984), in Finnish.

Stenberg, J., Frederick, W.J., Bostrom, S., Hernberg, R., Hupa, M., "Optical pyrometric measurement of the temperature of black liquor particles during pyrolysis, combustion and gasification, in press.

Sumnicht, D., PhD Thesis, The Institute of Paper Chemistry, Appleton, WI (1989).

Tichenor, D.A., Mitchell, R.E., Hencken, K.R., Niksa, S., "Simultaneous in situ measurement of the size, temperature, and velocity of particles in a combustion environment," Twentieth Symp. (Intl.) on Combustion/The Combustion Institute, 1984, pp. 1213-1221. 
Treybal, R.E., Mass Transfer Operations, McGraw-Hill Book Company, New York (1981), p. 75.

Wendt J.O.L., Char Combustion. Combustion of Solid Fuels (course notes, Intl. Flame Research Foundation, Ijmuiden, The Netherlands (1988), p. 6.25. 


\section{ESTIMATION OF SWELLING FACTORS}

A great deal of information on the swelling of black liquors during combustion has been reported over the past decade. The research results have identified swelling as occurring differently in each of the separate stages of combustion (Hupa et al., 1987) and provided useful data on the effect of liquor composition and furnace variables on the magnitude of swelling (Hupa et al., 1982; Clay et al., 1985, 1987; Miller et al., 1986; Miller and Clay, 1986; Noopila and Hupa, 1988; Noopila, 1989; Frederick et al., 1989, 1991a,b; Frederick and Hupa, 1991). A quantitative model of the swelling process has also been presented (Frederick, 1990).

In this chapter we present a summary the results currently available on swelling of black liquor droplets in the form of a numerical model. The intent is to provide this information in the most useful form for those who are modeling the combustion of black liquor. We include models for swelling during drying, devolatilization, and char burning in the temperature range of interest to combustion processes $\left(600^{\circ} \mathrm{C}\right.$ and above). Most of the data from which these models have been developed has been presented and analyzed elsewhere, and references to those original works are provided. A new analysis of data on the effects of temperature and gas composition on swelling during devolatilization is included as part of this chapter.

\subsection{Swelling During Drying}

During drying, black liquor droplets swell by a factor of 1.54 in diameter on average (Clay et al, 1987; Frederick et al., 1991). Droplets swell almost instantaneously (within 0.1-0.2 s) by this amount once the droplet has entered the hot furnace environment, and they can be treated as being at constant diameter prior to the onset of devolatilization. Measured swelling factors are normally distributed with a standard deviation of 0.10 (Frederick et al, 1991). This value can be used to treat the variation in swelling during drying statistically if desired.

There is no effect of furnace temperature, gas composition, liquor composition, initial dry solids content, or initial droplet mass on swelling during drying (Frederick et al., 1991).

The following relationship can be used to estimate the swelling factor during drying:

$$
S F_{\text {dry }}=1.54, \sigma=0.10
$$

where $S F_{d r y}=D / D_{0}$ during drying, $\mathrm{D}$ is the droplet diameter, $\mathrm{D}_{\mathrm{o}}$ is the initial droplet diameter, and $s$ is the standard deviation.

\subsection{Swelling During Devolatilization}

During devolatilization, black liquor droplets swell rapidly and continuously to a maximum volume at the end of devolatilization. The normalized particle diameter (Eq. 6.2) follows a path which is independent of furnace temperature, gas composition, liquor 
composition, and initial dry solids content (Frederick, 1990). An empirical equation which describes swelling during devolatilization is

$$
\frac{\left(D-D_{i}\right)}{\left(D_{\max }-D_{i}\right)}=X_{D E V O L}^{0.8}
$$

where $\mathrm{D}$ is the equivalent diameter of the particle and $\mathrm{D}_{\mathrm{i}}$, the droplet diameter at the onset of the devolatilization stage, is equal to $1.54 \mathrm{D}_{0} . \mathrm{D}_{\max }$ is the diameter at maximum swelling which always occurs at the end of the devolatilization stage. The devolatilization process is treated as a heat transfer driven process and $X_{\mathrm{DEVOL}}$ is the degree of completion of the devolatilization stage. It is defined as $X_{D E V O L}=Q_{\text {devol }} / Q_{\text {tot }}$ where $Q_{\text {devol }}$ is the heat transferred to the droplet from the onset of devolatilization to the time of interest and $Q_{\text {tot }}$ is the total heat which must be transferred to complete the devolatilization stage. $X_{D E V O L}=0$ at the onset of devolatilization and 1 at the end.

$\mathrm{SV}_{\max }$ is the specific volume of the swollen droplet at the end of devolatilization and is referred to as the maximum swollen volume. It is defined as the ratio of the particle volume at maximum to the initial dry solids mass, and is related to $D_{\max }$ as:

$$
S V_{\max }=\frac{1}{\rho_{\mathrm{BL}}}\left[\frac{\mathrm{D}_{\max }}{\mathrm{D}_{\mathrm{o}}}\right]^{3}
$$

where $D_{0}$ is the initial diameter of the unswollen black liquor droplet and $r_{B L}$ is its density.

The maximum swollen volume attained during combustion depends on the composition of the liquor (Hupa, et al, 1982, 1987; Clay and Miller, 1986; Miller et al, 1986; Alén et al., 1992), and can depend upon the initial dry solids content (Frederick et al., 1991). It cannot be estimated with sufficient accuracy for modeling purposes but must be measured experimentally. Estimation of swelling factors during devolatilization is further complicated by the fact that $\mathrm{SV}_{\max }$ also depends upon the furnace temperature and gas composition. These variables can, however, be accounted for based on currently available experimental data as discussed in Section 4.3.1.

\subsubsection{Effect of Furnace Temperature and Gas Composition}

Furnace temperature, oxygen content, $\mathrm{CO}_{2}$ content, and water vapor content have all been shown to affect $S_{\max }$ (Hupa, et al., 1982, 1987; Frederick, 1990). Figure 4.1 shows maximum swollen volumes for two different kraft liquors burned at different furnace temperatures and various furnace gas compositions. Data for one of the liquors was obtained at both $5 \% \mathrm{O} 2$ and $21 \% \mathrm{O}_{2}$ at furnace temperatures of $600-900^{\circ} \mathrm{C}$. Data for the second liquor was obtained at a furnace temperature of $800^{\circ} \mathrm{C}$ in gases containing $20 \% \mathrm{CO}_{2}$ and $2-17 \%$ oxygen. The oxygen content which corresponds to each data point for this liquor is also shown 
in Figure 6.1. These data illustrate clearly the large differences in $\mathrm{SV}_{\max }$ that can be obtained at different laboratory conditions with the same liquor but at different combustion conditions.

The data in Figure 6.1 show that liquor droplets swell less both in higher temperature environments and when oxygen contents are higher. These two variables may not be independent since a higher oxygen content means that the volatiles leaving the particle will burn more intensely near the particle surface, increasing the temperature to which the droplet is subjected.

We tested the hypothesis that it is the gas temperature immediately surrounding the droplet that determines how much it swells. Since it is not possible to measure accurately the gas temperature near the particle surface, we used a nonadiabatic flame temperature equation (Saastamoinen, 1988) to estimate it instead:

$$
\mathrm{T}_{\mathrm{g}}^{*}=\mathrm{T}_{\mathrm{g}}+\frac{0.232 \mathrm{k}_{\mathrm{f}} \mathrm{f}_{\mathrm{g}} \Delta \mathrm{H}_{\mathrm{c}} \mathrm{Y}_{\mathrm{O}_{2}}}{0.21 \mathrm{C}_{\mathrm{p}}}
$$

where $\mathrm{T}_{\mathrm{g}}^{*}$ is the gas temperature near the particle surface $\left({ }^{\circ} \mathrm{C}\right), \mathrm{T}_{\mathrm{g}}$ is the ambient gas temperature $\left({ }^{\circ} \mathrm{C}\right), \mathrm{k}_{\mathrm{f}}$ is the flame efficiency factor $(1.0$ for an adiabatic flame, 0.12 for black liquor droplets burned in oxygen-containing gases; Frederick, 1990), $\mathrm{f}_{\mathrm{g}}$ is the stoichiometric $\mathrm{CO} / \mathrm{O}_{2}$ mass ratio (1.75), $\Delta \mathrm{H}_{\mathrm{c}}$ is the heat of combustion of the pyrolysis products $\left(10^{4} \mathrm{~J} / \mathrm{g}\right.$; Frederick, 1990), $\mathrm{Y}_{\mathrm{O}_{2}}$ is the oxygen mole fraction in the bulk gas, and $\mathrm{C}_{\mathrm{p}}$ is the heat capacity of the gas $\left(1.17 \mathrm{~J} / \mathrm{g}^{\circ} \mathrm{C}\right)^{2}$. Substituting all of the numerical constants gives

$$
\mathrm{T}_{\mathrm{g}}^{*}=\mathrm{T}_{\mathrm{g}}+1980 \mathrm{Y}_{\mathrm{O}_{2}}
$$

where $\mathrm{T}_{\mathrm{g}}$ and $\mathrm{T}_{\mathrm{g}}^{*}$ are in ${ }^{\circ} \mathrm{C}, \mathrm{Y}_{\mathrm{O}_{2}}$ has units of mole fraction $\mathrm{O}_{2}$, and the numerical constant has units of ${ }^{8} \mathrm{C} /$ mole fraction $\mathrm{O}_{2}$.

The $\mathrm{SV}_{\max }$ data from Figure 6.1 are plotted in Figure 6.2 versus the gas temperature near the droplet surface. When plotted this way, the data for each liquor fall on a separate line.

To reduce this data to a single correlation for all kraft liquors, we assumed that the relative change in the swollen volume with temperature was the same for all liquors. We then reduced the data to a nondimensional form by (a) interpolating or extrapolating to find the value of $\mathrm{SV}_{\max }$ when $\mathrm{T}_{\mathrm{g}}^{*}=800^{\circ} \mathrm{C}$, and (b) dividing each experimental value of $\mathrm{SV}_{\max }$ by the corresponding $\mathrm{SV}_{\max }\left(\mathrm{T}_{\mathrm{g}}^{*}=800^{\circ} \mathrm{C}\right)$.

The data from Figure 6.2 is plotted in this reduced form on semilogarithmic coordinates in Figure 6.3. Also included are data for three other liquors, two kraft (liquors C,D) and one sodium-base neutral sulfite semichem (NSSC) liquor (E), from an earlier study by Frederick et al. (1991). The kraft data fall on or near a single curve when plotted this way. There is no difference between the data in air and at lower $\mathrm{O}_{2}$ contents, and $\mathrm{CO}_{2}$ per se has no effect. 


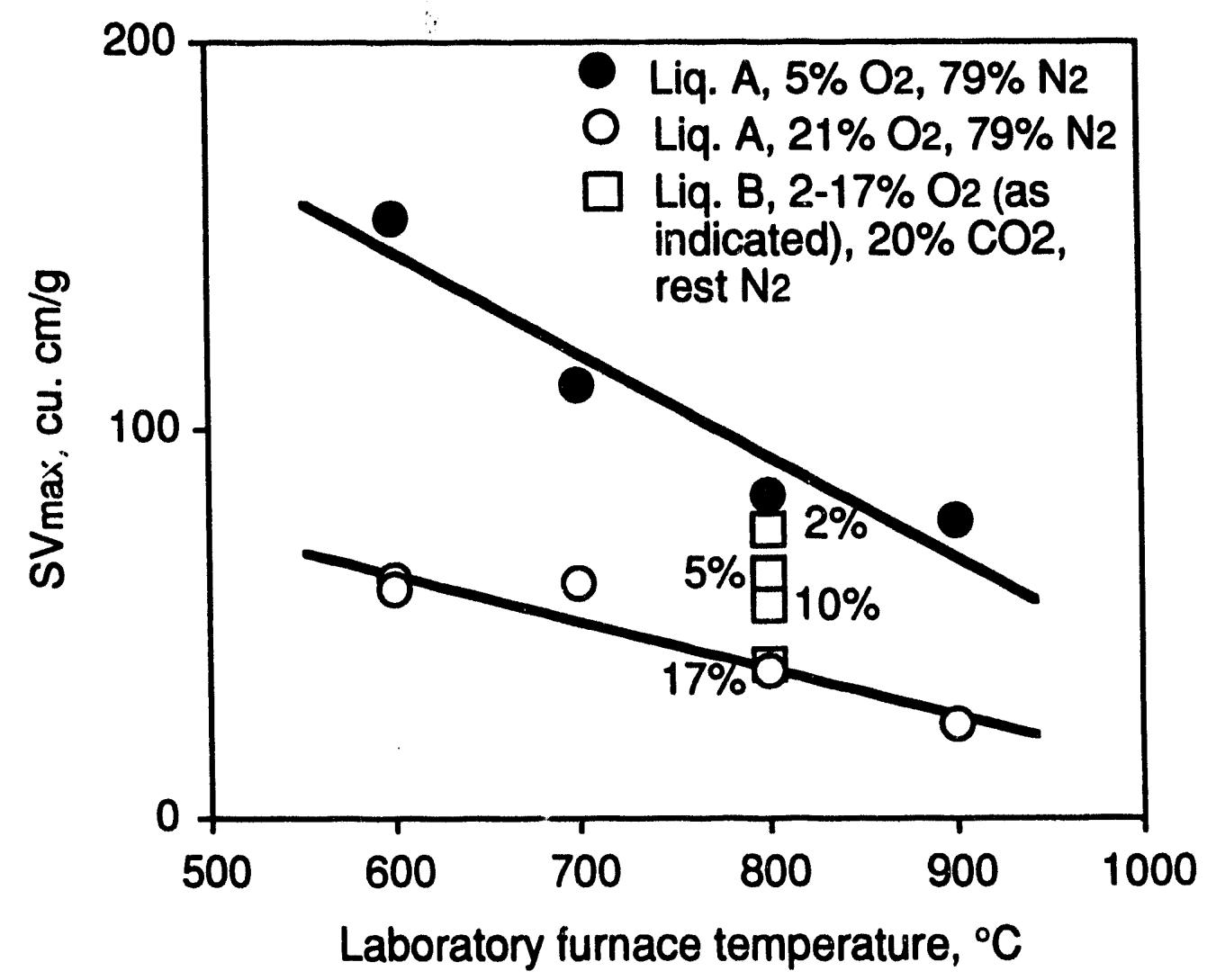

Figure 6.1. Effect of furnace temperature and gas composition on the maximum swollen volume for two kraft black liquors burned under different conditions in a laboratory furnace. 


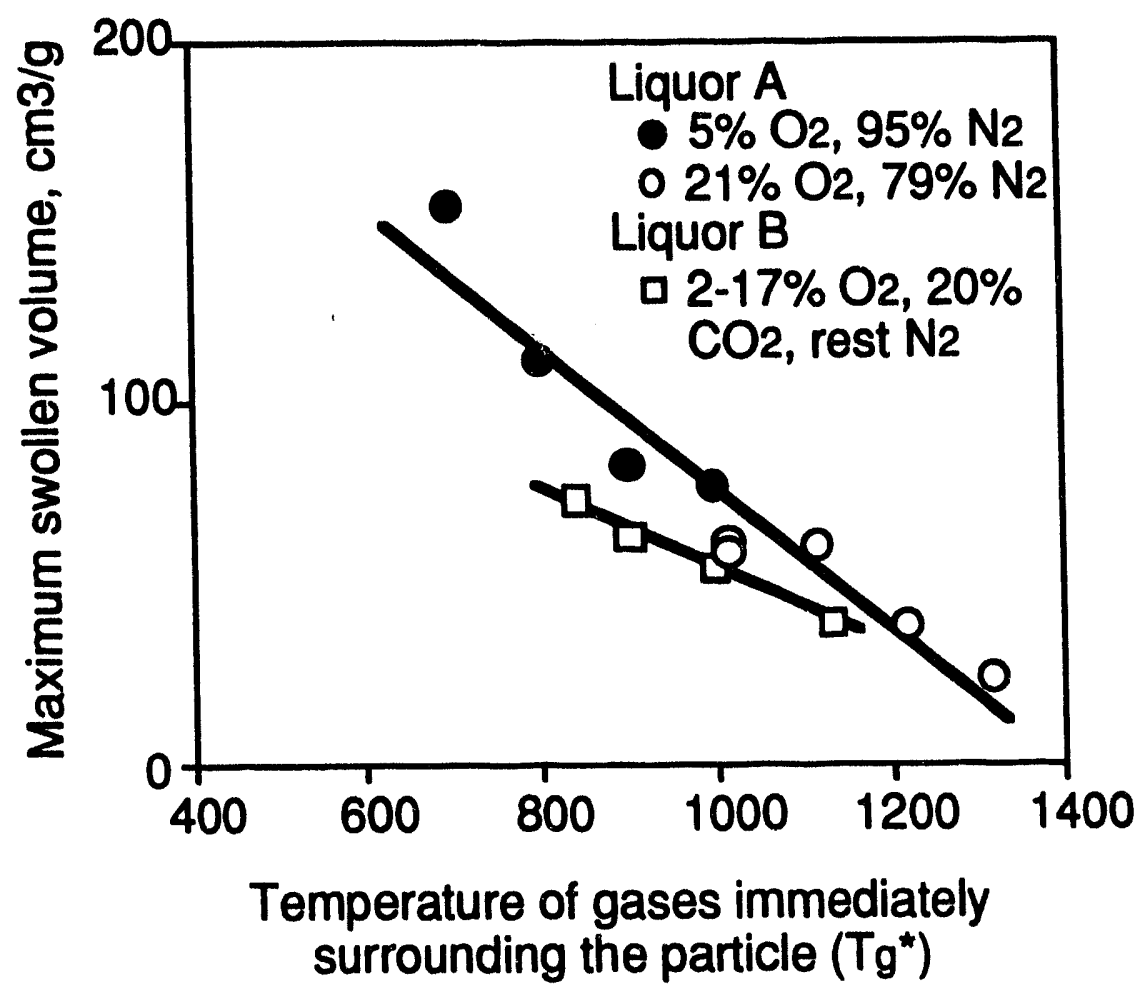

Figure 6.2. Maximum swollen volumes versus $\mathrm{T}_{\mathbf{g}}{ }^{*}$ for the two liquors in Figure 6.1. 


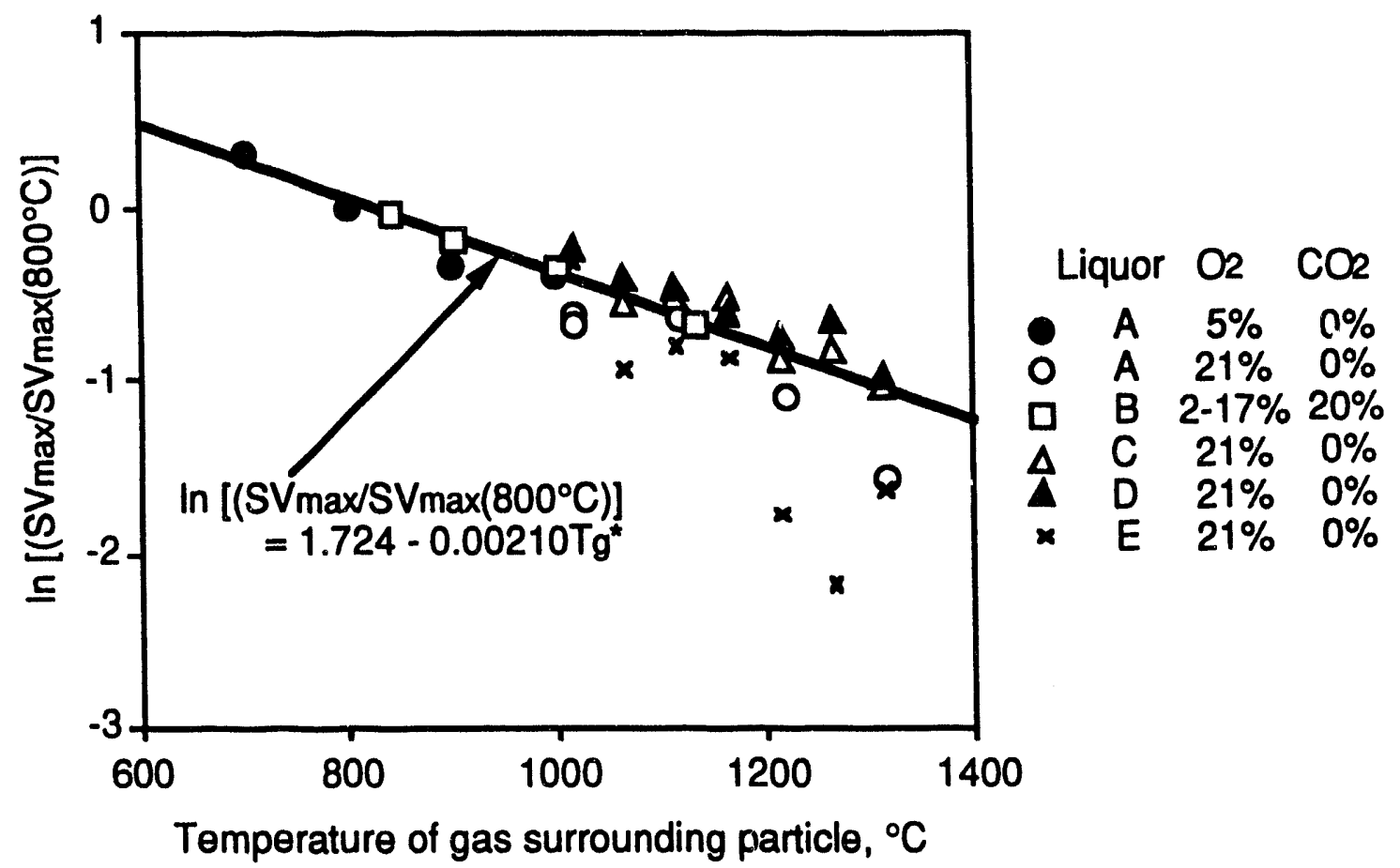

Figure 6.3. The effect of the temperature of the gases immediately surrounding a black liquor droplet on $S V_{\max }$. The gas temperature environment $\left(\mathrm{T}_{\mathrm{g}}{ }^{*}\right)$ was estimated from Equation 5. The liquors are A,C - pine kraft, B - Douglas fir kraft, D - birch kraft, E - sodium base sulfite semichem. Liquors A and C-E were at $60 \%$ dry solids content and liquor B at $68 \%$. 
There is more scatter at higher $\mathrm{T}_{\mathrm{g}}^{*}$ s where the $S V_{\max }$ values are smaller, probably because of the lower accuracy in measuring the diameters of smaller droplets. These results indicate that our assumption, that the relative change in swelling with temperature for kraft liquors is liquor independent, is adequate for modeling purposes. It also indicates that the effect of gas composition on $\mathrm{SV}_{\max }$ when oxygen is present can be accounted for as a temperature effect. The fact that there is no difference between the measurements in $\mathrm{O}_{2} / \mathrm{N}_{2}$ versus $\mathrm{CO}_{2} / \mathrm{O}_{2} / \mathrm{N}_{2}$ environments indicates that the results can be generalized to furnace conditions.

The correlation in Fig 6.3 is a regression fit to the kraft liquor data only - the NSSC data was not used to generate it. The NSSC data appears to have a steeper temperature dependence, but the data are too limited to develop a correlation for NSSC liquors in general.

\subsubsection{Effect of Dry Solids Content}

The limited data available indicates that $\mathrm{SV}_{\max }$ is independent of dry solids content for some but not all liquors (Figure 6.4; Frederick et al., 1991). The data in this figure show that, for the three liquors measured, the pine kraft liquor swells more at higher dry solids content while the birch kraft and NSSC liquors do not. These trends should not be assumed to be general based on this limited data. More data with additional liquors is needed before the effect of dry solids content on swelling will be predictable.

\subsubsection{Recommended Procedure for Estimating Swelling Factors During Devolatilization}

Although efforts to understand the relationship between black liquor composition and swelling during devolatilization have been made, it is not yet possible to estimate $S V_{\max }$ for a given liquor based on its composition. It is necessary therefore in modeling to begin with experimentally measured $\mathrm{SV}_{\max }$ data for the liquor of interest. Procedures for measuring swelling during devolatilization have been developed by Hupa (Hupa et al., 1982, 1987; Noopila and Hupa, 1988, Clay et al. (1985, 1987), and Verrill (1992). We recommend Hupa's procedure because of its simplicity and the decoupling of flow and combustion phenomena during the experiments. The procedure is described in detail by Noopila and Hupa (1988). We recommend that the droplets be burned in air at several temperatures (e.g. $600-900^{\circ} \mathrm{C}$ ) and at the solids content of interest.

To obtain $S \mathrm{~V}_{\text {max }}$ at other temperatures and gas compositions, we recommend the following procedure:

1. Calculate $\mathrm{T}_{\mathrm{g}(\exp )}^{*}$ for each measured value of $\mathrm{SV}_{\max }$ using Eq. (6.5) and the experimental furnace temperature and gas composition.

2. Interpolate or extrapolate to determine $S V \max$ for $\mathrm{T}_{\mathrm{g}}^{*}=800^{\circ} \mathrm{C}$. This is $\mathrm{SV}_{\max }\left(\mathrm{T}_{\mathrm{g}}^{*}=800^{\circ} \mathrm{C}\right)$. 


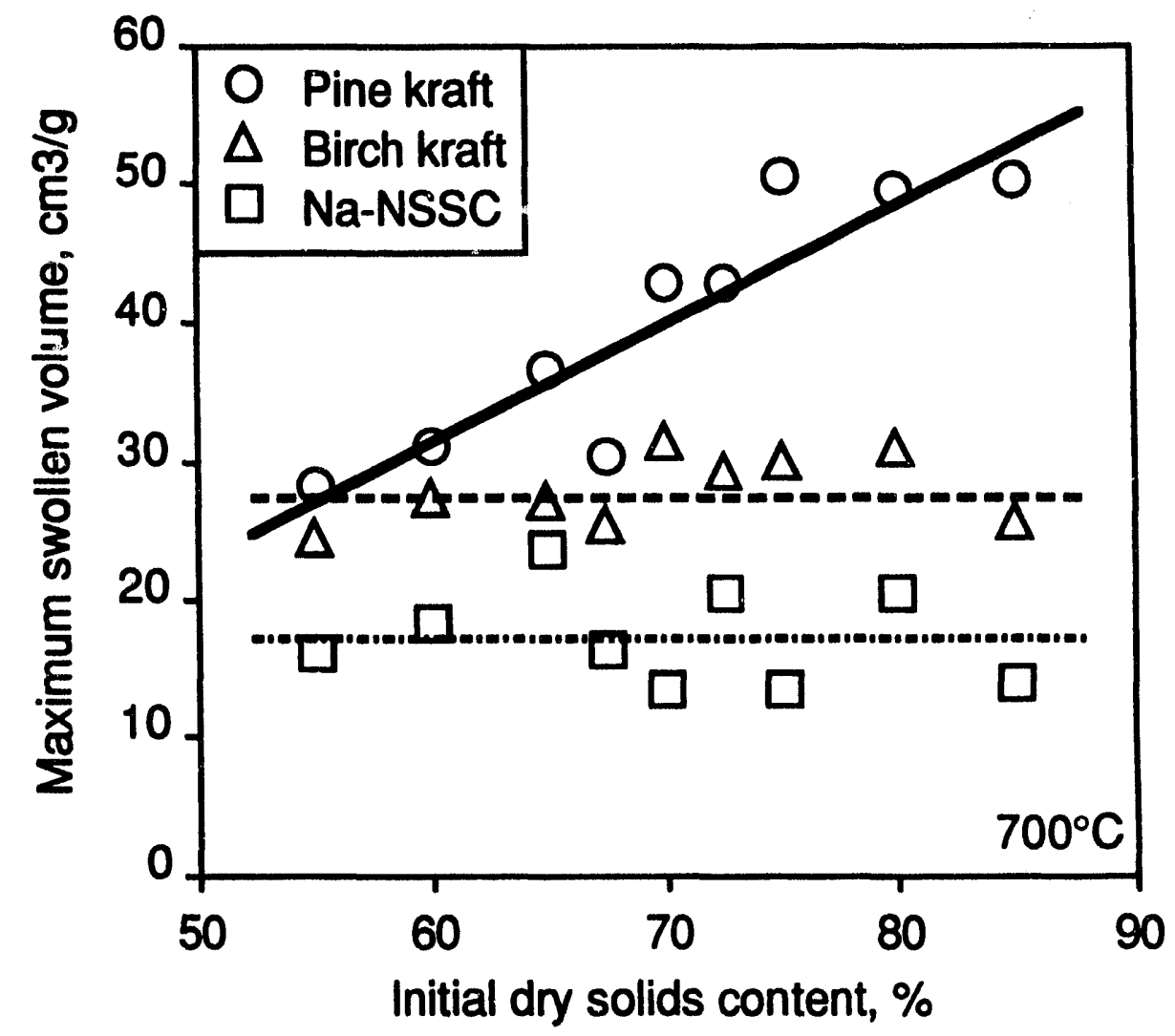

Figure 6.4. Effect of initial dry solids content on $\mathrm{SV}_{\max }$ for three liquors burned in air at $700^{\circ} \mathrm{C}$ (from Frederick et al., 1991) 
3. Use $S V_{\max }\left(\mathrm{T}_{\mathrm{g}}^{*}=800^{\circ} \mathrm{C}\right.$ ) to calculate $\mathrm{SV}_{\max }$ at $\mathrm{T}_{\mathrm{g}}^{*}$ corresponding to the temperature and oxygen content of interest from the correlation:

$$
\ln \left[\left(\mathrm{SV}_{\max } / \mathrm{SV}_{\max }\left(\mathrm{T}_{\mathrm{g}}^{*}=800^{\circ} \mathrm{C}\right)\right]=1.724-0.00210 \mathrm{~T}_{\mathrm{g}}^{*}\right.
$$

where the $T_{g}^{*}$ value in the right side of Eq. (6.6) corresponds to the furnace temperature and oxygen content for the modeling calculations.

4. Calculate the swelling factor during devolatilization as

$$
S F_{v o l}=D / D_{\max }
$$

where $D$ is obtained from Eq. (6.2) and $D_{\max }$ from Eq. (6.3).

\subsubsection{Effect of a Nonisothermal Gas Environment on $\mathrm{SV}_{\text {MAX }}$}

The data and correlations presented in this chapter are based on droplet combustion measurements under isothermal conditions. It is not yet possible to account for the effects of a nonisothermal environment on the maximum swollen volume during devolatilization. It may be that the swollen volume at the end of devolatilization depends strongly upon the amount of organic carbon remaining in the char at that point. Figure 6.5 contains a cross-plot of, $\mathrm{SV}_{\max }$ data for Liquor A in Figure 6.2 versus the carbon content of the droplet residue from pyrolysis experiments with the same liquor at different temperatures (from Figure 3.11). Also shown are the corresponding furnace temperatures. Figure 6.5 suggests a strong relationship between swollen volume and carbon content of the char. Work is currently in progress to develop a kinetic model for black liquor devolatilization. This will provide a means of estimating the carbon remaining in a black liquor char particle following devolatilization for droplets heated nonisothermally. Additional swollen volume and char carbon data will be needed to establish a relationship between maximum swollen volume and the carbon content of the char residue. This information can then be used to determine whether a universal correlation can be used to estimate $\mathrm{SV}_{\max }$ under nonisothermal conditions.

\subsection{Particle Shrinkage During Char Burning}

As during devolatilization, the diameter of a particle during the char combustion stage follows a dimensionless path which is independent of furnace temperature, gas composition, liquor composition, or initial dry solids content (Frederick, 1990). An empirical equation which describes the particle diameter during char burning is 


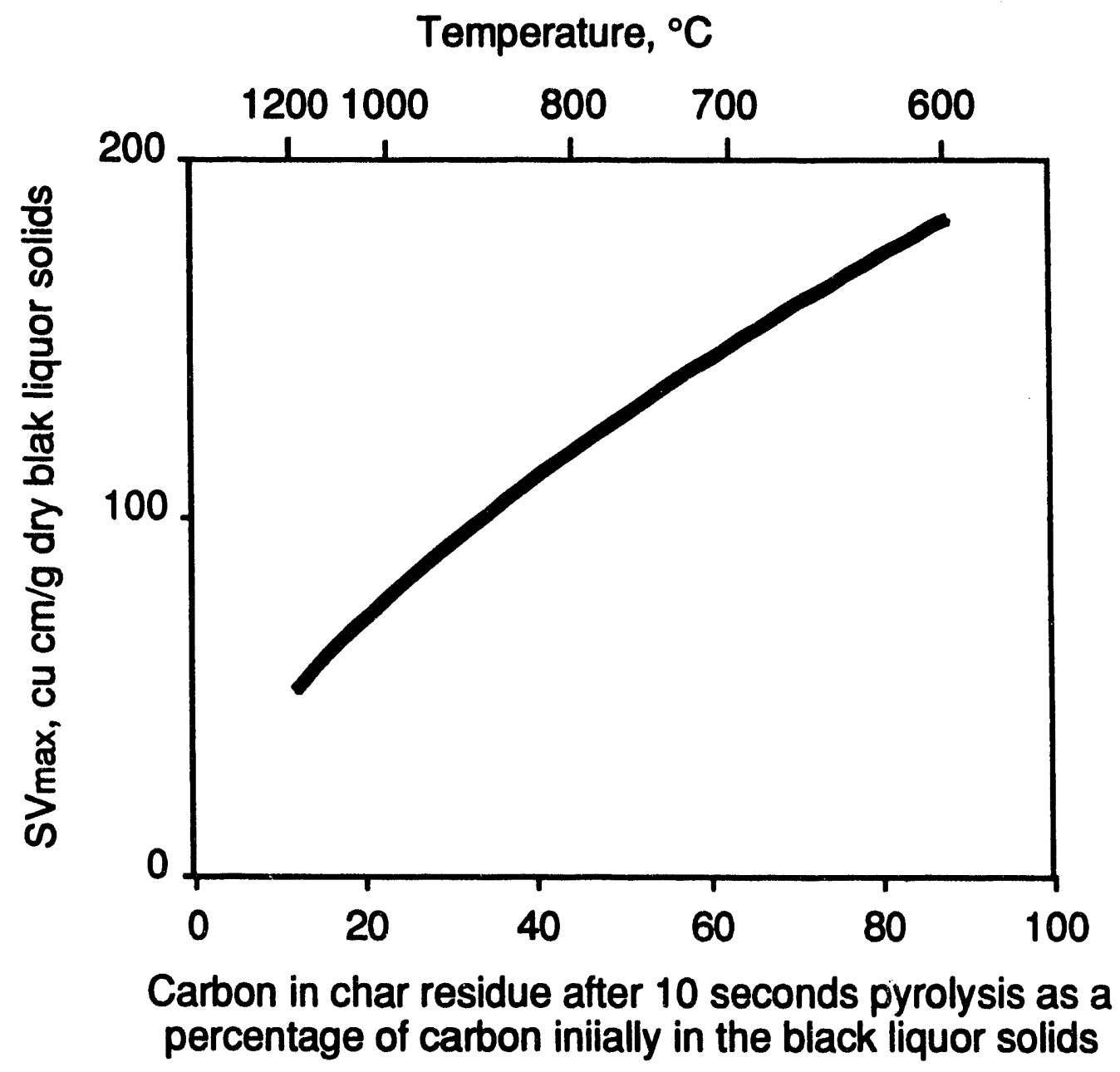

Figure 6.5. Maximum swollen volume per gram of carbon in char versus the carbon content of char after 10 seconds pyrolysis in $95 \% \mathrm{~N}_{2} / 5 \% \mathrm{CO}$. 


$$
\frac{D^{3}-D_{\max }^{3}}{D_{\max }^{3}-D_{8}^{3}}=1-X_{C B}
$$

where $D_{s}$ is the diameter of the smelt bead which remains after char burning is complete and $\mathrm{X}_{\mathrm{CB}}$ is the degree of completion of the char burning stage. The char burning process is complete when enough orygen has been supplied as $\mathrm{O}_{2}, \mathrm{H}_{2} \mathrm{O}$, or $\mathrm{CO}_{2}$ to completely burn and/or gasify the fixed carbon in the char. $X_{C B}$ is defined as $X_{C B}=m_{C B}(t) / m_{t o t}$ where $m_{C B}(t)$ is the moles of oxygen supplied to the droplet from the onset of char burning to the time of interest and $m_{\text {tot }}$ is the total oxygen which must be transferred to complete the char burning stage. $X_{C B}=0$ at the onset of char burning and 1 at the end. No experimentally measured parameters except $D_{\max }$ are needed to describe the particle diameter during char burning. $D_{\max }$ can be obtained from $\mathrm{SV}_{\max }$ via Eq. (6.3).

The swelling factor during char burning is calculated as

$$
S F_{\text {char }}=D / D_{\max }
$$

with D obtained from Eq. (6.8) and $D_{\max }$ from Eq. (6.3).

\subsection{Summary}

The swelling factors for black liquor droplets during combustion can be estimated from simple correlations based on experimental data. The only liquor-specific parameter required is the maximum swollen volume during devolatilization. Although the effects of furnace variables and droplet size on maximum swollen volume are well enough known for quantitative estimations, the effects of liquor composition are not, and maximum swollen volume must be measured experimentally.

When $\mathbf{S V}_{\max }$ data are available at a few temperatures, it is possible to estimate its value at other furnace oxygen contents and temperatures for isothermal environments based on Eq. (6.6).

It is not yet possible to account for the effects of a nonisothermal environment on the maximum swollen volume during devolatilization. This is currently being investigated. 


\subsection{References}

Alén, R., Hupa, M., Noopila, T., Holzforschung, 46:337-342 (1992).

Clay, D.T., Grace, T.M., Kapheim, R.J., Semerjian, H.G., Macek, A., Charagundla, S.R., "Fundamental study of black liquor combustion - Report No. 1-Phase 1," U.S. DOE Report DOE/CE/40637-T1 (DE85013773), January 1985.

Clay, D.T., Lien, S.J., Grace, T.M., Macek, A., et al., "Fundamental studies of black liquor combustion - Report No. 2," U.S. DOE Report DE88005756, January 1987.

Frederick, W.J., "Combustion processes in black liquor recovery: analysis and interpretation of combustion rate data and an engineering design model," U.S. DOE Report DOE/CE/40637-T8 (DE90012712), March 1990.

Frederick, W.J., Noopila, T., Hupa, M., "An analysis of swelling during the combustion of pulping liquor droplets," Combustion Chemistry Research Group Report 89-12, Ảbo Akademi University, Turku, Finland (1989).

Frederick, W.J., Noopila, T., Hupa, M., "Combustion behavior of black liquor at high solids firing conditions," Tappi J., 74(12):163-170 (1991a).

Frederick, W.J., Noopila, T., Hupa, M., "Swelling of pulping liquor droplets during combustion," J. Pulp Paper Sci., 17(5):J164-J170 (1991b).

Hupa, M., Backman, R., Hyöty, P., "Investigation of fireside deposition and corrosion in sulphate and sodium bases sulphite recovery boilers," Proc. Black Liquor Recovery Boiler Symposium 1982, Helsinki (August 31 - September 1, 1982).

Hupa, M., Frederick, W.J., "Combustion of black liquor droplets," Proc. 1991 TAPPI Kraft Recovery Operations Seminar, TAPPI Press, Atlanta (1991), pp. 191-200.

Hupa, M., Solin, P., Hyöty, P., "Combustion behavior of black liquor droplets," J. Pulp Paper Sci., 13(2):J67-72 (1987).

Miller, P.T., Clay, D.T., and Lonsky, W.F.W., "The influence of composition on the swelling of kraft black liquor during pyrolysis," TAPPI Engr. Conf., Seattle, September 1986.

Miller, P.T., Clay, D.T., "Swelling of kraft black liquor during pyrolysis," AIChE For. Prod. Div. Symp., V. 1 (1986), pp. 152-159.

Noopila, T. and Hupa, M., "Measuring the combustion properties of black liquors by different techniques," Combustion Chemistry Research Group Report 88-5, Ábo Akademi, Turku, Finland (1988). 
Noopila, T., "The influence of droplet size and kappa number on black liquor burning behaviour - a study in a convective gas environment," Combustion Chemistry Research Group Report 89-17, Ábo Akademi, Turku, Finland (1989).

Saastamoinen, J., "Modelling of coal pyrolysis and combustion, " Am. Flame Rsch Comm. 1988 Fall Int'l Symp., Pittsburgh, October 4-6, 1988.

Verrill, C.L., PhD Thesis, The Institute of Paper Science and Technology, Atlanta (1992). 


\section{APPENDIX 1}

\section{DROPLET TRAJECTORY PROGRAM RATA2}

A1-1 
St Input Name Output Unit Comment

DROPLET TRAJECTORY MODEL (RATA)

(Modified 28.1.91)

$\begin{array}{lll}\text { DRYTIN .375 } & \text { s } & \text { Calculated drying time } \\ \text { VOLTIM } 1.775 & \text { s } & \text { Devolatilization time } \\ \text { BURNTI } 2.15 & \text { s } & \text { Char burning time }\end{array}$

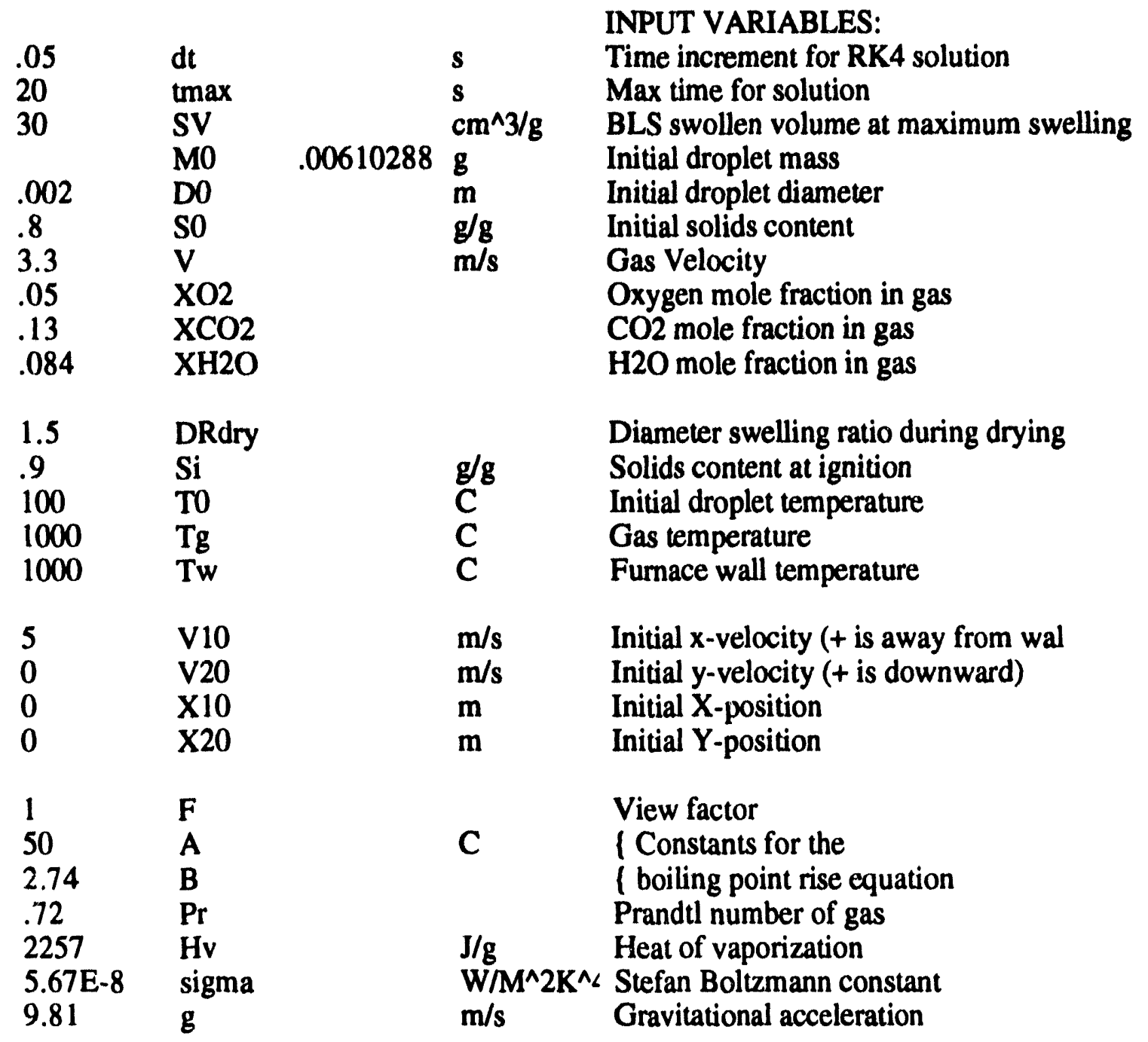

\begin{tabular}{|c|c|c|c|}
\hline & 757 & C & $\begin{array}{l}\text { OUTPUT VARIABLES: } \\
\text { Max droplet temperature }\end{array}$ \\
\hline kvisg & .00018114 & $m^{\wedge} 2 / s$ & Gas kinematic viscosity \\
\hline densg & .00027571 & $\mathrm{~g} / \mathrm{cm}^{\wedge} 3$ & Gas density \\
\hline CpO & 2.741888 & $\mathrm{~J} / \mathrm{g} \mathrm{K}$ & Initial heat capacity \\
\hline Cpf & 2.3427654 & $\mathrm{~J} / \mathrm{g} \mathrm{K}$ & Final heat capacity \\
\hline den & 1.4576936 & $\mathrm{~g} / \mathrm{cm}^{\wedge} 3$ & Initial density (before swelling) \\
\hline Qsens & .1443027 & 5 & Sensible heat to drop \\
\hline vap & 1.530466 & $\mathbf{J}$ & Heat to vaporize water \\
\hline Qtot & 1.6747687 & $\mathbf{J}$ & Total heat required \\
\hline Tb0 & 127.12917 & C & Boiling point at SO \\
\hline Tbf & 137.4623 & & Bulk drop temp at end of drying \\
\hline $\mathrm{k} 0 \mathrm{~b}$ & .14668623 & $\mathrm{~W} / \mathrm{mK}$ & Black liquor therm cond. at SO \\
\hline kt & .14651852 & $\mathrm{~W} / \mathrm{mK}$ & ry $\mathrm{BL}$ therm cond at $\mathrm{Tb}$ \\
\hline
\end{tabular}


St Input $\quad \frac{\text { Name }}{\text { Mdry }} \quad \frac{\text { Output }}{.00542478} \frac{\text { Unit }}{\mathrm{g}} \quad \frac{\text { Comment }}{\text { Droplet mass after drying }}$

\begin{tabular}{|c|c|c|c|c|}
\hline \multirow[t]{2}{*}{$\begin{array}{l}.12 \\
1.75 \\
10000 \\
1.17 \\
0\end{array}$} & $\begin{array}{l}k i \\
\text { fg } \\
\text { Hcomb } \\
\text { Cpgas } \\
\text { Qrxn }\end{array}$ & & $\begin{array}{l}\mathrm{J} / \mathrm{g} \\
\mathrm{J} / \mathrm{gK} \\
\mathrm{J}\end{array}$ & $\begin{array}{l}\text { Empirical flame cfliciency } \\
\text { Stoich ratio of } \mathrm{CO} / \mathrm{O} 2 \text { for } \mathrm{CO} \text { combustio } \\
\text { Heat of combustion for } \mathrm{CO} \Rightarrow \mathrm{CO} 2 \\
\text { Gas heat capacity } \\
\text { Heat released during devolatilization }\end{array}$ \\
\hline & $\begin{array}{l}\text { vmf } \\
\text { Tflame } \\
\text { Dmax } \\
\text { Cp } \\
\text { Qtotv } \\
\text { Mvol }\end{array}$ & $\begin{array}{l}.343 \\
1099.1453 \\
.00653343 \\
3.1553351 \\
11.828999 \\
.00320767\end{array}$ & $\begin{array}{l}\mathrm{C} \\
\mathrm{m} \\
\mathrm{J} / \mathrm{g} \mathrm{K} \\
\mathrm{J} \\
\mathrm{g}\end{array}$ & $\begin{array}{l}\text { Mass fraction of volatiles in BLS } \\
\text { Gas temperature } \\
\text { Droplet diameter at max volume } \\
\text { Average heat capacity } \\
\text { Total heat required } \\
\text { Droplet mass after devolatilization }\end{array}$ \\
\hline
\end{tabular}

\begin{tabular}{|c|c|c|c|c|}
\hline \multirow{24}{*}{$\begin{array}{l}.561 \\
.000378 \\
.5 \\
0 \\
0 \\
.212 \\
0 \\
.000018 \\
.0000144 \\
.0000238 \\
82.057 \\
1 \\
.48\end{array}$} & & $A c=0.561$ for $k r a f t, 0.752$ for NSSC \\
\hline & & & $1 /{ }^{\circ} \mathrm{C}$ & $B c=3.78 \mathrm{e}-4$ for $k r a f t, 5.00 e-4$ for NS \\
\hline & DRs & & & Smelt bead/initial droplet diam ratio \\
\hline & $\begin{array}{l}\text { fco } \\
\text { RCH }\end{array}$ & & & $\begin{array}{l}\text { Mass fr. } \mathrm{C} \Rightarrow \mathrm{CO} \\
\text { Mass ratio } \mathrm{H} / \mathrm{C} \text { in burned char }\end{array}$ \\
\hline & Xna & & & Mass fr. Na in BLS \\
\hline & RSBLS & & & Ratio of sulfide/Na in BLS (corrected \\
\hline & DOX & & $\mathrm{m}^{\wedge} 2 / \mathrm{s}$ & Diffusivity of $\mathrm{O} 2 / \mathrm{N} 2,0 \mathrm{C}$ \\
\hline & $\mathrm{DCO} 2$ & & $m^{\wedge} 2 / s$ & Diffusivity of $\mathrm{CO} 2 / \mathrm{N} 2,0 \mathrm{C}$ \\
\hline & DH2O & & $m^{\wedge} 2 / s$ & Diffusivity of $\mathrm{H} 2 \mathrm{O} / \mathrm{N} 2,0 \mathrm{C}$ \\
\hline & & & atm $\mathrm{cm}^{\wedge} 3 /$ & Ideal gas constant \\
\hline & $\mathbf{P}$ & & atm & Ambient pressure \\
\hline & Xsmlt & & $g / g$ & Mass fraction smelt in BL solids \\
\hline & DRmax & 3.2667147 & & Max DR (at end of devolatilization) \\
\hline & Omega & .70068807 & & Parameter for $\mathrm{kd}(\mathrm{T})$ \\
\hline & & 177 & & Fraction of BLS burned as carbon \\
\hline & $\operatorname{cox}$ & 15.317079 & $g / m^{2} 3$ & Oxygen concentration at $\mathrm{XO} 2$ \\
\hline & $\mathrm{CCO} 2$ & 54.758556 & $g / m^{n} 3$ & $\mathrm{CO} 2$ concentration at $\mathrm{XCO} 2$ \\
\hline & CH2O & 14.474639 & $\mathrm{~g} / \mathrm{m}^{\wedge} 3$ & Water vapor concentration at $\mathrm{XH} 2 \mathrm{O}$ \\
\hline & DiffO2 & .00024263 & $\mathrm{~m}^{\wedge} 2 / \mathrm{s}$ & Diffusivity of $\mathrm{O} 2$ in air at $\mathrm{Tg}$ \\
\hline & DiffCO2 & .00019411 & $m^{\wedge} 2 / s$ & Diffusivity of $\mathrm{CO} 2$ in air at $\mathrm{Tg}$ \\
\hline & DiffH2O & .00032081 & $m^{\wedge} 2 / s$ & Diffusivity of $\mathrm{H} 2 \mathrm{O}$ in air at $\mathrm{Tg}$ \\
\hline & Msmlt & .0023435 & g & Droplet mass after char combustion \\
\hline & Mc & .00086417 & g & Carbon in char converted to gases \\
\hline & Moxtot & .00230445 & $\mathbf{g}$ & Mass of oxygen required \\
\hline 6 & ne & & & $\begin{array}{l}\text { RUNGE-KUTTA PARAMETERS: } \\
\text { number of equations }\end{array}$ \\
\hline
\end{tabular}

CHAR COMBUSTION VARIABLES:

Constants for Xc vs Tflame $\left(700-1400^{\circ} \mathrm{C}\right.$

Smelt bead/initial droplet diam ratio

Mass ratio $\mathrm{H} / \mathrm{C}$ in burned char

Mass $\mathrm{fr}$. Na in BLS

Diffusivity of $02 / \mathrm{N} 2,0 \mathrm{C}$

$\mathrm{m}^{\wedge} 2 / \mathrm{s} \quad$ Diffusivity of $\mathrm{CO} 2 / \mathrm{N} 2,0 \mathrm{C}$

$\mathrm{m}^{\wedge} 2 / \mathrm{s}$ Diffusivity of $\mathrm{H} 2 \mathrm{O} / \mathrm{N} 2,0 \mathrm{C}$

atm $\mathrm{cm}^{\wedge} 3$ / Ideal gas constant

atm Ambient pressure

g/g Mass fraction smelt in BL solids

DRmax 3.2667147

Max DR (at end of devolatilization)

Parameter for $\mathrm{kd}(\mathrm{T})$

Oxygen concentration at XO2

20ncentration at $\mathrm{XCO} 2$

Diffusivity of $\mathrm{O} 2$ in air at $\mathrm{Tg}$

Diffusivity of $\mathrm{CO} 2$ in air at $\mathrm{Tg}$

Diffusivity of $\mathrm{H} 2 \mathrm{O}$ in air at $\mathrm{Tg}$

Droplet mass after char combustion

Carbon in char converted to gases

Mass of oxygen required

number of equations 


\section{S Rule}

"Model for Droplet Drying With External Heat Transfer Control of the Drying

"Rate

"This model uses a RK4 subroutine to calculate the drying profile for a black "liquor droplet. The time to a given dryness is calculated by interpolation.

"CALCULATIONS:

"Black Liquor density

$*$ dens $=(0.997+.649 * \mathrm{SO}) *\left(1-3.69 \mathrm{E}-4 *(\mathrm{~T} 0-25)-1.94 \mathrm{E}-6 *(\mathrm{~T} 0-25)^{\wedge} 2\right)$

"Initial droplet mass or diameter, given the other

* M0 $=1000000 * 3.14 / 6 *$ dens*D0*3

C DO $=.01 *(\mathrm{M} 0 / \text { dens } * 6 / 3.14)^{\wedge} .333$

"Maximum droplet size

* DRmax $=\left(\mathrm{SV}^{*}\right.$ dens*S0)^0.333

* Dmax = DRmax*DO

$C$ call CARBON(Tg;Xc)

C vmf $=1$ - Xc - Xsmlt

C Mdry $=\mathrm{M} 0 * \mathrm{~S} 0 / \mathrm{Si}$

C Mvol $=\mathrm{M} 0 * \mathrm{SO}^{*}(1-\mathrm{vmf})$

C Msmlt $=$ Xsmlt $* \mathrm{M} 0 * \mathrm{SO}$

"Initial and final droplet temperature

* $\mathrm{Tb} 0=100+A^{*} \mathrm{SO}^{\wedge} \mathrm{B}$

* $\mathrm{Tbf}=100+\mathrm{A}^{*} \mathrm{Si}^{\wedge} \mathrm{B}$

"Black Liquor Thermal Conductivity:

$* \mathrm{k} 0 \mathrm{bl}=(.00144 * \mathrm{~Tb} 0-.335 * \mathrm{SO}+0.58) / \mathrm{DRdry}{ }^{\wedge} 3$

$*$ kbls $=\left(0.796-.335^{*} \mathrm{Si}\right) / \mathrm{DRdry}{ }^{\wedge} 3$

"Heat capacity of black liquor

* $\mathrm{Cp} 0=(1-\mathrm{S} 0) * 4.216+\mathrm{S} 0 *(1.675+.00331 * \mathrm{~T} 0)+(4.87-.020 * \mathrm{~T} 0) *(1-\mathrm{S} 0) * \mathrm{~S} 0 \wedge 3$

"Note: the following Cp eqn uses S0, not Si because the process is assumed

" to be 1) heating to the final state and 2) separation of vapor from

" liquor.

$* \mathrm{Cpf}=(1-\mathrm{Si}) * 4.216+\mathrm{S} 0 *(1.675+.00331 * \mathrm{Tbf})+(4.87-.020 * \mathrm{Tbf}) *(1-\mathrm{S} 0) * \mathrm{~S} 0 \wedge 3$

"Heat capacity of char

* Tmax $=284+0.473 * \mathrm{Tg}$

* $\mathrm{Cp}=1.675+0.00331 *(\mathrm{Tbf}+\mathrm{Tmax}) / 2$

"Flame temperature calculation

* Tflame $=\mathrm{Tg}+\mathrm{kf} *$ fg*Hcomb*.232/.21*X02/Cpgas

"Total heat required for devolatilization

* Qtotv = M0*SO/Si*Cp*(Tmax-Tbf + Qrxn + M0*SO*(1/Si-1)*Hv

* call CARBON(Tg;Xc)

* vmf $=1$ - Xc - Xsmlt

*

$*$ Mdry $=\mathrm{M} 0 * \mathrm{~S} 0 / \mathrm{Si}$ 
* Mvol $=\mathrm{MO}$ *SO*(1-vmf)

* Msmlt $=$ Xsmlt*MO*SO

"Total heat required to ignition

"for black liquor

* Qsens $=\mathrm{M0} *(\mathrm{Cpf} * \mathrm{TbO}-\mathrm{Cp} 0 * \mathrm{TO})$

* Qvap = MO*(1-SO/Si)*Hv

* Qtotd = Qsens + Qvap

"From devolatilization

* $\mathrm{kvisg}=1 \mathrm{E}-6 *\left(13.3175+0.1005^{*} \mathrm{Tg}+6.732 \mathrm{E}-5^{*} \mathrm{Tg}^{\wedge} 2\right)$

$*$ densg $=\mathrm{P} * 28.8 / \mathrm{R} / \mathrm{Tg}+273)$

"From char combustion

* $\mathrm{Mc}=\mathrm{M} 0 * \mathrm{SO}^{*} \mathrm{Xc}$

* Moxtot $=$ Mc*(fco*16/12 + (1 - fco $\left.* 32 / 12+\mathrm{RCH}^{*} 8\right)-\mathrm{RSBLS}^{*} 64 / 96 * \mathrm{M0} * \mathrm{S0}$ "(1/91)

$* \mathrm{COX}=32000000 * \mathrm{P} / \mathrm{R} /(\mathrm{Tg}+273) * \mathrm{XO} 2$

* $\mathrm{CCO} 2=44000000 * \mathrm{P} / \mathrm{R} /(\mathrm{Tg}+273) * \mathrm{XCO} 2$

* $\mathrm{CH} 2 \mathrm{O}=18000000 * \mathrm{P} / \mathrm{R} / \mathrm{Tg}+273) * \mathrm{XH} 2 \mathrm{O}$

* Omega $=1.480-0.2510 * \log (\mathrm{Tg}+273)$

* DiffO2 $=$ DOX*(.938/Omega $)^{*}(\mathrm{Tg} / 273+1)^{\wedge} 1.5$

* DiffCO2 = DCO2*(.938/Omega $*(\mathrm{Tg} / 273+1)^{\wedge} 1.5$

$*$ DiffH2O = DH2O*(.938/Omega $)^{*}(\mathrm{Tg} / 273+1)^{\wedge} 1.5$

* call TIMESETO

* place $(' y 1,1)=0 \quad$ " ( initialize Q)

* place $($ 'y2,1) $=0$

* place $(' y 3,1)=V 10$

* place $(' y 4,1)=$ V20

* place $(' y 5,1)=\mathrm{X} 10$

* place $($ 'y6,1) = X20

* $\operatorname{place}(' y 7,1)=$ D0

* place $(' y 8,1)=\mathrm{M} 0$

* place ('y9,1) = Tb0

* place ('STIME,1) $=0$

* place $($ 'STIME,4) =0

* call RK4()

* DRYTIME = 'STIME[2]

* VOLTIME = 'STIME[3]

* BURNTIME = 'STIME[4] 


$\begin{array}{llll}\text { Name } & \text { Type } & \text { Arguments } & \text { Comment } \\ \text { RK4 } & \text { Procedure } & 0 ; 0 & \text { Classical Fourth Order Runge-Kutta method } \\ \text { EQ } & \text { Procedure } & 9 ; 6 & \text { Differential equations for droplet drying } \\ \text { TIMESET } & \text { Procedure } & 0 ; 0 & \text { Sets time steps and zeros y1 (mass) } \\ \text { STAGE } & \text { Procedure } & 3 ; 1 & \text { Change points } \\ \text { DRY } & \text { Procedure } & 4 ; 2 & \text { Drying model } \\ \text { DEVOL } & \text { Procedure } & 4 ; 2 & \text { Devolatilization model } \\ \text { BURN } & \text { Procedure } & 4 ; 2 & \text { Char burning model } \\ \text { PROPS } & \text { Procedure } & 1 ; 2 & \text { Transport properties of nitrogen } \\ \text { CARBON } & \text { Procedure } & 1 ; 1 & \text { Fraction of BLS burned as carbon }\end{array}$


Comment:

Parameter Variables:

Input Variables:

Output Variables:

S Statement

"Notation: ne number of 1st order equations

" EQ name of the function with lst order equations

" $x$ independent variable (list)

" $\quad y$ list with names of dependent variables (lists) y1, y2,...

" $\quad \mathrm{k}$ list with names of RK coefficients (lists) k1, k2,...

" Description: This procedure represents an implementation of a classical

" 4th order Runge-Kutta procedure for numerical integration of differential

" equations. In this implementation, the set of 1 st order equations must be

" available in a procedure function named $E Q$. Whenever this function is

" called from here, the current values of independent variable $x$ and

" functions $y 1, y 2, \ldots$ must be passed over as input variables represented

" by $x$, 'ye[1], 'ye[2] ,... . The returned values of the right hand

" sides of the 1st order equations are used as RK coefficients $\left.\mathrm{k} 1{ }^{*}\right]$,

" ' $\left.\mathrm{k} 2{ }^{*}\right]$, ... (see marked function calls below; they have to be modified

" when the number of 1 st order equations changes).

" The values of independent variables must be available in list $x$, and the

" solution is accumulated in lists $\mathrm{y} 1, \mathrm{y} 2, \ldots$. The names of these lists

" must be declared as symbolic values in the master list $y$. The same

" applies to the lists $k 1, k 2, \ldots$ of RK coefficients whose names must

" be declared in the master list $\mathrm{k}$. The initial values must be assigned

$"$ as the first elements in the lists $\mathrm{y} 1, \mathrm{y} 2, \ldots$.

"This procedure has been modified for the DROPDRY calculations.

"Modifications are indicated as such.

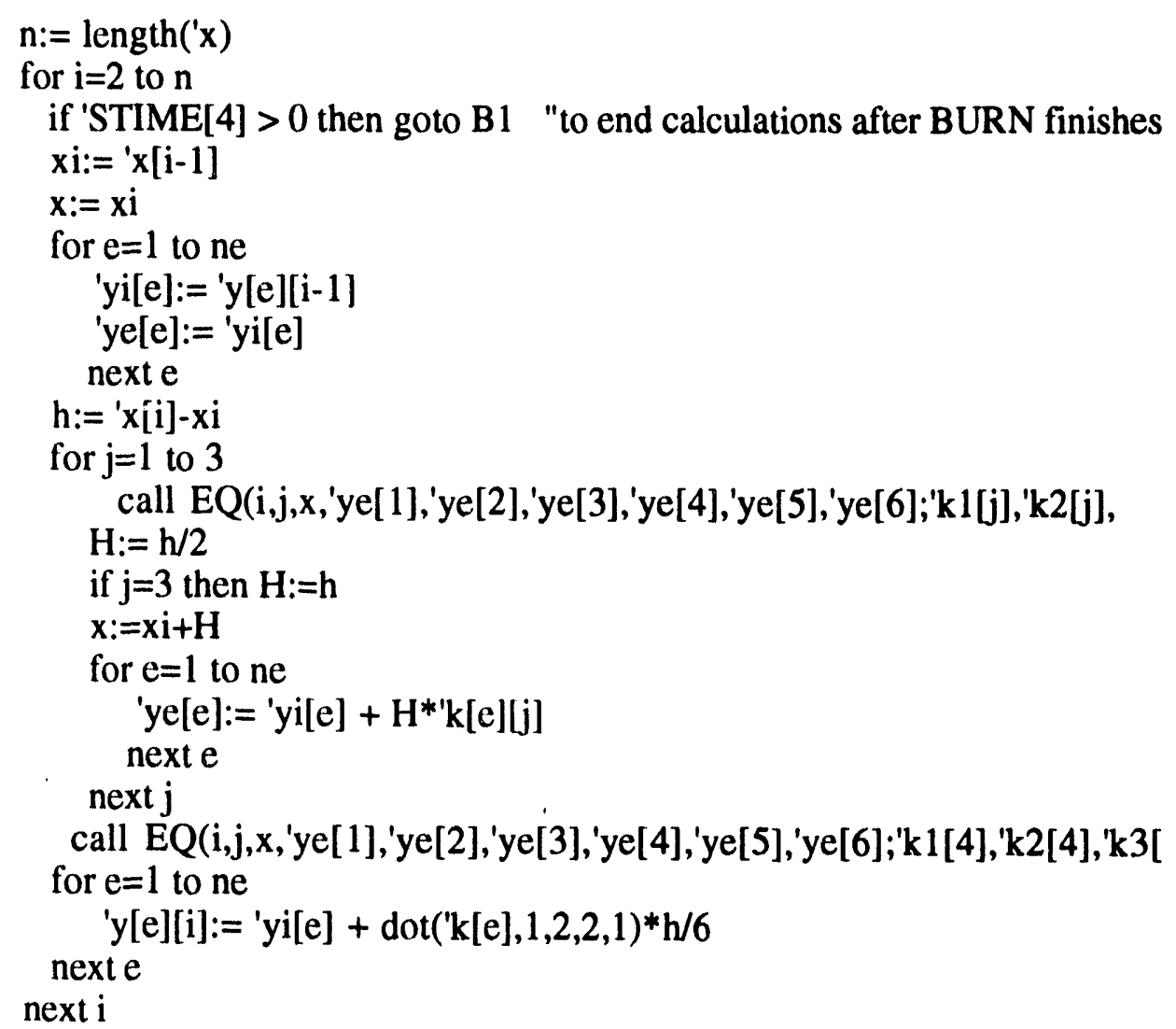


S Statement

call delete('yi)

call delete('ye)

B1:return 
Comment: Differential equations for droplet drying

Parameter Variables: $\quad$ V,dt,kvisg,densg,vmf,g,Msmlt

Input Variables:

Output Variables:

S Statement

mc:=count('y8)

$\mathrm{dc}:=\operatorname{count}(\mathrm{y} 7)$

$\mathrm{M}:=$ 'y8[mc]

$\mathrm{D}:=\mathrm{y} 7[\mathrm{dc}]$

call STAGE(i,t,M;nstage)

Vtot: $=\left(\mathrm{V} 1 \wedge 2+(\mathrm{V} 2+\mathrm{V})^{\wedge} 2\right)^{\wedge} 0.5$

Re:=D*Vtotkvisg

If nstage $=1$ then goto $B 1$ else goto $B 2$

B1:call DRY(i,j,Q,Vtot;q2r,massrate)

$\mathrm{dQ} \% \mathrm{dt}:=\mathrm{q} 2 \mathrm{r}$

$\mathrm{dMox} \% \mathrm{dt}:=$ massrate

goto $\mathrm{B} 7$

$B 2$ :If nstage $=2$ then goto $B 3$ else goto $B 4$

B3:call DEVOL (i,j,Q,Vtot;q2r,massrate)

$\mathrm{dQ} \% \mathrm{dt}:=\mathrm{q} 2 \mathrm{r}$

$\mathrm{dMox} \% \mathrm{dt}:=$ massrate

goto $B 7$

B4:If nstage $=3$ then goto $\mathrm{B} 5$ else goto $\mathrm{B} 6$

B5:call BURN(i,j,Mox,Vtot;q2r,massrate)

$\mathrm{dQ} \% \mathrm{dt}:=\mathrm{q} 2 \mathrm{r}$

$\mathrm{dMox} \% \mathrm{dt}:=$ massrate

goto $\mathrm{B} 7$

B6:dQ\%dt:=0

$\mathrm{dMox} \% \mathrm{dt}:=0$

$\mathrm{B} 7$ :If $\mathrm{Re}<30$ then goto $\mathrm{B} 8$ else goto $\mathrm{B} 9$

$B 8: C d:=28 / \operatorname{Re}^{\wedge} 0.75$

goto $\mathrm{B} 10$

B9:Cd: $=12 / \operatorname{Re}^{\wedge} 0.5$

B10:

if $\mathrm{M}<$ Msmlt then goto $\mathrm{B} 11$ else goto $\mathrm{B} 12$

B11:M:= Msmlt

B12:

$\mathrm{A} 2:=3.14 * \mathrm{D}^{\wedge} 2 / 4$

Fdtot:=Cd*A2*densg*Vtot^2/2*1E6

Fd1: $=(\mathrm{V} 1 / \mathrm{Vtot})^{\wedge} 2^{*} \mathrm{Fdtot}$

$\mathrm{Fd} 2:=((\mathrm{V} 2+\mathrm{V}) / \mathrm{V} \text { tot })^{\wedge} 2 *$ Fdtot

$\mathrm{dV} 1 \% \mathrm{dt}:=-\mathrm{Fd} 1 / \mathrm{M}$

$\mathrm{dV} 2 \% \mathrm{dt}:=\mathrm{g}-\mathrm{Fd} 2 / \mathrm{M}$

$\mathrm{dX} 1 \% \mathrm{dt}:=\mathrm{V} 1$

$\mathrm{dX} 2 \% \mathrm{dt}:=-\mathrm{V} 2$

return 
Comment:

Parameter Variables:

Input Variables:

Output Variables:

\section{S Statement}

call blank(' $x$ )

call blank('y1)

call blank('y2)

call blank('y3)

call blank('y4)

call blank('y5)

call blank('y6)

call blank('y7)

call blank('y8)

call blank('y9)

call blank('STIME)

call blank('ycheck)

$\mathrm{n}:=\operatorname{tmax} / \mathrm{dt}$

place('x,1):=0

for $i=2$ to $n+1$

'x[i]:= $x[i-1]+d t$

next $\mathrm{i}$
Sets time steps and zeros yl (mass)

tmax,dt 
Comment: Change points

Parameter Variables: $\quad$ Mdry,Mvol,Msmlt

Input Variables:

Output Variables:

i,t,M

nstage

S Statement

If $\mathrm{M}>\mathrm{Mdry}$ then nstage $=1$ else goto $\mathrm{B} 1$

return

$\mathrm{B} 1$ :If 'STIME[1] $=0$ then goto $\mathrm{B} 2$ else goto $\mathrm{B} 3$

B2:'STIME[1]:=1

nstage: $=2$

'STIME[2]:=t

return

B3:If $\mathrm{M}>\mathrm{Mvol}$ then nstage $=2$ else goto $\mathrm{B} 4$

return

B4:If 'STIME[1]=1 then goto B5 else goto B6

B5:'STIME[1]:=2

nstage: $=3$

'STIME[3]:=t-'STIME[2]

return

B6:If $\mathrm{M}>\mathrm{Msmlt}$ then nstage $=3$ else goto $\mathrm{B} 7$

return

B7:If 'STIME[1]=2 then goto B8 else goto B9

B8: 'STIME[1]:=3

nstage: $=4$

'STIME[4]:=t-'STIME[3]-'STIME[2]

B9:nstage: $=4$

return 
Comment: Drying model

Parameter Variables: $\quad$ D0,DRdry,F,g,k0bl,kbls,M0,Qtotd,S0,Si,sigma,Tb0,Tbf,Tg,Tw

Input Variables:

Output Variables:

$\mathrm{i}, \mathrm{j}, \mathrm{Q}, \mathrm{Vtot}$

$\mathrm{q} 2 \mathrm{r}$, massrate

S Statement

$\mathrm{M}:=\mathrm{M} 0 *(1-\mathrm{Q} / \mathrm{Qtotd} *(1-\mathrm{S} 0 / \mathrm{Si}))$

$D:=D 0^{*}$ DRdry

if $i=1$ then goto $B 1$ else goto $B 2$

B1:Ts: $=$ 'y9[i]

goto B3

$B 2: j:=i-1$

Ts: $=$ 'y9[j]

B3:

$\mathrm{Tf}:=(\mathrm{Ts}+\mathrm{Tg} / 2)$

call PROPS(Tf;kvisg,kg)

Re: $=D^{*}$ Vtot/kvisg

$\mathrm{Gr}:=\mathrm{g}^{*} \mathrm{ABS}(\mathrm{Tg}-\mathrm{Ts}) * \mathrm{D}^{\wedge} 3 /(\mathrm{Tg}+273) / \mathrm{kvisg}^{\wedge} 2$

$\mathrm{h}:=\mathrm{kg} / \mathrm{D}^{*}\left(2+0.39 * \mathrm{Gr}^{\wedge} 0.25+0.37 * \operatorname{Re}^{\wedge} 0.6\right)$

$A:=3.14 * D^{\wedge} 2$

radflux:= $F^{*}$ sigma ${ }^{*}\left((\mathrm{~T} w+273)^{\wedge} 4-(\mathrm{Ts}+273)^{\wedge} 4\right)$

hprime $=\mathrm{h}+$ radflux $/(\mathrm{Tg}-\mathrm{Ts})$

$\mathrm{Tb}:=\mathrm{Tb} 0+(\mathrm{Q} / \mathrm{Qtotd}) *(\mathrm{Tbf}-\mathrm{Tb} 0)$

$\mathrm{SR}:=(1-\mathrm{SO}) / \mathrm{S} 0+\mathrm{Q} / \mathrm{Qtotd}{ }^{*}((1-\mathrm{Si}) / \mathrm{Si}-(1-\mathrm{SO}) / \mathrm{SO})$

$\mathrm{S}:=1 /(1+\mathrm{SR})$

kdrop:= k0bl + (kbls - k0bl)*(S-SO)/(1-S0)

$\mathrm{r} 2 \mathrm{r}:=1 / \mathrm{hprime}+\mathrm{D} / \mathrm{kdrop} / 6$

$\mathrm{q} 2 \mathrm{r}:=\mathrm{A} *(\mathrm{Tg}-\mathrm{Tb}) / \mathrm{r} 2 \mathrm{r}$

Ts: $=\mathrm{Tg}$ - q2r/hprime/A

'y9[i]:= Ts

'y7[i]:= D

'y8[i]:= M

massrate: $=0$

return 
Comment:

Parameter Variables:

Input Variables:

Output Variables:

S Statement

$\mathrm{M}:=\mathrm{M} 0 * \mathrm{~S} 0 / \mathrm{Si}-((\mathrm{Q}-\mathrm{Qtotd}) / \mathrm{Qtotv}) * \mathrm{M} 0 * \mathrm{SO} *(\mathrm{vmf}+1 / \mathrm{Si}-1)$

$\mathrm{D}:=$ 'y7[i-1] + ((Q-Qtotd)/Qtotv)^0.8*(Dmax-'y7[i-1])

if $\mathrm{i}=1$ then goto $\mathrm{B} 1$ else goto $\mathrm{B} 2$

B1:Ts:= 'y9[i]

goto $\mathrm{B} 3$

$B 2: \mathrm{j}:=\mathrm{i}-1$

Ts: = 'y9[j]

B3:

Tf1:= (Tflame+Tg)/2

Tf:= MIN(Tf1,1800)

call PROPS(Tf;kvisg,kg)

Re:= D*Vtot/kvisg

$\mathrm{Gr}:=\mathrm{g}^{*} \mathrm{ABS}(\mathrm{Tflame}-\mathrm{Ts}) * \mathrm{D}^{\wedge} 3 /($ Tflame +273$) / \mathrm{kvisg}{ }^{\wedge} 2$

$\mathrm{h}:=\mathrm{kg} / \mathrm{D} *\left(2+0.39 * \mathrm{Gr}^{\wedge} 0.25+0.37 * \operatorname{Re}^{\wedge} 0.6\right)$

$\mathrm{A}:=3.14 * \mathrm{D}^{\wedge} 2$

radflux: $=F^{*}$ sigma* $\left((T w+273)^{\wedge} 4-(T s+273)^{\wedge} 4\right)$

hprime $=\mathrm{h}+$ radflux/(Tflame-Ts)

$\mathrm{Tb}:=\mathrm{Tbf}+((\mathrm{Q}-\mathrm{Qtotd}) / \mathrm{Qtotv}) *(\mathrm{Tmax}-\mathrm{Tbf})$

$\mathrm{r} 2 \mathrm{r}:=1 / \mathrm{hprime}+\mathrm{D} / \mathrm{kbls} / 6$

$\mathrm{q} 2 \mathrm{r}:=\mathrm{A} *(\mathrm{Tflame}-\mathrm{Tb}) / \mathrm{r} 2 \mathrm{r}$

Ts:= Tflame $-\mathrm{q} 2 \mathrm{r} / \mathrm{hprime} / \mathrm{A}$

'y9[i]:= Ts

'y7[i]:= D

'y8[i]: = M

massrate: $=0$

return
Devolatilization model

\section{$\mathrm{i}, \mathrm{j}, \mathrm{Q}, \mathrm{Vtot}$}

2r,massrate 


\section{APPENDIX 2}

MAXIMUM SURFACE TEMPERATURES DURING CHAR BURNING FOR BLACK LIQUOR DROPLETS BURNED IN OXYGENNITROGEN MIXTURES 
Appendix 2. Maximum surface temperatures during char burning for black liquor droplets burned in oxygen - nitrogen mixtures.

\begin{tabular}{|c|c|c|c|}
\hline Temperature, ${ }^{\circ} \mathrm{C}$ & $\begin{array}{c}\text { Oxygen in } \\
\text { gas, \% }\end{array}$ & $\begin{array}{l}\text { Initial droplet } \\
\text { mass, mg }\end{array}$ & ${ }^{\mathrm{T}} \mathrm{Cmax}$ \\
\hline \multirow{13}{*}{800} & 21 & 3.6 & 1074 \\
\hline & & 3.6 & 1041 \\
\hline & & 5.6 & 1155 \\
\hline & & 5.7 & 1158 \\
\hline & & 6.0 & 1054 \\
\hline & & 6.3 & 1103 \\
\hline & & 6.3 & 1192 \\
\hline & & 7.3 & 1130 \\
\hline & & 7.8 & 1061 \\
\hline & & 8.3 & 1228 \\
\hline & & 11.0 & 1138 \\
\hline & & 12.1 & 1303 \\
\hline & & 12.1 & 1020 \\
\hline \multirow[t]{10}{*}{800} & 16.8 & 6.3 & 1023 \\
\hline & & 7.6 & 1073 \\
\hline & & 7.6 & 1119 \\
\hline & & 8.4 & 1000 \\
\hline & & 8.6 & 1005 \\
\hline & & 9.1 & 1039 \\
\hline & & 12.6 & 944 \\
\hline & & 13.6 & 994 \\
\hline & & 21.4 & 917 \\
\hline & & 23.5 & 1123 \\
\hline \multirow[t]{4}{*}{800} & 15.8 & 3.8 & 1005 \\
\hline & & 7.1 & 980 \\
\hline & & 10.8 & 965 \\
\hline & & 14.2 & 890 \\
\hline \multirow[t]{3}{*}{800} & 12.6 & 4.7 & 873 \\
\hline & & 4.9 & 986 \\
\hline & & 5.2 & 1011 \\
\hline
\end{tabular}




$\begin{array}{cccc} & & 6.2 & 984 \\ & & 8.3 & 956 \\ & & 9.9 & 1006 \\ & & 10.1 & 1023 \\ & & 10.3 & 999 \\ 800 & & 12.0 & 970 \\ & & & \\ & & & 933 \\ & & 6.4 & 920 \\ & & 7.3 & \\ & & & 900 \\ & & & 950 \\ & & 2.6 & 855 \\ & & 4.7 & 860 \\ & & 4.9 & 825 \\ & & 5.2 & 900 \\ & & 14.6 & 875\end{array}$




\section{APPENDIX 3}

MASS TRANSFER AND PORE DIFFUSION EFFECTS EVALUATION PROGRAM THIELE2 
St Imout Name outout Init comment

THIELE

Estimates Thiele moduli for the combustion of black liquor char by reactions with oxygen (directly and fia the sulfate/sulfide cycle), carbon dioxide, and water vapor

OVERALL RATES RELATIVE TO THE FILM MASS TRANSFER AND KINETIC RATES 02: overall/film mass transfer CO2: overall/film mass transfer H2O: overall/film mass transfer 02: overall/kinetic

$\mathrm{CO} 2$ : overall/kinetic

H2O: overall/kinetic

\section{INPUT VARIABLES}

initial droplet diameter

mass $\mathrm{fr}$. solids in droplet initially oxygen partial pressure

$\mathrm{CO} 2$ partial pressure

CO partial pressure

bar

bar

H2O partial pressure

$.03 \quad \mathrm{PH} 2$

L $\quad 873$

$$
\mathbf{T}
$$

K

gas temperature

INPUT PARAMETERS AND CONSTANTS

$\mathrm{CO} /(\mathrm{CO}+\mathrm{CO} 2)$ mole ratio produced by oxygen reactions with char $g$ char/g BLS after devolatilization Swelling factor at max volume

$\begin{array}{ll}.6 & \text { Xmc } \\ 3 & \text { DRmax } \\ 122 & \text { Asp } \\ .15 & \text { SO4 } \\ 16 & \text { C } \\ 1400 & \text { dens } \\ .000082 & \text { Rgas } \\ .000018 & \text { Diff0 } \\ 9.81 & \text { g } \\ 50 & \text { Mss }\end{array}$
$\mathrm{m}^{\wedge} 2 / \mathrm{g}$ specific area of $C$ in kraft char $\mathrm{SO} / \mathrm{Na} 2$ mole ratio $\mathrm{C} / \mathrm{Na2}$ mole ratio $\mathrm{kg} / \mathrm{m}^{\wedge} 3$ black liquor density atm $\mathrm{m}^{\wedge} 3 / \mathrm{m}$ ideal gas constant $\mathrm{m}^{\wedge} 2 / \mathrm{s}$ diffusivity of 02 in air, $0^{\circ} \mathrm{C}$ $\mathrm{m} / \mathrm{s}^{\wedge} 2$ acceleration due to gravity Sulfate/sulfide rate multiplier

\begin{tabular}{|c|c|c|c|}
\hline & & & CALCULATED VARIABLES \\
\hline D & .009 & m & \\
\hline vt & 3.7588324 & $\mathrm{~m} / \mathrm{s}$ & particle terminal velocity \\
\hline Aint & 1.0860318 & $\mathrm{~m}^{\wedge} 2$ & internal surface area of char \\
\hline Ts & 923 & $\mathrm{~K}$ & particle surface temperature \\
\hline Tf & 898 & $\mathbf{K}$ & gas film temperature \\
\hline Vpart & $1.413 \mathrm{E}-8$ & $m^{\wedge} 3$ & particle volume \\
\hline $\mathrm{Na} 2$ & $6.4507 \mathrm{E}-5$ & mol/parti & moles of $\mathrm{Na} 2$ in particle \\
\hline Cpart & .0010321 & & moles $C$ in particle \\
\hline Gr & .00394962 & & Grashof number \\
\hline $\operatorname{Re}$ & 335.55271 & & Reynolds number \\
\hline kvis & .00010082 & $m^{\wedge} 2 / s$ & kinematic viscosity of gas \\
\hline SG & .02333333 & & specific gravity of char particle \\
\hline O2byMT & $3.8685 \mathrm{E}-5$ & $\mathrm{~mol} 02 / \mathrm{s}$ & oxygen mass transfer rate \\
\hline CO2byMT & .00008362 & $\mathrm{~mol} \mathrm{CO} 2 / \mathrm{s}$ & $\mathrm{CO} 2$ mass transfer rate \\
\hline H2ObyMT & .00017221 & mol $\mathrm{H} 2 \mathrm{O} / \mathrm{s}$ & H2O mass transfer rate \\
\hline do2sdt & $6.5643 \mathrm{E}-6$ & mol $02 / s$ & rxn rate by sulfate/sulfide cycle \\
\hline do20xdt & $1.6318 \mathrm{E}-6$ & $\mathrm{~mol} 02 / \mathrm{s}$ & ren rate by $d$ \\
\hline & $9.1736 \mathrm{E}-8$ & $\mathrm{~mol} \mathrm{CO} 2 / \mathrm{s}$ & on \\
\hline
\end{tabular}


St Inout Name outout Unit comment

dH2Odt $5.5415 \mathrm{E}-7 \mathrm{~mol} \mathrm{H} 2 \mathrm{O} / \mathrm{s}$ reaction rate with $\mathrm{H} 2 \mathrm{O}$

Diffo2 $.00014462 \mathrm{~m}^{\wedge} 2 / \mathrm{s}$ diffusivity of 02 in air at gas temp.

DiffCO2 $.00011248 \mathrm{~m}^{\wedge} 2 / \mathrm{s}$ diffusivity of $\mathrm{CO} 2$ in air at gas temp.

DiffH2O $.00019282 \mathrm{~m}^{\wedge} 2 / \mathrm{s}$ diffusivity of $\mathrm{H} 2 \mathrm{O}$ in air at gas temp.

$\mathrm{ScO} 2.69712917 \quad$ Schmidt number

$\mathrm{ScCO} 2.89630893 \quad$ Schmidt number

$\mathrm{ScH} 2 \mathrm{O} \quad .52284688 \quad$ Schmidt number

ConcO2 .69846059 mol/ $\mathrm{m}^{\wedge} 3 \quad 02$ concentration

ConcCO2 $1.8159975 \mathrm{~mol} / \mathrm{m}^{\wedge} 3$ CO2 concentration

ConcH2O $2.5144581 \mathrm{~mol} / \mathrm{m}^{\wedge} 3 \quad \mathrm{H} 2 \mathrm{O}$ concentration

$\mathrm{kgO2} .21776172 \mathrm{~m} / \mathrm{s} \quad$ Mass transfer coefficient

$\mathrm{kgCO} 2.18104148 \mathrm{~m} / \mathrm{s} \quad$ Mass transfer coefficient

$\mathrm{kgH} 2 \mathrm{O} \quad .26927669 \mathrm{~m} / \mathrm{s} \quad$ Mass transfer coefficient

THO2 $3.004092 \quad$ oxygen reactions

THCO2 .36037209 CO2 gasification

THH2O $.67647862 \quad$ H2O gasification

BiO2 2.2586625 mass transfer Biot number

$\mathrm{BiCO} 2$ 2.4143062 mass transfer Biot number

BiH2O 2.0947386 mass transfer Biot number

$\begin{array}{llll}\mathrm{L} & \text { EFFO2 } & .3312465 & \text { Effectiveness factor } \\ \mathrm{L} & \text { EFFCO2 } & .95884712 & \text { Effectiveness factor } \\ \mathrm{L} & \text { EFFH2O } & .87101845 & \text { Effectiveness factor } \\ & \text { ROO2 } & 2.5369 \mathrm{E}-6 \mathrm{~mol} \mathrm{O2} / \mathrm{s} \text { Overall rate of O2 consumption } \\ \text { ROCO2 } & 8.7868 \mathrm{E}-8 \mathrm{~mol} \mathrm{CO2} / \mathrm{s} \text { Overall rate of CO2 consumption } \\ & \text { ROH2O } & 4.8133 \mathrm{E}-7 \mathrm{~mol} \mathrm{H} 2 \mathrm{~S} / \mathrm{s} \text { Overall rate of } \mathrm{H} 2 \mathrm{O} \text { consumption }\end{array}$




\section{S Rule}

"Thiele

* Aint $=$ Asp $* 3.14 / 6 * D 0^{\wedge} 3 *$ dens $* 1000 * S 0 * X m C$

* $\mathrm{D}=\mathrm{DRmax}{ }^{*} \mathrm{DO}$

* Vpart $=3.14 / 6 * D 0 \wedge 3$

* Na2 $=$ Vpart*dens $* 1000 * S 0 * .2 / 46$

$\star$ Cpart $=\mathrm{Na2}{ }^{\star} \mathrm{C}$

"Reaction rates (based on Sumicht and Li PhD theses):

"by sulfate/sulfide cycle

$\star \mathrm{dO2Sdt}=$ Mss*Cpart $* 2620 * \mathrm{SO} 4 /(.0011+\mathrm{SO} 4) * \exp (-29200 / 1.987 / \mathrm{T})$

"by direct reaction with oxygen

*. do20Xdt $=0.6 * 10000 / 12 *$ Aint $* 19 * \exp (-33950 / 1.987 / \mathrm{T}) * \mathrm{PO} 2$

"by reaction with $\mathrm{CO} 2$

$* \mathrm{dCO} 2 \mathrm{dt}=\mathrm{Cpart} * 32 \mathrm{E} 6 * \mathrm{PCO} 2 /(\mathrm{PCO} 2+3.4 * \mathrm{PCO}) * \exp (-22500 / \mathrm{T})$ "Li PhD

"by reaction with $\mathrm{H} 2 \mathrm{O}$

$\star d H 2 O d t=$ Cpart $* 2.56 e 9 * \mathrm{PH} 2 \mathrm{O} /(\mathrm{PH} 2 \mathrm{O}+1.42 * \mathrm{PH} 2) * \exp (-25300 / \mathrm{T})$ "Li PhD

"Note: rates are carbon consumption per particle, as moles/s

"Mass transfer rates

* $\mathrm{ConcO} 2=\mathrm{PO} 2 / \mathrm{Rgas} / \mathrm{T}$

* $\mathrm{ConcCO} 2=\mathrm{PCO} 2 /$ Rgas $/ \mathrm{T}$

$\star$ Conch2O $=\mathrm{PH} 2 \mathrm{O} /$ Rgas $/ \mathrm{T}$

* DiffO2 = Diff0* (Tf/273)^1.75

* DiffCO2 $=$ DiffO2*14/18

* DiffH2O $=$ DiffO2 $* 24 / 18$

$\star \mathrm{kgO2}=\operatorname{DiffO} 2 / \mathrm{D}^{\star}\left(2+0.569 *\left(\mathrm{Gr}^{\star} \mathrm{SCO} 2\right)^{\wedge} .25+0.347^{\star}\left(\mathrm{Re}^{\star} \mathrm{SCO} 2^{\wedge} .5\right)^{\wedge} .62\right)$

$\star k^{*} \mathrm{kCO} 2=\operatorname{DiffCO} 2 / \mathrm{D}^{*}\left(2+0.569 *\left(\mathrm{Gr}{ }^{\star} \mathrm{SCCO} 2\right)^{\wedge} .25+0.347^{*}\left(\mathrm{Re}^{\star} \mathrm{SCCO} 2^{\wedge} .5\right)^{\wedge} .62\right)$

$\star \mathrm{kgH}_{2} \mathrm{O}=\mathrm{DiffH} 2 \mathrm{O} / \mathrm{D}^{*}\left(2+0.569 *\left(\mathrm{Gr}{ }^{\star} \mathrm{ScH} 2 \mathrm{O}\right)^{\wedge} .25+0.347^{\star}\left(\mathrm{Re}^{\star} \mathrm{SCH} 2 \mathrm{O}^{\wedge} .5\right)^{\wedge} .62\right)$

$\star \mathrm{Gr}=\mathrm{g}^{\star}(\mathrm{Ts}-\mathrm{T}) \star \mathrm{D}^{\wedge} 3 / \mathrm{Tf} / \mathrm{kvis}$

* $\mathrm{ScO} 2=\mathrm{kvis} / \mathrm{DiffO} 2$

* $\mathrm{ScCO} 2=\mathrm{kvis} / \mathrm{DiffCO} 2$

* $\mathrm{ScH} 2 \mathrm{O}=\mathrm{kvis} / \mathrm{DiffH} 2 \mathrm{O}$

* $\operatorname{Re}=D^{*} \mathrm{vt} / \mathrm{kvis}$

$\star$ kvis $=-8.7664 \mathrm{e}-5+2.0989 \mathrm{e}-7{ }^{\star} \mathrm{Tf}$

$\star T S=T+50$

$* \mathrm{Tf}=(\mathrm{T}+\mathrm{TS}) / 2$

*vt $=11640 * S G^{\wedge} 0.71 * D^{\wedge} 1.14$

$\star S G=$ dens $/ 1000 / D R \max { }^{\wedge} 3 \star X m C^{\star}{ }^{\star} S 0$

* O2byMT $=\mathrm{kgO} 2 * 3.14 * \mathrm{D}^{\wedge} 2 * \mathrm{ConcO} 2$

$\star$ CO2byMT $=\mathrm{kgCO} 2 * 3.14 * \mathrm{D}^{\wedge} 2 * \mathrm{ConcCO} 2$

$\star \mathrm{H} 2 \mathrm{ObyMT}=\mathrm{kgH} 2 \mathrm{O} * 3.14 * \mathrm{D}^{\wedge} 2{ }^{*} \mathrm{ConcH} 2 \mathrm{O}$

"Biot numbers and Thiele Moduli

* $\mathrm{BiO} 2=\mathrm{kgO2}{ }^{*} \mathrm{D} / \mathrm{DiffO} 2 / 6$ "Bi is independent of gas type because $\mathrm{kmt}=\mathrm{k}^{\star} \mathrm{Diff}$

$\star \mathrm{BiCO} 2=\mathrm{kgCO} 2 * \mathrm{D} / \mathrm{DiffCO} 2 / 6$

$\star \mathrm{BiH} 2 \mathrm{O}=\mathrm{kgH} 2 \mathrm{O} * \mathrm{D} / \mathrm{DiffH} 2 \mathrm{O} / 6$

* THO2 = D/6*sgrt ((dO2Sdt + d02OXdt $) /$ Vpart $/$ DiffO2 $)$

* $\mathrm{THCO} 2=\mathrm{D} / 6^{\star} \operatorname{Sgrt}(\mathrm{dCO} 2 \mathrm{dt} /$ Vpart $/ \mathrm{DiffCO} 2)$

* THH2O $=\mathrm{D} / 6{ }^{*}$ sqrt $($ dH2Odt $/$ Vpart $/$ DiffH2O $)$

* EFFO2 $=\tanh (\mathrm{THO} 2) / \mathrm{THO} 2$

* $\mathrm{EFFCO} 2=\tanh (\mathrm{THCO} 2) / \mathrm{THCO} 2$

* EFFH2O $=\tanh (\mathrm{THH} 2 \mathrm{O}) / \mathrm{THH} 2 \mathrm{O}$

* $1 /$ ROO2 $=1 /$ O2byMT $+1 /(\mathrm{dO} 2 \mathrm{Sd} t+\mathrm{dO} 2 \mathrm{OXd} t) / \mathrm{EFFO} 2$

* $1 / \mathrm{ROCO} 2=1 / \mathrm{CO} 2 \mathrm{byMT}+1 / \mathrm{dCO} 2 \mathrm{dt} / \mathrm{EFFCO} 2$

* $1 / \mathrm{ROH} 2 \mathrm{O}=1 / \mathrm{H} 2 \mathrm{ObyMT}+1 / \mathrm{dH} 2 \mathrm{Odt} / \mathrm{EFFH} 2 \mathrm{O}$

* $\mathrm{RMTO} 2=\mathrm{ROO2} / \mathrm{O} 2 \mathrm{bYMT}$

* $\mathrm{RMTCO} 2=\mathrm{ROCO} 2 / \mathrm{CO} 2$ byMT

* RMTH2O $=$ ROH2O/H2ObyMT 
S Rule

* RKINO2 $=\mathrm{ROO2} /(\mathrm{dO} 2 \mathrm{Sd} t+\mathrm{dO2OXdt})$

* $\mathrm{RKINCO2}=\mathrm{ROCO} 2 / \mathrm{dCO} 2 \mathrm{dt}$

* RKINH2O = ROH2O/dH2Odt 


\section{APPENDIX 4}

COMPOSITION AND HEATING VALUES FOR THE LIQUORS USED IN THE VOLATILES AND CHAR CARBON YIELD STUDIES 


\section{Appendix 4.}

Composition and Heating Values for the Liquors Used in the Volatiles and Char Carbon Yield Studies

Liquor

Type

Sulfated ash, \%

Carbon, \%

Hydrogen, \%

Nitrogen, $\%$

Sulfur, \%

Chlorine, \%

Sodium, \%

Potassium, \%

Calcium

Silicon, \%

Tall oil, \%

$\mathrm{NaOH}, \%$

$\mathrm{Na} 2 \mathrm{~S}, \%$

$\mathrm{Na}_{2} \mathrm{SO}_{4}, \%$

$\mathrm{Na}_{2} \mathrm{CO}_{3}, \%$

Heating value, MJ/kg

\begin{tabular}{|c|c|c|c|c|c|c|c|}
\hline $\begin{array}{c}\text { A } \\
\text { Pine } \\
\text { kraft }\end{array}$ & $\begin{array}{c}\text { B } \\
\text { Pine } \\
\text { kraft }\end{array}$ & $\begin{array}{c}C \\
\text { Pine } \\
\text { kraft } \\
45.5\end{array}$ & $\begin{array}{l}\text { D } \\
\text { Pine } \\
\text { kraft } \\
\mathbf{4 4 . 3}\end{array}$ & $\begin{array}{c}\text { E } \\
\text { Birch } \\
\text { kraft }\end{array}$ & $\begin{array}{l}\text { F } \\
\text { Birch } \\
\text { kraft } \\
51.6\end{array}$ & $\begin{array}{c}\mathrm{G} \\
\mathrm{Na}- \\
\mathrm{NSSC}\end{array}$ & $\begin{array}{c}\mathrm{H} \\
\mathrm{NH}_{3}- \\
\mathrm{NSSC} \\
3.5\end{array}$ \\
\hline 39.8 & 30.1 & 36.6 & 36.4 & 37.0 & 31.1 & 36.7 & 39.0 \\
\hline 4.2 & 3.5 & 3.7 & 3.7 & & & & 5.7 \\
\hline 0.1 & 0.1 & 0.1 & 0.2 & & & 5.4 & $\begin{array}{l}5.2 \\
6.9\end{array}$ \\
\hline $\begin{array}{l}3.97 \\
0.33\end{array}$ & $\begin{array}{l}6.75 \\
0.85\end{array}$ & $\begin{array}{l}4.8 \\
0.4\end{array}$ & $\begin{array}{l}4.8 \\
0.5\end{array}$ & 5.1 & & 0.4 & \\
\hline 15.5 & 18.9 & 20.0 & 19.8 & 18.7 & 21.0 & 13.8 & 0.2 \\
\hline \multirow[t]{8}{*}{0.07} & 2.51 & 1.3 & 1.3 & 1.2 & & & 0.08 \\
\hline & & & 0.009 & & & & \\
\hline & & 0.2 & $\begin{array}{l}0.06 \\
0.5\end{array}$ & & & & \\
\hline & & & 1.0 & & 0.0 & & \\
\hline & & & 6.1 & & 8.2 & & \\
\hline & & & 4.3 & & 6.3 & & \\
\hline & & & 7.0 & & 8.8 & & \\
\hline & & 14.58 & 14.45 & & 12.80 & & 18.42 \\
\hline
\end{tabular}



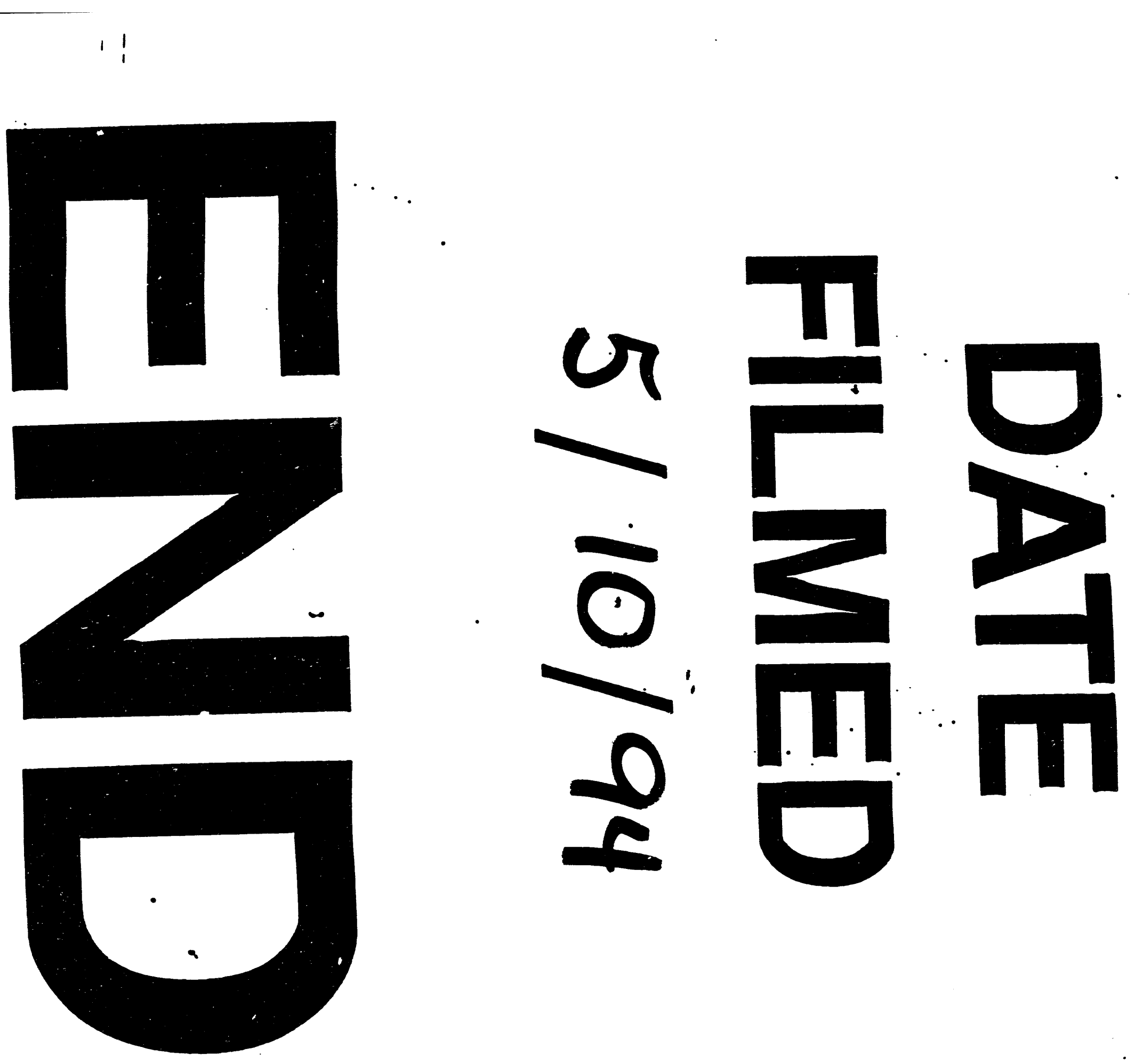


$$
\begin{aligned}
& \text { (3) }
\end{aligned}
$$

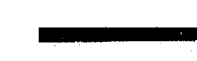

